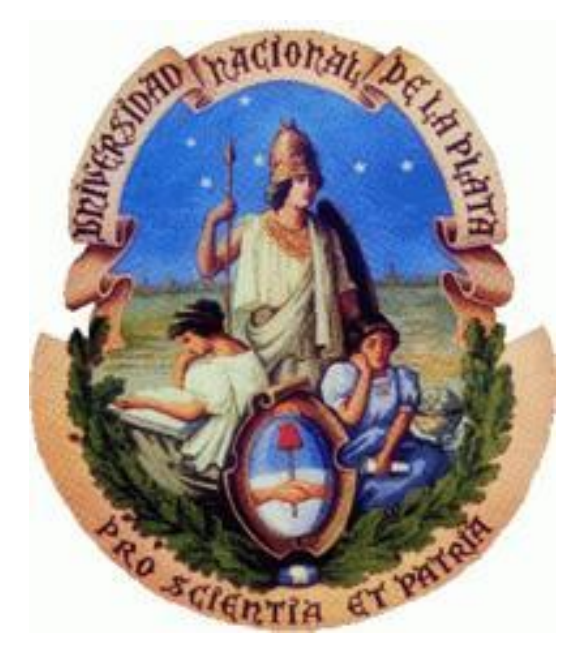

Universidad Nacional de La Plata

Facultad de Psicología

Secretaría de Posgrado

Carrera de Doctorado en Psicología

\title{
Tesis
}

Orientación y discapacidad visual. Factores que inciden en las elecciones de los adolescentes

Lic. y Esp. María Laura Castignani

Directora: Dra. Mirta Gavilán

Año 2017 


\section{Orientación y discapacidad visual. Factores que inciden en las elecciones de los adolescentes}




\section{Dedicatoria}

A mis queridos padres, Adelina y Raúl.

A Fermín, mi dulce y bello hijo, y a

Miguel, mi eterno y amado compañero 


\section{Agradecimientos}

desarrollo de la presente tesis de doctorado, ha sido posible gracias al

acompañamiento de personas sumamente significativas para mí, quiénes se brindaron con total predisposición y han sido pilares fundamentales para sostener este largo recorrido.

En primer lugar a mi querida directora, Dra. Mirta Gavilán, quién con su incondicional asistencia y apoyo, me impulsó para que pueda emprender esta investigación. Su capacidad excepcional de trabajo y su inventiva para generar nuevos proyectos dónde poder formarnos profesionalmente, dan cuenta de la pasión con la que emprende todo desafío, y así ha sido su tarea como directora de esta tesis, cautivándome por la interesante temática de la Orientación y la discapacidad y guiando con total rigurosidad, cada avance producido.

Un agradecimiento muy especial, a todos los participantes por la colaboración y el compromiso asumido para poder implementar el proyecto de investigación. En primer lugar, a los directivos, docentes, profesionales del Equipo de Orientación Escolar y demás actores institucionales de la Escuela de Enseñanza Especial seleccionada, por el espacio brindado en todos los años de trabajo, dónde siempre fue muy valorada la propuesta y gestionaron sin reparo alguno, todas las facilidades y condiciones para que pueda llevarse a cabo. En segundo lugar, a los padres y jóvenes que participaron de la propuesta, verdaderos "especialistas" en la temática de la discapacidad y sin los cuales, todo este trabajo no tendría razón de ser

A mis compañeras de la cátedra de Orientación Vocacional y del Centro de Orientación Vocacional-Ocupacional (UNLP), en especial, a las psicólogas Cristina Quiles y Teresita Cha, generadoras también de innumerables proyectos. Junto a ellas pude dar mis primeros pasos como profesional y fueron acompañando todo el recorrido realizado hasta el momento, celebrando con entusiasmo y alegría tanto los crecimientos profesionales, como los personales y familiares.

A los docentes de la Carrera de Doctorado, con quiénes pudimos construir nuevos conocimientos fomentando el desarrollo de un espíritu crítico en nuestra tarea como 
orientadores. Destaco particularmente a la Profesora Telma Piacente, quién siendo yo aún alumna de la carrera de grado, echó luz a este interés por la investigación, convocándome a descubrir este aspecto de mi vocación, que culminó con una tesis de doctorado. A la profesora Carmen Talou, con quién di mis primeros pasos en mi carrera docente, como auxiliar alumna en la cátedra Psicopatología II, gracias a su generosidad y pasión por la profesión, descubrí las posibles líneas de investigación y las áreas de vacancia en la temática de la discapacidad.

A mis compañeras de la Cátedra de Psicología Preventiva (UNLP), en especial a las profesoras Adriana Villalva y Mabel Tejo, quienes también me han acompañado en esta labor, y a mis alumnos con quienes he compartido mis intereses en esta temática.

Asimismo deseo expresar mi gratitud al Consejo Nacional de Investigaciones Científicas y Técnicas (CONICET), que ha posibilitado la implementación de mi Plan de Tesis Doctoral, a través de las becas que me fueran oportunamente otorgadas, coadyuvando de manera significativa a mi formación en investigación. Asimismo, a la Comisión de Investigaciones Científicas de la Provincia de Buenos Aires, que acompañó financiando mis primeros proyectos de investigación como becaria de dicha entidad.

A los amigos que esta hermosa profesión me dio y que se han convertido en mis "hermanos de la vida", acompañando y alentando cada trayecto de mi recorrido profesional: María Natalia García, Soledad Altamirano, Natalia Ciano, Yanina Ghio, Javiera Paini, Cintia Aguirre y Nicolás Nuñez Fornarini.

A mis colegas docentes con quienes en el 2012 dimos los primeros pasos para crear la entonces, Comisión de Discapacidad de la Facultad de Psicología (UNLP), y con quiénes compartimos la convicción de que es posible una educación realmente inclusiva: Sonia Borzi, Paula Cardós y Rosario Izurieta.

A los compañeros de la Comisión Universitaria sobre Discapacidad (CUD) de la UNLP, hoy, Dirección de Inclusión, Discapacidad y DDHH, especialmente a su coordinadora, Lic. Sandra Katz y al equipo entrañable que conforman Ana Rucci, 
Evelina Díaz, María Innaro, Gonzalo Ithurbide, Cecilia Napóli, Alejandra Sofía y Mabel Peiró, por tantos momentos compartidos, charlas, debates y propuestas, luchando diariamente por el cumplimiento de los derechos de las personas con discapacidad.

A las autoridades y compañeros del Colegio Nacional "Rafael Hernández" con quiénes en el último tiempo, he podido compartir las convicciones de una educación inclusiva.

Finalmente, a mis padres, que pese a estar lejos del ámbito académico y a varios kilómetros de esta ciudad, fueron quiénes me inculcaron la importancia de la perseverancia, alentando todos los pasos de esta producción intelectual. A mis hermanos, mayores Pablo y Fernando, quiénes siempre estuvieron presentes acompañando cada paso de mi vida. A Miguel, por su amor incondicional, compañero de tantos años y cómplice perfecto de todas mis "aventuras" académicas. Por último a mi querido hijo Fermín, quién vivenció la elaboración de esta tesis incluso antes de su llegada, y a quién podré devolverle los ratos de juegos que le quité, para que por fin su mamá, pueda terminar la tan esperada tesis. 


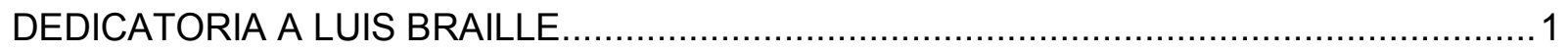

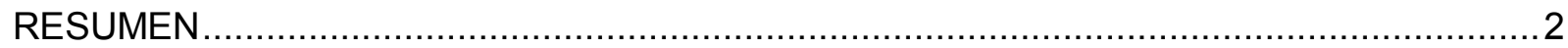

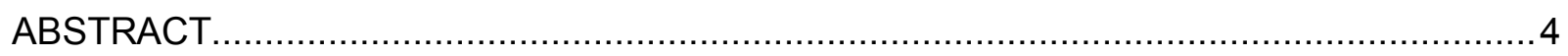

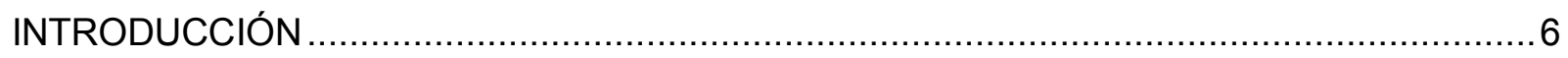

CAPÍTULO 1 PERSPECTIVAS TEÓRICAS SOBRE ORIENTACIÓN Y_DISCAPACIDAD ....10

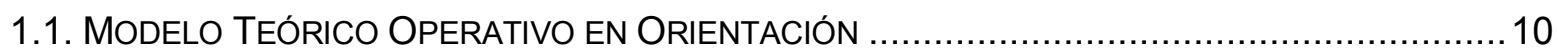

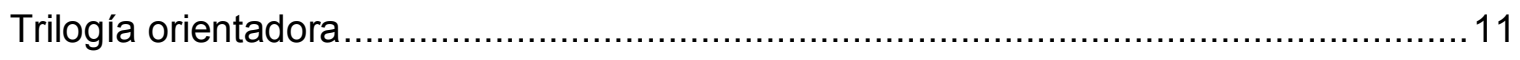

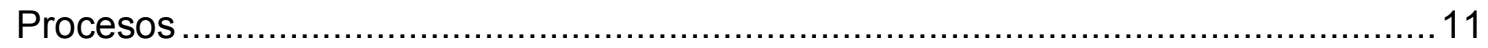

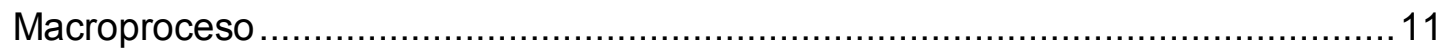

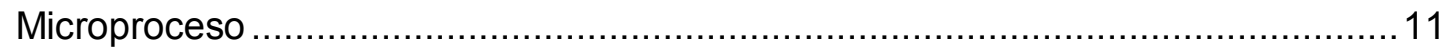

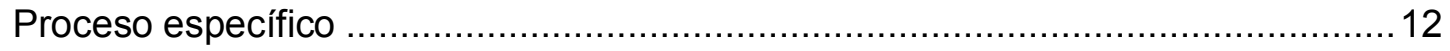

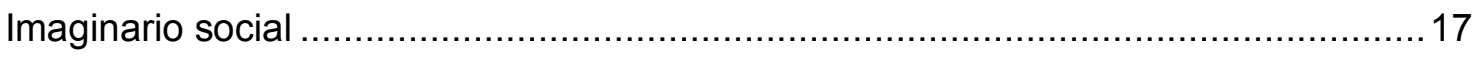

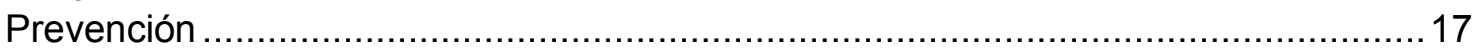

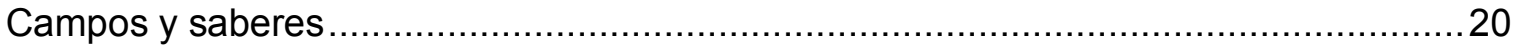

Campos

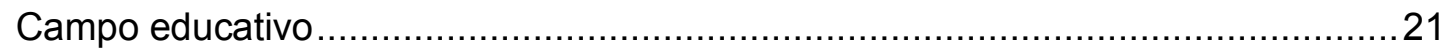

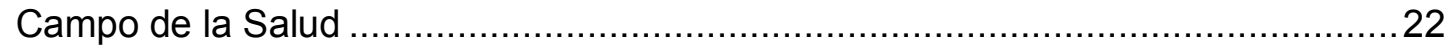

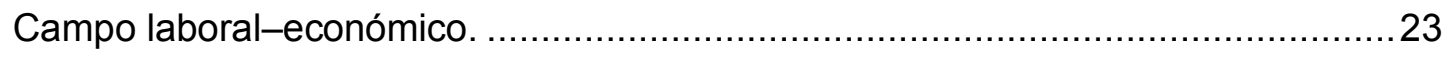

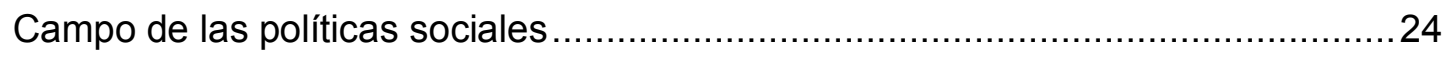

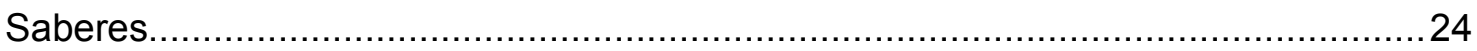

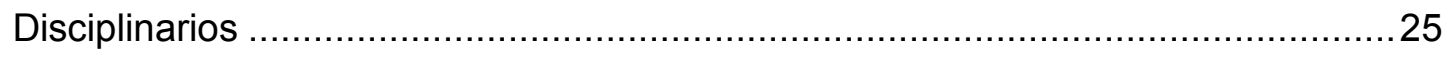

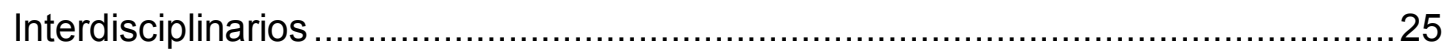

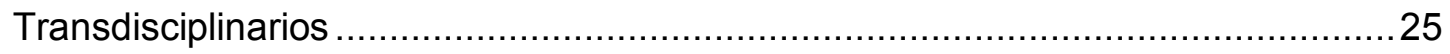

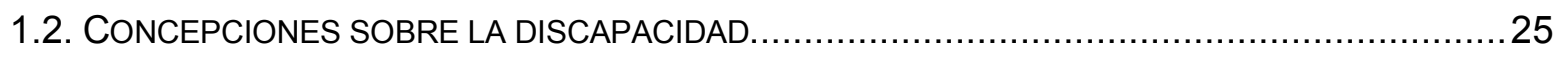

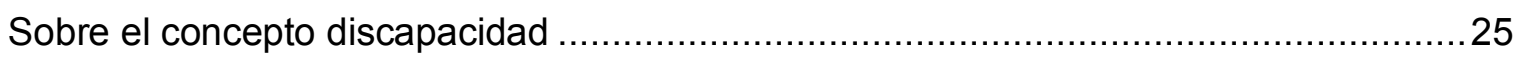

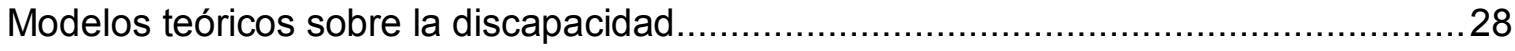

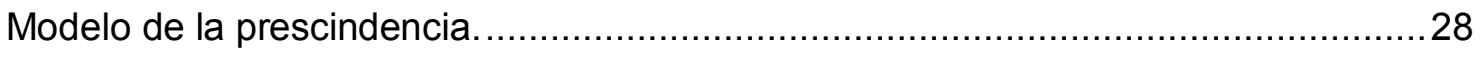

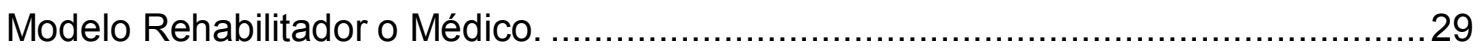

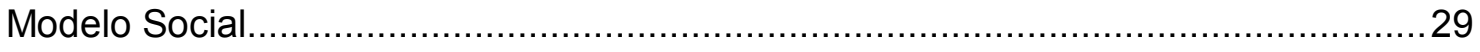

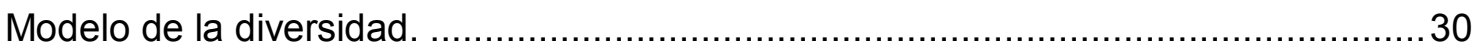

1.3. NORMATIVAS NACIONALES E INTERNACIONALES SOBRE EL DERECHO A LA EDUCACIÓN

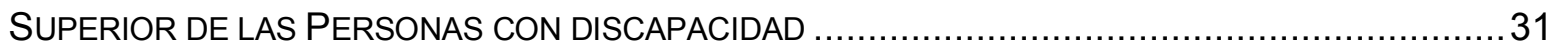

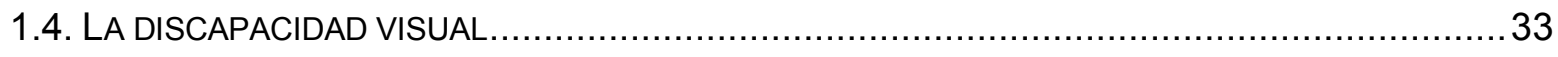

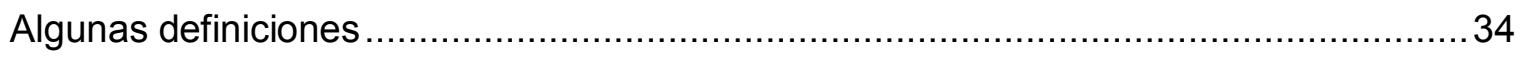

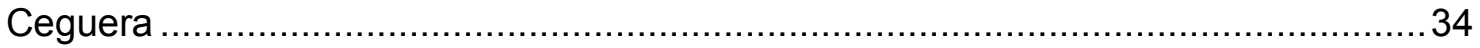

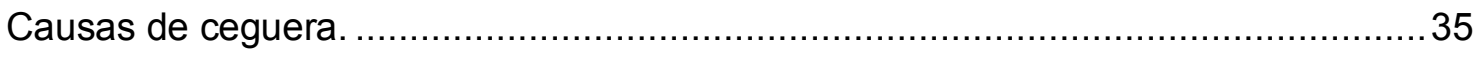

Principales características de los sujetos con ceguera. ..........................................35

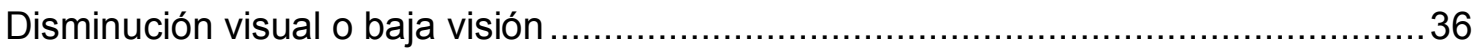

Principales características de los sujetos con Disminución visual ............................38

Tesis Doctoral. "Orientación y Discapacidad Visual. Factores que inciden en la elección de los adolescentes" 


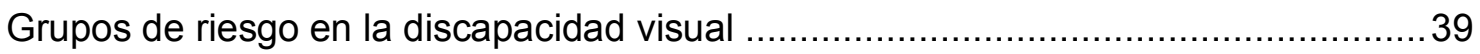

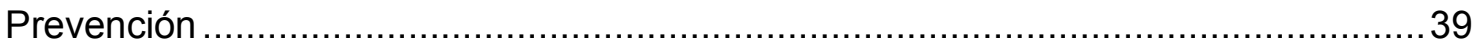

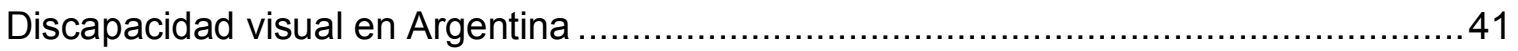

CAPITULO 2 ANTECEDENTES_ORIENTACIÓN Y ATENCIÓN A LA DIVERSIDAD .............42

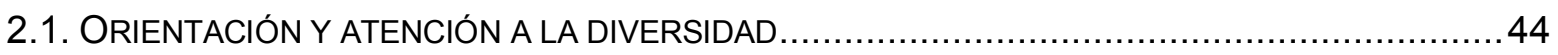

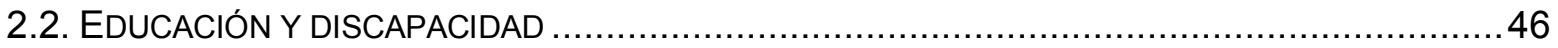

2.3. MODELOS Y ENFOQUES TEÓRICOS SOBRE PRÁCTICAS ORIENTADORAS DE LAS PERSONAS

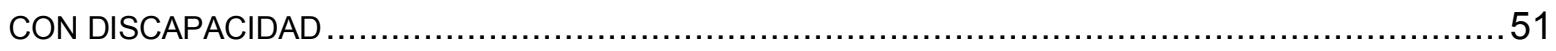

Prácticas y propuestas orientadoras en Europa y EEUU ………….........................52

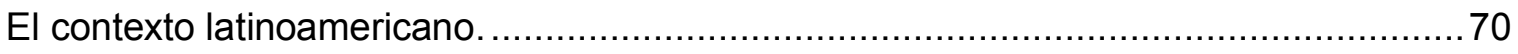

Prácticas y propuestas orientadoras en Argentina. .................................................. 74

CAPÍTULO 3 ANTECEDENTES_ORIENTACIÓN Y DISCAPACIDAD VISUAL ....................90

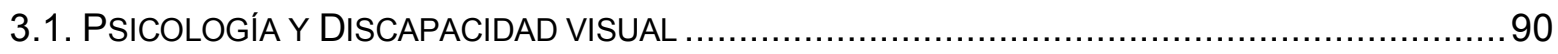

3.2. DE LAS NECESIDADES EDUCATIVAS ESPECIALES A LAS BARRERAS PARA EL APRENDIZAJE Y

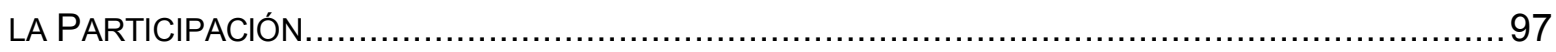

3.3. NECESIDADES ESPECIFICAS DE LOS SUJETOS CON CEGUERA ……............................ 99

3.4. NECESIDADES ESPECÍFICAS DE LOS SUJETOS CON DISMINUCIÓN VISUAL ........................100

3.5. LA INCLUSIÓN EDUCATIVA DE LOS ALUMNOS CON DISCAPACIDAD VISUAL ......................100

3.6. LA EDUCACIÓN SUPERIOR DE LAS PERSONAS CON DISCAPACIDAD VISUAL......................104

3.7. ALGUNOS ANTECEDENTES EN ORIENTACIÓN EN DISCAPACIDAD VISUAL .........................106

3.8. SISTEMA DE ASESORAMIENTO VOCACIONAL PARA CIEGOS (SAV-C) EN ESPAÑA ............111

3.9. EXPERIENCIAS DE ORIENTACIÓN EN SUJETOS CON DISCAPACIDAD VISUAL EN ARGENTINA

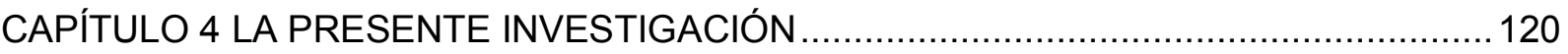

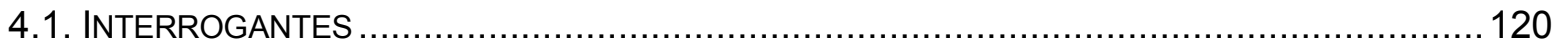

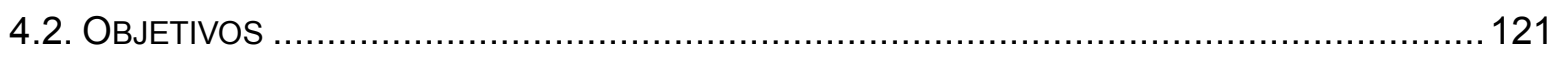

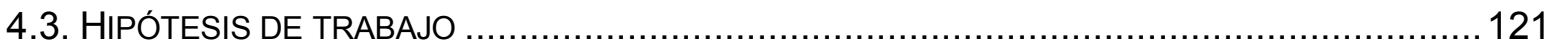

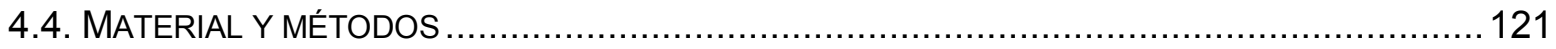

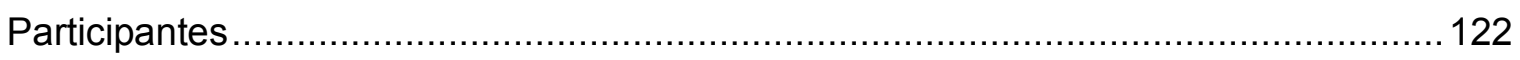

Procedimientos e Instrumentos/técnicas de obtención de datos ................................ 123

Procedimientos de análisis y elaboración de los datos ...........................................127

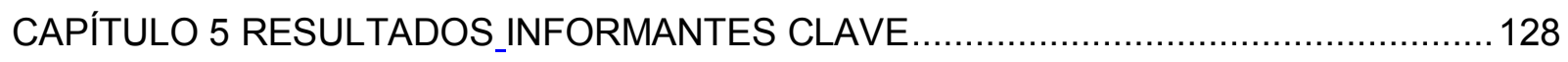

5.1. CARACTERÍSTICA DE LA ESCUELA DE EdUCACIÓN ESPECIAL SELECCIONADA..................128

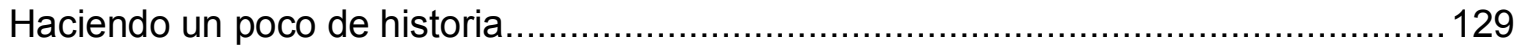

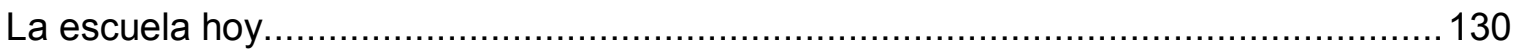

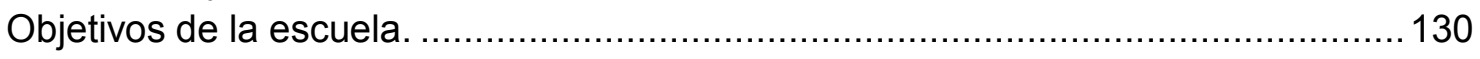

Equipo profesional-técnico-docente. …….......................................................131

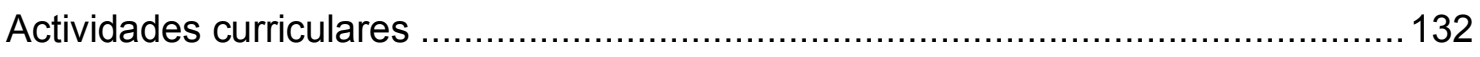

llustración particularizada de las entrevistas realizadas .......................................132

5.2. RESULTADOS SOBRE LOS ALUMNOS UNIVERSITARIOS CON DISCAPACIDAD VISUAL...........137

5.3. RESULTADOS DE LAS ENTREVISTAS CON PADRES DE HIJOS CON DISCAPACIDAD VISUAL .. 142

Tesis Doctoral. "Orientación y Discapacidad Visual. Factores que inciden en la elección de los adolescentes" 
6.1. RESULTADOS CORRESPONDIENTES AL PROCESO ESPECÍFICO INDIVIDUAL ....................146 Ilustración particularizada sobre los casos estudiados .......................................... 151

6.2. RESULTADOS DEL PROGRAMA CORRESPONDIENTE AL MICROPROCESO ........................159 llustración particularizada sobre los talleres y casos individuales .............................. 164

CAPÍTULO 7 DISCUSIÓN GENERAL Y CONCLUSIONES ......................................... 172

7.1 FACTORES INTRÍNSECOS 173

7.2. FACTORES EXTRÍNSECOS.

7.3. LIMITACIONES DEL PRESENTE ESTUDIO Y PERSPECTIVAS PARA FUTURAS INVESTIGACIONES

REFERENCIAS 187

ANEXO 1 TÉCNICAS E INSTRUMENTOS UTILIZADOS EN EL PROCESO ESPECÍFICO INDIVIDUAL. 196

ANEXO 2 EJEMPLO DE TALLER (MICROPROCESO). 199

ANEXO 3 ENCUESTA DE EVALUACIÓN 202

ANEXO 4 EJEMPLO DE TALLER CON INFORMANTES CLAVE ALUMNOS UNIVERSITARIOS. 


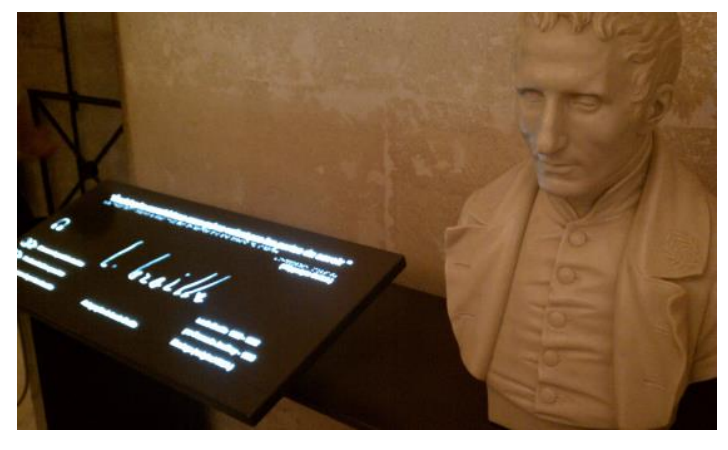

Dedicatoria a Luis Braille "A celui qui a ouvert à tous ceux qui ne voient pas les portes du savoir» Hippolyte Coltat (Panteón, París) 


\section{Resumen}

n esta investigación se indagaron los factores que orientaron las elecciones educativas y ocupacionales de adolescentes y jóvenes con discapacidad visual: ciegos, disminuidos visuales profundos y disminuidos visuales leves, que finalizaban sus estudios secundarios. Se enmarca en el Modelo Teórico Operativo (Gavilán 2006, 2017), en la consideración del Modelo de la Diversidad de la Discapacidad y en las perspectivas actuales sobre la Discapacidad Visual. La relevancia del tema reside en la insuficiencia de desarrollos teóricos y de las subsecuentes intervenciones específicas en Orientación, sobre las que aparece un conocimiento parcial de las acciones que se realizan a ese respecto. En tal sentido los orientadores enfrentan nuevos desafíos para dar cuenta de las elecciones pasibles de realizar por colectivos particulares, entre ellos los sujetos con discapacidad visual, cuyas necesidades específicas no siempre son atendidas adecuadamente. A partir de esas consideraciones surgieron interrogantes sobre la perspectiva subjetiva frente a la propia discapacidad y las de la familia, las condiciones que posibilitan u obstaculizan el acceso a instituciones educativas y laborales, los apoyos necesarios para asegurar la equidad de posibilidades y la disponibilidad y adecuación de estrategias y/o acciones de orientación, que dieron lugar a los objetivos e hipótesis de partida. Para recabar la información necesaria, con un enfoque cualitativo en un estudio descriptivo-narrativo se incluyeron 22 participantes ciegos y disminuidos visuales profundos y leves, de 16 a 21 años de edad y 20 informantes clave: personal de la escuela especializada en el tema, padres de los participantes con discapacidad visual y alumnos universitarios con la misma discapacidad que cursan diferentes carreras en la UNLP. La indagación de los participantes con discapacidad visual se realizó a través de dos modalidades del modelo teórico adoptado: el Proceso Específico Individual y el Microproceso, que incluyen entrevistas de diversa filiación, técnicas específicas sobre aspectos particularizados y talleres. En el caso de los informantes clave, se implementaron entrevistas semi-estructuradas y talleres sobre temas particulares. El corpus conformado por el conjunto de los resultados fue sometido al análisis comparativo constante para proceder a su categorización, que ha permitido identificar tres 
hallazgos clave. En primer lugar la incidencia de la perspectiva subjetiva de los propios sujetos frente a su discapacidad visual como factor preponderante en sus elecciones, acentuada o morigerada según la perspectiva de los familiares. En segundo lugar, la semejanza de los factores responsables de las elecciones educativas y/u ocupacionales con los que operan en la población vidente, pero matizados por la situación de discapacidad. Finalmente, la insuficiencia/inadecuación de procesos de orientación. De ello surge que la implementación de la Orientación conforme al modelo que sustentamos permite visualizar su potencialidad para esclarecer el conjunto de las cuestiones planteadas con el propósito último de garantizar la equidad de oportunidades para todos.

Palabras clave: orientación, discapacidad visual, ceguera, disminución visual leve, disminución visual profunda, perspectiva subjetiva. 
Abstract

his research explores reasons behind guided the educational and occupational choices of adolescents and young people with visual impairment: blind, moderate low vision, and profound low vision, once they had which completed their secondary studies. This study is based on the Operative Theoretical Model (Gavilán 2006, 2017), on the Diversity Disability Model and on the current perspectives on Visual Disability. The relevance of the topic lies in the scarce development of theoretical production and the subsequent specific interventions in the Orientation which reveal a partial knowledge taken in orientation. In this sense, counselors face new challenges to account for the possible choices made by special groups, including visually disabled people whose special needs are not always adequately addressed. Starting from these conditions, questions arose about the subjective perspective regarding the disability of the subjects and those of the family, conditions that make possible or hinder access to educational institutions and working opportunities, the necessary support to ensure the equity of possibilities and the availability and adequacy of strategies and/or orientation actions, which gave rise to the objectives and hypotheses of departure. To gather the necessary information, a qualitative approach was adopted to develop a descriptive-narrative study which included 22 blind and visually impaired participants, deep and light, ranging from 16 to 21 years of age and 20 key informants selected from the staff of the specialized school in the subject, parents of the visually impaired participants and university's students with the same disability attending different courses at the UNLP. The participants with visual impairment were examined by means of two modalities of the theoretical model adopted: the Individual Specific Process and the Microprocess, which include interviews of different affiliations, specific techniques on particularized aspects and workshops. In the case of the key informants, semi-structured interviews and workshops on specific topics were implemented. The corpus conformed by the whole of the results were analyzed lead to a categorization (constant comparative analysis, Glasser y Straus, 1967/2006), which allowed to identify three key findings. First, the incidence of the subjective perspective of the subjects themselves vis-a-vis their visual disability as a preponderant factor in their choices accentuated or 
tempered according to the family perspective. Second, the similarity of the factors responsible for educational and/or occupational choices with those operating in the sighted population, but conditioned by the disability situation. Finally, the insufficiency/inadequacy of orientation processes. It follows that the implementation according to the Orientation model we support allows visualizing its potential to clarify the set of issues raised with the ultimate purpose of ensuring equal opportunities for all.

Key Words: orientation, disability, blindness, moderate low vision, profound low vision, subjective viewpoint. 


\section{Introducción}

sta investigación estuvo destinada a examinar los factores que orientaron las elecciones educativas y ocupacionales de adolescentes y jóvenes con discapacidad visual: ciegos, disminuidos visuales profundos y disminuidos visuales leves, que finalizaban sus estudios secundarios.

La relevancia del tema investigado, parte del análisis de los antecedentes internacionales y nacionales (desarrollados en los Capítulos 2 y 3 ) que ponen en evidencia una insuficiencia de desarrollos teóricos y de las subsecuentes intervenciones específicas sobre las elecciones vocacionales ocupacionales de los sujetos con discapacidad visual. Asimismo aparece un conocimiento parcial de las acciones en orientación que se realizan a ese respecto.

Sobre la base de la necesidad de dar respuesta a las demandas emanadas de la complejidad del mundo actual, signadas por un contexto que atraviesa profundas transformaciones políticas, económicas y socioculturales, la Orientación enfrenta nuevos desafíos que han modificado y ampliado la mirada del orientador. Las propuestas de orientación en diferentes contextos mundiales hacen referencia a la preparación para el trabajo y la formación calificada, sin desestimar aquello que los individuos quieren y desean como proyecto de vida (Gavilán, 2006, 2017).

Sin embargo, los sujetos con algún tipo de discapacidad no siempre han recibido las intervenciones orientativas necesarias, particularmente en momentos en los que se producen "cortes significativos" (Gavilán, 2006, p. 122) que conducen a la necesidad de elegir el destino educativo y/u ocupacional, como sucede cuando se finalizan los estudios secundarios. En este sentido, el enfoque preponderante del déficit, el desconocimiento de la problemática psicológica de las personas con Discapacidad Visual y las consultas que se efectúan en centros especializados, entre ellos el Centro de Orientación Vocacional Ocupacional de la Universidad Nacional de La Plata, impulsan el estudio de ese colectivo particular y testimonian la importancia del tema investigado. 
Bajo esas consideraciones, desde el enfoque teórico adoptado sobre la orientación y la discapacidad, particularmente sobre la discapacidad visual y a partir del análisis de los antecedentes en el tema, que dan cuenta de la escasez, particularmente a nivel local, de investigaciones previas, surgieron los interrogantes que orientaron el desarrollo de esta tesis.

Los interrogantes sobre los factores que inciden en las elecciones de los adolescentes y jóvenes ciegos, disminuidos visuales profundos y leves en relación con el mundo del estudio y/o el trabajo, refieren a la perspectiva subjetiva frente a su propia discapacidad, la de sus familias, las condiciones que posibilitan u obstaculizan su acceso a instituciones educativas y laborales, los apoyos necesarios para asegurar la equidad de posibilidades y la disponibilidad y adecuación de estrategias y/o acciones de orientación

En función de ello, con un enfoque cualitativo de diseño descriptivo narrativo (Hernández Sampieri, Fernández Collado \& Baptista Lucio, 2010), se recabó la información necesaria para dar respuesta a tales interrogantes, en el marco del Modelo Teórico Operativo en Orientación (Gavilán, 2006), en la perspectiva del Modelo de la Diversidad de la Discapacidad y de las concepciones actuales sobre la Discapacidad Visual.

Para ello se incluyeron participantes con discapacidad visual de ambos sexos, de 16 a 21 años edad, en la etapa de tránsito de la escolaridad secundaria al mundo educativo y/o ocupacional, e informantes clave: personal de la escuela especializada en el tema (directivos, profesionales y docentes), padres de los participantes con discapacidad visual y alumnos universitarios con la misma discapacidad que cursan diferentes carreras en la UNLP.

Se trata en el primer caso de indagaciones sobre los propios sujetos con discapacidad visual. En el segundo, de aquellos aspectos contextuales que complementan y amplían el conjunto de las informaciones. Particularmente se ha atendido, en primer lugar, a las perspectivas de otros actores sobre las eventuales dificultades a enfrentar por los adolescentes seleccionados, compartidas o no por los 
padres y vivenciadas por los estudiantes que ya han ingresado a los estudios universitarios o al mundo del trabajo.

En segundo lugar, con referencia al equipo directivo, docente y profesional que actúa a nivel secundario y universitario, sobre la disponibilidad y adecuación de estrategias de orientación así como sobre el conocimiento de las necesidades específicas y las consecuentes adaptaciones y apoyos que se requieren para este grupo, de modo tal de garantizar la mencionada equidad de oportunidades.

\section{Organización de la tesis}

En función de ello, esta tesis está organizada en los siguientes capítulos. En el Capítulo 1 se ofrece el marco teórico sobre la orientación educativa y ocupacional y la perspectiva sobre la discapacidad en la que se enmarca. Se especifican, en primer lugar, las nociones sobre la Trilogía Orientadora (Gavilán 2006), que involucra los ejes referidos a los procesos, el imaginario social y la prevención, así como los diferentes campos y saberes en los que se contextualizan. En segundo lugar, las perspectivas frente a la discapacidad en general que han dado lugar a diferentes modelos cuyo análisis ha permitido posicionarse en el Modelo de la Diversidad. Asimismo se proporciona una breve referencia a las normativas nacionales e internacionales en la materia. Se finaliza atendiendo a cuestiones específicas relativas a las consideraciones actuales sobre la ceguera y la disminución visual, tales como definiciones, prevalencia, características. El Capítulo 2, destinado al análisis de los antecedentes sobre las relaciones entre orientación y atención a la diversidad y entre educación y discapacidad, explicita los modelos y enfoques teóricos sobre las prácticas orientadoras en el tema a nivel nacional e internacional. El capítulo 3 atiende específicamente a los antecedentes referidos a la orientación y la discapacidad visual, la problemática de las necesidades específicas y la inclusión de ciegos en la educación superior, así como ejemplos de un sistema particular de asesoramiento para ciegos y las normativas en la materia y algunas experiencias en Orientación en discapacidad visual en Argentina. El recorrido realizado conduce al Capítulo 4, en el que se presenta la investigación realizada. Se especifican los interrogantes, objetivos e hipótesis de trabajo así como la metodología adoptada, que comprende el diseño de investigación, los participantes incluidos, las técnicas e 
instrumentos y procedimientos de obtención y análisis de los de datos. Los dos dispositivos emanados del Modelo Teórico Operativo que corresponden al Proceso específico Individual y al Microproceso se utilizaron para la obtención de la información sobre los propios adolescentes. Para hacer lo propio con los informantes clave se utilizaron entrevistas adaptadas del mismo modelo en función de aspectos específicos a ser indagados. Los Capítulos 5 y 6 , núcleo central de esta tesis, ofrecen los resultados y las discusiones a las que han dado lugar, en relación con los interrogantes, objetivos e hipótesis de partida. El primero de ellos respecto de la información recabada de los informantes clave, el segundo de la obtenida de los participantes con discapacidad visual. Finalmente en el Capítulo 7 aparecen las conclusiones a las que se ha arribado, ofreciendo un cuadro de conjunto sobre factores intrínsecos (de los propios sujetos) y extrínsecos (de su entorno) que inciden de manera facilitadora u obstaculizadora en las elecciones a realizar.

En conjunto de la tesis apunta a contribuir a esclarecer desde la perspectiva del marco teórico de la orientación que adoptamos, cuestiones involucradas en la atención a la diversidad, de la que forman parte los ciegos y disminuidos visuales, que atienda a garantizar la equidad de oportunidades para todos. 


\section{Capítulo 1 \\ Perspectivas teóricas sobre orientación y discapacidad}

E

n este capítulo abordaremos las perspectivas teóricas sobre la orientación educativa y ocupacional y sobre la discapacidad en la que se enmarca la presente tesis. Se trata del Modelo Teórico Operativo en Orientación (Gavilán, 2006, 2017), del Modelo de la Diversidad de la Discapacidad (Palacios \& Romañach, 2007) y de las perspectivas actuales sobre la Discapacidad Visual.

\subsection{Modelo Teórico Operativo en Orientación}

La presente tesis se referencia en el Modelo Teórico Operativo en Orientación (Gavilán, 2006, 2017), que considera a la orientación en un sentido abarcativo y amplio que incluye las diversas respuestas de elección que deben realizar las personas a lo largo de la vida. Dicho de otro modo, no se reduce sólo al pasaje de un ciclo educativo a otro, sino que incluye diferentes experiencias relacionadas con el estudio, el trabajo, la preparación para el retiro, la reconversión e inestabilidad laboral, el desempleo y/o las nuevas elecciones que las personas deben realizar en el transcurso de su vida.

Es importante señalar que si bien en diferentes contextos mundiales la Orientación se vincula con la preparación calificada y la formación profesional, no deja de lado las preferencias y deseos del proyecto de vida de los sujetos involucrados. Desde esta concepción entonces, se define a la Orientación como:

El conjunto de estrategias y tácticas que emplea el psicólogo y/o el psicopedagogo especializado en Orientación para que el orientado o sujeto de la Orientación, individual o colectivamente, mediante una actitud comprensiva, reflexiva y comprometida, pueda elaborar un proyecto educativo, laboral, personal y/o social a lo largo de la vida (Gavilán, 2006, p.194). 


\section{Trilogía orientadora}

El Modelo parte de este concepto complejo que da cuenta de la articulación de tres ejes fundamentales alrededor de la Orientación: procesos, imaginario social y prevención.

Procesos. Involucran la consideración de distintas formas de intervención en Orientación que incluyen la dimensión temporal, a partir de la cual se pueden diferenciar tres niveles relacionados con las elecciones educativas u ocupacionales: macroproceso, microproceso y proceso específico.

Macroproceso. Corresponde a los factores que directa o indirectamente influyen en los sistemas de vida, tales como las representaciones sociales que de acuerdo al contexto referido a un momento histórico, político y económico de una comunidad determinada, encuadran los futuros proyectos educativos, personales y laborales. Aquí es importante tener presente, particularmente, el contexto familiar y sus expectativas educativas-ocupacionales respecto de sus hijos.

El macroproceso es parte de un orden sistémico, que opera o puede operar en materia de orientación, junto con el microproceso y el proceso específico. En líneas generales los procesos macro influyen en los microprocesos, debido a que los sistemas políticos actúan, constantemente, sobre las situaciones económicas particulares y viceversa; además, guardan relación con el contexto internacional.

Desde ese nivel, la investigación realizada por Gavilán, Cha, Quiles y Neer (1997) refleja que los factores que influyen en las elecciones de los adolescentes corresponden, en primer término, a sus intereses en las tareas que podrán realizar en el destino educativo o laboral elegido. En segundo lugar, a intereses tales como el status, la demanda laboral, la retribución económica, entre otros. Todos los aspectos correspondientes al macroproceso actúan como un continuo a través de los agentes sistemáticos y asistemáticos de la cultura.

Microproceso. Refiere a distintos momentos evolutivos o sociales en los que en una cultura determinada se deben tomar decisiones frente a distintas opciones. Por ejemplo, en nuestro país el pasaje de la escolaridad primaria a la secundaria, de ésta a los estudios superiores, de los estudios superiores al proceso productivo y de allí a 
la preparación para el retiro, etc. Se trata de "cortes" significativos dentro del continuo (Gavilán, 2006, p. 122); aquí el adolescente/adulto y/o adulto mayor deben optar por un proyecto educativo, laboral, personal, social. Las intervenciones se llevan a cabo mediante la implementación de programas específicos, destinados a grupos particulares, en diversas instituciones a cargo de agentes especializados.

En estos microprocesos el sistema educativo, el productivo o el de políticas sociales deben implementar planes, estrategias y tácticas para llevar a cabo las acciones orientadoras. El sistema educativo es el que actúa en primera instancia como eje de la prevención. Para elaborar un proyecto de intervención orientadora, Gavilán (2006, 2017) plantea una serie de criterios a tener en cuenta, vinculados con el análisis institucional, que incluye el objetivo de la institución, su estructura o sistema, su nivel de organización, su inserción dentro de la comunidad, su nivel de comunicación con otros efectores así como el lugar geográfico, nivel de enseñanza, recursos humanos y materiales, cantidad de divisiones y alumnos a incluir, etc.

Los procesos que se implementan a este nivel se trabajan con una metodología grupal, mediante talleres, grupos operativos o grupos de reflexión. No obstante, no se excluye la incorporación de algunas técnicas de exploración y la realización de entrevistas individuales en los casos que así lo requieran. Por ejemplo, cuando algunos de los participantes del programa, no logran elaborar un proyecto educativo y/o laboral, se los puede incluir en un proceso específico de asistencia de orientación, dentro de la institución y/o fuera de ella.

Proceso específico. Se define como

La acción orientadora que se lleva a cabo en forma individual y/o grupal, con aquellos sujetos que necesitan una intervención más personalizada en el momento de la elección. Este tipo de proceso lo lleva a cabo un profesional psicólogo o psicopedagogo especializado en Orientación Vocacional que, en forma conjunta con el consultante, elabora un encuadre de orientación, con el objeto de lograr una identificación vocacional ocupacional como parte integrante de la identidad personal de este sujeto (Gavilán, 2006, p.130). 
Se vincula con las teorías psicodinámicas de la elección, especialmente con referencia a Bohoslavsky (1985), uno de los representantes más importantes en nuestro país de la perspectiva clínica en Orientación. La entrevista aparece, en consecuencia, como el principal instrumento de trabajo para el orientador. En este sentido, la elaboración del primer diagnóstico o diagnóstico de orientabilidad es uno de los aspectos significativos dentro del encuadre de trabajo de un proceso específico.

Müller (2009), a su vez, hace referencia a la entrevista clínica operativa en Orientación "que incluye la focalización o centramiento en la temática y problemática orientadora y en todo aquello que contribuya a esclarecerla" (p. 32). Entonces, es operativa porque está centrada en la tarea manifiesta (promover aprendizajes, optimizar recursos, aprender a elegir) y latente (elaborar obstáculos que dificulten el logro de objetivos). Está focalizada en la situación actual, estructurada alrededor de un eje constituido por el motivo de consulta y el conflicto nuclear subyacente. Se concentra selectivamente en los "puntos de urgencia" o "emergentes" internos (confusión, indecisión, desmotivación, desconcentración, bajo rendimiento) y externos (presiones familiares y sociales sobre las elecciones educativas y/o laborales). Se escucha el texto (manifiesto), el subtexto (latente) y se tiene una visión del contexto (situación) del consultante/alumno, teniendo en cuenta su subjetividad.

El rol del orientador es el de "acompañamiento", que se aleja de aquel que proporciona consejos o asume una "actitud directiva". Es el orientado quien va a ser el protagonista en la resolución de problemas vocacionales, teniendo fundamental importancia su subjetividad (Suarez, 2005, p. 63).

El proceso asistencial de la orientación será diferente según se trate de un consultante que se encuentra en diferentes situaciones tales como:

a) ya ha realizado una experiencia institucional educativa previa de orientación vocacional (microproceso);

b) es la primera vez que se incluye en un proceso orientador;

c) habiendo iniciado un estudio, luego lo ha abandonado (reorientación). 
Además, este encuentro entre orientador y orientado va a depender del origen de la demanda (padres, docentes, directivos, amigos, profesionales o el mismo sujeto); y del lugar desde donde se realice el pedido de intervención (escuela, hospital, centros de orientación, consultorios, etcétera).

Todas estas situaciones van a formar parte del encuadre, cuyas constantes serán: ámbito, horario, honorarios (si el ámbito es privado), rol del orientador y del orientado y las variables dependientes de la situación de elección del orientado.

Dentro del encuadre de trabajo se debe establecer con cierta elasticidad, el tiempo de duración del proceso (que puede oscilar entre 10 y 16 encuentros, una o dos veces semanales), y fijar los diferentes roles.

La entrevista como instrumento primordial, asume diferentes modalidades, que se especifican sucintamente a continuación.

1) La primera o las primeras entrevistas de orientación. Permiten conocer la demanda del sujeto, sus preocupaciones manifiestas, la situación por la que está atravesando. Posibilitan establecer el diagnóstico o pre-diagnóstico sobre el grado de orientabilidad del sujeto, es decir, el grado de compromiso del joven con su situación de elección; plantear cuál es la problemática que trae el orientado y qué le impide llegar a una elección (Gavilán \& Souto, 1982). Para la elaboración de este "primer diagnóstico" Bohoslavsky (1985), enumera diferentes criterios a tener en cuenta: manejo del tiempo, momentos referidos al proceso de decisión, ansiedades predominantes, carreras previstas, identificaciones predominantes, situaciones por la que atraviesa, fantasías de resolución y deuteroelección.

Para BohosIvasky la Orientación persigue un objetivo observable, la elección de una carrera o trabajo, y otros dos no observables: la deuteroelección que permite al adolescente aprender a elegir y la promoción de la identidad vocacional, por lo tanto de la identidad personal.

En síntesis, el objetivo de ese primer encuentro es, por un lado "descifrar el modo en que se llega al proceso de orientación; qué se busca de la Orientación y cuáles son los verdaderos móviles de la demanda manifiesta" (Gavilán \& Souto, 1982). Por el 
otro, formular el encuadre de trabajo y recordarlo cada vez que sea necesario hacerlo.

2) Entrevistas de profundización. Su propósito es doble. Por un lado conocer la historia personal del orientado, que incluye sus trayectos educativos y/o laborales, el posicionamiento familiar o del contexto vincular significativo para el orientado, con relación a la elaboración de su proyecto personal, las identificaciones predominantes y fantasías respecto de su proyecto de vida. Por el otro, explorar rasgos de personalidad, visualizar tensiones de dependencia/independencia, grado de autonomía en la toma de decisiones y de autoconocimiento o conocimiento de sí mismo, reconocimiento del contexto y de la realidad en la que está inserto (Quiles, 2012). Pueden incluirse técnicas específicas como la Autobiografía vocacional (Müller, 2009) y el Árbol genealógico vocacional- Argevoc (Migliano, 1986), entre otras.

3) Entrevistas de esclarecimiento. Aquí se intenta identificar y señalar cuáles son los facilitadores u obstaculizadores en el proceso, es decir, descifrar los motivos por los cuales el orientado no puede elegir, cuáles son las identificaciones que obstaculizan el aquí y ahora de la elección, y los mecanismos que implementa para no tomar decisiones.

4) Entrevistas de administración de técnicas de exploración. Se trata de la administración de instrumentos seleccionados para recabar datos de un aspecto específico del orientado, que pueda tener alguna gravitación en la elección de carreras y/o trabajo (Gavilán, 2006, p.135). Su propósito es explorar a través de distintas pruebas, psicométricas y proyectivas, diversos aspectos de la personalidad, tales como aspectos intelectuales, intereses, aptitudes, que el orientador considere significativas para el proceso que está implementando. Se administran de acuerdo con la modalidad y duración del proceso (de modo individual o grupal) y según la etapa evolutiva del orientado.

5) Entrevistas de información. La información ocupacional es parte significativa dentro del proceso de orientación y refiere a las carreras, ocupaciones, áreas de trabajo, demanda profesional, etc. (Bohoslvasky, 1985, p.157). Persiguen un doble 
objetivo: pedagógico y psicológico. El adolescente que generalmente consulta, tiene información, pero la misma puede estar distorsionada o ser incompleta. Por lo tanto, el rol del psicólogo orientador será corregir esas distorsiones y movilizar al sujeto en la búsqueda de la información (y proporcionarla) sobre la oferta educativa y laboral, los lugares de estudio, el campo laboral, etc., ampliando de esta manera la toma de conocimientos sobre el tema. La información debe brindarse de manera gradual. En un primer nivel, es necesario acercarse de forma general a la gran oferta de los distintos centros educativos, de modo tal de asegurar la elección sin desconocer el resto de las opciones existentes. En un segundo nivel, más específico, se profundiza la información de las alternativas por las que los orientado han optado, por razones específicas. Por último, en el nivel del contacto directo el sujeto puede acercarse a los lugares de estudio, entrevistarse con profesionales, etc. De esta manera, se produce un acercamiento a la información que conlleva a una extensión decreciente y a una profundización creciente (Brea, 1965). Algunos procedimientos y técnicas para trabajar la información son: Técnica de Realidad Ocupacional (RO), Juegos con diccionarios y guías de carreras, Materiales impresos e informatizados, Entrevistas telefónicas, Entrevistas y encuentros presenciales, Visitas a instituciones, Paneles, Mesas redondas, Talleres, Monografías profesionales, Videos, Películas (Bohoslasky, 1985; Muller, 2009).

6) Entrevistas de integración y síntesis. Suponen la integración de todos los aspectos vistos y profundizados durante el proceso y una autoevaluación por parte del orientado de su recorrido hasta su decisión final. El orientador puntuará los aspectos más significativos del proceso con relación a lo verbalizado y a lo no verbalizado por el orientado. En esta última etapa se incluyen numerosos aspectos: la situación demandante, los caminos transitados, los obstáculos encontrados, las vivencias del sujeto, los interrogantes formulados y las respuestas alcanzadas, el estado en que se encuentra en la actualidad y el grado de decisión vocacional respecto de la elección realizada, por ejemplo:

1) carrera,

2) trabajo, 
3) trabajo y estudio,

4) área educativa -con la demora temporal para la decisión definitiva,

5) integración a un proyecto solidario, recreativo, económico, etc.

Imaginario social. En este eje, Gavilán (2006) retoma los aportes de Castoriadis sobre la "Institución Imaginaria de la Sociedad", y "reduce" el concepto de "imaginario social", a una categoría instrumental más circunscripta y más operativa. Castoriadis distingue entre el imaginario social "efectivo" y un imaginario social "radical". El primero es el que mantiene unida a la sociedad: es un legitimador de un orden existente; es, en definitiva, "Io instituido". En cambio, el imaginario social "radical" tiene la capacidad de transformar el universo de significaciones adoptado, mediante novedosas propuestas imaginarias, es decir, es "lo instituyente" que se encarga de la producción de nuevas formas de significación (Castoriadis, 1988). El juego dialéctico entre lo instituido y lo instituyente explica los procesos de consolidación y sus brotes de ruptura y cambio

Entonces, desde el Modelo Teórico Operativo en Orientación, se rescata del concepto original, la designación de su status de productor de realidad y el carácter de "inventado", que se sitúa frente a los procesos reales como su opuesto, pero que paradójicamente, provoca modificaciones en la realidad, de igual modo que lo hacen dichos procesos reales. Por este motivo, algunos conjuntos sociales imaginan, fantasean y sostienen que acontecen cosas, que en realidad no suceden. Esto pasa con supuestas situaciones respecto del empleo, la economía, las ocupaciones futuras, los saberes que serán exigidos, entre otros.

Prevención. Los términos "prevención" y "prevenir" han estado, y están, implícita o explícitamente, incluidos en todos los enfoques de la Orientación, ya sea en sus antecedentes históricos, o en los problemas específicos a dilucidar.

Se entiende a la prevención como la capacidad que posee el ser humano y su grupo social para anticiparse, con diferentes estrategias, a situaciones que puedan provocar diversos tipos de daño, posibilitando así crear y/o fortalecer los conocimientos, actitudes, habilidades y valores que ayudarán a impedir o minimizar el daño. 
Siguiendo los aportes de Buela-Casal, Carrasco Giménez y Fernández Ríos (1997), se define a la Psicología Preventiva como:

Un campo interdisciplinario de investigación y acción que desde una perspectiva proactiva, ecológica, y ética y una concepción integral del ser humano en su contexto sociocomunitario real y concreto, trata de utilizar los principios y la tecnología de la intervención actualmente disponible en cualquier disciplina, que resulten útiles para la prevención de la enfermedad, la promoción de la salud física y mental, y de la calidad de vida a nivel comunitario, tanto a corto como a largo plazo (Buela-Casal, Carrasco Gimenez, \& Fernandez Rios, 1997, p. 78).

Por otro lado, es importante mencionar la clasificación que realizó Caplan (1986) sobre los tres niveles de prevención que desarrolla:

- Prevención primaria: son las estrategias que se llevan a cabo en una población para evitar que aparezcan determinadas situaciones anómalas.

- Prevención secundaria: son las acciones que se realizan para reducir un trastorno o disminuirlo.

- Prevención terciaria: se lleva adelante para tratar de reducir en la comunidad o población las consecuencias derivadas de los padecimientos físicos, psíquicos y sociales y estimular en los individuos sus propias consecuencias.

Gavilán (2017) refiere no obstante, que actualmente autores como Fernández Ríos y Gómez Fraguela (2007), proponen los siguientes niveles de prevención:

a) Prevención primaria proactiva (universal), centrada en el sujeto. Son acciones que intentan evitar cualquier consecuencia negativa frente a factores de riesgo en sujetos en los cuales la patología que se pretende combatir, aún no se ha presentado.

b) Prevención primaria proactiva (universal) centrada en el contexto. Intenta evitar problemas que incluyen a todos los integrantes de una comunidad dada, actuando sobre el ambiente con el propósito de minimizar los factores de riesgo.

c) Prevención primaria reactiva (selectiva) centrada en el sujeto. Se refiere a intervenciones diseñadas para actuar sobre un grupo de individuos que 
presenta alto riesgo de sufrir una patología concreta. Es primaria porque las acciones se llevan a cabo antes que la patología se desarrolle y selectiva porque está dirigida solo a aquellos sujetos que se encuentran expuestos a la situación de riesgo. Se trata de darles herramientas para que puedan afrontar dichos riesgos.

d) Prevención primaria reactiva (selectiva), centrada en el contexto. Se refiere a aquellas intervenciones que se llevan a cabo no sobre individuos, sino sobre sistemas o contextos en los cuales se desarrollan dichos sujetos.

e) Prevención secundaria (reactiva) centrada en el sujeto. Son actuaciones dirigidas a reducir la prevalencia de una determinada enfermedad o problema social. Se trata de la detección temprana de una problemática particular, de descubrir los primeros síntomas para evitar que la enfermedad se extienda en la población o que se cronifique.

f) Prevención secundaria (reactiva) centrada en el contexto. Son las estrategias que pueden aplicarse con la intención de mejorar el contexto sociomaterial en el cual se desarrolla la vida de las personas. Serán acciones tendientes a reducir situaciones estresantes y/o de violencia, estimular las redes de apoyo social, optimizar la calidad de vida, etc.

Ahora bien, dentro del contexto educativo, aparece como fundamental y más abarcativa, la prevención primaria en orientación, que debería incluirse en forma sistemática a partir del ingreso del alumno al sistema educativo formal, de modo tal de:

- Apuntar al ejercicio de roles.

- Reconocer los intereses.

- Promover la autonomía.

- Estimular la autoestima.

- Lograr el reconocimiento y/o aceptación de la diferencia.

- Favorecer el conocimiento. 
Bajo esas consideraciones, la Orientación desde un enfoque preventivo, requiere de un Modelo Integral de Prevención que combina y articula los aportes de dos modelos (Gavilán, 2006):

1) Modelo epidemiológico social: establece sus unidades de análisis en las poblaciones. Permite contextualizar las respuestas individuales en términos del medio social donde se desarrollan, detectar situaciones de riesgo bio- psicosocial y llevar adelante técnicas de movilización para enfrentar dichas situaciones.

2) Modelo Educativo formal y no formal: se apoya en la educación básica formal y no formal; y tiene como contexto a la comunidad educativa considerada eje de la prevención primaria.

Por último, en relación con las modalidades de la prevención, en el Modelo Teórico Operativo el énfasis está puesto en la modalidad múltiple o inespecífica. Efectivamente, la índole del planteo integral que se propone, y teniendo presente que la institución educativa puede ejercer un rol de contención y no de exclusión, todas las acciones que se emprenden tienden a estimular la comunicación, la participación, la cooperación y la creatividad. Es decir, constituyen acciones de prevención tendientes a lograr mejores estilos de vida. Se apunta con ella a promover el conocimiento y la reflexión sobre distintas problemáticas, a través de los contenidos curriculares y de la profundización que cada grupo humano considere necesaria.

Ahora bien, en ese Modelo, la autora va a plantear como hipótesis que la Orientación necesita ampliar su campo de trabajo e investigación con nuevos ejes, campos y saberes. Los definidos y los que puedan incorporarse deben articularse con los saberes interdisciplinarios y transdisciplinarios, para adecuar la Orientación a las exigencias actuales y proporcionar los modelos operativos apropiados.

\section{Campos y saberes}

Los tres ejes considerados, proceso, imaginario social y prevención, se manifestarán en diferentes campos y saberes. Entre los primeros se encuentran los campos de la educación, el trabajo, la salud y las políticas sociales. Entre los segundos los saberes disciplinarios, interdisciplinarios y transdisciplinarios. 


\section{Campos}

El campo, es un espacio de saberes y prácticas relacionadas con una misma problemática, y con un conjunto de temas que se desprenden de la misma; saberes y prácticas que se pueden enfocar desde la disciplina, desde la interdisciplina -en tanto actividades que se complementan-, y/o desde la transdisciplina -entendida como un campo constituido a partir de distintas miradas (Gavilán, 2006, p.113). La autora toma los aportes de Bordieu (2003) sobre Campo, quién lo entiende como un espacio de lucha, donde los distintos contendientes tratan de defender o apropiarse de un material cultural y simbólico que se constituye en el objeto apetecido por los agentes sociales.

Los campos permiten ampliar el ámbito de investigación y de trabajo; incluyen tanto la Psicología, que adquiere su rol preponderante en el microproceso y el proceso específico de la orientación, como al resto de las disciplinas que la acompañan, a saber: Ciencias de la Educación, Sociología, Relaciones del Trabajo, Antropología, Economía, Ciencias Políticas y Trabajo Social.

Campo educativo. Comprende el estado de la educación en el sistema formal y no formal de la enseñanza. Abarca la problemática de los objetivos y logros en el estudio, así como el nivel de deserción y la instrumentación de respuestas frente a las diferentes demandas que requieren estrategias específicas para poder incluir a todos los sujetos. Esto último es primordial en el caso de sujetos que presentan alguna discapacidad. Al respecto en la Declaración de Salamanca de 1994, se aboga en favor de la escuela inclusiva y la promoción de una educación para todos, especialmente para los que tienen necesidades educativas especiales. El principio fundamental que rige las escuelas integradoras es que todos los niños deben aprender juntos, siempre que sea posible, más allá de sus dificultades y diferencias. La escolarización de niños en Escuelas Especiales debiera ser una excepción, que sólo sería recomendable aplicar en aquellos casos, poco frecuentes, en los que se demuestre que la educación en las clases ordinarias no puede satisfacer las necesidades educativas o sociales del niño, o cuando sea necesario para el bienestar del propio niño o el de los otros niños. 
Campo de la Salud. Comprende el conjunto de programas, objetivos, acciones y estrategias tendientes a lograr el completo estado de bienestar físico psíquico y social y no sólo ausencia de enfermedad. En esta definición de la OMS (Organización Mundial de la Salud), según Gavilán debería sustituirse el término "completo" por el término "relativo", porque hablar de "completo estado" significa asumir una posición utópica, teniendo en cuenta que las situaciones difieren en cada contexto espacio-temporal.

Por ello resulta interesante incorporar el concepto de salud que plantea Saforcada (2010) como

La situación de relativo bienestar físico, psíquico, espiritual, social y ambiental (el máximo posible en cada momento histórico y circunstancia sociocultural determinada), debiéndose tener en cuenta que dicha situación es producto de la interacción permanente y recíprocamente transformadora entre las personas y sus ambientes, comprendiendo que todos estos componentes integran a su vez el complejo sistema de la trama de la vida (p.104)

La salud desde el enfoque positivo o integral nos habla de la importancia de la calidad de vida, vinculándola con la justicia y la ética, y teniendo en cuenta los aportes de varias disciplinas de contenidos muy diferentes. En su esencia existe el carácter valorativo, contextual e histórico al que debe atenerse, así como también su fidelidad a los valores humanos que constituyen expresión de progreso social y respeto a una individualidad que sepan armonizar necesidades individuales y sociales. Partiendo de estas exigencias, entender la calidad de vida como la necesidad de vivienda digna, trabajo adecuado, educación de calidad, servicios de salud, etc. permitirá valorar las condiciones de vida de las personas y comunidades, para poder estimar el grado de progreso alcanzado y seleccionar las formas de interacción humana y del medio ambiente que resulten más adecuados. Por todo lo expuesto, al hablar de salud integral estamos hablando de calidad de vida dentro de cada situación contextual. Por último, debemos dejar de hablar y nominar al sujeto como enfermo mental o a su padecimiento como enfermedad mental ya que se trata de una totalidad, de modo tal que cuando aparece un problema físico o psicológico afectan por igual su subjetividad. En consecuencia debemos hablar de salud integral, 
que estará compuesta por el conjunto de interacciones de la persona, su familia, el entorno, las diversas relaciones sociales, comunitarias, el contexto sociocultural y la posibilidad de que se cumplan los derechos humanos esenciales como: salud, educación, vivienda, trabajo (Gavilán, 2015).

El campo de la salud incluye entonces la promoción, la prevención y la asistencia para el mejoramiento de la calidad de vida. Las acciones generadas en este campo dependen de las políticas gubernamentales operativizadas en el ámbito provincial y municipal, a través de los hospitales y servicios de alta y mediana complejidad, centros de salud, centros de atención primaria de la salud, planes y programas -muy especialmente aquellos que se dedican a la prevención en poblaciones vulnerables (adultos mayores, embarazadas, lactantes).

Campo laboral-económico. Hace referencia a todas las actividades relacionadas con el mundo del trabajo: inserción, desocupación, precarización, inestabilidad.

En este aspecto, de acuerdo con la OMS, alrededor del 10\% de la población mundial tiene alguna discapacidad, esto equivale a unas 600.000.000 de personas (Gómez Jarabe \& Bonantini, 2008, p. 73)

En Argentina según la encuesta permanente de hogares existe un $7,3 \%$ de la población que tiene algún tipo de discapacidad. Si bien se cuenta con legislación y programas referidos a la atención de las necesidades de este sector poblacional muy pocas veces se cumplen las leyes establecidas. En líneas generales podemos sostener que el problema de la "discapacidad" se encuentra considerado en la Constitución Nacional en sus artículos 16, 43 y 75 inciso 23, en los que se establece la igualdad de todos los ciudadanos y la admisibilidad a todos los empleos sin otra condición que la idoneidad, el derecho al recurso de amparo ante cualquier arbitrariedad del Estado y la obligatoriedad del Congreso de promover la igualdad real de oportunidades y de trato y del pleno goce de los derechos constitucionales. Le siguen leyes como la Ley 24.147 que regula la creación de talleres y grupos laborales protegidos, la Ley 25.689 que establece cupos para discapacitados en el empleo público nacional y la Ley 24.314 que obliga a la supresión de barreras físicas con todas las indicaciones arquitectónicas del espacio público y las reglamentaciones 
pertinentes para el transporte público urbano, de corta y media y larga distancia, subsidios, etc.

Sin embargo, es interesante analizar cómo se refleja esta realidad en la discapacidad y el empleo. En general los programas de asistencia a las personas con discapacidad se caracterizan por tener la misma estructura de los programas de asistencia a los desocupados: asistencia económica mínima, información general, registros de personas para una probable inserción laboral e incentivos empresariales para la contratación de personas con dificultades físicas o psíquicas. Los programas de inserción laboral para las personas con discapacidad no son parte de una política de Estado para afrontar los problemas de empleo de la población con discapacidades, y sólo se limitan a realizar registros (de oferta y demanda de empleo) o brindar algún tipo de asistencia económica (que en todos los casos es insuficiente), pero no trabajan en la determinación de las problemáticas que acontecen en la vida cotidiana de estas personas.

Campo de las políticas sociales. Son conjuntos de estrategias que apuntan a lograr resultados esperados sobre sectores o segmentos sociales discriminados según recortes.

Habitualmente suele circunscribirse el campo de las políticas sociales al área exclusivamente pública en todos los niveles estatales. Pero progresivamente van ocupando un significativo espacio las organizaciones sociales que surgen de la misma sociedad. De esta manera se ha producido un importante desarrollo de las organizaciones llamadas del "Tercer sector" (ONGs, fundaciones, asociaciones, redes sociales).

\section{Saberes}

En el Modelo Teórico Operativo propuesto, la autora desagrega un espacio de reflexión singular denominado saberes específicos que recorren todo el espacio de los ejes y campos incluidos.

Su incorporación atiende, en principio, al valor de las nociones de disciplina, interdisciplina y transdisciplina, que reside en la capacidad para abordar, separada y conjuntamente, una serie de problemas que influyen en su propuesta, que tiene en 
cuenta la complejidad que adquieren en su desarrollo problemático. "Hemos denominado saberes, específicos y ampliados, a estas maneras de trabajar conjuntos restringidos y conjuntos complejos, donde se articulan diversas disciplinas en nuevos espacios de saber" (Gavilán, 2006, p.175).

Disciplinarios. Sucintamente, la disciplina abarca el conjunto de estrategias, métodos, saberes y prácticas relacionadas sistemáticamente, que establecen un objeto de conocimiento sobre un área determinada del mundo.

Interdisciplinarios. A su vez, la interdisciplina proporciona un mayor acercamiento a enfoques vinculados con objetos de conocimientos más complejos e interrelacionados con respecto a diversos referentes reales.

Transdisciplinarios. Por último, y teniendo en cuenta el paradigma de la complejidad que plantea Morin (1990), la autora sostiene que se puede pensar en la Transdisciplina como una etapa de fusión y difusión del saber, donde varias disciplinas se amalgaman y construyen un objeto de conocimiento común. De este modo supone un paso más y dificultades mayores, ya que implica crear saberes y prácticas con problemas y recorridos propios. Aquí el mismo objeto de conocimiento y acción es transdisciplinario y sus problemáticas también lo son. El supuesto epistemológico subyacente señala que el todo es más que la suma de las partes, de modo tal que deben considerarse enfoques totalizadores "macro" que superen las fragmentaciones habituales.

La Transdisciplina entonces, abre nuevos saberes y prácticas antes desconocidos, que no invalidan los desarrollos uni e interdisciplinarios, sino que más bien considera a todos ellos en paralelo y en interacción, como modos específicos de desarrollo de los campos del saber.

\subsection{Concepciones sobre la discapacidad}

\section{Sobre el concepto discapacidad}

A lo largo de la historia, han sido varias las denominaciones que han recibido las personas con discapacidad. En esta Tesis partimos de la Clasificación Internacional del Funcionamiento, de la Discapacidad y de la Salud (CIF). Este documento es el 
instrumento oficial por medio del cual desde año 2001, la Organización Mundial de la Salud (OMS) define y clasifica la discapacidad. Parte de un modelo bio-psico-social y marca una evolución conceptual al proponer superar enfoques reduccionistas que ponen el acento en lo "dañado". La versión anterior de la OMS (1980) conocida como la Clasificación Internacional de la Deficiencia, de la Discapacidad y de la Minusvalía (CIDDM), a partir de una perspectiva médica, propone una clasificación diferencial entre las deficiencias (efectos orgánicos), las discapacidades (efectos funcionales) y las minusvalías (efectos sociales).

En la definición actual, se parte de la totalidad del individuo, al que se lo entiende como sujeto de derechos y obligaciones. Se conceptualiza a la "discapacidad como los aspectos negativos del funcionamiento humano, es decir limitaciones en la actividad y restricciones en la participación, a partir de un estado o condición de salud de una persona en interacción con el contexto" (Pantano, 2007, p. 106).

Los aportes de Pantano (2007) esclarecen el concepto, desde el enfoque social de la discapacidad. Menciona que de este modo la 'discapacidad', pasa a ser un término abarcativo, 'paraguas o baúl', debajo o dentro del cual se entienden la deficiencia, la discapacidad y la minusvalía.

La discapacidad puede ser considerada un término técnico que resume todo un proceso que involucra a la persona con un estado negativo o problema de salud en interacción con el contexto, y que puede afectar las actividades y la participación propias del funcionamiento humano. Se funda en un problema de salud y se constituye en la interacción de la persona (con ese problema) y el entorno. En este sentido, puede decirse que el estado de salud o la deficiencia de la persona afectada explica, entonces, sólo una parte de la 'condición de discapacidad'. Una persona estará más o menos limitada de acuerdo a sus propias características y a las del ámbito en que se desarrolle, es decir al escenario histórico, cultural y geográfico. Entonces en primer lugar hablamos de personas que tienen algún tipo de discapacidad, más allá del tipo de discapacidad del que se trate, como un sujeto de derechos y obligaciones. La sociedad está integrada por personas, algunos con y 
algunos sin discapacidad. Pero desde un enfoque de derechos, son todos ciudadanos (Pantano, 2007).

Esta consideración es acorde con lo que se plantea en la Convención Internacional sobre los Derechos de las Personas con Discapacidad, aprobada por las Naciones Unidas en 2006, e incorporada a nuestra legislación nacional en 2008 (Ley 26.378).

Allí se explicita que:

La discapacidad es un concepto que evoluciona y que resulta de la interacción entre las personas con deficiencias y las barreras debidas a la actitud y al entorno que evitan su participación plena y efectiva en la sociedad, en igualdad de condiciones con las demás. (ONU, 2006, p 2)

Las Personas con Discapacidad incluyen a "aquellos sujetos que tienen deficiencias físicas, mentales, intelectuales o sensoriales a largo plazo que, al interactuar con diversas barreras, puedan impedir su participación plena y efectiva en la sociedad, en igualdad de condiciones con las demás" (ONU,2006, p.4).

Entonces, la discapacidad no puede ser considerada con un estatuto fijo, sino como una condición relacional que surge de la interacción entre limitaciones funcionales del sujeto y las barreras que limitan las actividades y la participación propias del funcionamiento humano.

El artículo 27 de la mencionada Convención, hace referencia al trabajo y empleo, y se explicita que las personas con discapacidad deben tener acceso a programas generales de orientación técnica y vocacional, servicios de colocación y formación profesional y continua. Asimismo atiende a que se promueva la creación de programas de rehabilitación vocacional y profesional, mantenimiento de empleo y reincorporación al trabajo, dirigidos a personas con discapacidad. En este sentido, para el campo de la Orientación, este documento internacional da fuerza a la concreción de propuestas de intervención con personas con discapacidad, para la elaboración de proyectos educativos, laborales y/o personales, entendidos como un derecho.

Ahora bien, siguiendo con los aportes de Palacios y Romañach (2007), ellos sustituyen el término "Discapacidad" por el de "Diversidad funcional". En esta tesis 
vamos a mantener la denominación Personas con Discapacidad (en adelante, PCD) que es la que se adopta en la Convención Internacional sobre los Derechos de las Personas con Discapacidad (ONU, 2006), que describimos anteriormente.

\section{Modelos teóricos sobre la discapacidad}

Desde una perspectiva histórica, los autores recorren los diferentes modelos, que resultaron ser la base del tratamiento que ha recibido la discapacidad. Podemos distinguir entonces el modelo de la prescindencia, el modelo rehabilitador-médico, el modelo social y el modelo de la diversidad.

Modelo de la prescindencia. Consideraba que las causas de la discapacidad tenían un motivo religioso, las personas con discapacidad eran consideradas innecesarias para la comunidad, porque no contribuían con sus necesidades y, además, se creía que albergaban mensajes diabólicos, consecuencia del enojo de los dioses, o que sus vidas no merecían la pena ser vividas en función de las desgracias que las identificaban. De este modo, la sociedad prescindía de ellas, implementando distintas políticas, que los autores van a desarrollar como dos submodelos: el eugenésico y el de la marginación.

a) Sub modelo Eugenésico. Se sitúa en la antigüedad clásica, particularmente en la sociedad griega y la romana. Basándose en motivos religiosos y políticos, consideraba inconveniente el desarrollo y crecimiento de niños con discapacidad. La solución adoptada era prescindir del individuo con discapacidad mediante el recurso a prácticas eugenésicas, como el infanticidio.

b) Sub modelo de la Marginación. Durante la Edad Media, se consideraba a la discapacidad como una situación inmodificable. El médico o el sacerdote eran los encargados de diagnosticar diferencialmente si un comportamiento extraño correspondía a un proceso natural o uno diabólico. La solución era la exclusión, ya sea como consecuencia de subestimar a las PCD y considerarlas objeto de compasión, o como consecuencia del temor y/o el rechazo por considerarlas objeto de maleficios, o también como advertencia de un peligro inminente. Dentro de esta categoría entraban también los pobres y los marginados signados por un destino marcado por la exclusión. 
Modelo Rehabilitador o Médico. Este modelo es el que ha hegemonizado, al menos desde la Segunda Guerra Mundial, el abordaje de la discapacidad desde el sistema de salud. La persona con discapacidad pasa a ser un objeto de asistencia, sobre el que se hacen diferentes especificaciones, a saber:

- Las causas de la discapacidad dejan de ser religiosas para ser científicas (la discapacidad se predica en términos de salud o enfermedad).

- Las personas con discapacidad ya no serían "inútiles", pueden aportar en la comunidad, pero a condición de que sean "rehabilitadas" o "normalizadas".

- Se promueve el fortalecimiento de la "educación especial" (dirigida a las capacidades "residuales") y de la "rehabilitación" en el sentido mencionado, y con ello se fomenta e impulsa la institucionalización y el empleo protegido, en lugar del empleo legítimo, como modelo de "protección".

- Se produce una identificación de la discapacidad con el concepto de enfermedad.

- La asistencia social pasa a ser el principal medio de subsistencia de las personas con discapacidad a través de la proliferación de jubilaciones, pensiones, subsidios etc. como solución predominante.

- Se pone un excesivo énfasis en el diagnóstico clínico (el problema aparece cuando el médico o el sistema de salud no sólo determina el diagnóstico clínico, sino que por su intermedio incide en la forma de vida de las personas con discapacidad).

Modelo Social. Comienza a fines de la década de los años sesenta del siglo pasado, en Estados Unidos e Inglaterra. Considera que las causas que dan origen a la discapacidad no son ni religiosas, ni científicas, sino que son preponderantemente sociales; y que las personas con discapacidad pueden aportar a las necesidades de la comunidad en igual medida que el resto de personas, pero siempre desde la valoración y el respeto de su condición de personas y de la diversidad.

Este modelo se encuentra íntimamente relacionado con la asunción de ciertos valores intrínsecos de los derechos humanos, que aspira a potenciar el respeto por la dignidad humana, la igualdad y la libertad personal, propiciando la inclusión social. Se asienta sobre la base de determinados principios: autonomía y vida 
independiente, no discriminación, accesibilidad universal, educación inclusiva, diálogo civil, entre otros. Parte de la premisa de que la discapacidad es una construcción y un modo de opresión social y el resultado de una sociedad que no considera ni tiene presente a las personas con discapacidad. Asimismo, apunta a su autonomía para decidir respecto de su propia vida, y para ello se centra en la eliminación de cualquier tipo de barreras, a los fines de brindar una adecuada equiparación de oportunidades.

Modelo de la diversidad. Palacios y Romañach (2007), van a sostener que en la actualidad podríamos hablar de un cuarto modelo: el Modelo de la diversidad, que en cierta medida constituye una variable del Modelo Social. Se trata de un modelo basado en los postulados de los Movimientos de la Vida Independiente, que demanda la consideración de la persona con discapacidad (o con diversidad funcional, término utilizado por este movimiento) como un ser valioso en sí mismo por su diversidad.

El Movimiento de Vida Independiente revela la intención fundamental de que cada sujeto mantenga el control sobre su propia vida, eligiendo opciones estables que minimicen la dependencia de los demás en la realización de las actividades de la vida diaria. Esta propuesta se enfrenta tanto a los modelos centrados en la Deficiencia, como a los Modelos Médicos.

Los dos primeros modelos tienen una visión negativa de la situación que provoca la Discapacidad, con consecuencias para su consideración. El Modelo médico, a su vez, identifica al profesional de la medicina como técnicamente competente para tomar decisiones sobre la persona a la que trata y ha mostrado ser inadecuado para la realización de las actividades de la vida cotidiana y para la adquisición de las habilidades necesarias para conseguir empleo de las PCD.

Por su parte el Modelo de la Diversidad, demanda el reconocimiento de derechos específicos de estos grupos, no tanto desde una argumentación de tipo universalista, sino más bien de tipo particularista.

En esta tesis, entonces nos vamos a posicionar en el Modelo de la "Diversidad" (Palacios \& Romañach, 2007) y vamos a considerar aspectos específicos de las 
normativas nacionales e internacionales sobre el derecho a la educación de las PCD, que completaremos en el tratamiento de los antecedentes en materia de discapacidad visual.

\subsection{Normativas nacionales e internacionales sobre el derecho a la Educación Superior de las Personas con discapacidad}

A continuación, mencionaremos algunos tratados internacionales, documentos legales y normativas generales, tanto nacionales como internacionales, sobre el derecho a la Educación Superior de las personas con discapacidad. Los mismos, aportan la matriz jurídica-normativa necesaria para nuestro posicionamiento teórico.

En primer lugar, retomamos la ya mencionada Convención Internacional sobre los Derechos de las Personas con Discapacidad (ONU; 2006), en cuya elaboración participaron las propias personas con discapacidad. Su inclusión ha dado cuenta de la importancia de la implicación de este colectivo para que efectivamente se logre "promover, proteger y asegurar el goce pleno y en condiciones de igualdad de todos los derechos humanos y libertades fundamentales para todas las personas con discapacidad, y promover el respeto de su dignidad inherente" (ONU, 2006, p.3).

En su artículo 9 de Accesibilidad, establece que los Estados Parte adoptarán medidas pertinentes para asegurar el acceso de las personas con discapacidad, en igualdad de condiciones con las demás, con respecto al entorno físico, el transporte, la información y las comunicaciones, incluidos los sistemas y las tecnologías de la información y las comunicaciones, y a otros servicios e instalaciones abiertos al público o de uso público, tanto en zonas urbanas como rurales.

En su artículo 24 de Educación, establece que los Estados Parte reconocen el derecho de las personas con discapacidad a la educación superior, la formación profesional, la educación para adultos y el aprendizaje durante toda la vida sin discriminación y en igualdad de condiciones con los demás.

El Instituto Internacional de la UNESCO para la Educación Superior en América Latina y el Caribe (IESALC) es un organismo dedicado a la promoción de la educación superior, que actúa como centro de reflexión y vínculo para armonizar, promover y coordinar todas las iniciativas y demandas relacionadas con los sistemas 
de Educación Superior en la región. Implementa en Latinoamérica y el Caribe el programa que, en materia de educación superior, aprueba la Conferencia General de la UNESCO. En el capítulo 10 de este informe denominado "Integración/inclusión de las personas con discapacidad en la Educación Superior", se exhorta a los gobiernos y a las agencias de acreditación de la Educación Superior a tomar diferentes medidas en favor de las personas con discapacidad y en particular, para su inclusión en los estudios superiores.

Otro documento de relevancia es La Declaración de Lisboa: Opiniones de los Jóvenes sobre Inclusión Educativa (2007), que constituye la misma, es el resultado de las propuestas consensuadas entre los jóvenes con Necesidades Educativas Especiales de Educación Secundaria, Formación Profesional y Enseñanza Superior, de 29 países. Allí expresaron sus opiniones acerca de la educación inclusiva y los jóvenes concluyeron: "Somos los constructores de nuestro futuro. Necesitamos eliminar las barreras que hay en nuestro interior y las del exterior. Debemos crecer más allá de nuestras discapacidades, solo así el mundo nos aceptará mejor".

Según la Conferencia Mundial de Educación Superior: se establece que los Estados miembros en colaboración con todos los actores involucrados, deberían poner en marcha políticas y estrategias a nivel institucional y del sistema que apunten a garantizar el ingreso equitativo a grupos sub representados, tales como trabajadores pobres, minorías, personas con discapacidad, migrantes, refugiados y otras poblaciones vulnerables (CMES - UNESCO 2009).

En nuestro país, la Ley de Educación Superior 24.521 y su modificación Ley 25.573 (2002) establece en su Artículo $2^{\circ}$ que:

El Estado al que le cabe responsabilidad indelegable en la prestación del servicio de educación superior de carácter público, reconoce y garantiza el derecho a cumplir con ese nivel de la enseñanza a todos aquellos que quieran hacerlo y cuenten con la formación y capacidad requeridas ( $p .1)$.

En el artículo $13^{\circ}$, indica que los estudiantes de las instituciones estatales de educación superior tienen derecho a ingresar al sistema sin discriminaciones de ninguna naturaleza (inciso a), a obtener becas, créditos y otras formas de apoyo 
económico y social que garanticen la igualdad de oportunidades y posibilidades, particularmente para el acceso y permanencia en los estudios de grado (inciso c), y en especial las personas con discapacidad tendrán derecho, durante las evaluaciones, a contar con los servicios de interpretación y los apoyos técnicos necesarios y suficientes.

Por último, en el Preámbulo del Estatuto de la Universidad Nacional de La Plata (2008), se establece que:

La UNLP como institución pública, gratuita de educación superior, se ofrece abierta e inclusiva para toda la sociedad y establece como sus objetivos principales los de favorecer el acceso a sus aulas el conjunto del pueblo argentino y hacer llegar a cada rincón de la Patria los frutos de su labor. (..). Estará inspirada en los principios reformistas, asegurando la completa libertad académica, sin discriminación, limitaciones o imposiciones, buscando generar profesionales íntegros, capaces de afrontar los desafíos de su tiempo y comprometidos con la realidad de su gente. Asimismo, y para asegurar sus objetivos, establecerá políticas que tiendan a facilitar el ingreso, permanencia y egreso de los sectores más vulnerables de la sociedad (p. 3).

En su Artículo $109^{\circ}$ refiere que la Universidad asume como función indelegable el diseño y la ejecución de políticas de Bienestar Universitario y Asuntos Estudiantiles, con el objeto principal de propender al mejoramiento constante de la calidad de vida de los integrantes de la comunidad universitaria, a la vez que garantizar la efectiva igualdad de oportunidades para el acceso a la educación superior. En particular, y sin perjuicio de otros que surjan lógicamente de los fines generales enunciados anteriormente, serán objetivos específicos de estas políticas, entre ellas (inciso 5), procurar la equiparación de las oportunidades de las personas con discapacidad (docentes, estudiantes, no docentes, graduados) en la Educación Superior.

\subsection{La discapacidad visual}

En el desarrollo de esta tesis hacemos mención a la discapacidad visual bajo la consideración que incluye tanto la ceguera como la disminución visual o baja visión. Refiere por lo tanto a cualquier alteración del sentido de la vista, sea está total (ceguera) o parcial (disminución visual). 
Según Cuevas (2006) la discapacidad visual:

Se ha convertido en las últimas décadas en un área de preocupación para los centros asistenciales. Según el último informe del Programa de Prevención de Ceguera de la OMS, de los 1800 millones de niños menores de 15 años distribuidos en el mundo, 1.5 millones son ciegos. Este informe también señala que la mayor parte de estos niños habitan en países en vías de desarrollo. En el caso particular de América Latina, el índice de prevalencia de la ceguera infantil es de 0,6\% (Cuevas, 2006, p. 97).

Se considera que en la actualidad la discapacidad visual no es un fenómeno aislado, no es sólo el déficit que la persona posee, sino que hay otras variables que intervienen en su determinación. En este sentido, se deben tener en cuenta, la organización psicológica, el desarrollo de la inteligencia, las necesidades sociales y los modelos pedagógicos, ya que en estos últimos no sólo se hace referencia a la inserción escolar, sino también al aprendizaje de las habilidades necesarias para el desempeño en la vida cotidiana (Cuevas, 2006).

En función de ello en este capítulo se expondrán las definiciones usuales y actuales sobre esta discapacidad, así como las principales características que la identifican.

\section{Algunas definiciones}

Abordar el tema de la discapacidad visual requiere en primer lugar hacer algunas distinciones analíticas entre ceguera y disminución visual, para pasar luego a sus características.

\section{Ceguera}

La ceguera en sí, no es una enfermedad, es el resultado, la consecuencia final de una enfermedad, un accidente o ambos. La misma se establece en función de dos parámetros: la agudeza y el campo visual.

La agudeza visual (AV) es la capacidad que tiene el ojo para percibir los detalles de un objeto. Tendremos una mejor agudeza visual cuanto mejor veamos los detalles de lo que estamos observando, que se perciben habitualmente en la parte central de la retina. La AV normal es de $3 / 3$ o 1 , la ceguera total se expresaría como 0 (Cangelosi, 2006, p. 61$62)$. 
El campo visual (CV) es todo el espacio que el ojo puede percibir simultáneamente sin realizar ningún movimiento (ni de ojos ni del resto del cuerpo), la medición se expresa mediante un número de grados que pone de manifiesto la fracción de campo que la persona ve (Cangelosi, 2006, p.62-63).

Causas de ceguera. La ceguera, tiene muchas causas, sin embargo la incidencia de ceguera verdadera en muchos países aún es baja. Las causas principales son los accidentes, la diabetes y la degeneración macular.

A nivel mundial, la más significativa es la deficiencia de vitamina A. No obstante, la distribución mundial de las principales causas de ceguera son las siguientes, por orden de frecuencia:

1. Cataratas (opacidad del cristalino que impide el paso de la luz).

2. Errores de refracción (miopía, hipermetropía o astigmatismo) no corregidos.

3. Glaucoma (grupo de enfermedades en las que se produce un daño del nervio óptico).

4. Degeneración macular relacionada con la edad (enfermedad que produce una pérdida del campo de visión central).

5. Otras causas importantes son las opacidades corneales (enfermedades oculares que producen cicatrices de la córnea), retinopatía diabética (afección de la retina relacionada con la diabetes), tracoma y afecciones oculares infantiles tales como cataratas, retinopatía de los prematuros (afección de la retina observada en los niños prematuros).

Principales características de los sujetos con ceguera. La ceguera implica una serie de características singulares en relación, obviamente con la ausencia de visión, que afecta las posibilidades de movimiento y privilegia la entrada de la información por vía auditiva y táctil. Esta situación se traduce en una mayor dependencia de los demás en determinadas situaciones, tales como los espacios nuevos o las posibles alteraciones de un lugar conocido. Si bien pueden hacer la mayoría de las cosas que hace un vidente, se necesitará un tipo de aprendizaje, en el que la imitación se verá dificultada. La entrada de información por vía auditiva y táctil redunda en una la percepción limitada y fragmentada; produciendo una falta de perspectiva global. Sus manos no solo son el órgano de prensión, sino también de conocimiento. Esta nueva 
función, percepción háptica (tacto en movimiento), necesita entrenamiento para su desarrollo.

Según Leonhardt (1992), en general, se pueden presentar las siguientes características:

- El mundo está desdibujado. Sufre distorsiones sistemáticas de la realidad, lo que le lleva a una interpretación equivocada.

- Su percepción es analítica, secuencial. Esto provoca un ritmo más lento en los aprendizajes.

- El desarrollo motor se ve dificultado. Requiere más tiempo para descubrir los objetos y así poder manipularlos.

- Presenta dificultades en la atención por lo difuso de los estímulos que llegan.

- Manifiesta fatiga después de mirar y prestar atención a una tarea visual.

- Encuentra dificultad para imitar conductas, gestos y juegos.

\section{Disminución visual o baja visión}

La Organización Mundial de la Salud sugirió, a partir de la consideración de esos dos parámetros (agudeza visual y campo visual) una clasificación de las discapacidades. Esto ha servido a los distintos países en la toma de decisiones respecto a la prestación de determinados servicios sociales a las personas afectas de discapacidad visual. Más tarde se eliminó la categorización establecida, por las injusticias que pudieran producirse en la toma de decisiones aludida; aunque sin sugerir solución alternativa.

Si bien no hay un criterio unificado con respecto a la definición de la disminución visual a nivel mundial, los parámetros de la agudeza visual (AV) y del campo visual (CV) son los usualmente utilizados para su identificación. De la misma manera, no hay una definición unívoca con respecto a la denominación, por ese motivo, algunos autores hablan de Disminución Visual y otros de Baja Visión. A los fines de este trabajo, elegimos la primera.

Asimismo, siguiendo a Cangelosi (2006), podemos adaptar los siguientes criterios de clasificación a los fines de esta investigación, evitando el criterio estrictamente numérico. De este modo aparecen las siguientes categorías: 
1. Ceguera: ausencia de percepción luminosa, es decir ninguna percepción visual.

2. Disminución visual profunda: presencia de resto visual que requiere el uso de técnicas propias de las personas ciegas.

3. Disminución visual leve: capacidad de desempeño visual casi al mismo nivel que las personas con capacidad visual normal.

Por lo tanto, dentro de este colectivo encontramos personas con dificultades de diverso grado, que padecen diferentes alteraciones oculares y funcionales. Cuevas (2006) quien retoma la clasificación de Leonhardt (1992) y considera otros criterios, diferencia a ese respecto cuatro grupos:

1) Ciegos congénitos. Presentan ceguera desde el momento de su nacimiento o en el período prenatal, como es el caso de la retinopatía. Lowenfeld (1981), Leonhardt (1992) entre otros investigadores coinciden al manifestar el alto riesgo y la vulnerabilidad que presenta en su desarrollo el niño ciego, así como las consecuencias que suponen para su educación. Lowenfeld (1977) describe tres limitaciones básicas:

> En la cantidad y la variedad de experiencias que la persona puede realizar.

$>$ En la capacidad de conocer el espacio que lo rodea y moverse libremente.

$>$ En el control del mundo que lo rodea y las relaciones que establece con su entorno (Lowenfeld, 1977, citado por Cuevas, 2006, p.99).

2) Niños con baja visión. La eficacia visual de esta población es muy diversa, constituyendo un grupo muy heterogéneo. Diferentes factores, como la inteligencia general, la motivación, la estimulación visual, las influencias del entorno y la propia organización subjetiva intervendrían en el mejor aprovechamiento de la visión. E perfil cognitivo de estos niños es disarmónico. El desarrollo de la motricidad se presenta retrasado, traduciéndose en inhabilidades para el desempeño de la vida diaria. Esto se traduce en el riesgo de demandar sobre asistencia por parte de sus cuidadores y docentes, en desmedro de su autonomía. La adquisición del 
pensamiento lógico y las nociones conservadoras que se corresponden a cada etapa se desarrollan más lentamente que en sus pares con visión normal ${ }^{1}$

3) Niños con ceguera adquirida (luego del primer año de vida). Estos niños han utilizado su resto visual, aunque con grandes dificultades, durante parte del período sensorio motor. Esto influye tanto en la organización de las diversas estructuras mentales como en la interacción social.

4) Niños ciegos o de baja visión con afectación del sistema nervioso central. Estos niños presentan aún mayor heterogeneidad en su desarrollo, dependiendo de la afectación de las distintas áreas cerebrales. El ritmo de evolución de estos niños será aún más lento y estará notablemente afectado por la precocidad de la intervención profesional.

Principales características de los sujetos con Disminución visual. En este caso se trata de problemas derivados de la falta de agudeza visual (capacidad de percibir detalles con nitidez), que conlleva dificultades en la interpretación de símbolos pequeños, en la percepción del contraste, en la visión de distancia (pantalla del maestro, pizarrón, etc.), en la acomodación de la visión de la pantalla al papel o al teclado y viceversa; necesidades de una iluminación específica; percepción distorsionada de la realidad. En cuanto a los problemas derivados de las alteraciones del campo visual, pueden aparecer patologías que afectan al campo periférico y/o al campo central.

- Campo periférico: lo que está afectado es la visión periférica, el niño ve sólo un trozo de pantalla, justo aquel al que dirige su mirada. Dificultad en la visión completa de elementos o símbolos de gran tamaño, la interpretación de escenas en movimiento, localización de elementos por la pantalla y, como consecuencia de todo ello, la velocidad de ejecución de las tareas.

- Campo central: el niño puede ver partes de la pantalla, pero no justo donde mira, lo que además de repercutir en los aspectos anteriormente mencionados, afecta a la agudeza visual.

\footnotetext{
${ }^{1}$ Actualmente este es un aspecto controversial
} 
- Problemas que afectan preferentemente al control óculo-motor: se dificulta la coordinación visomotora, en la fijación, en los cambios de mirada de pantalla al teclado.

Grupos de riesgo en la discapacidad visual. Se han tomado en consideración diferentes indicadores para caracterizar los grupos de riesgo: edad y localización geográfica (OMS, 2014).

Edad: Se estima que el $82 \%$ de todas las personas con ceguera son mayores de 50 años. Se prevé que este número aumentará con el envejecimiento de la población mundial. La principal causa de ceguera entre estas personas son las cataratas, que es un trastorno curable. La ceguera infantil sigue siendo un problema importante a nivel mundial. Se calcula que 1,4 millones de menores de 15 años son ciegos durante muchos años. Por otra parte, más de 12 millones de niños de 5 a 15 años sufren discapacidad visual por errores de refracción (miopía, hipermetropía o astigmatismo) no corregidos, trastornos que se pueden diagnosticar y corregir fácilmente con el uso de lentes.

Localización geográfica: La discapacidad visual no está distribuida uniformemente por el mundo. El $90 \%$ de las personas con discapacidad visual vive en países de ingresos bajos. Para esas personas, el acceso a servicios de prevención, educación y tratamiento, así como de rehabilitación, aún no es universal.

Prevención. Hasta el $80 \%$ de los casos de discapacidad visual y ceguera en adultos son prevenibles o tratables. En los países de ingresos bajos y medios-bajos la mayoría de los casos de discapacidad visual son prevenibles o curables. Para lograr una reducción sustancial es preciso informar al público general acerca de las medidas de prevención. El sistema de atención de salud debe incluir servicios de oftalmología con el fin de alcanzar la cobertura sanitaria universal.

Desde los años noventa se han hecho importantes progresos a escala mundial en materia de prevención en las áreas siguientes:

- Desarrollo de los servicios de atención oftálmica, que ha permitido incrementar su disponibilidad y asequibilidad. 
- Aumento del compromiso de los líderes nacionales, los profesionales médicos y los asociados del sector privado y empresarial con la prevención y la curación.

- Aumento de la concienciación y del uso de los servicios de atención oftálmica por parte de los pacientes y la población general, y aplicación de estrategias de atención oftálmica eficaces para eliminar las causas infecciosas de pérdida de la visión.

La OMS colabora con los Estados Miembro y con asociados de los sectores público y privado en la prevención de la ceguera y la restauración de la vista. Proporciona asistencia técnica, actividades de seguimiento y coordinación entre los asociados para fortalecer las medidas adoptadas en los países para eliminar la ceguera evitable, tratar las enfermedades oculares, ampliar el acceso a los servicios de atención oftálmica y mejorar la rehabilitación de las personas con discapacidad visual residual, gracias al uso de instrumentos y al aprendizaje de habilidades útiles para la vida cotidiana.

En el año 2013, la Asamblea Mundial de la Salud aprobó el Plan de acción para la prevención de la ceguera y la discapacidad visual, 2014-2019, a modo de hoja de ruta para los Estados Miembro, la Secretaría de la OMS y los asociados internacionales, con el objetivo de lograr una reducción mensurable de la discapacidad visual evitable de un $25 \%$ de aquí a 2019.

La labor de la OMS en este ámbito se centra en reforzar los esfuerzos desplegados a nivel nacional y de países para la eliminación de la ceguera evitable, ayudar a los dispensadores nacionales de atención sanitaria a tratar las enfermedades oculares, ampliar el acceso a los servicios oftalmológicos y expandir las intervenciones de rehabilitación para personas con discapacidad visual residual. Se otorga especial importancia a la creación y el fortalecimiento de los sistemas de salud. El decenio estará centrado en la creación de sistemas de salud, accesibles e integrales. (OMS, 2014) 


\section{Discapacidad visual en Argentina}

En el colectivo de personas con discapacidad, que se estima en alrededor del $15 \%$ de la población mundial, 45 millones corresponden a personas ciegas. Debe señalarse que si se hubieran aplicado en ellas los conocimientos básicos de atención ocular, más de la mitad estaría disfrutando de su visión. Otros 135 millones padecen algún grado de deficiencia visual significativa, con gran riesgo de volverse ciegos. Aproximadamente un $87 \%$ de las persona con esta discapacidad viven en países en desarrollo.

En nuestro país los resultados de la Encuesta Nacional de Personas con Discapacidad (ENDI, 2002-2003) indican que su prevalencia es del 7,1\%, respecto de la población total de 30.757.628 habitantes, Al identificar el tipo de discapacidad, la encuesta explicita los siguientes porcentajes: Motora 39,5\%, Visual 22\%, Mental $15,1 \%$ y Auditiva 18\%. "Las personas con discapacidad visual, constituyen las segundas en el orden de importancia de representatividad estadística" (Grzona, 2009).

En cuanto a su escolarización, la asistencia a Educación Común y Especial es una de las modalidades características de la integración de niños y jóvenes con discapacidad visual. En las de enseñanza especial reciben las técnicas específicas referidas a Orientación y Movilidad, Tiflotecnología, entre otras. La encuesta revela en relación con lo que en ese momento comprendía la EGB (edades entre 0- 14 años) los siguientes guarismos de concurrencia: Educación Común, 56, 5\%, Educación Especial 17, 7 \%, Educación Común y Especial 7\%, Nunca asistió: 10, $1 \%$.

Recapitulando, esta tesis se enmarca en las consideraciones teóricas que emergen del Modelo Teórico Operativo y del Modelo de la Diversidad de la Discapacidad, de las concepciones actuales sobre discapacidad visual así como de la información relevada en el recorrido de los antecedentes en el tema, que ofreceremos en los Capítulos 2 y 3 . Ello ha posibilitado extraer los insumos para plantear los interrogantes, objetivos e hipótesis de trabajo de la presente tesis, que expondremos en el Capítulo 4. 


\section{Capítulo 2 \\ Antecedentes. Orientación y atención a la diversidad}

ctualmente bajo el término Orientación se define un conjunto de
perspectivas teóricas y aplicadas que han sufrido nominaciones diversas a
lo largo del tiempo, tales como Orientación Vocacional, Orientación Laboral, Orientación Educativa y Ocupacional, entre otras. Seleccionamos en esta tesis la nominación simple de Orientación, bajo la consideración de su consenso creciente entre los especialistas en el tema, sin desmedro de otras denominaciones en el análisis de los antecedentes incluidos.

El devenir histórico de su nacimiento y desarrollo permite concebirla en la actualidad como un campo interdisciplinar múltiple y complejo, que ha producido grandes avances tanto desde las perspectivas teóricas en las que se fundamenta como en los dispositivos de intervención que pueden implementarse. En ambos casos se trata de dar respuesta a las nuevas demandas que surgen signadas por un contexto que atraviesa profundas transformaciones políticas, económicas y socioculturales. Las propuestas de orientación en diferentes ámbitos mundiales hacen referencia a la preparación para el trabajo y la formación calificada; sin desestimar aquello que los individuos quieren y desean como proyecto de vida (Gavilán, 2006). En este sentido, la emergencia de nuevas subjetividades atravesadas por los valores actuales de consumo y la revolución de las redes sociales, ha cambiado las coordenadas témporo-espaciales, apelando a una cultura del zapping, a la lógica del instante y a la necesidad de la satisfacción en la inmediatez.

La complejidad de ese contexto genera permanentes desafíos para la Orientación modificando y ampliando la mirada del orientador más allá del sistema educativo formal y no formal, para abarcar la diversidad de los programas de proyección comunitaria y la atención de los sistemas económicos, laborales, tecnológicos y socioculturales.

Aparece en consecuencia un incremento de la demanda de orientación educacional/ocupacional, particularmente de parte de los adolescentes y jóvenes. 
que están culminando sus estudios secundarios. Ello supone pensar la elección de una carrera u ocupación futuros, en el marco de un proyecto personal más amplio. Terminar la escolaridad media implica transitar una crisis, un reacomodamiento que conlleva a la reconstitución de representaciones vinculadas con la situación presente y la posterior, cuyos efectos tienen fuertes implicancias en la constitución subjetiva de los procesos identificatorios. Comporta a su vez, un proceso de duelo que surge ante la pérdida del rol de alumno del nivel secundario, para posicionarse en otro rol que implica nuevas responsabilidades y compromisos, como estudiar una carrera de nivel superior $y / o$ insertarse en el mundo del trabajo.

Por otro lado, en la investigación Imaginario social-realidad ocupacional (Gavilán, Cha, Quiles \& Neer, 1995-1999), se estudiaron los factores de influencia en la elección. Parte de representaciones sociales que circulan en relación a las elecciones de los jóvenes, dónde está instalada la idea de que los sujetos eligen una carrera, en primer término, para lograr un bienestar económico, o por el nivel de demanda laboral, el estatus, entre otros. No obstante, mediante los resultados obtenidos en la investigación mencionada, se observa que el $60 \%$ de los sujetos seleccionados prioriza, en la elección vocacional, el carácter de las tareas que realizará en la profesión. Por otro lado, diferentes autores han caracterizado a la adolescencia como una etapa en la cual el sujeto hace primar en sus elecciones, aquello que opina el grupo de pares, los ídolos o personajes representativos, los medios de comunicación; y observan que los padres ocuparían un lugar secundario en estas decisiones. No obstante, han obtenido resultados diferentes: el $56 \%$ de los participantes manifestó que recibió de su familia los aportes más importantes para definir su elección; el 18\%, de los procesos de Orientación; el 9\%, de los medios de comunicación; el $7 \%$ de la escuela, y el $4 \%$ de otros adultos.

La temática referida al lugar que tiene la familia en el proceso de elección de los jóvenes está asociada a cómo perciben los adolescentes la relación con los padres. Esto fue abordado en algunas investigaciones realizadas en otros países en los últimos treinta años y en nuestro país por Batistuta y Falco (1997), quiénes concluyen que: "los padres continúan siendo las personas más importantes en la vida 
afectiva de los adolescentes y no son reemplazados ni por los amigos ni por la pareja".

Por su parte, la escuela como institución, desde hace muchos años, está atravesada por múltiples problemáticas y demandas de un entramado social progresivamente de mayor complejidad. La globalización de la economía, los avances tecnológicos, y la elevada competitividad laboral, exige a los individuos una formación educativa/ocupacional que contemple el desarrollo de competencias diversas que le permitan desempeñar tareas diferentes. La adecuada articulación entre educación, capacitación y trabajo, tal como plantea Di Doménico y Amadio (2007) adquiere una importancia sustantiva ya que de ello dependerá, en gran medida, la posibilidad de construir un proyecto personal y social para ingresar sea al mundo del trabajo o al de la educación superior.

Ahora bien, desde la Orientación cabe interrogarse por aquello que ocurre con los jóvenes próximos a egresar que presentan alguna discapacidad, cuáles, si existen, son las estrategias que se implementan desde el sistema educativo para acompañarlos en la transición hacia la actividad laboral y/o hacia los estudios universitarios y finalmente cómo se promueve el desarrollo de las competencias necesarias para un tránsito exitoso en uno o ambos recorridos.

\subsection{Orientación y atención a la diversidad}

Para la Orientación es importante tener en cuenta que cualquier sujeto con discapacidad puede tener dificultades en el desempeño de una ocupación o en sus estudios como cualquier otro joven. Pero deben implementarse medidas integrales que les permitan contar con los apoyos necesarios, para que esto no ocurra por razones que vayan más allá de su discapacidad. Dicho de otro modo, la discapacidad por sí sola no debería ser el determinante del futuro de ese sujeto. Al respecto debe considerarse que no constituye un estatuto fijo, sino una condición relacional que surge de la interacción entre limitaciones funcionales del sujeto y un ambiente "discapacitante" que no tiene en cuenta las diferencias, o no las atiende suficientemente. 
La discapacidad se concibe entonces como una categoría social y política, una condición producida por la interrelación de las estructuras económica, social y cultural con la discapacidad, es decir, es una forma de opresión social que impone limitaciones a los sujetos que presentan algún déficit (Angelino, 2009).

Estos aspectos implican la conformación de nuevas formas de encarar los procesos de Orientación, que incluya a todos los sujetos sin excepciones, de modo tal que los orientadores deben actualizarse permanentemente con el fin de dar respuesta a la diversidad cultural, lingüística, étnica, social en el marco de las potencialidades de la persona con discapacidad.

Según González Bello (2007) para la generalidad de los países de Europa y América del Norte la temática de la orientación y la diversidad se relaciona con la atención a los niños(as) y jóvenes con necesidades especiales, que asisten a una institución educativa y para quienes se elaboran programas de enseñanza dirigidos a lograr una mejor adaptación al sistema social prevaleciente. En la mayoría de los casos se considera que la problemática de las necesidades específicas es imputable a factores genéticos o personales que sólo responden a características internas de los individuos que las presentan, obviando los factores externos que, en algunos casos, pueden resultar más determinantes y decisivos a la hora de la manifestación conductual. No obstante, el autor considera que los profesionales de la Orientación, tanto en la práctica privada o pública de los países europeos, deben hacer consideraciones más específicas en el momento de atender a niños(as), jóvenes y adultos(as), en su condición de inmigrantes, provenientes de América Latina. En un sentido amplio propone hacer Orientación en la Diversidad más que Orientación para la Diversidad, bajo la concepción de una Orientación para todos que implica la eliminación de la expresión "necesidades especiales", cuya connotación en nuestros países no resulta la más apropiada, ya que incluye la idea de una Orientación Étnica. Definitivamente una de las opciones más favorables para el abordaje de la diversidad la constituye una acción desde la Educación, y concretamente desde la Escuela, como institución del Estado.

La mejor manera de atender la diversidad será elaborar proyectos y programaciones que favorezcan aquellos cambios habituales que el profesorado introduce en su enseñanza 
para dar respuestas a las diferencias individuales en estilos de aprendizaje, intereses o dificultades transitorias de aprendizaje (Peña y López, 2005, p. 32, citado por Gonzalez Bello, 2007, p. 6).

En este sentido, el desafío educativo del Siglo XXI consiste en brindar respuestas que garanticen la Atención a la Diversidad y, a su vez, se basen en el respeto del:

1) Principio de Igualdad por el cual se deben ofrecer las mismas oportunidades a todos.

2) Principio de Equidad que reconoce que cada persona tiene necesidades y el derecho a que se respeten sus características personales.

La atención de la diversidad implica en consecuencia las siguientes cuestiones:

- La aceptación de la existencia de diferentes historias y contextos de vida.

- El reconocimiento de diferentes motivaciones, intereses, actitudes y expectativas frente al objeto de conocimiento.

- La toma de conciencia de la existencia de diferentes puntos de partida en la construcción de los aprendizajes, debido a actitudes, conocimientos e ideas previas propias de cada alumno.

- La admisión de la presencia de diferentes estilos, ritmos, competencias curriculares y contextos de aprendizaje dentro de una misma aula.

\subsection{Educación y discapacidad}

Durante las primeras décadas del siglo pasado la educación de las personas con discapacidad no fue objeto de reflexión en relación con las prácticas educativas e institucionales, sino todo lo contrario. Prevaleció un modelo normativo-prescriptivo y médico, que ubicaba a la persona con discapacidad desde el déficit, desde lo que debía desarrollar de manera individual, -"normalizar"- para alcanzar los logros esperados. Esto alejaba las posibilidades de elección de los alumnos limitando muchas veces sus elecciones vocacionales a las posibilidades de acceso existentes, acordes a su déficit individual, obviando los deseos, motivaciones y anhelos personales y profesionales. Las prácticas de Orientación en nuestro país, consolidaron esta concepción, ya que hacia mediados del siglo $X X$, se priorizaba un modelo psicotécnico de ajuste y adecuación. Tal es así, que en 1949, la Orientación 
Vocacional se incorpora a la Constitución Nacional. Allí se explicitaba que la orientación profesional de los jóvenes, concebida como un complemento de la acción de instruir y educar, es una función social que el Estado ampara y fomenta mediante instituciones que guíen a los jóvenes hacia las actividades para las que posean naturales aptitudes y capacidad, con el fin de que la adecuada elección profesional redunde en beneficio suyo y de la sociedad. Frente a la doble incapacidad supuesta a los alumnos y a sus padres para contenerla, el Estado asumía una función tutelar, con el fin de mejorar la productividad y evitar el derroche de recursos personales. Entonces, en este contexto, frente a la necesidad de las industrias de una mano de obra calificada, la elección de una profesión u ocupación no podía resultar de una decisión improvisada sino que tenía que ser el fruto de un proceso tan científico como fuera posible. $Y$ en ese marco la orientación profesional y la psicotecnia adquirían todo su relieve. (Gavilán, 2006)

Ahora bien, con relación a las personas con discapacidad, en 1946, el Ministro de Salud, Dr. Ramón Carrillo, tomando como referencia la Disabled Persons Employment Act de Inglaterra ${ }^{2}$, se proclamó a favor de la votación de una ley por la que se obligaba a que el $2 \%$ de las plazas de la administración pública y de las industrias privadas, fueran ocupadas por inválidos recuperados. También se recomendó una "asistencia integral del inválido" basada en una "asistencia recuperativa", que no sólo lo asistiera médicamente, sino que lo rehabilitara o le enseñara un nuevo oficio y le proporcionara un puesto de trabajo. Sin embargo, con excepción de algunos responsables políticos peronistas, el derecho a la formación profesional y al trabajo de los lisiados no estaba promovido por las autoridades. En este sentido, las asociaciones de ciegos por esa época, se movilizaron para defender su derecho a una formación profesional y el acceso a un trabajo digno. En 1947, en el país, algunas asociaciones de ciegos se reagruparon, tales como La Fraternal, Luis Braille de la Plata y Sociedad por los Derechos del Ciego, y luego la Biblioteca Argentina para Ciegos. Uno de sus objetivos fue formar la Junta de Vinculación Tiflológica, organismo que representa los intereses de los ciegos (Bregain, 2011).

\footnotetext{
${ }^{2}$ En 1944, la adopción del Disabled Persons Employment Act en Inglaterra llama la atención de varios médicos en la Argentina, ya que esta medida preveía que el Estado y las empresas privadas reservaran el $3 \%$ de sus puestos de trabajo para los lisiados y les reservaban ciertas ocupaciones.
} 
Entonces, en sus comienzos la Orientación en nuestro país, se relacionaba con la selección profesional, se proponía un abordaje psicotécnico en relación con el mundo laboral, adecuando -"ajustando"- las aptitudes personales para compatibilizarlos con los requerimientos de las condiciones laborales.

Ahora bien, estas prácticas, con el aporte de otros referentes teóricos nacionales, como fue el caso de Bohoslavsky hacia la década del '70, fueron virando hacia un modelo más clínico, que permitió rescatar la singularidad del sujeto de la elección. Cabe destacar, que esto también coincidió con el desarrollo de las carreras de Psicología en el país, con la consecuente incorporación de los psicólogos para trabajar con los anteriores orientadores. De este modo surgieron las primeras experiencias de trabajos grupales con adolescentes, en las cuales se tenía en cuenta la inclusión del inconsciente en la elección vocacional y el nuevo rol de las técnicas proyectivas en el proceso de orientación.

Por otro lado, en el campo de la discapacidad, también se produjo un cambio con relación a su concepción, entendiéndola ahora desde un modelo social, modelo que obligó a revisar las prácticas docentes e institucionales vinculadas a la educación superior y, en consecuencia, modificó las prácticas de Orientación.

En este sentido las acciones de orientación en la actualidad, intentan colaborar con el ideal democratizador de la Universidad pública, partiendo del reconocimiento de que las diferencias y desigualdades sociales, educativas, culturales, económicas de la historia y del presente de los sujetos, inciden marcadamente en las posibilidades reales de concretar sus proyectos de formación en el nivel superior (Larramendy, Peryera \& Rusler, 2012, p. 33).

De este modo, garantizar y poner en acto el derecho a la educación de las personas con discapacidad, requiere de una nueva y diversificada formación docente que posibilite la comprensión y la intervención activa ante situaciones áulicas, que demandan nuevos posicionamientos y nuevas estrategias pedagógicas conforme, además, a los cambios de escenarios que se están produciendo en la universidad en la que estamos inmersos (Reznik, 2012, p. 6). 
En el marco de esa intención democratizadora, la masificación y diversificación del alumnado universitario constituyen logros indiscutibles y altamente valorados y presentan, al mismo tiempo, una nueva complejidad que desafía a la Universidad a encontrar nuevas respuestas. Así, es necesario re pensar las condiciones políticas, institucionales, académicas y pedagógicas en las que sería posible no solamente extender el alcance de la universidad y asegurar el ingreso progresivamente creciente de personas con discapacidad, sino también favorecer su permanencia y graduación en carreras de alta calidad en la formación científica y profesional.

Las dificultades para las personas con discapacidad no son solamente una cuestión edilicia o de acceso a la tecnología, sino peores, percibiéndose una desvaloración a su presencia en ámbitos académicos, un malestar que produce en muchas personas la presencia de alguien con discapacidad. Este rechazo proviene de los estereotipos profesionales, grabados a fuego durante la formación de grado a través de una multitud de mensajes implícitos sobre presentación y conducta del egresado (...). El ingreso a las profesiones requiere de algo más que un esfuerzo intelectual para acceder al conocimiento en una materia, implica también el disciplinamiento del cuerpo en torno a estereotipos. Hay destrezas que parecen constituirse como condensaciones de un saber profesional, produciendo un efecto por exclusión. Estas prefiguraciones de las destrezas exigidas a un graduado están presentes entre los docentes, el estudiantado y el ámbito de la administración de las universidades argentinas y representan un obstáculo mayor que las barreras edilicias y tecnológicas (Seda, citado por Larramendy, Peryera \& Rusler, 2012, p. 42)

Katz y Larroca (2009) plantean, que un número escaso de personas con discapacidad acceden a la educación básica y media regular, es menor aún en el caso de la educación superior.

Uno de los mayores obstáculos que enfrenta una persona con discapacidad en Argentina para acceder, permanecer y egresar de la educación superior están relacionados a las barreras actitudinales, a la percepción social de la discapacidad, dado que aún existen graves prejuicios relacionados a la discapacidad que suscitan conflictos en las relaciones interpersonales (p. 117)

Hoy el problema de la Orientación exige ser re-conceptualizado como un problema inter-trans-disciplinario, en el que la teoría enfoque los nudos estructurales de sus 
relaciones complejas en su articulación con la investigación empírica y las intervenciones orientadoras encuentren las situaciones en las que se establece la prueba a través de la experiencia de modo tal que se enriquezcan con estrategias adecuadas y efectivas (Gavilán, 2012, p. 11).

El Modelo Teórico Operativo en Orientación (Gavilán, 2006) funciona como un nexo entre la teoría y la práctica, formalizando un instrumento de articulación e intervención relacionado especialmente con la problemática de elección de los sujetos a lo largo de la vida. La Orientación se define entonces como:

El conjunto de estrategias y tácticas que emplea el psicólogo y/o el psicopedagogo especializado en Orientación para que el orientado o sujeto de la Orientación, individual o colectivamente, mediante una actitud comprensiva, reflexiva y comprometida, pueda elaborar un proyecto educativo, laboral, personal y/o social a lo largo de la vida (Gavilán, 2006, p.194).

Se la considera como un proceso continuo a lo largo de toda la vida del individuo en el que se recortan diferentes momentos del ciclo vital: pubertad, adolescencia, juventud, adultez, vejez.

En relación con las intervenciones de Orientación en sujetos con Discapacidad, Rocha y Perrilli (2008) proponen tres líneas argumentales que trazan otra mirada sobre los modos de trabajar con esta población:

1) Analizar los sentidos del etiquetamiento.

2) Visibilizar a los invisibles.

3) Salirse de la Orientación para interrogarse sobre ella.

Desde el campo de la Orientación resulta imprescindible elaborar nuevas formas de encarar los procesos de intervención y contar con una escuela (y una Universidad) capaz de armar tramas horizontales, con pluralidad de instituciones y actores sociales para el análisis y revisión de diferentes e importantes aspectos tales como las adaptaciones, la elaboración de proyectos específicos y, sobre todo, con la primacía de la acción permanente y comprometida del orientador (Castignani, 2012, p. 143).

En este sentido las propuestas de intervención orientadoras deben vehiculizar lo que propone la Convención Internacional sobre los Derechos de las Personas con 
Discapacidad y su protocolo facultativo, (ONU, 2006) en su Art. 27, incisos d y k, que señalan:

d) Permitir que las personas con discapacidad tengan acceso efectivo a programas generales de orientación técnica y vocacional, servicios de colocación y formación profesional y continua.

k) Promover la creación de programas de rehabilitación vocacional y profesional, mantenimiento de empleo y reincorporación al trabajo dirigidos a personas con discapacidad (ONU, 2006).

\subsection{Modelos y enfoques teóricos sobre prácticas orientadoras de las personas con discapacidad}

A continuación se presentarán los principales antecedentes y referentes teóricos encontrados en relación con la Orientación en sujetos con discapacidad en general (en el Capítulo 3 de hace lo propio con los específicos vinculados a los sujetos con discapacidad visual), objeto de la presente tesis, tanto a nivel internacional como nacional.

En la revisión bibliográfica sobre el tema de la Orientación en sujetos con discapacidad, en primera instancia aparece una variedad en la denominación del término discapacidad, dando cuenta de los momentos históricos y de los contextos en que fueron planteados los distintos modelos para su tratamiento y de la forma en que influyeron en las prácticas orientadoras en cada época en particular. En segunda instancia, encontramos que los principales precursores en la implementación de propuestas de orientación en sujetos con discapacidad, aparecen en el contexto europeo, especialmente en España, hecho que contrasta con la situación en América Latina y en nuestro país en particular. Por último, estas propuestas en su mayoría están orientadas a un tipo de discapacidad, la intelectual y, en consecuencia, los diseños de las intervenciones orientadoras se dirigen a la inserción laboral de este colectivo. Esto es acorde con las políticas públicas y legislaciones vigentes sobre el acceso y mantenimiento del empleo en estos contextos. 


\section{Prácticas y propuestas orientadoras en Europa y EEUU}

Un primer trabajo que aborda la temática es el que desarrollaron García Pastor y Alvarez Rojo (1997) sobre la "Orientación Vocacional de jóvenes con necesidades especiales. Un programa de transición a la vida adulta". Se trata de un programa que se estructura a partir de lo que sucede en Madrid en relación con el "Discurso de la diversidad". Los autores hacen una revisión de los enfoques teóricos que han servido de base para la planificación de acciones formativo-orientadora, posicionándose en el enfoque ecológico:

(...) desde el momento en que los programas de integración han ido incluyendo a los alumnos con necesidades educativas especiales en el marco más amplio de la orientación vocacional "normalizada" y bajo la influencia del movimiento de la educación para la carrera, los planteamientos centrados en la conducta adaptada o en competencias sociales van dando paso a un enfoque más amplio que deja de centrarse sólo en el sujeto: son los modelos basados en la comunidad o ecológicos que se desarrollan en la actualidad (García Pastor \& Alvarez Rojo, 1997, p. 25).

Realizan una clasificación de los modelos y enfoques teóricos que han sido la base de las prácticas orientadoras:

a) Propuestas de intervención realizadas en el seno de la rehabilitación profesional/vocacional como estructura de presentación de servicios: modelos de ajuste laboral. Entre ellos que se encuentran el Modelo de Krumboltz para la elección vocacional a partir de la Teoría del Aprendizaje Social; las Teorías del ajuste al trabajo que tienen como base la Teoría de Rasgos y Factores y el Modelo de Redesarrollo Vocacional, una ampliación del anterior.

b) Los planteamientos de algunas teorías del Desarrollo de la Carrera. Destacan dos modelos: el Modelo de desarrollo vocacional de Super y la Teoría de la acomodación y del compromiso de Gottfredson.

c) Las propuestas derivadas del movimiento de reforma de la escuela en EEUU, conocido como Educación para la Carrera.

d) Los planteamientos convergentes de dos enfoques de gran aceptación en la actualidad: el Movimiento de Vida independiente y el Modelo Ecológico. 
Los autores dan cuenta de cómo desde los comienzos y hasta épocas recientes, la mayoría de las ofertas de acción orientadora para las personas con discapacidad eran teorías del ajuste laboral. Es decir, con una perspectiva del ajuste de todos los trabajadores a las posibilidades que ofrece el mercado laboral, obviando las cuestiones del desarrollo y de la elección vocacional (García Pastor \& Alvarez Rojo, 1997, p. 25). El Modelo de rehabilitación profesional/vocacional (modelo de ajuste laboral) se enmarca en teorías netamente racionalistas que, en contraste con las humanistas, enfatizan la solución lógica e intelectual de los problemas humanos. Se concibe a la Orientación como una experiencia racional en la que es posible hacer predicciones sobre el futuro profesional mediante la evaluación de las aptitudes y destrezas ocupacionales del sujeto y de los requerimientos o exigencias de las ocupaciones, produciendo una congruencia o correspondencia entre los sujetos y las profesiones.

Sin embargo, los autores destacan las limitaciones que presentan estas propuestas, a la luz de los planteamientos integradores y normalizadores actuales, a saber:

La consideración del contexto en el desarrollo de la carrera ha sido relativamente esporádica y no integrada en el conjunto de la investigación y la teoría.

La reducción de la intervención orientadora a lo profesional (inserción y desempeño en el empleo) dejando de lado otras necesidades de la persona (afectos, independencia personal, participación en la comunidad) sin cuya satisfacción la integración social va a ser necesariamente precaria.

La acción orientadora centrada en el sujeto, a pesar de la incorporación del contexto como un elemento fundamental implicado en el desarrollo vocacional o en el proceso de ajuste al trabajo.

Frente a estas falencias los autores plantean que la elaboración de planes y programas de transición a la vida adulta debe estar guiada principalmente por su adecuación al contexto donde los destinatarios han de insertarse. En esta línea, destacan dentro de los modelos teóricos mencionados, el Modelo Ecológico del desarrollo vocacional. El mismo tiene sus raíces en diferentes planteamientos de la Psicología del Desarrollo. El rasgo definitorio de este enfoque es la preocupación por 
las relaciones persona-ambiente. A diferencia de los planteamientos tradicionales (basados en el análisis de los rasgos de la personalidad y centrados en el estudio de las características del individuo) este enfoque se ha centrado en el estudio detallado del ambiente y en el tipo de interacciones que los individuos establecen con él, con el objetivo de poder establecer algunos nexos causales entre ciertas formas de interacción ambiente-individuo y el futuro desarrollo vocacional de las personas Además, la contextualización del sujeto no excluye la consideración de su singularidad; por consiguiente, desde esta perspectiva ecológica, la acción educativa y orientadora ha de organizarse con referencia a dos polos: el ambiente en el que el individuo va a desarrollarse y las percepciones individuales respecto al trabajo y la formación para el mismo. Los programas de orientación vocacional han de contemplar la preparación del sujeto para la transición entre diferentes ambientes y entre diferentes roles vitales.

Los nuevos planteamientos se centran en el reconocimiento del sujeto como un todo. Como alternativa al uso de los tests normalizados (enfoque tradicional) se propone las alternativas que ofrecen el diagnóstico prescriptivo, el análisis de tareas y el diagnóstico de habilidades. Partiendo de la necesidad de obtener un tipo de información capaz de captar las posibilidades del sujeto en interacción con su ambiente surgen las estrategias metodológicas de las propuestas innovadoras. Las técnicas utilizadas para ello son: instrumentos autoaplicables, autobiografía, evaluación en grupo, identificación del "estilo de vida" propio, entrevista y observación. Los autores van a proponer la evaluación situacional- cológica. La organización de la misma, atiende a dimensiones que se refieren al sujeto, al contexto y al trabajo. Las técnicas utilizadas son: entrevistas, observación,I análisis de documentos de las pruebas situacionales o de ejecución. Las fases de evaluación (recogida de datos, análisis de datos, toma de decisiones) van encaminadas a la comprensión del sujeto y su contexto, de modo que pueda elaborarse de forma completa el perfil de empleabilidad, que tras la discusión y toma de decisiones (con el sujeto y familia), se pueda diseñar el PIT (Programa Individualizado de Transición). El proceso de transición es un proceso dilatado en el tiempo y multidimensional, se contempla desde la escolaridad obligatoria a la inserción sociolaboral del sujeto. 
El programa "¿Y después, qué? Programa de transición a la vida adulta para jóvenes con necesidades educativas especiales", es un programa que también desarrollan los autores y se centra en la participación activa de los jóvenes, dónde ellos mismos serán los que deban potenciar las habilidades y destrezas teniendo presente una secuencia de tareas vitales:

1) Conocerse y valorarse,

2) analizar su entorno,

3) planificar actuaciones y

4) actuar y aprender de la experiencia.

Por otra parte, los autores toman también los aportes del Movimiento de Vida Independiente, para diseñar estrategias orientadoras con los sujetos con discapacidad. Este movimiento revela la intención fundamental de que cada sujeto mantenga el control sobre su propia vida, eligiendo opciones estables que minimicen la dependencia de los demás en la realización de las actividades de la vida cotidiana. Como propuesta a la inserción laboral se han planteado los servicios de transición escuela-trabajo y los servicios de empleo con apoyo. En el pasado se pensaba que las personas con discapacidad intelectual funcionarían mejor en unos ambientes especialmente diseñados para ellos "el empleo protegido". Sin embargo esta estrategia de inserción no ha aportado una alternativa real a las necesidades de vida independiente de estas personas en cuanto al salario que proporcionaban, a las posibilidades de obtención de una ocupación en el mercado libre de empleo y al proceso de integración social. Frente a esta situación se defiende hoy el derecho a que las personas con discapacidad puedan elegir ambientes laborales no protegidos donde puedan desarrollar un trabajo significativo, a diferencia de lo que sería una tendencia meramente ocupacional. El trabajo significativo hace referencia a una serie de acciones que, si no estuvieran hechas por una persona con discapacidad serían realizadas por personas sin discapacidad por la remuneración a recibir. Por lo tanto algunas de las premisas en las que se basa la defensa de ambientes no protegidos de trabajo para las personas con discapacidad son las siguientes: 
La mayoría de las personas con discapacidad son capaces de realizar un trabajo significativo en ambientes no protegidos.

> Los ambientes profesionales no protegidos son inherentemente menos restrictivos, más proclives a la realización de trabajos significativos y más defendibles, tanto desde el punto de vista evolutivo como educativo.

Las escuelas deben operar de tal modo que maximicen la probabilidad de que las personas con discapacidad trabajen en ambientes no protegidos desde la adolescencia hasta la edad adulta.

A partir de las constataciones anteriores se ha generado otra alternativa, la del "empleo con apoyo", que desarrolla los postulados del Movimiento de Vida Independiente en el ambiente laboral. Se pretende que la formación para el empleo y el desempeño de un puesto de trabajo tengan lugar en ambientes ocupacionales del mercado libre de empleo o bien en estrecha dependencia con dicho mercado. El apoyo en el empleo implica la existencia de un trabajo remunerado, un trabajo en el mercado laboral con las consiguientes condiciones de competitividad. Una de las mayores dificultades es que los empleadores visualicen que los sujetos con discapacidad pueden ser trabajadores competitivos. El objetivo fundamental que se persigue es el de ofrecer oportunidades para que estos trabajadores puedan demostrar sus competencias.

Pallisera Diaz (2010) desde la Universidad de Girona (España) realiza un análisis sobre los servicios en España que se ofrecen para la inclusión social, dando cuenta que es necesario apoyar a las personas con discapacidad para que puedan elaborar sus proyectos de vida y efectivizarlos. "En el nuevo modelo 'el centro de atención' es la persona con discapacidad", su entorno próximo, la familia, cobra una especial importancia en el amplio contexto de la comunidad, donde se hallan los servicios sociales y educativos, culturales, de ocio, etc. Apoyar a las personas para realizar sus propios proyectos de inclusión social, activando la participación de las redes de soporte naturales supone una transformación real de la relación educativa, en un proceso de empoderamiento de la persona con discapacidad y de su entorno (Pallisera Diaz, 2010, p.79). 
Jenaro Río, Caballo Escribano \& Verdugo Alonso (1999) diseñaron un Cuestionario de Evaluación del Potencial de Autoempleo para personas con discapacidad. La creación de empresas propias es una alternativa posible y deseable para la integración laboral de estas personas. Es necesario desarrollar programas de formación con el objetivo de prepararlas para emprender un negocio. El objetivo de esta investigación fue identificar las características psicológicas necesarias para obtener éxito en el autoempleo y desarrollar un instrumento con las adecuadas características psicométricas para evaluar el potencial para el autoempleo.

Riaño Galán (2012) plantea a su vez, que la transición de los jóvenes a la vida adulta debe concebirse como un proceso centrado en la persona, ya que el paso a la edad adulta constituye una de las etapas más importantes de los ciclos vitales que implica la entrada al mundo del trabajo, la elección de pareja, la consecución de vivienda, la elección de un círculo de amigos y la integración activa en la sociedad. Por lo tanto, este proceso supone la participación de un equipo interdisciplinario que piense y planifique los momentos de esta etapa, y trabaje en la consecución de recursos para garantizar la satisfacción de necesidades personales y sociales (Riaño Galán, 2012, p.16). En el marco de la investigación "Programa de Cualificación Profesional Inicial. Itinerario Laboral y Planificación Centrada en las Personas con Necesidades Diversas" y de la Asociación de Aprendizaje Grundtvig "Teaching in Competences. A step towards inclusion", se ha desarrollado un programa de inserción laboral centrado en la persona e implementado en el centro español durante el curso 2010/2011. El mismo ha permitido ampliar la formación básica del alumno en diferentes contextos y favorecer su desarrollo personal y social; iniciarlo en conocimientos básicos en la categoría de auxiliar, familiarizándose con el mundo laboral. Como resultado de este estudio, los autores concluyen que un programa formativo por competencias, es importante para el trabajo, y proponen estrategias educativas que facilitan la conformación de estas competencias, como la solución de problemas, el pensamiento crítico o la participación en equipos de trabajo.

Mendia (1994) menciona los componentes del proceso de transición al mundo del trabajo en jóvenes con necesidades especiales. La transición incluye cuatro ámbitos básicos que conducen al joven al estatus de adulto: el currículum formativo (de la 
escuela a la escuela), el tránsito de la escuela a la vida activa (de la escuela al trabajo), la ubicación y definición en el campo del trabajo (del trabajo al trabajo) y la adquisición de independencia económico familiar (de la familia a la familia). Los itinerarios concretos de transición se construyen a partir de ofertas educativas y laborales radicadas en un territorio y según claves o referencias sociales, culturales y económicas, que son particulares.

Bayot, Rincón, \& Hernandez Pina (2002) dan cuenta de las características que poseen las personas con déficits y que logran un éxito vocacional:

a. Una actitud positiva hacia el trabajo.

b. Una actitud positiva hacia ellos mismos.

c. Metas vocacionales realistas.

d. Buenas capacidades de orientación y de movilidad.

e. Buenas capacidades de comunicación.

f. Alto nivel de independencia en la vida diaria.

g. Buenos niveles de integración en la Comunidad.

h. Un alto nivel de contactos sociales.

Por otro lado, dan cuenta de una serie de factores que suelen desconocer los estudiantes con déficits y necesidades educativas especiales de una serie de temas que les son propios tales como:

a. La legislación de su país que les afecta.

b. Los beneficios sanitarios de los que pueden disponer.

c. La existencia de Servicios de Asesoramiento tanto generales como específicos.

d. Los programas y guías de asesoramiento vocacional existentes.

e. Su propio desarrollo en la carrera.

f. La elaboración adecuada de cartas de presentación y del currículo.

g. Las habilidades necesarias para la búsqueda de empleo.

h. Las acomodaciones necesarias a realizar tanto en el estudio como en el trabajo y en el ambiente laboral debido a su discapacidad.

i. Cuándo y cómo comunicar su discapacidad en un proceso de búsqueda de empleo. 
Como se ha visto hasta aquí, son varios los artículos que hacen mención al concepto de transición, especialmente de la escuela al mundo del trabajo. Por ello, es importante tomar la definición que plantea la European Agency for Development in Special Needs Education (Agencia Europea para el Desarrollo de la Educación Especial), ya que es uno de los organismos internacionales más importantes en el tema de Necesidades Educativas Especiales (en adelante, NEE).

El concepto de Transición de la escuela al empleo o al mundo laboral incluye tres ideas principales:

1. Proceso: el trabajo preparatorio y el periodo de tiempo necesarios para la transición.

2. Traspaso: movimiento de un nivel educativo o etapa de la vida al siguiente

3. Cambio: modificaciones en términos de situaciones personales y profesionales

Entonces, para la Agencia Europea la transición al empleo es parte de un proceso largo y complejo, por el que se pasa en todas las etapas de la vida, que necesita ser dirigida de la forma más adecuada. "Una buena vida para todos", así como "un buen trabajo para todos" son los objetivos últimos de un buen proceso general de transición La transición de la escuela al empleo debería incluir la participación continua del joven, la participación de su familia, la coordinación entre todos los servicios involucrados y la estrecha cooperación con el sector del empleo (European Agency for Development in Special Needs Education, 2002, p.10)

Ahora bien, esta Agencia, en el año 2002 presentó un informe, sobre un estudio realizado acerca de la "Transición de la escuela al empleo" dando cuenta de las problemáticas que los jóvenes con necesidades especiales tienen para incorporarse al mundo del trabajo. Estas dificultades se deben en primer lugar, a su escolarización, en la que han encontrado un alto porcentaje de abandono, bajo nivel de acceso a la educación y la formación, carencia o limitación de titulaciones por parte de las personas con discapacidad, baja estima de las capacidades (se subestiman sus capacidades). En segundo lugar, con relación al empleo encontraron cifras elevadas de desempleo, bajo nivel de acceso al empleo, dificultades para 
enfrentarse con las condiciones laborales cambiantes, actitudes negativas de los empresarios, limitado contacto entre educación y empleo.

En este sentido, la Agencia desarrollo el Programa Individual de Transición (PIT) que es un instrumento en forma de documento en el que se refleja el pasado, presente y futuro deseable del joven. Se incluye información relacionada con la propia vida, tales como circunstancias familiares, historia médica, ocio, valores y características culturales, así como información de su educación y formación. El objetivo de este programa es contribuir a:

- Acrecentar las oportunidades del/de la joven de obtener un empleo digno.

- Unificar los intereses, deseos, motivaciones, competencias, capacidades, actitudes y habilidades del joven con las necesidades de la profesión, trabajo, entorno laboral y empresas.

- Aumentar la autonomía, motivación, auto-percepción y autoestima del joven.

- Crear una situación favorable para el joven y los empresarios.

Un programa de transición está estrechamente relacionado con una adaptación curricular individual y debería prepararse tan pronto como fuera posible antes de terminar la educación obligatoria. Pretende llenar el vacío entre el centro escolar y el empleo. Un PIT ofrece un marco que pretende asegurar una mejor entrada al mundo laboral. Refleja un proceso dinámico en el que están presentes, tanto las características de los jóvenes (destrezas, capacidades, competencias y expectativas) como las demandas y necesidades del sector del empleo. (Programa Individual del Transición al Empleo, 2006, p. 23)

La Dra. Cristina Jenaro (1999) pertenece al INICO, (Instituto Universitario de Integración en la Comunidad) de la Universidad de Salamanca. Nos brinda algunos aportes sobre la transición a la vida adulta en jóvenes con discapacidad debe comenzar por el planteamiento de metas y una de ellas es el empleo. Sin embargo, la autora distingue dos aproximaciones en relación con la integración laboral de personas con discapacidad:

- Enfoque evolutivo: aquí la persona con discapacidad pasa a desempeñar un trabajo en la comunidad una vez que es capaz de realizarlo 
independientemente. Esta visión hace referencia a un continuo de servicios, de estar "preparado" o "a punto para" surgido en los años 60. Esta línea es todavía parte del sistema de rehabilitación para adultos con discapacidad, en dónde se define a la independencia como la capacidad para trabajar en la comunidad sin apoyos.

- Enfoque Funcional: aquí la meta no es la independencia, sino la interdependencia, y ello porque se considera que lo que varía son las intensidades de apoyos requeridos. Desde este enfoque, el empleo es una meta inmediata y el servicio integrado en la comunidad es el apoyo que se ofrece para asegurar este objetivo.

Además, el concepto de independencia es considerado no sólo limitador sino incierto y en contra de los derechos de todos los ciudadanos a participar en las comunidades con el mayor grado posible. Por esta razón es necesario conocer los recursos y apoyos de la comunidad, identificando a las personas clave y a sus funciones (por ejemplo, familia/amigos, personas con experiencia en transiciones similares, profesionales). Para realizar esto la exploración de las alternativas requiere salir del consultorio, visitar diferentes lugares, hablar con representantes de diferentes agencias y organizaciones, analizar los servicios de la comunidad, aprender su lenguaje y la terminología. Por lo tanto, en el caso del empleo implicará analizar el mercado laboral, las empresas de la comunidad, y distintas ocupaciones y trabajos dentro de cada grupo ocupacional. Además es necesario evaluar las opciones y analizar las ventajas y desventajas de éstas. Esta tarea ha de realizarse junto con el equipo de planificación de la transición, que debe estar conformada por la persona con discapacidad y por su grupo significativo o grupo natural de apoyo.

Una vez identificados las condiciones que implican el desempeñarse en determinado campo laboral, se desarrollará un plan, destinado a que se ayude a la persona con discapacidad a tomar decisiones informadas, donde el sujeto pueda decidir quién lo escuchará, quién lo apoyará, y quienes serán las conexiones para conseguir dinero, recursos, y apoyos. El Plan debe ser puesto en marcha, evaluado y revisado. 
Por último, la autora enumera tres pasos en la preparación de un estudiante para la transición:

1. Identificar intereses y capacidades del estudiante: se realiza, mediante instrumentos de evaluación, formales o informales, ya sea la entrevista y la observación en situaciones naturales, junto con la utilización de instrumentos de evaluación de la madurez vocacional. Esta evaluación está destinada a determinar las necesidades de un estudiante, con el objetivo de poner en marcha programas que palien dicha situación. Ellos han desarrollado el PEPO (Programa de Evaluación y Orientación Profesional (Verdugo, Jenaro, y Arias, 1998, citado por Jenaro, 1999), en el que consideran que la evaluación de los intereses y capacidades del estudiante no sólo ha de tener en cuenta la atención a las habilidades profesionales, sino también dar respuesta a aspectos médicos, capacidades físicas, competencia sociales. Esto es importante para relacionarlo con las áreas de habilidades adaptativas y ambientales donde se prevé que el joven se desenvuelva en un futuro.

2. Ayudar a los estudiantes a desarrollar, poner en marcha y evaluar un plan de acción: se pueden utilizar diferentes metodologías, como la resolución de problemas, entrevistas, etc. Una de las estrategias novedosas que desarrolló el equipo de la Dra. Jenaro, para llevar a cabo esta planificación es la puesta en marcha de los denominados PATH (Planificación de Futuros Alternativos con Esperanza). Tiene como objetivo la realización de un plan de transición escrito en el que se detecten las necesidades de apoyo en las diferentes áreas de habilidades adaptativas, así como las personas responsables de proporcionar dichos apoyos. La planificación escrita de la transición se constituye no sólo de un medio para evaluar los progresos del estudiante, sino también de un medio objetivo para determinar la eficacia de nuestros esfuerzos como profesionales. De ahí que la evaluación previa, los esfuerzos durante y tras la salida de cada uno de los jóvenes del programa formativo o del programa de transición deban acompañarse de formularios que permitan analizar los resultados de estos esfuerzos. Además, debe realizarse un seguimiento de cada uno de los jóvenes que abandonan o finalizan nuestro programa. 
3. Crear oportunidades de empleo: la valoración no sólo de aspectos estrictamente relacionados con las características de un trabajo, sino también con todas aquellas que conlleva el clima laboral, ya que de ellas va a depender la posibilidad de contar con apoyos naturales en el lugar de trabajo para las personas con discapacidad.

Jurado (2005) plantea que a raíz de las dificultades que deben enfrentar los jóvenes con discapacidad en los procesos de transición, las tecnologías serán un elemento que permitirán afianzar más las posibilidades de su eficacia. Las tecnologías no deben percibirse como computadoras, circuitos, cables, recursos mecánicos, sino que pueden ser algo más, deben formar parte de un proceso integral de asistencia, de soporte a los individuos para que se maximice su potencial de respuestas, su potencial adaptativo, considerando las características únicas de cada individuo (Jurado, 2005, p. 8).

La importancia social y educativa de las tecnologías de la información y comunicación (TICs), radica en el uso que se realice en función de las necesidades que tiene la persona y de los objetivos que pretenda lograr. El desarrollo tecnológico ha abierto nuevas puertas y posibilidades para que el proceso de enseñanzaaprendizaje se afiance. Permite, fundamentalmente responder a las exigencias del aprendizaje y satisfacer necesidades educativas, a través de la provisión de recursos adaptados.

Las tecnologías de la información y la comunicación, en su conjunto posibilitan eliminar muchas de las barreras de acceso a los contextos de aprendizaje (Jurado, 1999), ya que:

Fomentan la interacción del alumno con el entorno. Tal es el caso de los sistemas tecnológicos adaptados (tecnologías asistidas) a personas con discapacidad sensorial o motora.

Acrecientan la motivación hacia el aprendizaje, en la medida que las tareas implicadas en el mismo, en la realización de actividades, proporciona refuerzos inmediatos. El alumno puede controlar, intervenir y tomar decisiones, conformando, además, una experiencia que permite afianzar el auto concepto. 
> Facilitan la adecuación al ritmo de aprendizaje del alumno cuando no predetermina el tiempo de aprendizaje posibilitando la flexibilidad temporal y horaria.

En la Universidad de Granada, Polo Sanchéz y López Justicia (2004) analizaron los factores en el proceso de inserción sociolaboral de estudiantes con discapacidad de la Universidad de Granada. Elaboraron una escala de Transición de Minusválidos Físicos y Sensoriales al Mundo Laboral, con el objetivo de conocer las barreras sociopersonales/laborales de estudiantes universitarios granadinos con esas discapacidades $(n=29)$. Los principales resultados encontrados, con respecto a las necesidades formativas detectadas por los estudiantes para acceder en el futuro al empleo, dan cuenta que un alto porcentaje de encuestados no dieron respuesta al apartado referido a las herramientas de uso en la búsqueda de empleo, lo que puede deberse bien a que no se habían iniciado aún en la búsqueda, o bien al desconocimiento de medios que le permitan el acceso al mundo laboral. Entre los que afirmaron manejar herramientas destacaron hacer uso de internet y la solicitud de empleo mediante la autocandidatura en empresas. Entre las principales necesidades formativas puestas de manifiesto por estos estudiantes destacan en mayor grado el uso de las nuevas tecnologías, seguido de las prácticas en empresa. Un dato relevante encontrado, es el valor que conceden especialmente las personas con discapacidad visual a las Nuevas Tecnologías de acceso a la información, lo que concuerda con otras publicaciones centradas en esta temática (Crudden, 2002; Williamson, Albrecht, Shauder, \& Bow, 2001).

En relación con la percepción del grado de influencia de las relaciones interpersonales, concluyen que los universitarios con discapacidad no sienten prejuicios de parte de sus compañeros. Se consideran personas muy sociables, valoradas por los demás en el trabajo que desempeñan, lo que les lleva a sentirse autorrealizados. Sin embargo, cuando analizan el tipo de discapacidad, observaron que el $42,9 \%$ de los discapacitados visuales no tienen dicha sensación, lo que puede deberse, como apuntan Burlinghan (1979) y López-Justicia, Fernández de Haro, Amezcua y Pichardo (2000) a que muchos jóvenes que padecen déficit visual suelen 
manifestar diversos problemas psicosociales como consecuencia de su problemática, tales como mayor dependencia de los demás, falta de iniciativa o menor sociabilidad. Los datos obtenidos les permitieron concluir a las autoras que los estudiantes universitarios con déficit suelen necesitar respuestas que compensen su punto de vista deficitario de cara a la inserción sociolaboral. Así, demandan mayor información y asesoramiento en estrategias y técnicas de búsqueda de empleo, formación en Nuevas Tecnologías y cursos de especialización. No obstante, la existencia de barreras, de obstáculos, en el camino a la integración sociolaboral de la persona discapacitada no significa que no sea posible, es importante clarificar cuales son los factores de influencia diferencial en función de la discapacidad, para poder distinguir cuales son las acciones más oportunas. La comprensión de la problemática facilita la actitud a adoptar y los profesionales que se dedican a la integración laboral del discapacitado, los miembros de esta sociedad, debemos reflexionar acerca de cuál debe ser nuestro punto de vista para lograr un cambio y tener claro que este cambio no involucra solo a un grupo particular, sino a la sociedad en su conjunto.

Repetto (2002) hace mención a la orientación intercultural y la define como aquella que trabaja con sujetos de diferentes culturas, en lo referente a etnias, religiones, lenguas, situación social y género. Además incluye el trabajo con sujetos que tienen capacidades diferentes. Las diferencias entre los sujetos han existido a lo largo del desarrollo de la humanidad pero el movimiento de la orientación intercultural ha surgido tan solo a mediados del XX en los Estados Unidos, con la creación de la Asociación Americana de Personal y de Orientación. Aunque se trate de un punto de partida, debe tenerse en cuenta que en este período no se trataba de una orientación que comprendía y respetaba verdaderamente las diferencias culturales, sino que su objetivo era asimilar al referido a las minorías en la cultura norteamericana dominante.

A partir de los $60^{\prime}$ creció la responsabilidad en el trabajo de los orientadores y en los $70^{\prime}$ aparecieron numerosas investigaciones sobre orientación intercultural, que en los $80^{\prime}$ y $90^{\prime}$ siguieron creciendo junto a las realizaciones prácticas. Sin embargo hasta la fecha sigue siendo insuficiente y en la actualidad se reconoce que las teorías, 
técnicas, estrategias e intervenciones aún no son las más apropiadas para trabajar con estas poblaciones.

Repetto habla de la necesidad de adoptar una dimensión intercultural en la práctica orientadora para trabajar desde un enfoque inclusivo e integrador que sea transformador de la realidad: sociedades que valoren y respeten el pluralismo cultural, el valor de la diversidad, la equidad y la justicia social. El orientador además de una adecuada formación requiere de ciertas competencias multiculturales, definidas como la capacidad para comprender la dinámica cultural de los sujetos y trabajar facilitando su mejor desarrollo. Entre tales requerimientos se encuentran:

- Conocer las propias teorías, valores y prejuicios.

- Comprender las diferencias culturales.

- Ser capaz de definir las características más importantes de las organizaciones integradoras en tanto que disponen de competencias multiculturales tales como desarrollar un plan de acción para la multiculturalidad y la diversidad, favorecer la construcción de un clima de responsabilidad hacia el multiculturalismo, etc.

Atender a la diversidad y trabajar con los que son diferentes resulta de suma importancia, pero tal como hemos visto, los orientadores en este campo tienen aún mucho trabajo por hacer.

En el contexto de EEUU se encuentra el Programa Nacional de Rehabilitación Profesional (Dupes, 2005) que ayuda a las personas con discapacidades, a definir un objetivo profesional y obtener empleo. Todas las capitales estatales cuentan con una oficina central de Rehabilitación Profesional y sucursales en todo el estado que pueden encontrarse en el listado de servicios estatales de la guía telefónica bajo el rubro "Servicios de Rehabilitación o Servicios de Rehabilitación Profesional".

Es importante destacar que este programa, tiene condiciones de acceso, no es un programa de ayuda social. El programa funciona mediante:

1. Orientación profesional. Un asesor trabaja sólo con la persona para ofrecerle apoyo y ayuda para lograr su objetivo. Los servicios que reciba dependerán de lo que la persona y su asesor crean que es necesario para ayudarle a conseguir empleo. 
Este servicio le presta colaboración para conocer mejor su potencial, fijar objetivos profesionales realistas, modificar su objetivo profesional cuando sea necesario y adquirir buenos hábitos de trabajo. El proceso de valoración e información puede incluir:

- información sobre su discapacidad, educación y situación social o familiar;

- una evaluación de sus conocimientos, habilidades e intereses;

- una valoración de sus antecedentes profesionales, hábitos de trabajo y concesiones laborales;

- un análisis del mercado laboral local;

- una evaluación de sus necesidades tecnológicas para determinar qué adaptaciones serían necesarias en el lugar de trabajo;

- un análisis de sus necesidades salariales y en cuanto a prestaciones.

2. Servicios de Rehabilitación Profesional. Los mismos abarcan cualquier servicio que se necesite para ayudarle a encontrar empleo. Tras la evaluación, puede que reciba uno o más de los siguientes servicios:

- De evaluación, que identifican cuáles son sus puntos fuertes y limitaciones mediante una evaluación médica, psiquiátrica, social y psicológica.

- De evaluación profesional, destinada a identificar intereses, disposición para trabajar, habilidades y oportunidades locales de trabajo.

- De orientación, para establecer una relación continua entre la persona con discapacidad y su asesor a medida que analizan los resultados de la evaluación y desarrollan un plan de trabajo realista.

- De restitución, con el propósito de aumentar el potencial laboral mediante el uso de tratamientos médicos relacionados con la discapacidad.

- De preparación laboral, destinado a ayudar a desarrollar las habilidades laborales que permitirán encontrar empleo. Esto se puede conseguir mediante la experiencia como voluntario, la capacitación en el puesto de trabajo, la formación profesional o la formación en el aula.

- De ayuda, que pueden abarcar la asistencia en el transporte, la compra de instrumentos o equipo o la ayuda para vivir de forma independiente. 
- De colocación laboral, para desarrollar oportunidades de trabajo y encontrar un trabajo que se adapte a los intereses y habilidades.

- De vida independiente, dirigidos a proporcionar evaluaciones y servicios que pueden ayudar a afrontar los problemas diarios que afectan a la rehabilitación y objetivos laborales. Algunos ejemplos son el acceso a los recursos comunitarios, la defensa de los derechos, la gestión monetaria y las habilidades de organización personal.

- De tecnología para usuarios con necesidades especiales, para ayudar a evaluar, seleccionar y adquirir un dispositivo o equipo destinado a mejorar el potencial laboral.

3. Formación y educación. Hay disponibles varias opciones de formación, dependiendo de las habilidades y objetivos de la persona con discapacidad.

- La capacitación en el puesto de trabajo puede proporcionarse como un programa de formación organizada que le brinda la oportunidad de aprender un oficio en condiciones reales.

- El trabajo por cuenta propia ofrece una gran flexibilidad para cualquier discapacidad. Los servicios de apoyo incluyen: estudios de viabilidad/mercado; asesoramiento de empresas y asesores de marketing; ayuda para la adquisición de fondos para empresas de nueva creación o compra de equipo.

- El empleo subvencionado, para casos más graves, puede estar disponible para la persona con discapacidad y/o su empleador para ofrecerle apoyo intensivo a la hora de acceder y desempeñar su trabajo, tanto en el mismo lugar como fuera de él.

- La formación profesional de breve duración está diseñada para estudiantes que desean introducirse de forma inmediata en el mercado laboral. El currículo puede requerir una dedicación de varias horas a dos años.

- La enseñanza universitaria es el camino que prefieren aquéllos que quieren lograr ciertos objetivos profesionales. Las agencias de Rehabilitación Profesional pueden proporcionar varios tipos de ayuda dependiendo de sus necesidades económicas. Sin embargo, primero se debe solicitar ayuda económica a la universidad en la que se planea estudiar. Cualquier beca que se 
obtenga debe ser empleada para la erogación de los gastos de educación antes de que el dispositivo de Rehabilitación Profesional abone cualquier importe relacionado con los estudios.

4. Colocación laboral. Aunque el programa de Rehabilitación Profesional ayuda a las personas a prepararse en el campo laboral, no es una agencia de empleo. Se trata que la persona con discapacidad, cuando esté preparada, tendrá que buscar trabajo como cualquier otra sin discapacidad. Sin embargo, el dispositivo de Rehabilitación Profesional puede colaborar en la búsqueda, por ejemplo, a encontrar ofertas de trabajo, rellenar solicitudes, elaborar el currículo o practicar y conseguir entrevistas de trabajo. Además, puede ayudar a enfrentar los problemas en el trabajo por discapacidad, como por ejemplo:

- Adaptarse al nuevo trabajo y estilo de vida.

- Saber qué decir sobre la discapacidad a los entrevistadores, empleadores y compañeros de trabajo.

- Negociar con un empleador algunos cambios en las obligaciones laborales, modificaciones en el lugar de trabajo o adquisición de dispositivos necesarios a causa de la discapacidad.

Por otro lado, los programas de transición ofrecen ayuda y orientación a los estudiantes con discapacidades cuando terminan la enseñanza media y acceden a un puesto de trabajo. Estos programas pueden colaborar con los estudiantes a identificar intereses profesionales, conocer las habilidades y formación que se necesitan para prepararse y acceder a esos campos de trabajo.

Algunos de los programas de Transición que se desarrollan son: HEATH Resource Center (Centro de Recursos HEATH), El Centro Nacional de Enseñanza Media y Transición (National Center on Secondary Education and Transition), el Directorio del Centro Nacional de Difusión de Información para Niños con Discapacidades (National Dissemination Center for Children with Disabilities National Directory), Recursos para adultos con discapacidades (Resources for Adults with Disabilities) y la Red Nacional de Transición (National Transition Network). 
El contexto latinoamericano. Encontramos como referente en el tema, la Tesis Doctoral "Madurez vocacional de Jóvenes colombianos con discapacidad: evaluación e intervención" (Rodríguez Franco, 2007). La autora parte del concepto de Madurez Vocacional desarrollado por Donald Super (1977). Con este constructo se alude al grado en que una persona ha adquirido el conocimiento y las habilidades necesarias para tomar decisiones vocacionales realistas y apropiadas (Rodriguez Franco, 2007, p. 27). No obstante, va a optar por la definición de Farley, Bolton y Little (1990), ya que va a centrarse en un período concreto del ciclo vital: la transición de los jóvenes hacia el mundo laboral. Según los autores existen tres factores de madurez vocacional de los jóvenes en transición al mundo laboral, cada uno compuesto por una serie de habilidades y conocimientos:

1. Habilidades para la elección. Conocimiento de sí mismo, conocimiento del mundo laboral, habilidades para la toma de decisiones, habilidades de planificación.

2. Habilidades para la obtención. Orientación hacia el empleo, habilidades de búsqueda de empleo

3. Habilidades para el mantenimiento. Habilidades interpersonales y de afrontamiento, hábitos laborales.

Su trabajo incluye evidencias documentales con relación al desarrollo vocacional en jóvenes con discapacidad, mencionando que existen dos tipos de causas que dan cuentan de las dificultades que se les puedan presentar y por consiguiente en su integración socio-laboral individual y contextual. Desde una perspectiva individual alguna de las variables influyentes son las competencias profesionales, la experiencia laboral, el entrenamiento recibido, la información ocupacional, las actitudes hacia sí mismo y hacia el trabajo y el tipo, curso y severidad de afrontamiento de la discapacidad (Verdugo, Jenaro y Arias, 1998). Desde el plano contextual los factores que condicionan el acceso al empleo y, en general, el desarrollo de la carrera son, entre otros, las actitudes de los empresarios, el entorno familiar y las políticas en materia de empleo.

Por otra parte, se destaca que en los estudios pioneros y en las diferentes teorías en el campo del desarrollo vocacional uno de los principales problemas está relacionado 
con los diseños e instrumentos de investigación empleados, que han sido adaptados de estudios con personas sin discapacidad, en su mayoría varones, de raza blanca y de clase media en el contexto norteamericano (Goldberg, 1992), desconociendo las necesidades particulares de las personas con discapacidad.

Luego realiza una interesante clasificación, entre el desarrollo vocacional de personas con discapacidad congénita y adquirida. La discapacidad congénita hace referencia a cualquier limitación funcional física, sensorial o mental que posee el individuo desde su concepción y nacimiento. Las discapacidades del desarrollo se derivan de deficiencias crónicas, físicas o mentales que se manifiestan antes de los 22 años y que dan como resultado una limitación funcional substancial en tres o más áreas de la actividad diaria (autocuidado, aprendizaje, movilidad, independencia, autodirección y autosuficiencia económica). Sin embargo, no conducen sistemáticamente a alteraciones en los patrones de desarrollo vocacional. No obstante, existen algunos condicionantes que pueden actuar como factores de riesgo relacionados con la restricción significativa en las experiencias de juego y escolarización, con la consecuente reducción de experiencias de aprendizaje, un menor auto-concepto, y unas bajas expectativas frente a las capacidades personales (Hanley-Maxwell y Szymanski, 1996). Además, y dado que el desarrollo vocacional es un proceso que demanda capacidades cognitivas (Philips, 1992; Super, 1977), las limitaciones en las habilidades de procesamiento impactan de manera proporcional al nivel de madurez vocacional alcanzado. Personas con mayor afectación en las habilidades de aprendizaje han demostrado una menor madurez vocacional (Ohler y Levinson, 1995). Por último, variables de índole ambiental (p.ej., los apoyos y la formación suministrados) parecen tener más influencia que la discapacidad en sí misma (Brolin, 1976; Goldberg, 1992).

Cuando se trata de una discapacidad adquirida, aparecen restricciones para realizar una o varias actividades derivadas de trastornos osteo-articulares, musculares, del sistema nervioso, circulatorio, respiratorio, endocrino-metabólico o sensorial, originados en enfermedades o traumatismos ocurridos luego de iniciado y alcanzado un desarrollo normal. En este grupo ha sido bastante explorado el proceso de adaptación a la discapacidad. Dicho proceso ha sido estudiado desde dos puntos de 
vista, el evolutivo y el individual. El primero se basa en la existencia de unas etapas universales subsecuentes a la aparición de la discapacidad y el segundo defiende que no constan pruebas de tales etapas y que el proceso es particular en cada individuo.

Franco (2007) cita a Jenaro (1997), quién en los estudios vocacionales sobre personas con discapacidad física adquirida, afirma que el principal reto al que deben enfrentarse es el ajuste o reajuste profesional una vez sobrevenida la discapacidad. El momento en que se adquiere la discapacidad es uno de los factores que determina el desarrollo vocacional. Así, la condición discapacitante puede originarse antes de ingresar al mundo del trabajo o una vez que se ha iniciado una carrera. Por lo tanto la persona puede o no haber recibido la formación educativa requerida para acceder al empleo y puede o no haber alcanzado la autosuficiencia económica.

Finalmente, la autora desarrolla un "Programa de intervención sobre la madurez vocacional", compuesto por las tres áreas temáticas relacionadas con los tipos de habilidades que componen la madurez vocacional: las habilidades para la elección, para la obtención y para el mantenimiento de un empleo. Los resultados del estudio realizado, evidencian que la presencia de una discapacidad intelectual afecta significativamente la madurez vocacional. Han detectado un perfil inferior respecto a sus iguales sin discapacidad en las puntuaciones obtenidas en todos los instrumentos de madurez vocacional y en los factores que los componen. Concretamente, el grupo estudiado poseía menos habilidades para buscar información relacionada con las opciones formativas disponibles. Asimismo, presentaban menor conocimiento de los requisitos profesionales y una identidad profesional menos clara, que se reflejan en las dificultades para elegir una alternativa ocupacional viable y sobre todo acorde a las capacidades individuales. También encontraron que la conciencia con respecto a los propios atributos laborales (comunicación y liderazgo, ajuste al cambio, empatía y socialización) en términos generales está desajustada. Todos estos hechos dificultan una adecuada elección profesional, un desacuerdo entre los intereses y las posibilidades reales. De igual manera han encontrado evidencias que constatan la desventaja ante la que se encuentran estas personas, a la hora de obtener un empleo, el grupo con 
necesidades específicas presenta mayores dificultades para cumplimentar el currículo vitae y el desempeño adecuado en la entrevista. Al analizar los resultados referidos al mantenimiento del empleo, los datos indican que estos jóvenes presentan déficits en la orientación a la tarea y en habilidades interpersonales, así como una menor motivación hacia el trabajo y algunas dificultades para aceptar el rol laboral y a las figuras de autoridad.

La autora concluye que estos resultados indican que los jóvenes con discapacidad poseen menores habilidades para realizar actividades concretas que les conduzcan a conocer el mundo profesional y a reconocer sus potencialidades $y$, sobre todo, tienen menor claridad sobre el trabajo que desean y podrían desempeñar. Ahora bien, una variable que incide significativamente en la madurez vocacional es la formación recibida, aspecto sobre el que existe un indudable consenso (OIT, 1998; Verdugo, Jenaro \& Arias, 1998, entre otros). Los participantes con mayores niveles formativos presentan mejores habilidades y conocimientos que les permiten enfrentarse a momentos vocacionales con mayor efectividad. Igualmente han demostrado que con un entrenamiento específico es posible mejorar significativamente la madurez vocacional en sus tres componentes constitutivos, las habilidades para elegir, obtener y mantener un empleo.

Córdoba Andrade, Aya Gomez, Ibañez García, Monsalve Robayo \& Gómez Salazar (2011) realizaron una sistematización de las herramientas utilizadas para la evaluación de impacto del Programa Opciones y Apoyos para la Transición a la Vida Adulta (OAT). El mismo, surge como iniciativa de un grupo de familias colombianas, con el apoyo de la Academia y empresas privadas. El programa es pionero en el país y está destinado a los jóvenes con discapacidad intelectual, trabaja en la transición hacia la vida adulta en espacios reales de formación y en el contexto universitario. El objetivo es facilitar a los jóvenes el desarrollo de proyectos propios de vida productiva y plena, con metas como la inclusión laboral, la formación profesional o técnica, o proyectos productivos en diferentes modalidades. Su núcleo esencial de desarrollo es la realización de un trabajo sistemático de orientación personal y profesional acorde con las actuales definiciones y conceptos de discapacidad 
intelectual y del Modelo Social de Discapacidad, que desde el paradigma de los apoyos, busca incidir en mejorar la calidad de vida de los jóvenes y sus familias. La transición a la vida adulta genera en el entorno familiar nuevas dinámicas de relación, que rompen con modelos de sobreprotección y desvalorización que se constituyen como obstáculos de crecimiento y autogestión de los jóvenes.

Prácticas y propuestas orientadoras en Argentina. Según Rocha, Capel, Durand, Gómez, y Balero, (2011) no existen registros bibliográficos sobre algún momento inaugural en donde la Orientación demuestre cierto interés sobre la temática en cuestión. Las únicas marcas en este sentido se produjeron hace aproximadamente veinte años atrás cuando tres profesionales destacados en ambas disciplinas (Sergio Rascovan, Liliana Pantano y Cecilia Impini) conformaron un grupo dedicado a pensar este entrecruzamiento. Otro hecho importante tuvo lugar en APORA (Asociación de los Profesionales de la Orientación de la República Argentina) en el año 2010, en donde se creó formalmente el área de Orientación y discapacidad ${ }^{3}$. Precisamente en el año 2011, realizaron un estudio para indagar el "Estado de situación de las prácticas de Orientación Vocacional Ocupacional en sujetos con discapacidad en la República Argentina" (Rocha, et al., 2011). A partir de una muestra aleatoria sobre los diferentes servicios y profesionales de Orientación Vocacional-Ocupacional en el país, intentaron dar un inicio en la búsqueda y análisis del estado de los abordajes existentes sobre Orientación en Discapacidad. En este punto, resulta interesante analizar las respuestas ante las siguientes preguntas cualitativas:

Pregunta 1: En caso de que no existan consultas o sean pocas. ¿Cuáles cree Ud. que son los principales motivos por los que no consultan? (los sujetos con discapacidad). Las respuestas se agruparon en cuatro ítems:

1.1) Pocas expectativas de proyecto de vida por parte de las personas con discapacidad y sus familias:

- Muchos de ellos no ven el ingreso a la Universidad como una opción posible.

- Tanto en docentes como padres, la Orientación Vocacional no es una inquietud.

- Por una falta de creencia personal o de los padres.

- No esperan demasiado de sus hijos sobre todo en su vida adulta.

${ }^{3}$ La autora de esta Tesis fue invitada a participar de la jornada inaugural.

Tesis Doctoral. "Orientación y Discapacidad Visual. Factores que inciden en la elección de los adolescentes" 
Estas frases están íntimamente relacionadas con los imaginarios sociales erróneos que se configuran sobre el campo de la discapacidad. Los mitos, creencias y prejuicios que la sociedad teje acerca de este colectivo de personas llegan a instalarse en el propio seno de la familia del sujeto con discapacidad y hasta en los modos de ver las prácticas que los profesionales realizan, es decir que se reproduce un imaginario que supone a este sujeto atado a un destino programado al no poder.

1.2) Poca información y/o divulgación:

- Por falta de información en relación a los Servicios de Orientación y falta de ofertas de Servicios de Capacitación.

- Por escasa o nula información por parte de las familias respecto de que son sujetos con expectativas juveniles.

- Por desconocimiento de las posibilidades para seguir estudiando.

- Falta de promoción por parte de los agentes de salud sobre: mecanismos, dinámicas y centros que se especializan en estos tratamientos.

Si bien, se sabe que en la actualidad es cada vez más amplia la oferta de servicios, accesibilidades y apoyos hacia las personas en cuestión, en materia de Orientación, tanto los servicios como los profesionales que trabajan en forma individual, no difunden sus propuestas hacia este sector. Ahora bien, por un lado puede pensarse que los mismos sujetos y sus familias no se sienten convocados por este tipo de prácticas, o por otro lado, se puede inferir que los orientadores tienen dificultades para lograr que convocar a ese colectivo para realizar un proceso de Orientación

1.3) Por miedos o dificultades personales, familiares, etc.

- Por miedos en relación a la inserción laboral por discriminación.

- Por baja autoestima.

- Negación y escepticismo de la familia.

Lo interesante a observar aquí es que estas dificultades son visualizadas por los orientadores a la hora de pensar las razones por las que estos sujetos no consultan. Este obstáculo -a nuestro criterio- es desconocido en su profundidad por muchos profesionales proveniente del campo de la orientación.

1.4) Por las representaciones e imaginarios sociales. 
- Por el fuerte peso que tienen las etiquetas que les han puesto desde muy pequeños.

- Porque pensar en un proyecto a futuro para los jóvenes con discapacidad es casi un imposible, desde la representación social actual.

- Porque otros eligen por ellos. La sociedad decide que es lo mejor para ellos, borrándolos como sujetos de deseo y de elección.

El análisis de este punto está estrechamente vinculado con el 1.3). Mientras en el primero puede pensarse que los imaginarios se han encarnado en el sujeto y en su familia, aquí la cuestión pasa por el "fuerte peso" que tienen, no solo los imaginarios y representaciones sociales, sino también los "diagnósticos" a los que se ven sometidos constantemente -y a lo largo de su vida- estos sujetos Estos diagnósticospronósticos configuran el campo de las representaciones de muchos profesionales que abordan este campo, específicamente de aquellos que promueven las teorías psicométricas. Por ello (a nuestro entender), el profesional de la orientación debe adquirir un rol que subvierta estas posiciones dogmáticas apostando a que el sujeto ponga en juego su propio "deseo".

Pregunta 2. ¿Consideran que los Orientadores están formados adecuadamente para abordar procesos de orientación con sujetos con discapacidad? Los que respondieron que "no", mencionaron:

- Escasa bibliografía- poca demanda.

- No todos tienen formación para trabajar con sujetos con discapacidad.

- No existen o no están suficientemente comunicadas ofertas formativas de posgrado en la temática.

- No se encuentran difundidas estas prácticas. No es un área que haya sido incluida con fuerza en el campo de la orientación.

- Faltan investigaciones y bibliografía específica que permita seguir repensando estas prácticas.

- Porque en las carreras de grado donde se dicta OV en general no está incluida la temática.

Los que respondieron "En parte" adujeron a los siguientes motivos:

- No sé si lo suficiente, siempre se puede estar mejor formados.

- Debiera haber más formación. 
- Hay mucha gente muy capaz y con muy buena formación, pero que la hizo con la experiencia y con todo un recorrido teórico complejo y diverso.

- Depende de la orientación que elija el orientador respecto de su trabajo.

- Se piensa esa posibilidad si el profesional se orienta o especializa en discapacidad.

Con relación a la realidad existente acerca de formación insuficiente de los orientadores para realizar procesos de orientación con sujetos con discapacidad se perfilan diferentes posibilidades:

a) Tendría que haber formación sobre discapacidad dentro de la misma formación que reciben los orientadores.

b) El orientador podría formarse por cuenta propia en materia de discapacidad.

c) Tendría que existir una formación específica que abarque el entrecruzamiento de esta práctica con el campo de la discapacidad.

En este análisis es pertinente pensar que hay quienes opinan que algunos orientadores pueden o no dedicarse a esta tarea de orientar a jóvenes con discapacidad pensándolo desde la idea de que se puede "elegir" con quien trabajar, esto nos llevaría a considerar la ética profesional en relación con la práctica: "quienes deseen o no dedicarse al trabajo orientativo con sujetos con discapacidad pueden optar por tal elección". Por lo tanto, pensar en la escasa formación en materia de Orientación y discapacidad nos conduce a interrogarnos, no solamente por la misma dificultad o carencia en la formación sino también por el sentido ético de estas prácticas. Podríamos, entonces, reflexionar sobre tres diferentes posibilidades en función del deber $o$ el querer, que se vinculan con las tres posibilidades antes propuestas:

a) Debe ser una formación que reciban todos (en tanto y en cuanto todos tienen derecho a recibir Orientación Vocacional Ocupacional, tengan o no discapacidad).

b) Puede dedicarse quien se interese.

c) Debe ser una formación de post grado "opcional” para aquellos que deseen especializarse. 
A continuación, desarrollaremos algunos antecedentes de prácticas orientadoras en personas con discapacidad, realizadas ya sea en instituciones públicas o privadas, o como iniciativa individual de algunos profesionales dedicados a la Orientación en el ámbito privado como en el público.

En nuestro país podemos tomar como referencia en esta temática a Calleja \& Britez (2005). Las autoras señalan que la implementación de la orientación vocacional con personas con capacidades diferentes es abordada desde el ámbito ocupacional, manteniendo como objetivo primordial acompañar al sujeto con discapacidad en la construcción de un proyecto de vida que le posibilite compensar sus dificultades, maximizando y desplegando sus potencialidades.

Por otra parte, mencionan que la Orientación vocacional en el terreno de la discapacidad siempre va acompañada de la Orientación personal. La misma tiene como objetivo, en primer lugar acompañar al sujeto en el proceso de subjetivación, en principio debe advenir como sujeto, con el fin de posicionarse como tal y no como un "discapacitado", esto le va a permitir ser capaz de realizar elecciones propias y responsables. Aquí es primordial el rol de la familia para posibilitar este proceso para luego, poder abrirse al mundo social con autodeterminación, es decir, con la capacidad de elegir con autonomía. En segundo lugar, es importante trabajar con la conciencia de sí mismo (intereses, habilidades, aptitudes, preferencias), y la conciencia de oportunidades, (oportunidades de empleo y educación disponibles de acuerdo a los objetivos personales y a las posibilidades de acceso a las misma, es decir, oferta y competencia), evaluando que actividades posibilitarán el máximo desempeño de sus potencialidades acompañándolo para que maximice sus logros. En tercer lugar, hay que estimular el protagonismo en una búsqueda activa de los propios intereses y acompañarlos en el desarrollo de aptitudes para alcanzar logros deseados. Otros puntos a tener en cuenta son:

Posibilitar el desempeño adecuado en la vida cotidiana y en relación con los otros. Adquirir hábitos sociales y respeto por las normas de convivencia, que le posibiliten la integración social. Implementación de organizadores externos. 
Abordar con criterio de realidad. Poner en palabras las limitaciones de la patología, a fin de lograr la aceptación de las mismas. Generalmente en un principio se dan las elecciones fantaseadas regidas por el principio de placer o por la identificación con los "otros" significativos, surgen aquí los juegos de roles, poniendo de manifiesto el deseo de realizar actividades despeñadas por personas cercanas: ámbito fliar (ej., profesión de los hermanos, de los padres) ámbito institucional (ej. docentes, profesionales, etc).

Evaluar qué actividades tienen mayor correspondencia entre las posibilidades de ese sujeto y lo que ofrece la realidad.

Las autoras luego realizan todo un desarrollo sobre la naturaleza de la inserción o ubicación laboral de las personas con discapacidad intelectual. Mencionan que la inserción laboral es el logro final de todo un proceso de adaptación y formación laboral. Es el único y último objetivo de todo el proceso que posibilita la real independencia social y económica de la persona con discapacidad.

En primer término, para hacer frente al entorno en que se desenvuelven y se van a desenvolver las personas con discapacidad es vital trabajar la confianza en sí mismo, que el sujeto se conozca y se acepte como tal como es, que conozca sus capacidades y sus potencialidades sacando el máximo rendimiento de ellas, establecer estrategias que mejoren las relaciones con sus iguales. En síntesis, ofrecerles un apoyo para demostrar que son capaces de hacer muchas cosas, brindarles la oportunidad de que puedan expresar aquello que tienen para decir, que se sientan parte de este mundo del que son partícipes.

Shaferstein, Batlle \& Aisenson (2005) desarrollaron un proyecto de Orientación Vocacional y Ocupacional en una escuela pública (Capital Federal) que atendía a jóvenes sordos e hipoacúsicos, cuyas edades oscilaban entre los 20 y 21 años. El propósito general de la actividad fue efectuar intervenciones destinadas a la orientación personal, profesional y educacional de dichos jóvenes que se encontraban cursando el último año de la educación media, en su transición al mundo del trabajo y/o formación post-secundaria. 
El encuadre de trabajo incluyó una entrevista individual al inicio de la actividad a cada integrante del grupo, seis encuentros grupales y una entrevista individual de cierre. La modalidad de los encuentros grupales fue la de un taller reflexivo, coordinados por una Licenciada en Psicología, especializada en orientación con dominio de la Lengua de Señas Argentina.

La tarea desarrollada apuntó a ayudar a los jóvenes a tomar decisiones en los planos educativo y profesional, enmarcados en la construcción de su proyecto de vida. Según las autoras, la población sorda suele tener mayores dificultades para exteriorizar las inclinaciones personales para asumir un rol social, de acuerdo a la personalidad, los intereses y las aptitudes. Dicha dificultad se debería a una mayor determinación y presión del medio social y cultural. Aparecen trabas para ser aceptados en instituciones educativas o laborales, que de hecho, despiertan en la mayoría de estos jóvenes intensos temores. Emergen presiones hacia los sordos, según las cuáles estos debieran inclinarse hacia oficios definidos o ser absorbidos por entidades públicas como bancos, municipalidades o ministerios, para tareas preestablecidas como ser: recuento de dinero, manejo restringido de la computadora, tareas administrativas sencillas.

Se pudieron observar en los participantes cierta resistencia a adoptar una actitud activa con respecto a sus intenciones, expectativas y elecciones futuras. En los encuentros emergió una tendencia a aceptar las opciones que otros les daban, sin plantear su propia implicación en ello ni las estrategias posibles para, en un segundo tiempo, intentar lograr lo que deseaban. Por ejemplo, un joven decía: "Yo quiero trabajar en un banco, pero voy a trabajar en la ferretería de mi tío, porque ya me lo consiguió mi papá. Ahí también trabaja mi hermano".

Por otro lado, aparecieron algunas dificultades para reflexionar sobre sus posibilidades de elegir y tomar decisiones. Respondían: "si me gusta, si te dan un título, si es cerca de mi casa, si es barato, si es cómodo". Esto podría quizás estar vinculado a las restricciones propias del lenguaje utilizado, pero parecería, en especial, tener que ver con aspectos psicológicos vinculados a la falta de confianza en sí y en sus posibilidades. 
Entre los logros evidenciados a partir del trabajo realizado, caben mencionarse: la ampliación de estrategias de búsqueda de empleo, la expansión de las modalidades de búsqueda de información, la reflexión sobre los recursos y obstáculos con los que cuentan para afrontar la transición, el acompañamiento en el proceso de finalización del secundario, la relación con transiciones anteriores, la reflexión sobre sus posibilidades de elegir y tomar decisiones y el trabajo sobre gustos e intereses y ámbitos de inserción laboral posibles, así como sobre las diferencias entre el empleo a corto y largo plazo.

Las autoras concluyen que un adolescente sordo no está ni más ni menos limitado que cualquier otro adolescente, siempre y cuando se facilite el desarrollo de sus potencialidades creativas e intelectuales.

Posteriormente, Shaferstein \& Aisenson (2010) presentan algunas experiencias de trabajo realizadas con estudiantes universitarios de la Universidad de Buenos Aires. Destacan que el trabajo con personas con sordera o hipoacusia se realiza siguiendo los mismos objetivos planteados para la población en general. Entre ellos aparece:

a) Obtener información sobre las características de las carreras.

b) Promover el autoconocimiento y reflexionar sobre los recursos de los que disponen.

c) Construir proyectos personales de estudio y trabajo y elaborar las estrategias para realizarlos;

d) Tomar decisiones autónomas y responsables y g) prepararse para enfrentar las transiciones educativo- laborales.

Asimismo se incorporan otros objetivos específicos como favorecer un mayor conocimiento de sí mismo, a fin de potenciar los recursos personales con los que cuentan para que, conociendo mejor su propia situación y el contexto, puedan elaborar su proyecto personal.

La accesibilidad de los estudiantes con sordera a la universidad, no se agota en la figura del intérprete, ya que no todos utilizan lengua de señas. En este sentido, el psicólogo orientador trabaja acompañando a los jóvenes y facilitando la reflexión sobre expectativas e inquietudes que el comienzo de esta nueva etapa de transición 
suscita en ellos. A esto debe agregarse, reconociendo las diferencias que la discapacidad auditiva supone, la necesidad de realizar un seguimiento de sus trayectorias universitarias. Se considera fundamental la explicitación de las representaciones con las cuales los jóvenes dan cuenta de sus anticipaciones y posibilidades futuras, así como de su pasado y su realidad actual. Reflexionar sobre ello les permite incrementar su autonomía en la construcción de sus proyectos, brindándoles herramientas concretas, fortaleciendo sus potencialidades y apoyando la elaboración de estrategias para lograr sus metas.

Orientador y consultante trabajan en conjunto para construir estrategias que favorezcan la cursada: situar-se en el espacio frente a los profesores, solicitar que le reiteren personalmente la tarea para la próxima clase, utilizar una grabadora para que un familiar o amigo colabore con el desgrabado de las clases, recurrir a compañeros para compartir el material dictado. Las intervenciones en dichos procesos de desarrollo personal se enmarcan dentro de las tareas preventivas de la Orientación. La experiencia revela a las autoras, que en algunos casos en que la disminución de la audición no es reconocida como tal, las ansiedades generadas por el ocultamiento y el temor a ser expuesto suelen añadir mayores dificultades a los obstáculos propios de la sordera.

En los últimos tiempos, las nuevas tecnologías han ampliado los recursos de trabajo disponibles, y el seguimiento y contacto con los consultantes se puede realizar mediante el correo electrónico. La participación en sistemas semipresenciales de cursada favorece una adaptación paulatina en la transición desde la escuela secundaria a los estudios superiores.

Las autoras concluyen sobre la necesidad de reconocer las propias limitaciones como un problema concreto, esclarecer la situación particular, favorecer la elaboración de estrategias para disminuir las dificultades y el aprovechamiento de los recursos que cada alumno trae consigo y los que construye en nuevas instancias.

Cancelo (2006) sostiene que tanto el éxito como el fracaso en el proceso de orientación vocacional-profesional en sujetos con discapacidad intelectual (en adelante, DI) no deben considerarse como atributo de los individuos sino como 
organizaciones instituidas donde el rol protagónico del orientador debe ser revalidado. Todos los adolescentes con DI escolarizados se ven prontamente enfrentados a una situación de transición a los 16/17 años: inserción ocupacional temprana y precaria o concurrencia a Escuelas de Capacitación Laboral. La autora señala que el primer interrogante que surge en torno a esta temática está planteado en torno a la llamada Educación Especial ¿Constituye ésta un medio para canalizar las capacidades, necesidades e inclinaciones de alumnos con Necesidades Educativas .Especiales dentro del marco normativo y acorde con los lineamientos señalados en la estructura curricular de base para la Educación Especial, aun contemplando sus nuevos paradigmas?

En la Argentina, la alternativa históricamente más frecuente en la vida adulta de las personas escolarizadas con discapacidad intelectual han sido los Talleres protegidos de Producción. Este planteo exige repensar la orientación vocacional en adolescentes con DI, renunciando a un enfoque simplista y a miradas y razonamientos lineales y considerando en primer lugar la subjetividad. El éxito y el fracaso en el proceso de Orientación no deben considerarse como atributo de los individuos sino como organizaciones especializadas sociales e institucionales. En algunos casos, verdaderos rituales de la legitimación o degradación y exclusión.

El proceso de Orientación con adolescente con Discapacidad Intelectual presupone reconceptualizar la misión, funciones y dinámica del Equipo Transdisciplinario en las Escuelas Especiales y/o de Capacitación Laboral y reformular los roles de los integrantes de dicho Equipo. Exige además rever las técnicas e instrumentos de evaluación. Los elementos a considerar son:

- Nivel de autonomía personal.

- Reconocimiento de la condición de adulto.

- Actividad productiva que permita autonomía económica.

- Relaciones sociales y participación en la vida comunitaria.

- Cambio de rol en el grupo familiar.

- Garantizar que las personas con Discapacidad Intelectual tengan las mayores posibilidades para expresar su individualidad, sus preferencias y sus valores. 
- Proporcionar a los adolescentes y adultos con Discapacidad Intelectual una amplia gama de actividades en entornos normalizados, así como acceso a los medios económicos suficientes como para que dicha personas puedan participar en la sociedad de manera plena.

Convertirse en una persona adulta no es una cuestión de nivel intelectual, implica un largo proceso de responsabilidad y de toma de decisiones, Durante mucho tiempo se ha considerado a las personas con Discapacidad Intelectual incapaces de adquirir estas habilidades y por lo tanto, como niños eternos, sin opción a opinar ni decidir sobre sus vidas.

Ahora bien, sin lugar a dudas, el referente más actual en nuestro país en la temática de Orientación y Discapacidad es Rocha (2013), quien a partir de los aportes teóricos del psicoanálisis, plantea desarrollos específicos de intervenciones de Orientación en sujetos con Discapacidad Intelectual. Comienza por preguntarse ¿Cuáles son las elecciones de los jóvenes con discapacidad? ¿Los sujetos con discapacidad intelectual y/o mental eligen? ¿Se los deja elegir? ¿Dónde está el sujeto que elige? Aquí el autor no vacila en responder:

El sujeto que elige -cuando existe una discapacidad- siempre está; sólo que hay que salir a su encuentro...siempre hay alguien que espera que nosotros pongamos a su disposición nuestro propio deseo para que sirva como sostén o soporte de lo que en él pueda advenir (Rocha; 2013, p. 40).

En relación con la definición de la discapacidad, si bien retoma la propuesta por la CIF, aclara que la misma es un término técnico, es decir, que no nomina a un sujeto, sino que explica un estado o condición que porta una persona que se halla inserta dentro de un contexto histórico- socio- cultural (...) la persona no es discapacitada, sino que tiene una discapacidad. En este sentido, el deseo no se encuentra discapacitado, por lo tanto, un estado o condición de discapacidad no puede nominar a una persona, pero sí indefectiblemente generará efectos en esta y en su entorno (Rocha, 2013).

El autor describe algunos puntos relevantes en lo que respecta a la Orientación en sujetos con discapacidad intelectual: 
1) El momento de la elección: en los sujetos con discapacidad intelectual, se torna difícil hablar de "un momento" vinculado al proyecto de vida. Resulta diferente de lo que aparece generalmente en los jóvenes sin discapacidad, cuando se finalizan los estudios secundarios, época en la que se produce ese "tiempo inaugural" de pasaje hacia la vida adulta. Aquí encontramos "múltiples tiempos" que no se encuentran institucionalizados culturalmente. Estos tiempos de elección o transición al mundo adulto, estarán condicionados por múltiples determinantes:

- Grado o tipo de discapacidad que porte el joven.

- La forma en que se haya estructurado la subjetividad del joven.

- La "función familiar".

- Historia y trayectos institucionales.

- Los pocos haceres que obstaculizan la construcción del ser.

2) El pasaje a la adultez: en estrecha relación con el punto anterior, no hay un espacio instituido en la cultura que marque el momento de paso a la adultez, se acompaña de incertidumbre, ya que no existe una política clara que ofrezca más posibilidades de realización personal para este colectivo de personas. Este pasar a ser adulto estará determinado y condicionado por:

- El lugar que la familia le asigne al sujeto y a su discapacidad: es muy importante la postura de la familia por cuanto debe permitir el despliegue autónomo del sujeto. Son muy comunes las historias repetidas de sobreprotección que se dan en muchos senos familiares que estancan la realización personal del sujeto.

- Las posibilidades concretas que el sujeto tenga para dar ese paso: muchas veces se cuenta con todas las posibilidades subjetivas y de apoyo familiar pero se carecen de verdaderas propuestas para que se de ese pasaje.

- Los imaginarios sociales: la infantilización, la caridad y la lástima son situaciones muy generalizadas y esto funciona como un obstáculo a la hora de la construcción de una identidad adulta.

3) La forma de orientación: a diferencia de la Orientación habitual, estará determinada por el tipo de discapacidad que posea el orientado: si la discapacidad es 
de tipo intelectual y/o mental, seguramente los procesos se dirijan hacia la orientación ocupacional y a la construcción del ser adulto. Lo real, será algo que no podrá ser sorteado, ya que será evidente que la continuación de estudios superiores tendrá serias complicaciones, por lo que tanto, se trata de construir sobre las posibilidades reales que el déficit imponga.

4) El lugar del deseo en la elección: si pensamos -desde las prácticas de Orientación- que la búsqueda y los proyectos de vida se articulan desde el orden del deseo, nos encontramos con que en los jóvenes con discapacidad es precisamente el deseo el que muchas veces queda obturado, porque ellos mismos han ocupado el lugar de la falta,

5) La Orientación Vocacional en sujetos con discapacidad como instancia crítica: la Orientación debe constituirse desde una perspectiva crítica de los lugares cristalizados, en los que se encuentran la mayoría de las personas con discapacidad.

6) El lugar de la familia en los procesos de orientación: la entrevista con los padres será una tarea más del orientador, puesto que en ella se podrán despejar cuestiones relacionadas a cómo está viviendo los efectos que el proceso de Orientación produce en el joven y sus cambios subjetivos. Se busca que sea el joven el que elije.

En síntesis:

Postulamos a la orientación en sujetos con discapacidad intelectual como una práctica que apuesta a un proceso de elaboración psíquica, paso necesario para afrontar la construcción de etapas de transiciones que estos jóvenes deben realizar hacia el mundo adulto. La pensamos como una estrategia que no siempre estará direccionada hacia la elección de objetos vocacionales y como una práctica que sirve de eslabón a otras que tienden a permitir los procesos de autonomía de estos jóvenes (Rocha, 2013, p. 133).

Aquí la Orientación, no estará exclusivamente pensada hacia la elección de un proyecto educativo o laboral, sino que tendrá el valor de ser una herramienta que sirva para restituir el valor histórico del sujeto en cuanto partícipe de una cultura y contexto social determinado. Tendrá la posibilidad de trabajar sobre aquellos aspectos que nuestra sociedad desestima constantemente con respecto al futuro de estos jóvenes. 
Rocha (2013) expresa que la conformación y el armado de la estructura subjetiva del sujeto con discapacidad intelectual estará condicionada, en primer lugar, por la magnitud del déficit con la que este deba convivir, en segundo lugar, por el lugar que éste ocupe en su familia- ya sea de manera sana o patógena- y de la forma en que madre e hijo hagan frente a la realidad; y en tercer lugar, por las posibilidades concretas que la sociedad le otorgue a este sujeto para permitir el desarrollo y el despliegue de su autonomía. A partir de la experiencia realizada, el autor ha comparado que no es tanto el grado de retraso mental que el joven padezca lo que condiciona la posibilidad de enfrentar un proyecto social (llámese laboral o de otro orden), sino que esto estará mayormente influenciado por cómo se haya dado la relación entre su discapacidad, su madre, su familia y el otro social (Rocha, 2013, p.136).

Estos vínculos generarán una relación imaginaria especular que se refractará directamente hacia el interior del sujeto conformando una imagen inconsciente de sí. Esta imagen condicionará sus futuras relaciones sociales asignándole, y asignándose él mismo, roles y lugares determinados.

El negativismo, la autopercepción de la minusvalía y la dificultad de sostener un rol adolescente (entre otras cuestiones), parecen ser -en mayor medida- cuestiones propias de los efectos de este tipo de relación, y no exclusivamente de las limitaciones que la condición discapacitante le impone al sujeto. Uno de los objetivos del proceso de Orientación tendrá que ver con la tarea de desmantelar esos efectos, para de ese modo, dar lugar a que se propicien nuevas escenas que permitan proporcionar la posibilidad de subvertir estas posiciones. El autor destaca que es el grupo el espacio por excelencia de este escenario, en consecuencia, la labor del orientador apuntará a un trabajo de desmantelamiento de la discapacidad a través del dispositivo grupal. Entonces:

Los procesos de orientación no necesariamente adquirirán el sentido de una instancia atravesada por los jóvenes para "elegir algo" (estudio o trabajo), sino que buscarán generar las condiciones apropiadas para que éstos puedan subvertir- primero-, sus posiciones como sujetos que deben advenir al mundo adulto y sus lugares como seres libres de elección (Rocha, 2013, p. 138). 
Finalmente, Rocha (2013) presenta la implementación de talleres de Orientación con este colectivo. Lo planta como un instrumento "puente" entre el espacio protegido que proporciona la institución y el escenario social dónde todo sujeto debe advenir. Entonces uno de los requisitos más importantes para poder implementar un espaciotaller de Orientación Vocacional Ocupacional en una institución especializada o en otros lugares, es que todos los miembros que la componen sepan y entiendan muy bien de que se trata la propuesta y cuáles son sus principales fundamentos. Entonces, habrá tres pasos necesarios para crear un espacio-taller:

a. Conformación del equipo de trabajo: es recomendable que el equipo sea interdisciplinario, puesto que aparecerán en escenas otros profesionales con incumbencia en temas de discapacidad (Terapista Ocupacional, el docente especial, el trabajador social, el psicomotricista, el Acompañante terapéutico).

El equipo estará conformado por un coordinador, un co-coordinador y uno o dos profesionales que sean colaboradores del taller.

b. Reuniones grupales con los profesionales de la institución.

c. Entrevistas de admisión al espacio taller de Orientación: con los jóvenes y con los padres o tutores son necesarias antes del ingreso al taller, en ellas se trabajan y despejan aspectos cruciales que deberán ser puestos en palabra.

Este espacio taller de Orientación, puede ser implementado en todo tipo de instituciones, dada su plasticidad para adaptarse a las diferentes propuestas terapéuticas, educativas o socio-laborales en instancias institucionales o socio comunitarias tales como:

- Centros de Día.

- Centros Educativos Terapéuticos.

- Centros de Rehabilitación.

- Asociaciones civiles (ONG's).

- Municipios (Área discapacidad).

- Universidades.

- En prácticas privadas y en espacios donde se realice Orientación. 
Desde una perspectiva crítica de la Orientación en nuestro país, Rascovan (2013) tomando los aportes del psicoanálisis plantea que:

Hablar de los procesos de elección de proyectos de vida en los sujetos con discapacidad, significa al igual que con todo ser humano, enfrentarse con la castración, con el no todo... Hay un límite. Sin embargo, el tope hasta dónde cada uno se propone llegar es indelegable. Son los horizontes que cada quien se traza. Seguramente serán trayectorias más satisfactorias aquellas que supongan cierto registro de potencialidades y limitaciones. La OV como práctica de S-M no supone establecer veredictos, ni prescripciones, sino promover espacios de elaboración, de invención, de creación, alejados de concepciones cientificistas que se basan en el discurso del déficit (Rascovan, 2013, p. 20-21).

A su vez, Pantano (2011) desde el enfoque social de la discapacidad, propone "adaptar, modificar la oferta de la Orientación Vocacional y no a las personas". Plantea la importancia de pensar en una orientación vocacional y ocupacional no segregada, sino inclusiva, con "ajustes razonables" (CIPDC), para estar al servicio de todos y de todas (Pantano, 2011, p. 7).

En síntesis, en el recorrido realizado sobre los antecedentes generales de la Orientación y la Discapacidad en diversos contextos (Europa, EEUU, Latinoamérica y Argentina, en particular) encontramos desarrollos teóricos y aplicados de interés sobre los factores de las elecciones educacionales y ocupacionales de la población con diferentes tipos de discapacidad. En el capítulo siguiente (Capítulo 3) se presentarán los antecedentes específicos encontrados sobre Orientación y Discapacidad visual, que darán testimonio de la importancia del tema investigado, que será presentado en el Capítulo 4. 


\section{Capítulo 3 \\ Antecedentes. Orientación y discapacidad visual}

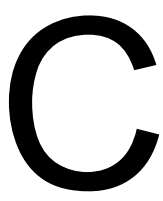

omo resultado de la revisión de la literatura especializada, encontramos que no son suficientes las propuestas que abordan la "psicología de la ceguera" en la adolescencia y juventud. La mayoría se basa particularmente en la ceguera en el período de la infancia y, consecuentemente, en la educación inicial y primaria (Leonhardt, 1992, Lowenfeld, 1981, Ochaita \& Rosa, 1988). En función de ello analizaremos algunos antecedentes sobre el tema.

\subsection{Psicología y Discapacidad visual}

En líneas generales los autores coinciden en que no hay una psicología especial de la ceguera, ni una personalidad única de las personas ciegas. Según el enfoque que plantean Ochaita y Rosa (1988), los ciegos no constituyen una población cuyas características tengan que describirse en contraste con la población considerada normal, sino que disponen de recursos físicos y psicológicos similares a los de los videntes, con excepción de la vista. Sin embargo, esto no significa que un ciego tenga un funcionamiento psicológico equivalente al de un vidente con los ojos tapados, ya que la falta de visión produce necesariamente una reestructuración del funcionamiento cognitivo así como del desarrollo de destrezas específicas. En nuestro país la psicoanalista Oyarzabal (2011) se dedicó al estudio de la percepción, especialmente de los bebés ciegos de nacimiento. La autora disiente con la perspectiva habitual de definir a los ciegos por aquello que les falta y que se prolonga en el eufemismo de llamarlos "no videntes". Por el contrario, refiere que el ciego no está privado de nada. "No se trata de negar el valor de la visión en el devenir humano, sino de saber que su falta no impide la constitución de la subjetividad ni la de una vida digna de ser vivida" (Oyarzabal, 2011, p. 19-20).

En el ámbito local, resultan de interés las consideraciones realizadas por Braslavsky (2006) quien toma los aportes de la teoría de Vigotsky sobre la psicología del ciego. Este autor realiza un recorrido sobre las diferentes concepciones a lo largo de la 
historia y encuentra que subyace en distintos momentos una idea central: "la ceguera no solo es la falta de vista (el defecto de un órgano particular) sino que además provoca gran reorganización de todas las fuerzas del organismo y la personalidad".(Vigotsky, citado por Braslavsky, 2006, p. 35). Ese autor divide este desarrollo histórico en tres etapas:

- Mística: domina durante la Antigüedad, la Edad Media y una parte considerable de la Historia Moderna. Durante esta etapa, la ceguera sugería una enorme infelicidad, miedo supersticioso, respeto y un trato del ciego como indefenso y abandonado. Pero al mismo tiempo, se afirmaba que el defecto desarrollaba en el ciego fuerzas místicas superiores que le daban una visión espiritual sustitutiva del sentido de vista perdido.

- Pre- científica e Ingenua: domina durante la llustración (s. XVIII), en el lugar de la mística surgió la ciencia y en el lugar del prejuicio, la experiencia y el estudio. Como consecuencia de la psicología y de la nueva comprensión de la ceguera, se inició la educación incorporando a los ciegos a la vida social, que abrió su acceso a la cultura. No obstante estos avances, Vigotsky discute la teoría de la "sustitución de los órganos de los sentidos", según la cual la sabia naturaleza habría dotado a los ciegos de un "sexto sentido"; esta teoría interpretaba erróneamente algunos hechos de la vida de los ciegos. Apelando a investigaciones de la época, demuestra que no existe una "compensación fisiológica directa del defecto de la vista", en cambio, propone otro tipo de compensación, sociopsicológica, "sin ocupar el lugar del órgano que falta". Pero destaca que a pesar de esta ingenuidad, la concepción biológica dio lugar a grandes avances con la incorporación de nuevas fuerzas a la ceguera, más allá del defecto orgánico. Un punto del sistema Braille ha hecho más por los ciegos que miles de filántropos; la posibilidad de leer y escribir ha resultado más importante que el "sexto sentido" y la agudeza del tacto y del oído.

- Científica o socio psicológica: Vigotsky encuentra en la teoría de la "psicología social de la personalidad" formulada por Adler, la "fuerza motriz" del desarrollo de la personalidad de las personas con defectos. Al entrar en relación con el medio 
externo, surge el conflicto provocado por la falta o deficiencia del órgano con las tareas que el medio le exige y si bien ese conflicto genera la posibilidad de morbilidad y mortalidad, ofrece a la vez grandes posibilidades y estímulos para la "super compensación". Las dificultades que la ceguera le crea al ciego para participar en la vida son las que avivan el conflicto y las tendencias a la super compensación, que están dirigidas a la formación de una personalidad capaz de conquistar una posición en la vida social. Por lo tanto, no sólo desarrollan el tacto y el oído, sino que "abarcan enteramente la personalidad en su conjunto. No tienden a sustituir la vista sino a vencer y super compensar el conflicto social y la inestabilidad psicológica como resultado del defecto físico". Se basa en uno de los pocos estudios disponibles en su tiempo sobre la personalidad total del ciego para insistir en la imposibilidad de buscar la compensación de la ceguera tan sólo en el desarrollo del tacto o la agudización del oído u otras funciones diferentes (como lo creyeron los científicos "ingenuos" del segundo período), y afirma que lo más característico de la personalidad del ciego consiste en la contradicción entre su incapacidad relativa en el aspecto espacial y la posibilidad de mantener, mediante el lenguaje, una relación total y completamente adecuada a los videntes y lograr la comprensión mutua.

Para el objeto de esta tesis, tomaremos algunos aportes del psicólogo González Fernández (2003), quien realiza una descripción de los adolescentes con discapacidad visual.

En el trabajo con adolescentes con déficit visual nos encontramos con dos importantes fuentes de desajuste psicológico: la adolescencia como período de cambio y el propio déficit visual. Ambas situaciones son potencialmente generadoras de desajuste, ya que pueden dificultar la construcción de una imagen de sí mismo acorde con la realidad y obstaculizar la puesta en práctica de procedimientos y ayudas eficaces que compensen las repercusiones que el déficit visual genera. En un primer apartado nos acercaremos a la problemática que puede generar el déficit visual en esta etapa del desarrollo, aclarando previamente cómo ambas situaciones pueden generar dificultades de ajuste personal. Olvidar las características especificas de la adolescencia puede llevar a una valoración inadecuada de los efectos que el déficit visual suele generar en estas edades y al fracaso 
de los procedimientos de intervención validados para otros grupos poblacionales (González Fernández, 2003, p. 302).

En relación a las demandas sociales en la adolescencia, el autor describe las cuatro siguientes:

a) Mayor independencia.

b) Modificación de las relaciones con los iguales y los adultos.

c) Ajuste sexual.

d) Preparación educativa y vocacional

El adolescente con déficit visual está sujeto a estos mismos cambios biológicos y, al menos en parte, a similares demandas sociales que el resto de los adolescentes, generando un cierto desajuste entre el entorno que le rodea, sus nuevos intereses y los cambios que se están produciendo. No obstante, el hecho diferencial del déficit visual suele añadir algunas particularidades que dificultan el proceso de ajuste en el que como adolescentes se encuentran inmersos. $Y$ es que el déficit visual puede generar una serie de dificultades que entran en conflicto con los intereses que suelen presentarse en estas edades. ¿Cómo influyen las dificultades de autonomía que se derivan del déficit visual en las ansias de independencia propias de la adolescencia? ¿Qué efecto tiene el mayor interés por los iguales cuando el déficit visual dificulta la participación en las actividades de relación social que habitualmente se desarrollan a estas edades? ¿Cómo afectan las ideas y valores que el adolescente tiene acerca de su déficit visual en el acercamiento sexual hacia otras personas? (González Fernández, 2003, p.305).

Los intereses de los adolescentes en este período hacen referencia a:

1) Mayores intereses de relación con los iguales.

2) Mayores deseos de independencia familiar.

3) Mayores intereses sexuales.

A partir de estos intereses generales, el autor va a describir cuáles pueden ser las posibles "repercusiones del déficit visual" (González Fernández, 2003, p. 305). Los deseos de relación entre iguales pueden verse afectados por el déficit visual. No olvidemos que muchas de las actividades que los adolescentes desarrollan suelen estar cargadas de contenidos visuales. En la medida en la que el déficit visual dificulte su realización puede afectar disminuyendo su participación y generando 
ideas que promuevan el desajuste. Así, las dificultades que para algunos adolescentes con graves déficits visuales supone asistir a una discoteca, participar en actividades deportivas o ir al cine pueden ir apartándole del grupo de compañeros y originar ideas negativas que afecten a su autoestima e influyan en otras relaciones con los iguales. Respecto al mayor deseo de independencia y de flexibilización de las normas familiares relacionadas con la autonomía, los jóvenes con déficits visuales y dificultades en su movilidad o en otros aspectos de su vida diaria, pueden encontrarse con un obstáculo insalvable que limite sus deseos o bien con familias que se opongan al temer por la seguridad de su hijo. Por último, el despertar sexual de los adolescentes en algunos casos es frenado por las ideas relacionadas con la valoración que creen que los demás hacen de su persona al padecer un déficit visual (López, Fernández, Amezcua, \& Pichardo, 2000, citado por González Fernández, 2003, p. 305).

Por otro lado, las concepciones que tienen los adolescentes acerca de su situación visual generan una forma de afrontar y de reaccionar emocionalmente ante las situaciones y dificultades que aparecen a lo largo de su ciclo vital. Desde el nacimiento el bebé con déficit visual se ve expuesto a un entorno sociocultural que no es indiferente a su situación visual, sino que reacciona ante su diferencia con respuestas que son interpretadas por el niño y contribuyen a consolidar progresivamente su concepción acerca de lo que le pasa, las repercusiones que genera y actitudes y valores relacionados con ello (Bronfenbrenner, 1987; Hoffman, Paris \& Hall, 1996; Ovejero, 1998; , citados por González Fernández, 2003, p. 307).

Entre las fuentes de información que la persona utiliza para ir construyendo un sistema de ideas y actitudes relacionadas con su situación visual se encuentran:

1) Entorno familiar: la familia es el primer elemento de contacto entre el propio niño y el mundo físico y social en el que vive. Sus propias ideas y actitudes respecto al déficit visual van a modular la forma de relacionarse con su hijo y van a influir desde los primeros momentos de vida.

2) Entorno social próximo: se constituye por las personas con las que el individuo mantiene contacto, vecinos, profesores, amigos, etc. En la medida en que las 
ideas y actitudes de este entorno próximo se expliciten en la relación con el niño con déficit visual, se irán convirtiendo en una fuente de información que alimente su sistema de ideas acerca de sí mismo y del mundo que le rodea.

3) Entorno sociocultural: la sociedad en la que vivimos mantiene una serie de concepciones y valores directa e indirectamente relacionados con el déficit visual. Así, en cada sociedad a lo largo de su historia ha habido una serie de ideas predominantes acerca de cómo son estas personas, cuáles son sus posibilidades y cómo pueden valorarse. Esta concepción cultural se encuentra en la base de muchas ideas y actitudes de las personas que rodean al joven con déficit visual y pueden exteriorizarse directamente a través de la relevancia que la sociedad otorga a la visión o las restricciones y sistemas de protección que la misma sociedad establece para las personas con déficit visual.

4) La propia persona: no se puede pensar que las actitudes e ideas de los niños sean únicamente fruto de la influencia de los distintos entornos en los que vive. Los adolescentes interpretan las situaciones en las que el déficit visual se manifiesta, contribuyendo progresivamente en la elaboración de formas de afrontar las situaciones, actitudes e ideas respecto a ellos mismos.

El autor menciona que estos entornos ejercen una influencia muy distinta en función del momento evolutivo en el que la persona se encuentre. Mientras que el contexto familiar constituye el núcleo fundamental durante los primeros años de vida, en la adolescencia pasa a un segundo plano, surgiendo la necesidad de distanciarse psicológicamente y situarse en un plano de mayor igualdad e independencia con los restantes miembros de la familia. Durante este período los amigos y compañeros relevan a la familia como la instancia que más influencia ejerce en los jóvenes. En este sentido entonces, debemos considerar los intereses propios de esta etapa, así como las dificultades que el adolescente puede encontrar para relacionarse con ellos. 
En relación con la posición subjetiva del adolescente frente a su discapacidad en el momento de la elección, nos parece importante tomar los aportes de Cattáneo (2008), quién ha realizado una investigación sobre las metas de vida de los adolescentes argentinos. Para el desarrollo de esta tesis, nos resultan significativas las definiciones que propone sobre:

Metas Realistas: aquellas que discriminan entre medios y fines dentro del proceso de consecución de las mismas, presentan anticipación y planificación del proceso, ajustadas a las posibilidades reales del sujeto vinculadas a las condiciones del punto de partida (socioeconómicas, competencias personales), al "espacio de experiencias" y al "horizonte de expectativas". Todo ello constituye una precondición para que las metas sean autonómicas.

Metas Pseudoautonómicas aquellas que aparentan falsas salidas, tienen que ver más con el desasimiento de las figuras parentales, que con la autonomía. Lo que impera es la inmediatez, la concretud. No se detecta una proyección real, ya que los adolescentes hacen un tratamiento diferente de la realidad, hay apariencia, pero falta esa combinación de precondiciones relacionadas con el proceso temporal, los medios para el logro no se expresan, las proyecciones a futuro aparecen idealizadas, fantaseadas, no se visualiza algún proceso y todo está puesto en el horizonte de expectativa, el tiempo es indefinido. No ponderan el espacio de experiencia, o es débil.

Metas Desiderativas: metas expresadas en términos de deseos más inmediatos, concretas, sin proceso para la consecución de las mismas, se destaca una fuerte idealización de situaciones, fantasías. Estas metas constituyen precondiciones para las metas Pseudoautonómicas (Cattáneo, 2008, p. 6).

Schorn (2003) tomando los aportes del psicoanálisis, hace referencia a las barreras psicológicas en la discapacidad y plantea su diferencia con los mecanismos de defensa. Estos últimos, surgen como respuesta a la invasión de la angustia, o a la aparición de un afecto traumático de una representación inaceptable. Las barreras psicológicas, no serían para ella una defensa sino una contradefensa. Surge como un plus que se estructura de manera rígida cuando se ha superado un quantum. Esto afecta tanto a la persona con discapacidad, como a la familia y a la comunidad. ( $p$. 9). 


\subsection{De las Necesidades Educativas Especiales a las Barreras para el Aprendizaje y la Participación}

A partir de la lectura especializada en la temática de la discapacidad visual (Cangelosi, 2006; Cuevas, 2006) encontramos que se refieren al término Necesidades Educativas Especiales (en adelante NEE). Coincidimos con Pantano (2007) quién afirma que la denominación, personas con necesidades especiales, lleva a pensar o a interpretar que las personas con discapacidad tienen necesidades que deben ser satisfechas en espacios segregados, también "especiales" (p. 109). Las personas con discapacidad, tienen las mismas necesidades que cualquier sujeto: fisiológicas, de alimentación, de autorrealización, entre otras. Algunas personas experimentan ciertas "dificultades para satisfacerlas" de manera común y corriente. En tal sentido, a veces se requieren adaptaciones o elementos particulares, por ejemplo un baño accesible para personas con discapacidad motora, que requiere más espacio para el giro de la silla, un barral y cierta elevación del inodoro (Pantano, 2007, p.10). La autora también sostiene que:

Muchas personas con discapacidad tienen necesidades especificas (por ejemplo de 'educación especial', de 'trabajo protegido', etc.), dentro de las generales (siguiendo con el ejemplo anterior, de aprender, de trabajar), relacionadas con las limitaciones o restricciones (por ejemplo de comprensión, de manejo del tiempo, etc.), que su deficiencia o estado negativo de salud impone a su funcionamiento (Pantano, 2007, p. 110)

Según un estudio sobre experiencias de inclusión educativa realizado en algunas regiones de Argentina (UNICEF, 2014) la categoría de NEE implicó un avance ya que permitió correr la mirada del sujeto portador de una limitación, para pensar en las adecuaciones que la escuela debía hacer para favorecer su aprendizaje. Sin embargo, este enfoque presenta algunas limitaciones como las siguientes.

- Se centran exclusivamente en las dificultades que experimentaban los alumnos "etiquetados" y no consideran las dificultades que podían experimentar todos los alumnos.

- Pueden generar expectativas más bajas de parte de los docentes hacia los alumnos con NEE.

Tesis Doctoral. "Orientación y Discapacidad Visual. Factores que inciden en la elección de los adolescentes" 
- Pueden reforzar en los docentes la creencia de que la educación del alumno con NEE fundamentalmente es responsabilidad de los especialistas.

Si bien en la actualidad y por los motivos enunciados ya no se habla en términos de NEE, este concepto representó una perspectiva de fuerte impacto, posibilitó el ingreso de niños y niñas con discapacidad a las escuelas comunes e instaló la idea sobre las posibilidades de aprendizaje de estos alumnos en instituciones comunes, dejando de ser exclusivamente sujetos de la educación especial, si se incorporan los ajustes y recursos específicos.

La nominación Barreras para el Aprendizaje y la Participación se adopta en el Index for Inclusion (Ainscow \& Booth, 2000, citado por UNICEF, 2014, p. 24) reemplazando la de Necesidades Educativas Especiales, para hacer referencia a las dificultades que experimenta cualquier alumno o alumna en relación con el aprendizaje. Se considera que éstas surgen de la interacción entre los estudiantes y sus contextos, es decir las personas, las políticas, las instituciones, las culturas y las circunstancias sociales y económicas que afectan a sus vidas. Las barreras pueden impedir el acceso a las escuelas o limitar la participación dentro de ellas. Son fundamentalmente culturales y se manifiestan en aspectos legales o normativos, arquitectónicos, de acceso a bienes culturales por falta de apoyos, por ejemplo, ausencia de medios y lenguajes alternativos de comunicación, tecnológicos, etc. (Ainscow \& Booth, 2000; López, 2001). Para que las escuelas y las aulas sean inclusivas es necesario la identificación y eliminación de obstáculos y barreras de modo tal que posibiliten la accesibilidad al entorno físico, social, económico y cultural, a la salud y la educación, a la información y las comunicaciones para que las personas con discapacidad puedan gozar plenamente de todos sus derechos.

A continuación, se describirán, las principales necesidades específicas que presentan los sujetos con discapacidad visual en el contexto educativo, las cuales deben ser considerados para realizar los ajustes y adecuaciones necesarios para garantizar su inclusión educativa. 


\subsection{Necesidades específicas de los sujetos con ceguera}

En su conjunto, las características que identifican a los sujetos con ceguera son solidarias de las necesidades específicas que requieren, entre las que se destacan:

- Necesidad de acceder al mundo físico a través de otros sentidos, dada su limitación para recibir información del mundo que le rodea. Esta información espontánea del medio queda reducida, deformada y necesita de otros sentidos, como el oído, el tacto o el olfato o de la información que pueden suministrar otras personas, para conocer el entorno. En el ámbito escolar se tendrán que adaptar los materiales para favorecer el acceso a los contenidos curriculares.

- Necesidad de aprender a orientarse y desplazarse en el espacio. Un aspecto a tener en cuenta es la dificultad para formarse una imagen mental del espacio circundante, así como para detectar los obstáculos que pueden interferir en los desplazamientos. De este modo debe adecuarse el ambiente, particularmente el de enseñanza, eliminando barreras arquitectónicas.

- Necesidad de adquirir un sistema alternativo de lectoescritura. Se trata del Sistema de escritura Braille, que consiste en un sistema táctil y cuyo proceso de aprendizaje requiere de una enseñanza y unos materiales específicos.

- Necesidad de aprender hábitos de autonomía personal. La ceguera impide la observación e imitación de los hábitos básicos de autonomía personal (vestido, aseo y alimentación). Mientras que las personas con visión normal perciben habitualmente las distintas actividades que se realizan en la vida cotidiana, las personas con ceguera necesitan vivir en su cuerpo las acciones que componen estas tareas $y$, en ocasiones, recibir información verbal complementaria por parte de los demás.

- Necesidad de conocer y asumir su situación visual. La persona con ceguera necesita conocer su déficit y las repercusiones que conlleva (potencialidades y limitaciones) para poder asumir su situación y formarse una autoimagen adecuada a su realidad. Sólo así podrán afrontar positivamente las dificultades 
que la vida sin visión les deparará en el ámbito personal, escolar, social y profesional.

\subsection{Necesidades específicas de los sujetos con disminución visual}

A continuación presentaremos las necesidades específicas de las personas que presentan disminución visual. En el contexto educativo, las mismas serán diferentes según el grado de visión o su funcionalidad. Así, en algunos casos habrá alumnos que necesiten trabajar con el Sistema Braille a pesar de que su resto visual le permita realizar otras tareas. Comparten con los ciegos algunas necesidades y resultan específicas, por ejemplo

- Necesidad de complementar la información recibida visualmente con otros sentidos. Cuando el resto visual no les permite acceder a toda la información, puede ser necesario complementarla a través de información verbal o táctil.

- Necesidad de mejorar la funcionalidad del resto visual mediante estimulación y entrenamiento visual. Habitualmente estos alumnos y alumnas necesitan "aprender a ver", es decir, aprender a utilizar su resto visual de la manera más eficaz posible.

- Necesidad de conocer y asumir su situación visual. Esto se acentúa en los alumnos y alumnas con disminución, ya que la presencia del resto visual hace que no se identifiquen como personas con déficits. En muchos casos conlleva al rechazo de las ayudas y programas educativos que compensarían las necesidades educativas que presentan.

\subsection{La inclusión educativa de los alumnos con Discapacidad Visual}

La educación inclusiva implica que todos los niños de una comunidad aprendan juntos, independientemente de sus características individuales. El centro de atención se dirige a la transformación de la organización y la propuesta educativa de la escuela, para acoger a todos los niños de modo tal que tengan éxito en sus aprendizajes (Blanco, 1999). 
Con la aprobación de la Convención Internacional sobre los Derechos de las Personas con Discapacidad (ONU, 2006), se reconoce el derecho a la educación de las personas con discapacidad estableciendo un sistema de educación inclusivo a todos los niveles así como la enseñanza a lo largo de la vida. Asimismo se expresa la necesidad de establecer una educación inclusiva que se define como una adecuación de los sistemas educativos para brindar educación para todos. Ya no son las personas con discapacidad quienes deben adecuarse a las escuelas para poder ser parte de ellas, sino que es la escuela quien debe reorganizarse para brindar una enseñanza a todos. Entonces, en primer lugar, se debe facilitar el acceso a los contenidos curriculares, como ya se señalara. Los alumnos con resto visual deben utilizar las ayudas ópticas prescritas para favorecer el acceso a la información textual y gráfica. Los alumnos con ceguera necesitarán de otros materiales que se describirán en cada una de las áreas curriculares. En segundo lugar, se deben incluir en las áreas curriculares las siguientes adaptaciones:

1. Área lingüística (lengua castellana y lenguas extranjeras). Las adaptaciones más importantes en esta área son las siguientes:

- Introducción del Sistema de escritura Braille como código de lectoescritura para los alumnos y alumnas con ceguera y de aquellos otros en los que su resto visual no les permita una lectoescritura funcional canónica.

- Reforzamiento de los contenidos relacionados con el lenguaje corporal y gestual.

- Reforzamiento de la caligrafía en los alumnos y alumnas con déficit visual que mantienen la lectoescritura habitual.

Para abordar estas modificaciones se cuenta fundamentalmente con los siguientes recursos:

Máquina de escritura en el sistema Braille: ha venido a sustituir al sistema manual de escritura con regleta y punzón. Permite una mayor soltura en la escritura y posterior lectura de un texto. Para escribir un carácter en Braille hay que pulsar a la vez las teclas (de seis) que corresponden a los puntos en relieve que lo componen. Su único 
inconveniente es el ruido que produce. La más utilizada es de la casa Perkins, aunque resulta algo pesada para su transporte. Es posible adaptarle una placa (Braille-N-Print) que permite almacenar un archivo corto para volcarlo en una impresora de tinta.

Sistema Braille hablado: se trata de un pequeño aparato con teclado Braille y voz sintética, que permite almacenar la información tecleada y escucharla. Puede conectarse a una computadora e imprimirse el texto en tinta o en Braille, lo que lo hace muy conveniente tanto para tomar apuntes como para realizar los exámenes.

Lector de pantalla: el más usado es el Jaws, es un programa que recoge información de la computadora y la ofrecen al usuario en voz y/o en el sistema Braille.

Adaptaciones de textos: los alumnos y alumnas con disminución visual suelen necesitar que los textos y dibujos presenten un buen contraste. Para ello, puede ser necesario que se remarquen los contornos y grafías y se adapten los dibujos.

El libro hablado. Es un aparato que permite grabar y reproducir en 4 pistas y dos velocidades, con lo que se le saca bastante provecho a cada cinta de casete. Este sistema no sólo le permite completar los apuntes, también pone a su disposición una gran variedad de libros para completar su formación. Es conveniente sacarle partido a este recurso ya que, debido a que la lectura en Braille es mucho más lenta, alguno de los libros recomendados para su lectura pueden pedirse en este formato.

2. Área científico - matemática. En esta área las adaptaciones se centran en:

- Introducción de la signografía específica Braille.

- Conocimiento y utilización de instrumentos específicos para el cálculo, como el ábaco, la caja de matemáticas y la calculadora parlante; para el dibujo geométrico, como el maletín de dibujo y material de medidas adaptadas, como reglas, transportador de ángulos, cartabones, metros, etc.

- Adaptación de modelos para la construcción de circuitos, máquinas, etc.

3. Área socio natural. Podemos destacar las siguientes adaptaciones: 
- Acercamiento al entorno socio-natural mediante salidas escolares programadas, reproducciones tridimensionales, dibujos en relieve e información verbal complementaria.

- Conocimiento y utilización de maquetas y mapas adaptados.

- Adquisición de habilidades de la vida diaria que permitan la autonomía personal del alumno y alumna.

4. Área de educación artística. Las adaptaciones en esta área serían las siguientes:

Música: Introducción de la signografía y adaptaciones de la escritura musical.

Plástica:

- Comprensión del dibujo como representación bidimensional de la realidad.

- Conocimiento y utilización de los materiales específicos de dibujo:

a) Plantillas de dibujo positivo: Hojas de plástico que permite dibujar con un punzón.

b) Tablero de fieltro o caucho: Complementa el anterior y permite trabajar también en hojas de papel braille. Su marco está diseñado para la colocación de reglas.

c) Estuche de dibujo: Se compone de diversos elementos (punzones, ruedas dentadas, transportador de ángulos, compás, etc.) para trabajar en relieve.

- Aprendizaje de estrategias que potencien la funcionalidad visual (estimulación y discriminación visual).

5. Área educación física. En esta área las adaptaciones principales se centran en:

- Utilización del alumno o alumna con ceguera como modelo para la explicación de los movimientos que debe realizar.

- Sustitución de las actividades deportivas que implican lanzamiento y recepción de objetos por otros que incluyen otros sentidos distintos al visual.

- Aprendizaje de técnicas de orientación y movilidad que permitan el desplazamiento autónomo en el entorno escolar y social de los alumnos y alumnas con ceguera o déficit visual. 
Orientaciones metodológicas. Además de las adaptaciones anteriormente señaladas es necesario tener en cuenta las siguientes orientaciones metodológicas que las complementan:

- El carácter analítico de la exploración táctil conlleva un ritmo de aprendizaje más lento. Los alumnos con ceguera necesitarán ir explorando por partes los objetos hasta descubrirlos o conocerlos.

- El aprendizaje vivencial, por medio de experiencias, resulta de suma importancia.

- Muchos de los aprendizajes de juegos, conductas, hábitos, técnicas para realizar trabajos se aprenden por imitación del contexto cultural que rodea al alumno o la alumna. Al faltar la visión, esta imitación no existe de modo tal que será necesario guiar físicamente a estos alumnos para que puedan hacer estos aprendizajes.

- Se debe asegurar que los alumnos con disminución visual aprovechen lo máximo posible el resto visual que poseen. Para ello habrá que proporcionarles unas condiciones óptimas que faciliten su aprendizaje, tales como: luminosidad, contraste, ubicación cercana al pizarrón, utilización de ayudas ópticas y no ópticas, como atril, flexo, etc.

- Los alumnos con disminución visual reciben poca información de su entorno, por lo que se debe seleccionarles en la medida de lo posible un repertorio de actividades más representativas (actividades tipo).

- Se debe partir de lo concreto y de lo particular hasta llegar a lo abstracto y general.

\subsection{La Educación Superior de las personas con discapacidad visual}

La Organización Nacional de Ciegos Españoles (ONCE), junto a varias Universidades de España, ha realizado diversas investigaciones vinculadas con la inclusión de las personas con Discapacidad Visual en la Educación Superior. "Los servicios de apoyo a los estudiantes con discapacidad de las Universidades 
españolas no comenzaron a generalizarse hasta los años 90. En 1994 sólo un $2 \%$ de la universidades tenían este servicio; en 2001, ya lo tenían el 75\%" (Abejón Mendoza, Martínez Solana, \& Terrón López, p. 179).

En la Universidad de Granada se ha comprobado en relación con la problemática de los recursos que garanticen la inclusión lo siguiente:

Los recursos espaciales, materiales y tecnológicos son indicadores de medida de la inclusión/exclusión socioeducativa...concretamente en los alumnos deficientes visuales, objeto de este artículo, los recursos aludidos son la piedra angular del éxito de la intervención educativa, con ciertas adaptaciones espacio-temporales y tiflotecnológicas, que han de ser tenidas en cuenta... (Rodriguez Fuentes, 2003).

En el contexto Latinoamericano, en México, la Asociación Nacional de Universidades e Instituciones de Educación Superior (ANUIES), ha desarrollado un Manual para la Integración de Personas con Discapacidad en las Instituciones de Educación Superior, donde se proponen entre otras cosas, actividades de apoyo académico para actividades docentes dirigidas a alumnos con Discapacidad Visual.

En el Informe sobre la Educación Superior en América Latina y el Caribe. 2000-2005, La metamorfosis de la Educación Superior se reconoce que "El uso de las tecnologías de apoyo, de las Tecnologías de la Información y las Comunicaciones (TIC) y de la educación a distancia como alternativa importante para las personas con discapacidad, aún es insuficiente en las IES" (IESALC -UNESCO, 2005, p. 152).

En nuestro país y desde la Universidad Nacional de Cuyo, Grzona (2009), ha realizado una sistematización sobre las barreras que los jóvenes con este tipo de discapacidad tienen que superar en el momento de continuar sus estudios superiores:

1. Barreras arquitectónicas: falta de iluminación y de mobiliario auxiliar, ausencia de barras guías, de texturas en el suelo y en las escaleras, de identificación de lugares a partir de carteles indicadores en macrotipos o en Sistema Braille.

2. Escasez de elementos tiflotecnológicos básicos y de materiales curriculares: necesarios en el tipo de formato más adecuado (Sistema braille o macrotipos). 
3. Barreras propias de las personas con discapacidad y sus familias: que han sido educadas como sujetos pasivos y no como sujetos de derechos; dotados de voz propia, que les permita ser co-responsables de cada toma de decisiones.

4. Barreras de la sociedad y barreras gubernamentales por la falta de decisiones políticas acompañadas de los recursos materiales y humanos necesarios.

Por último, en el año 2013, desde el Área de Accesibilidad de la Secretaría de Extensión de la Facultad de Ciencias Económicas de la UNLP, en colaboración con la Comisión Universitaria de Discapacidad (CUD) UNLP, se elaboró el manual "Consideraciones generales para la inclusión de personas con discapacidad en la universidad: por una Universidad accesible". Fue pensado como una orientación general en el tránsito de una persona con discapacidad a la Universidad y no como un "recetario o conjunto estricto de pasos a seguir" (Rucci: 2013).

\subsection{Algunos antecedentes en orientación en discapacidad visual}

En este sentido, es preciso retomar la trayectoria de La Organización Nacional de Ciegos Españoles (ONCE), mencionada más arriba. Surge en 1938 con el propósito de mejorar la calidad de vida de las personas con ceguera o deficiencia visual de toda España. En mayo de 1939, celebró su primer sorteo del cupón ${ }^{4}$, que dio trabajo a las personas con ceguera a la vez que recursos económicos a la organización.

Hacia las décadas de los '40-'50 comenzaron a trabajar fuertemente en la educación en centros educativos y bibliotecas específicos para niños con ceguera. En los años sesenta, se continuó fomentando la diversidad laboral y se crearon la Escuela de Telefonía, un centro de formación profesional y la Escuela Universitaria de Fisioterapia. Hacia los años '80, se pusieron en marcha proyectos que hicieron que la ONCE ocupara un lugar de gran importancia entre las organizaciones de y para las personas con ceguera de todo el mundo.

\footnotetext{
${ }^{4}$ Los sorteos de la ONCE engloban los diversos juegos de lotería con los que la Organización Nacional de Ciegos Españoles (ONCE) financia parcialmente su labor social. El más conocido y longevo de ellos es el cupón de la ONCE, estrenado en 1939, aunque en los últimos años muchos juegos de la ONCE se han ido incorporando junto a la venta del cupón original.
} 
En 1988 se crea la Fundación ONCE para la cooperación e integración social de personas con discapacidad. Actualmente, para llevar a cabo su labor cuenta con el apoyo de la Administración Pública a través de los Ministerios de Economía y Hacienda, Asuntos Sociales e Interior. Se trata de una organización que participa en diversos foros nacionales e internacionales sobre ceguera y discapacidad, promoviendo también distintas iniciativas para llevar adelante sus funciones. Además, para que las personas con ceguera o discapacidad visual puedan integrarse por completo en la sociedad, la ONCE desarrolla programas educativos y de formación, de prevención de la ceguera, de investigación en los más diversos campos, y de autonomía personal.

Desde su creación, esta organización presta atención educativa a las personas con grave deficiencia visual o ceguera. Al principio, los colegios de la ONCE eran la única opción educativa para los alumnos con ceguera o deficiencia visual grave en España. En la actualidad, la mayoría (más del 98\%) de estos niños y niñas están escolarizados en colegios comunes, en su pueblo, barrio o ciudad, y reciben una atención complementaria que responde a las necesidades educativas específicas derivadas de su situación visual. Para ello, cuentan con los recursos establecidos en los convenios de colaboración entre la ONCE y todas y cada una de las Administraciones Educativas.

En 1998 se crea la Fundación ONCE para la solidaridad con las personas ciegas de América Latina (FOAL) que coopera para mejorar la calidad de vida de las personas ciegas en la región, a través de programas educativos, de empleo, de formación o de rehabilitación en sus respectivos Estados. Los países que la integran son: Argentina, Brasil, Bolivia, Chile, Colombia, Costa Rica, Cuba, Ecuador, El Salvador, Guatemala, Honduras, México, Nicaragua, Panamá, Paraguay, Perú, República Dominicana, Uruguay, Venezuela.

Las principales líneas de actuación de la FOAL son la educación, la formación para el empleo, la inserción laboral y el fortalecimiento asociativo. 
Inclusión educativa. La educación de niños/as con discapacidad visual en América Latina ha cambiado significativamente a lo largo de estas últimas décadas. Los Ministerios de Educación están esforzándose para implantar políticas que favorezcan la inclusión de estos estudiantes en el sistema de educación regular. Es importante enfrentar a las instituciones públicas y privadas de los ámbitos educativos especiales y regulares que atienden a personas ciegas con la realidad de las políticas que se están aplicando, así como detectar las fallas y buscar entre los casos exitosos nuevas vías de actuación que permitan disminuir el grado de absentismo escolar y abandono que se produce al llegar a la escolaridad secundaria. Por todo ello FOAL se plantea seguir impulsando una atención educativa de calidad que permita asegurar el derecho a la educación de todos los niños y niñas con ceguera o deficiencia visual grave en Latinoamérica, de una forma más cercana al comprender la necesidad de compaginar el apoyo nacional a través de los Ministerios con el apoyo local en coordinación con las autoridades.

Formación e Inserción laboral. Con el fin de poder dar respuesta a la situación de vulnerabilidad extrema a la que se exponen las personas con discapacidad visual adultas, al carecer en un $80 \%$ de trabajo y no contar con apoyos o atención específica en sus estados, FOAL ha implementado un Programa de mejora de la empleabilidad basado en la formación para el empleo y el apoyo a la inserción laboral de las personas con esta discapacidad. Se trata del Proyecto "AGORA" (Aulas de Gestión Ocupacional de América Latina), a través del cual han constatado que un $70 \%$ de la población que se acerca al programa de inserción laboral, cuenta con menos de 9 años de educación formal, situación que equivale a los seis años de educación primaria, más algún año del ciclo básico de educación secundaria. Este nivel de formación es insuficiente, a la hora de pensar el ingreso al empleo, se tenga o no una discapacidad. AGORA trabaja en coordinación con los servicios de rehabilitación de cada país para que la formación impartida en el programa haga del proceso una rehabilitación integral que permita minimizar las dificultades económicas, psicológicas y sociales que se le presentan a la persona con discapacidad a la hora de vincularse a una vida adulta con las exigencias que requiere. 
Servicios de Rehabilitación Integral. Como área transversal para el colectivo se potencian los servicios de rehabilitación integral así como a la capacitación en las Tecnologías de Acceso a la Información y la comunicación a través de equipamiento y dispositivos tiflotécnicos.

Ahora bien, con respecto a la Orientación en los sujetos con discapacidad visual, Pérez, Rivas y Rocabiert (1992) mencionan algunos estudios realizados por diferentes autores sobre la conducta vocacional de las personas ciegas, a partir de los cuales mencionan una serie de aspectos a ser considerados.

En primer lugar, que al igual que la conducta vocacional de las personas videntes, la de los sujetos ciegos está influenciada por factores sociales (necesidades del mercado laboral, prestigio de algunas profesiones, etc.) e individuales (capacidades, intereses, actitudes). No obstante, se destaca que la ceguera, por sí misma, también influye en la conducta vocacional de estos individuos, ya que la limitación en la conducta vocacional de las personas ciegas, se vincula más a las representaciones sociales en relación con la ceguera que con cualquier otra cualidad inherente a la misma. Por otro lado, tomando otros aportes mencionan los de Graves \& Lyon , (1985), (citados en Pérez, Rivas \& Rocabiert, 1992), que distinguen atributos intrínsecos y extrínsecos. Los primeros, refieren a las características propias del problema visual; mientras que los segundos incluyen los factores sociales, tales como los perjuicios para con las personas ciegas o bien los factores no esenciales relacionados con la ceguera.

Pero además de la ceguera, y debido a lo que ella supone para los individuos que la padecen, tienen en cuenta otros factores o condicionantes que han dado cuenta de su influencia en la conducta vocacional:

a) El papel de los modelos y estereotipos. Este aspecto es importante, dado que aquellos individuos ciegos que estén actuando en profesiones que escapan a lo que cabría esperar para un invidente, por las limitaciones que la ceguera supone, pueden constituir modelos que ayudarán a los estudiantes a tomar decisiones que podrían considerarse como arriesgadas. En otros casos en los que la actuación refiere a profesiones tradicionalmente adaptadas a la limitación propia de la ceguera, también 
podrán influir como modelos las decisiones de los individuos en situación de elección.

b) La tecnología. Juega un doble papel, por un lado las nuevas tecnologías facilitan el acceso de las personas ciegas al mundo laboral; por el otro, los avances tecnológicos provocan una disminución de puestos de trabajo, que afecta a toda la población activa y en consecuencia a las personas ciegas, ya caracterizada por un alto nivel de desempleo.

c) El desconocimiento por parte de muchos individuos ciegos de sus capacidades, habilidades y del mundo laboral. Ello les puede dirigir en ocasiones a la elección de programas de formación profesional básico o de nivel muy específico relacionado con su handicap, sin tener en cuenta otras profesiones para las que se requiere una formación de nivel educativo superior.

d) El nivel de expectativas o aspiraciones de los estudiantes. Este es un aspecto importante a tener en cuenta, resultados a ese respecto son variados y pueden estar asociados a factores de tipo social y cultural, como muestran los estudios realizados en las India (Khan, 1986, citado en Pérez, Rivas \& Rocabiert, 1992), en los que se comprobó que las esperanzas ocupacionales de los niños ciegos son más bajas que las de los niños videntes y que están relacionadas con los trabajos que conocen y denotan un sentimiento de inferioridad.

Sin embargo, existe otro estudio (Tobin \& Hill, 1988) realizado en Gran Bretaña, que muestra que los puntos de vista de los sujetos ciegos estudiados con respecto a sus aficiones, intereses y actitudes, no se diferencian de manera significativa con los de los estudiantes con capacidad visual normal.

Asimismo, Bush-Lafrance (1988) en Canadá, comprueba que no existen diferencias entre las expectativas educativas de ciegos y videntes, mientras que aparecen diferencias con respecto a las expectativas ocupacionales, destacando además el hecho de que disminuyen conforme aumenta el grado de visión de los estudiantes ciegos.

A partir de estos antecedentes, Pérez, Rivas y Rocabiert (1992) refieren que en la conducta vocacional de las personas ciegas, entran a formar parte aspectos que tal 
vez no aparezcan (o al menos con la misma intensidad) en la población normal. Por eso se interrogan sobre el tipo de asesoramiento vocacional se ofrece actualmente a estas personas actualmente. Mencionan al respecto algunos estudios destinados a conocer la situación actual del asesoramiento vocacional que se realiza para poder dirigir mejor las intervenciones en el área.

En este sentido, el Centro de Entrenamiento e Investigación de Mississippi para la Ceguera y los Problemas Visuales, desarrolla actividades dirigidas a identificar, valorar y aumentar los servicios que supuestamente tienen como objetivo facilitar el empleo a las personas ciegas o con problemas visuales. En este Centro se diseñó un estudio en el que se comprobó que eran muchas las necesidades con respecto al desarrollo vocacional de las personas ciegas, pero los recursos disponibles para hacerles frente no respondían a todas ellas.

Otros estudios, como el Proyecto Avance para Sordos-Ciegos, se dirigen a facilitar a los estudiantes la transición de la escuela al mundo laboral, dándoles la posibilidad de comenzar a trabajar a tiempo parcial, mientras todavía acuden a la escuela.

Finalmente, se ha comprobado que en cuanto a la colocación de las personas ciegas, se obtienen mejores resultados cuanto esta labor se realiza de manera conjunta a través de un equipo formado por varios especialistas: técnico o ingeniero de rehabilitación, especialista en colocación, etc.

\subsection{Sistema de Asesoramiento Vocacional para ciegos (SAV-C) en España}

A continuación, resulta interesante hacer referencia al trabajo de Pérez, Rivas y Rocabiert (1992) que desarrollaron "El Sistema de Asesoramiento Vocacional para Ciegos" ya que por la índole de la especificidad en la temática, se convierte en un antecedente significativo para el desarrollo de la presente tesis. Este grupo de investigadores pertenecientes a la Facultad de Valencia realizaron un estudio con un grupo de alumnos ciegos, cuyo futuro profesional no se delimitaba en virtud de su ceguera, sino que buscaron nuevas vías para el desarrollo de actividades que parecían vedadas para los ciegos. Los autores mencionan que el tema del asesoramiento vocacional en estas personas, no ha sido estudiado en profundidad, posiblemente ante la idea de que el handicap visual determina las posibilidades de 
elección y, por tanto, el estudio de la conducta vocacional de las personas ciegas es prácticamente inédito en la literatura (Pérez, Rivas \& Rocabiert, 1992).

Rivas (1988) define a la conducta vocacional como un proceso de socialización y da cuenta de que no se ha trabajado suficientemente en relación con el mundo de la ceguera.

Creemos que la conducta vocacional en las personas ciegas es un proceso de socialización que implica la integración educativa y profesional, y en función de ello, las notas que hemos señalado para el SAV, son igualmente válidas para las personas ciegas, mediando la oportuna adaptación al handicap (Pérez, Rivas \& Rocabiert, 1992, p. 461).

En este sentido, Rivas, Rocabert, Ardit, Martinez, Gil, y Rius, J. (1990).realizaron la adaptación del Sistema de Asesoramiento Vocacional, a la población de individuos ciegos. Este sistema tiene un enfoque teórico conductual-cognitivo y está formado por una serie de instrumentos, a través de los cuales se recoge la diversidad de aspectos que forman la conducta vocacional, caracterizada por su multidimensionalidad. Estos instrumentos (SAV-90) se agrupan en cinco fases que intentan explorar todos los aspectos importantes relacionados con la conducta y el desarrollo vocacional de cualquier individuo. Estas fases son:

1. Situación Vocacional Personal: supone un primer acercamiento a la situación del estudiante.

2. Desarrollo Vocacional: una de las fases que aporta mayor información, dado que permite especificar el grupo vocacional al que va dirigido el individuo.

3. Conducta Vocacional: relacionada con la madurez del individuo en situación de elección. Explora la forma en que el estudiante toma sus decisiones, busca información importante para su futuro profesional, la influencia del ambiente, etc. Es interesante que en esta fase, los autores incorporaron una puntuación de "alerta", que constituye una combinación lineal de distintos factores incluidos en los instrumentos de esta fase, y que indica al estudiante la necesidad de recurrir al orientador ante la posible existencia de problemas en las decisiones vocacionales que pueda tomar. 
4. Aptitudes Básicas para los Estudios Universitarios: batería formada por diez pruebas que evalúan las capacidades necesarias para cursar estudios universitarios dentro del grupo vocacional en que se encuentra el estudiante.

5. Información vocacional y toma de decisiones: fase opcional que se incorporó en el (SAV-90). Su objetivo es proporcionar más información vocacional a los estudiantes que la necesiten e insistir en la toma de decisiones vocacionales cuando represente un problema importante para el estudiante.

En la adaptación realizada para la población de personas con ceguera, se tuvo en cuenta:

a. La presentación de todo el material en el sistema de escritura Braille (manuales, hojas de respuestas, información vocacional), con la finalidad de proporcionar a los estudiantes autonomía en la realización de las pruebas y facilitarles el manejo de los materiales.

b. Recopilación de todas las profesiones que actualmente desarrollan las personas ciegas, junto con las que puedan realizarse en un futuro próximo, gracias a los avances en campos como el de la tecnología. El propósito es que los estudiantes ciegos puedan contar con información acerca de las posibilidades profesionales actuales.

c. Recolección de datos específicos de los sujetos que van a influir en su toma de decisiones vocacionales:

- Intereses y preferencias vocacionales.

- Motivos que le dirigen hacia ellas.

- Expectativas de cara al futuro.

- Ambiente en el que ha vivido y realizado sus estudios, etc.

d) El tiempo de resolución mayor: por las características de la lectura en Braille, las personas ciegas van a necesitar más tiempo para leer el material y proporcionar las respuestas que se les solicitan

A continuación, se presentarán los instrumentos adaptados, teniendo en cuenta que el objetivo es la autonomía del estudiante a la hora de responder a las distintas 
pruebas, como lo muestra la posibilidad de responder en el sistema de escritura Braille:

a) Biodatos: su objetivo es que el estudiante reflexione sobre su conducta pasada y lo que piensa de ella en aspectos como el social, familiar, académico o ambiental. La adaptación incluyó cuestiones específicas relacionadas con la ceguera ya que pueden ser importantes en la conducta del individuo.

b) Cuestionario de Intereses Vocacionales: Preferencias e influjos (CIVC): mide los intereses vocacionales a través de las preferencias hacia determinados estudios y la influencia de algunos influjos socioambientales. Como base, presenta el anexo constituido por el documento: Áreas Vocacionales, en el que se encuentra la descripción de las áreas que aparecen en el cuestionario junto a las profesiones más representativas que comprende cada una.

En la adaptación eliminaron cuatro áreas (fantástica, aire libre-agropecuaria, aire libre-deporte y militar) porque consideraron que la mayoría de las profesiones no se adecúan a las características de la ceguera o si lo hacen (como ocurre con aire libredeporte) las personas ciegas no se dedican profesionalmente a la mayoría de las ocupaciones que contienen. Por otro lado, han unido las áreas artístico-musical y artístico-plástica en una única, dado que pertenecen al mismo grupo vocacional; de la artístico-plástica, han eliminado las profesiones que tenían a la visión como aspecto destacado.

De esta forma, las dieciséis áreas vocacionales quedan reducidas a once: teórico experimental, técnico-práctica, bioterápica, teórico-humanística, literaria, psicopedagógica, sociopolítica, económico-empresarial, persuasivo-comercial, administrativo-burocrática y artística. Estas áreas, en principio son encuadrables en los seis grupos vocacionales con los que los estudiantes comparan sus resultados (humanístico, psicopedagógico, económico-social, bioterápico, científico-tecnológico y artístico).

Estas once áreas han sido analizadas, con la finalidad de recoger todas aquellas profesiones adecuadas actualmente a las características de la ceguera. Ello ha supuesto incluir profesiones que no aparecían en el documento antes de su 
adaptación (venta de cupón ${ }^{5}$ ) o eliminar profesiones, que aunque aparecían, por el momento una persona ciega no podía asumirlas (por ej., piloto de avión).

c) Preferencias Vocacionales (PVC): Su objetivo es concretar más la opción vocacional del estudiante, de tal manera que le permite determinar en lo inmediato el grupo vocacional con el que comparará sus resultados. Partiendo de las áreas vocacionales que mayor puntuación han alcanzado en el CIVC, el estudiante, tomando como referencia el documento de áreas vocacionales, deberá concretar las seis profesiones que más le interesan o atraen.

d) Rejilla Vocacional (RVC): sobre la base de las mismas profesiones utilizadas en el PVC, permite al estudiante justificar su elección indicando los motivos (constructos) correspondientes en cada caso. Se han mantenido todos los constructos que aparecían en la rejilla original, excepto el $\mathrm{V}$ (aventura y riesgo) que se ha sustituido por "desafío y superación personal". Asimismo, se proporciona al estudiante la oportunidad de escribir al final de la hoja de respuestas algún constructo que él considere importante, que no aparezca reflejado en el listado que se le presenta (indicando la profesión a la que hace referencia), para así representar mejor la estructura cognitiva de estas personas.

e) Factores de Decisión Vocacional (FDVC): permite al estudiante reflexionar sobre la incidencia que pueden tener distintos factores socio-escolares y familiares en su toma de decisiones vocacionales y que pueden pasar inadvertidos. También aquí se incluyen elementos específicos (como la localización del lugar de estudios o trabajo, conocer personas ciegas y videntes que vayan a realizar o estén realizando los estudios que le interesan, el ambiente del lugar de estudios, la disponibilidad de medios técnicos, etc.) que pueden estar condicionando las decisiones a tomar.

Administración del SAV-C. A igual que en el caso del SAV, el SAV-C es una tecnología creada para aquellos que la necesiten y no una prueba colectiva, es decir, se debe administrar en los estudiantes que tengan dudas o deseen confirmar las decisiones vocacionales, a partir de sus características particulares.

\footnotetext{
${ }^{5}$ El que corresponde a la ONCE mencionado anteriormente.
} 
Por otro lado, la adaptación permite que los estudiantes puedan resolverlo de forma independiente, proporcionándoles de esta manera una mayor autonomía y libertad de actuación.

La intervención y colaboración del orientador será necesaria para solucionar las dudas que puedan surgir, así como para evaluar algunos de sus apartados, concretamente: Biodatos, Rejilla Vocacional y Factores de Decisión Vocacional. El orientador también deberá proporcionar información específica sobre determinadas profesiones que al estudiante le interesen, si las desconocen.Los autores destacan al respecto lo siguiente:

Es importante que además de las características del SAV, el asesor conozca también las de la adaptación y todos los aspectos importantes de la ceguera, para así comprender mejor la situación del estudiante que solicita su ayuda especializada. Ello le permitirá intervenir en aspectos concretos que pueden ir desde enviar al estudiante al encargado de Movilidad y Orientación para que le enseñe los nuevos recorridos que tendrá que realizar al tomar su decisión, a dialogar con la familia para facilitar la decisión del estudiante, etc (Pérez, Rivas \& Rocabiert, 1992, p. 466)

Finalmente, concluyen que si bien al principio, todo esto puede parecer complicado para quien por primera vez trabaje con personas ciegas, le ayudará a comenzar a considerar a la ceguera como una característica más de la persona que tiene delante y no como la única característica diferencial que la define. Tanto esta idea, como la de buscar todas aquellas actividades que una persona ciega es capaz de hacer, en lugar de centrarse en sus limitaciones, resultarán de gran ayuda a quien tenga que proporcionar asesoramiento vocacional a personas ciegas.

EI SAVC propone así una nueva modalidad de situación educativa, en la que la información vocacional adecuada se convierte en un aspecto fundamental, se permite al estudiante ciego participar activamente y donde el orientador se convierte en un colaborador.

En este programa de trabajo, se insiste no tanto en los instrumentos específicos para ciegos, sino en la intervención psicoeducativa, prestando atención a aquellos aspectos que facilitan su independencia. La intervención orientadora se ajustará a al 
déficit visual y a los impedimentos que la tecnología vaya eliminando, haciendo de esta área de intervención un aspecto fundamental dentro de la conducta vocacional.

Ahora bien, el SAV ha tenido sucesivas revisiones, incorporando los avances tecnológicos que lo han convertido en Sistemas de Autoayuda y Asesoramiento Vocacional Informáticos (SAAVI, 1998, 2003) para estudiantes de educación secundaria. Específicamente en el año 2000, desarrollaron el SAVI - 2000 (Sistema de Asesoramiento Vocacional Informático) que evalúa el proceso de toma de decisiones de los estudiantes de Secundaria y Bachillerato a través de nueve grupos vocacionales. En el año 2002 se adaptó en una versión dirigida expresamente a personas ciegas denominada SAVI-C (Rivas, Pérez y Ávila 2002). En esta ocasión, la adaptación realizada tiene un manejo muy sencillo ya que permite su utilización en las computadoras personales (con las adaptaciones tiflotécnicas necesarias que permitan la salida en voz o en sistema de escritura Braille) y en equipos informáticos diseñados específicamente para ciegos (PC-Hablado o Sonobraille). (Rivas, Tormos, \& Martínez, 2005).

\subsection{Experiencias de Orientación en sujetos con discapacidad visual en Argentina}

En el país, encontramos que las propuestas de intervención orientadoras con esta población, provienen de iniciativas privadas. En este sentido, Capel (2013) desde el área de discapacidad de APORA, desarrolló una intervención con una joven con discapacidad visual. La autora da cuenta que si bien en la actualidad existen diferentes herramientas tecnológicas e informatizadas, ninguna se articula de manera organizada y sistematizada con los sistemas educativos. Al respecto, si bien la orientada cursó su escolaridad secundaria integrada, ninguno de los docentes pudo acompañar a la joven en el uso e implementación de estas tecnologías, por ejemplo, la posibilidad de estudiar a distancia a través de Internet.

Capel (2013) menciona que los mitos, creencias y prejuicios que la sociedad teje sobre este colectivo de personas, llegan a instalarse en el propio seno de la familia del sujeto con discapacidad y hasta en los modos de ver las prácticas que los profesionales realizan, teniendo -como efecto inmediato- la reproducción social de un imaginario que supone a este sujeto atado a un destino programado de no poder. 
Concluye que aún se observa una carencia en la concentración de información dirigida hacia este colectivo de personas. Si bien se conoce que en la actualidad la oferta de servicios, accesibilidades y apoyos hacia las personas en cuestión es cada vez más amplia, en materia de Orientación tanto los servicios como los profesionales que trabajan en forma individual no difunden sus propuestas hacia este sector. La autora sostiene que como orientadores, debemos interrogarnos por la escasa formación en materia de discapacidad, "no solamente por la misma dificultad o carencia en la formación, sino también por el sentido ético de estas prácticas". (Capel, 2013)

La Federación Argentina de Instituciones de Ciegos y Amblíopes (FAICA), es una asociación civil que pertenece a la FOAL, y tiene por objetivo luchar en todo el país por la promoción integral de las capacidades de las personas ciegas y con baja visión, por su bienestar general y por el justo reconocimiento de su condición de ciudadanos útiles y activos, sustentando como principios fundamentales la preservación de la dignidad de las personas ciegas y con baja visión y su derecho a intervenir en todos los asuntos que les conciernen.

Desarrollan el Programa Agora Argentina de Formación e Inserción Laboral para las personas con Discapacidad visual, que cuenta con el apoyo de la Fundación ONCE para América Latina y constituye un trabajo conjunto con la Universidad Nacional del Museo Social Argentino.

La ONG, CILSA (Centro de Inclusión Libre y Solidario de Argentina) se funda en 1966 en Santa Fe (Argentina), aunque en la actualidad cuenta con fuerte presencia institucional en las siguientes ciudades: Santa Fe, Mendoza, Córdoba, Rosario, Buenos Aires, La Plata, Mar del Plata, San Miguel de Tucumán y Puerto Madryn . El propósito principal de CILSA es promover la inclusión plena de personas provenientes de sectores marginados de la sociedad, como niños, niñas y adolescentes en situación de vulnerabilidad social y personas con discapacidad.

En el año 2007, desarrollan el programa P.O.E.T.A. El mismo fue creado por la Fundación Trust for the Americas, organismo dependiente de la OEA, que eligió a CILSA como socio local. Trabaja directamente con la comunidad a través de los 
servicios y capacitaciones, promoviendo los términos de inclusión y el uso eficiente de las Tecnologías Adaptadas para personas con discapacidad. Trust for the Américas contribuye con CILSA otorgándole recursos de Microsoft en software de cómputos y tecnología adaptada. El objetivo que se persigue es aumentar la inclusión socioeconómica de personas con discapacidad y en situación de vulnerabilidad social ampliando sus oportunidades a través de la educación no formal en el uso de herramientas para enfrentarse al mercado laboral.

Durante el 2014 desde CILSA en la localidad de La Plata, se implementó el programa, desarrollando como contenidos:

1) Informática básica: Windows 7 , Word, Excel, Power Point, Internet.

2) Taller de preparación para el mundo del trabajo: Autoconocimiento y Perfil laboral, Construcción del CV y Carta de presentación, Búsqueda y Entrevista laboral, Elaboración de Proyectos

3) Orientación Vocacional-Ocupacional.

En síntesis, recopilando la revisión realizada y el marco teórico adoptado surge la necesidad de profundizar la indagación sobre los factores que impulsan las elecciones educativas y ocupacionales de los adolescentes y jóvenes con discapacidad visual, no suficientemente abordadas en la literatura incluida.

En función de ello en el capítulo siguiente se ofrecen los interrogantes de partida, los objetivos, hipótesis y metodología adoptada en la presente investigación. Se intenta contribuir a proporcionar evidencia empírica sobre el tema, a partir de la implementación de procesos de orientación en el marco del Modelo Teórico Operativo. 


\section{Capítulo 4 \\ La presente investigación}

a presente investigación estuvo destinada a examinar los factores que orientaron las elecciones vocacionales de adolescentes y jóvenes con discapacidad visual, ciegos, disminuidos visuales profundos o disminuidos visuales leves. Con un enfoque cualitativo de diseño descriptivo narrativo, se recabó la información en el marco del Modelo Teórico Operativo en Orientación (Gavilán, 2006), en la perspectiva del Modelo de la Diversidad de la Discapacidad (Palacios y Romañach, 2007) y la conceptuación actual sobre la discapacidad visual (Cangelosi, 2006; Cuevas, 2006)

\subsection{Interrogantes}

En función del análisis de los antecedentes y de la perspectiva teórica de partida se formularon los siguientes interrogantes que orientaron esta investigación.

1. ¿Cuál es la perspectiva subjetiva de la persona con discapacidad visual frente a sus posibles elecciones en el mundo educativo y del trabajo?

2. ¿Es diferente según se trate de jóvenes con ceguera o disminución visual profunda o de jóvenes con disminución visual leve?

3. Los factores que intervienen en las elecciones ¿Son diferentes según el grado de disminución, la aceptación o rechazo de tal condición de parte de los involucrados y de sus familias?

4. ¿Existen estrategias de intervención orientadoras o acciones particulares para los alumnos que finalizan los estudios secundarios que presentan discapacidad visual?

5. Si existen ¿Tienen en cuenta las características y necesidades particulares de las personas con discapacidad visual? 


\section{General}

\subsection{Objetivos}

Contribuir al conocimiento en el campo de la orientación educativa y ocupacional sobre los factores que inciden en las elecciones educativas y/u ocupacionales de personas con discapacidad visual.

\section{Específicos}

Identificar los factores que orientan las elecciones según se trate de ciegos, disminuidos visuales profundos o disminuidos visuales leves.

Examinar la perspectiva subjetiva de los adolescentes, relativa a la discapacidad visual que presentan.

Analizar posibles semejanzas o diferencias en esa perspectiva según su grado de severidad.

Examinar la presencia/ausencia de programas y/o acciones de orientación educativa y ocupacional en nuestro medio destinada a sujetos con discapacidad visual.

\subsection{Hipótesis de trabajo}

H1. Las elecciones educativas y/u ocupacionales de las personas con discapacidad visual están orientadas por la gravedad y la perspectiva subjetiva frente al déficit.

$\mathrm{H} 2$. Las elecciones educativas $u$ ocupacionales de las personas ciegas o con disminución visual profunda están orientadas por las condiciones de accesibilidad y adecuaciones de las instituciones receptoras.

H3. Las elecciones educativas u ocupacionales de las personas ciegas o con disminución visual leve resultan semejantes a las de las personas videntes.

\subsection{Material y métodos}

A partir de un enfoque cualitativo, con en un diseño descriptivo-narrativo, (Hernández Sampieri, Fernández Collado y Baptista Lucio, 2010) se recabó la información necesaria relativa a los interrogantes, objetivos e hipótesis formulados. 


\section{Participantes}

a) Alumnos de nivel secundario. Se incluyeron 22 participantes con discapacidad visual de distinta intensidad, de 16- 21 años de edad, alumnos que recibían apoyo de la escuela especial seleccionada desde la escolaridad primaria, que se encontraban finalizando el ciclo superior del nivel secundario en establecimientos de enseñanza común, durante los ciclos lectivos 2010-2013 y que aceptaron participar de la investigación. En la Tabla 1 aparecen los datos relativos al tipo de discapacidad en los diferentes años en los que fueron incluidos.

Tabla 1

Participantes alumnos secundarios según año, sexo y tipo de discapacidad

\begin{tabular}{|c|c|c|c|c|c|c|c|}
\hline \multirow[t]{2}{*}{ Años } & \multicolumn{2}{|c|}{ Ciegos } & \multicolumn{2}{|c|}{$\begin{array}{c}\text { Disminución visual } \\
\text { profunda }\end{array}$} & \multicolumn{2}{|c|}{ Disminución visual leve } & \multirow[t]{2}{*}{ Tota } \\
\hline & Masculino & Femenino & Masculino & Femenino & Masculino & Femenino & \\
\hline 2010 & - & - & 1 & 2 & 2 & - & 5 \\
\hline 2011 & - & - & 2 & - & 2 & 1 & 5 \\
\hline 2012 & - & 1 & 2 & - & - & - & 6 \\
\hline 2013 & 1 & 2 & - & - & 1 & - & 6 \\
\hline Totales & 2 & 3 & 6 & 3 & 6 & 2 & 22 \\
\hline
\end{tabular}

Cabe destacar, por un lado, que la matricula histórica aproximada de los alumnos con discapacidad visual que finalizan el nivel secundario de la escuela especial seleccionada, oscila entre 5 a 6 alumnos por año, motivo por el cual, se ha cubierto casi el $100 \%$ de los alumnos egresados en los años seleccionados. Por el otro, que los alumnos del nivel secundario reciben apoyo según sus necesidades educativas especiales de parte del personal de la escuela de enseñanza especial.

b) Informantes clave: se seleccionaron distintos informantes clave: 9 alumnos universitarios con discapacidad visual que cursaban sus estudios en distintas unidades académicas de la UNLP (Tabla 2); personal de la Institución Educativa de Enseñanza Especial (10) y familiares de los participantes incluidos $(\mathrm{N}=10)$. 
Tabla 2

Participantes alumnos universitarios según sexo, tipo de discapacidad y carrera que cursan

\begin{tabular}{lccccccc}
\hline \multirow{2}{*}{ Carreras } & \multicolumn{2}{c}{ Ciegos } & \multicolumn{2}{c}{$\begin{array}{c}\text { Disminución } \\
\text { visual profunda }\end{array}$} & \multicolumn{2}{c}{$\begin{array}{c}\text { Disminución } \\
\text { visual leve }\end{array}$} & \multirow{2}{*}{ Total } \\
\cline { 2 - 7 } & Masc. & Fem. & Masc. & Fem. & Masc. & Fem. & \\
\hline Ciencias Jurídicas & - & 2 & - & 1 & - & - & 3 \\
Trabajo Social & 1 & - & - & - & - & 1 & 2 \\
Comunicación Social & 1 & - & - & 1 & - & - & 2 \\
Psicología & - & - & - & - & - & 1 & 1 \\
Informática & 1 & - & - & - & - & - & 1 \\
Total & 3 & 2 & - & 2 & - & 2 & 9 \\
\hline
\end{tabular}

La selección de la Escuela de Educación Especial para el desarrollo de esta tesis, responde a que es una institución de referencia en la temática, ya que fue la primera en Latinoamérica destinada a la integración de personas ciegas o disminuidas visuales. En el capítulo 5, se encontrará una caracterización de la misma.

\section{Procedimientos e Instrumentos/técnicas de obtención de datos}

En primer lugar se procedió a establecer las conexiones interinstitucionales (Escuela de Enseñanza Especial-Universidad) que posibilitaron la selección de los participantes y la aplicación de los instrumentos seleccionados. Se seleccionaron los diez únicos jóvenes próximos a finalizar los estudios secundarios (5 durante el 2010 y 5 durante el 2011) que recibían apoyo específico de esta institución. En segundo lugar, y siguiendo con la metodología de trabajo seleccionada, se realizaron entrevistas en profundidad con los padres y/ o responsables de los jóvenes seleccionados, a fin de informarles acerca del objetivo de la investigación y para solicitar su consentimiento informado para la participación de sus hijos en este proyecto.

a) Alumnos de nivel secundario seleccionados para esta investigación.

Con posterioridad se entrevistaron a los jóvenes a ser incluidos, para informarles sobre la propuesta y solicitar su consentimiento para participar, asegurando el anonimato de los resultados. Luego se implementaron las distintas técnicas e instrumentos seleccionados, de acuerdo al modelo teórico adoptado.

La información se obtuvo a partir de dos modalidades implementadas en los procesos de orientación: el Proceso Específico Individual e intervenciones grupales a 
través de un programa institucional en el marco del Microproceso. En los anexos 1 y 2 se ofrece un detalle más pormenorizado de las técnicas e instrumentos utilizados.

En el período 2010-2011 se realizaron en promedio ocho entrevistas con los sujetos seleccionados, con una duración aproximada de una hora y media reloj cada una. Se llevaron a cabo en la institución de educación especial seleccionada, con una frecuencia quincenal.

En el período 2012-2013, se implementaron los talleres correspondientes a la modalidad del Microproceso (Gavilán 2006).

Se realizaron entre 7 talleres en cada año, con una duración aproximada de 2 horas cada uno. En algunos casos se realizaron entrevistas individuales durante la implementación de los talleres y de seguimiento una vez que finalizaron. Se realizaron en la misma institución o bien en el Centro de Orientación Vocacional Ocupacional de la Facultad de Psicología de la UNLP. A continuación se detallan las técnicas utilizadas en cada una de las modalidades seleccionadas para la obtención de datos de los alumnos con discapacidad visual incluidos.

Proceso específico individual. Comprende distintos tipos de entrevistas, con propósitos determinados, en algunas de ellas con la inclusión de técnicas de exploración psicológica.

> Primera o primeras entrevistas de orientación. Destinadas a conocer preocupaciones manifiestas y situación específica por la que atraviesan a la hora de tomar decisiones sobre su futuro educacional/ocupacional (diagnóstico o prediagnóstico sobre el grado de orientabilidad del sujeto).

- Entrevistas de profundización. Su propósito es conocer la historia personal del orientado, explorar rasgos de personalidad y el reconocimiento del contexto y de la realidad en la que está inserto (Quiles, 2012). Se pueden incluir técnicas específicas tales como la Autobiografía vocacional (Müller, 2009), focalizada en la indagación de las elecciones realizadas hasta la actualidad, en los intereses y sus formas de concreción, hobbies, elecciones de ocupaciones y estudios, grado de autonomía, persistencia en el logro de intereses, frustraciones y obstáculos; el Árbol genealógico vocacional- Argevoc (Migliano, 1986). Permite obtener 
información sobre: aspectos vocacionales de los seres significativos y su incidencia en la situación de elección actual, mandatos y expectativas familiares; aspectos de la historia familiar vinculados a las ocupaciones y a los estudios. Se utilizó una modificación adecuada para disminuidos visuales y ciegos, siempre que fue necesario, de la técnica grafo-verbal.

- Entrevistas de esclarecimiento. Su objetivo es descifrar los motivos por los cuales el orientado no puede elegir. Se utilizó complementariamente el Test de frases incompletas (Bohoslavsky, 1985) que permite explorar aspectos relativos a la identidad profesional. Fue administrado a los alumnos con ceguera a partir de la lectura oral de las frases y a los que presentaban disminución visual con la ampliación de las letras.

- Entrevistas de administración de técnicas de exploración. Se seleccionó la técnica de Observación libre, en distintas situaciones del desempeño de los participantes en las instituciones educativas que permiten registrar hechos significativos mediante notas de campo.

- Entrevistas de información. Están destinadas a proporcionar información ausente o insuficiente y a corregir posibles distorsiones de la que se dispone (Bohoslavsky, 1978, p. 157). Esta información se brinda de manera gradual y por niveles: general, sobre la totalidad de la oferta educativa actual; específico, dónde se profundiza la información de acuerdo a las áreas de interés y de contacto directo dónde el sujeto pueda acercarse a los lugares de estudio, entrevistarse con profesionales, etc.

Entrevistas de integración y síntesis: supone una integración de todos los aspectos vistos y profundizados durante el proceso y una autoevaluación por parte del orientado de su recorrido hasta su decisión final, la información obtenida refiere a: 1) elección de carrera y/o trabajo, 3) elección de un área educativa con demorará temporal de la decisión definitiva, 4) elección de otro tipo de proyecto. Para este último momento, se administró una encuesta de evaluación y cierre (Ver anexo 3) 
Microproceso. La modalidad de trabajo es grupal, a través del dispositivo taller una de las estrategias metodológicas más indicadas para este tipo de abordaje. Ese espacio permita a los participantes reflexionar, pensar y producir en pequeños grupos, generando un aprendizaje grupal a partir de la participación activa e interacción de los alumnos sobre las variables seleccionadas, en relación con: a) aproximación al primer diagnóstico de orientabilidad; b) expectativas, temores, ansiedades, fantasías, miedos, pérdidas esperadas, que traen los alumnos en relación a los talleres de orientación y su ulterior desarrollo.

\section{b) Informantes clave}

Alumnos universitarios. La información fue recabada a partir del dispositivo taller. (Ver anexo 4). Se implementaron 4 talleres con una frecuencia semanal, en el mes de octubre del año 2012, sobre los siguientes temas:

Identificar los factores que tuvieron en cuenta para la elección de la carrera.

Conocer los factores obstaculizan y facilitan el tránsito por los estudios superiores así como el ejercicio laboral de la profesión.

Personal de la Escuela de Enseñanza Especial (directivos, docentes, asistentes educacionales, maestros). Se utilizaron entrevistas semiestructuradas destinadas a recabar información sobre temas específicos.

> Relevar la historia institucional de la escuela así como de los programas de orientación que se implementan.

$>$ Identificar y seleccionar a los alumnos con discapacidad visual que podrían participar de la investigación.

$>$ Relevar historiales de vida o aspectos relevantes a los fines de la elección educativa y/u ocupacional de los futuros participantes.

Padres de los alumnos con discapacidad visual que finalizan los estudios secundarios. Se realizaron entrevistas semiestructuradas destinadas a recabar información sobre la historia de vida y la perspectiva subjetiva sobre la discapacidad de sus hijos y los proyectos futuros que expectan para ellos. 


\section{Procedimientos de análisis y elaboración de los datos}

Recogida la información, se elaboraron distintas matrices con datos significativos de cada uno de los participantes que provenían de las distintas técnicas e instrumentos utilizados. A partir del análisis comparativo constante (Glaser \& Strauss, 1967) del corpus obtenido, emanado de la observación, entrevistas, técnicas de exploración incluidas y producción en los talleres implementados, se delimitaron las categorías a ser consideradas en el análisis de los resultados respecto de los participantes incluidos, tanto de las personas con discapacidad como de los informantes clave.

Finalmente, realizado ese análisis, se delinearon las principales categorías acerca de los factores que inciden en las elecciones de los sujetos con discapacidad visual, destacando los hallazgos de mayor interés

En los capítulos siguientes se ofrecen los principales resultados, en primer lugar los correspondientes a los informantes clave (Cap. 5) que dan marco a los correspondientes de los participantes con discapacidad visual (Cap. 6). 


\section{Capítulo 5 Resultados. Informantes clave}

a información recabada de parte de los informantes clave incluidos en este trabajo refiere, por un lado, a la caracterización de la escuela de enseñanza especial encargada de los soportes que necesitan los discapacitados visuales a lo largo de la escolaridad primaria y secundaria. Ella permite conocer en mayor detalle las necesidades educativas especiales así como las eventuales dificultades que puedan aparecer en los estudios superiores y/o el trabajo. Se trata en este caso de las informaciones proporcionadas por los directivos e integrantes del equipo docente de la institución de enseñanza especial. Por el otro, el resto de los informantes clave, personal docente y profesional de escuelas secundarias han proporcionado datos que enriquecen los hallazgos sobre las condiciones de la escolaridad secundaria. A su vez los alumnos universitarios con el mismo tipo de discapacidad, han hecho lo propio respecto de las dificultades enfrentadas en los estudios superiores. El conjunto de esas informaciones permite enfocar con mayor precisión el análisis de las razones que impulsan las elecciones de los alumnos al finalizar los estudios secundarios.

A continuación se ofrece el análisis realizado sobre tales informaciones, que emanan de las observaciones y entrevistas realizadas.

\subsection{Característica de la Escuela de Educación Especial seleccionada}

Se trata de una escuela de enseñanza especial que atiende a niños y adolescentes ciegos y disminuidos visuales. Fue creada en la década del 50, desde el Ministerio de Educación de la Provincia de Buenos Aires. Depende de la dirección General de Escuelas y Cultura, Dirección de Educación Especial.

Cabe señalar que a partir de los años 60 , se inicia en la provincia la experiencia de educar a través del sistema de integración. Esta institución es la primera escuela de Latinoamérica destinada a la integración de personas ciegas o disminuidas visuales y ha sido considerada como de referencia en la temática. 
Se trata de una institución de confluencia a la que asisten alumnos que provienen de diferentes localidades aledañas, tales como Berisso, Ensenada, Florencio Varela, Brandsen y Berazategui, entre otros.

La escuela abarca desde la atención temprana destinadas a bebés hasta el nivel secundario, incluso acompaña a aquellos alumnos que han egresado y que por algún motivo necesitan alguna ayuda de la institución. Los propósitos que persiguen los directivos y docentes se relacionan con la contribución a la educación permanente del sujeto desde su nacimiento, para desarrollar al máximo sus potencialidades y lograr su integración pedagógica, familiar y social. Básicamente, su propósito general es la integración.

\section{Haciendo un poco de historia}

Con anterioridad a la década del 50 , la propuesta educativa en el país para los alumnos con esta discapacidad eran los internados, que funcionaban principalmente en Capital Federal

En general, el enfoque del problema educativo del ciego en la Argentina revela desconocimiento de la teoría y la práctica pedagógicas. Las instituciones se manejan con programas de caridad y conceptos tradicionales que deben revisarse. Es un fenómeno común a todos los campos de la pedagogía diferenciada". La mayoría de los institutos porteños, en realidad, son residenciales (internados); obstaculizan la integración de ciegos en escuelas comunes. Aunque a veces se aceptan alumnos en el nivel secundario, se desconoce que en la escuela primaria los chicos videntes reciben al ciego con menos prejuicios. Esta es, sin duda, la única forma de eliminar un mal social mayor: el rechazo que encuentra el ciego adulto en la sociedad. Según los expertos, se trata de un doble aprendizaje que comprende tanto a los no videntes como a la comunidad. (Walsh, 1970, en Revista Periscopio)

La aventura sobre la posibilidad de un nuevo enfoque empezó en 1950, cuando la pionera — recién egresada de la Escuela Normal de Maestros para Ciegos - se instaló en una vieja casona de la ciudad de La Plata.

Dos maestras, sin experiencia anterior, y ella debieron atender las necesidades de los primeros diez alumnos. Hoy, el equipo de la escuela está integrado por 25 técnicos: psiquiatras, asistentes sociales y educacionales, un fonoaudiólogo, profesores de música, 
ejercicios físicos y manualidades, y un fervoroso grupo de maestros. Los alumnos ya son más de cincuenta (Revista Periscopio, 1970).

A partir de la fundación de la institución de referencia, se inician los primeros contactos con las escuelas comunes para realizar la integración, que siguen un largo derrotero hasta la actualidad.

\section{La escuela hoy}

Con el pasar de los años, el Ministerio de Educación cedió el lugar en el que actualmente funciona la escuela, en un predio amplio, en el centro de un patio con césped, juegos de plaza y una playa de estacionamiento. Cuenta, además, con un hall de entrada amplio, dependencias destinadas a la dirección, la secretaria, la sala de música, al comedor, al gimnasio y a los baños. Una de las aulas está destinada a la estimulación temprana, y el resto a las actividades escolares específicas, que cuentan con los equipamientos específicos para la atención de este tipo de alumnos.

Aparecen en sus instalaciones decoraciones con juegos de madera, trabajos de los alumnos en cartulinas, la mayoría con relieve y otros con el sistema de escritura Braille. Asimismo hay un espacio específico en el que exponen distintos trofeos de Torball (deporte de pelota desarrollado para las personas ciegas y disminuidas visuales) ganados por los alumnos del colegio.

La escuela cuenta con dos camionetas destinada al traslado de los niños que habitan en la ciudad y en las zonas aledañas.

El comedor brinda desayuno y almuerzo para los alumnos que concurren en el turno de mañana y almuerzo y merienda para los que lo hacen por la tarde. Esta actividad, no es sólo de asistencia, sino que fundamentalmente se apunta al aprendizaje de competencias sociales.

Objetivos de la escuela. La escuela tiene como objetivo la integración, para intentar lograr una mayor inclusión. Para ello crean configuraciones de apoyo según las necesidades individuales relacionadas tanto con la vida cotidiana (por ejemplo "clases de ABC" donde se enseñan actividades como poner la mesa, servirse bebida en un vaso, combinar la ropa, etc.), como con la apropiación de los contenidos de la educación formal (por ejemplo, aprender el sistema de escritura Braille para 
alfabetizarse, capacitarse en el uso de las ayudas tiflotécnicas ${ }^{6}$, para poder usar las distintas herramientas que comprenden).

Equipo profesional-técnico-docente. Para cumplir con este objetivo, la institución cuenta con recursos humanos que conforman un equipo transdisciplinario integrado por:

El equipo directivo que coordina y supervisa el funcionamiento y la organización escolar. Conforman este equipo: la directora, vicedirectora, secretaria y prosecretaria.

El equipo técnico que realiza la admisión, evaluación y seguimiento de los alumnos, orientando el proceso de enseñanza y aprendizaje. Este equipo está integrado por: un médico psiquiatra, dos psicólogas, una psicopedagoga, dos asistentes sociales y dos fonoaudiólogas

El equipo del servicio de Estimulación Temprana, dónde se brinda orientación e información para acompañar el desarrollo integral del niño (de 0 a 36 meses) respetando sus tiempos y potencialidades. A esta área se la conoce como ATDI (Atención Temprana del Desarrollo Infantil). Está integrado por docentes especializados.

Los maestros integradores que establecen el nexo entre el equipo transdisciplinario de la escuela donde están integrados los alumnos, la escuela especial y los padres, y proporcionan al maestro los recursos y materiales para el abordaje específico de la discapacidad visual. Cuentan con 21 cargos de maestros integradores.

El equipo de maestros de áreas, que atienden en la sede escolar las necesidades individuales de los alumnos en áreas implementadas para tal fin: Orientación y Movilidad, sistema de escritura Braille, Apoyo Escolar, Fonoaudiología, Estimulación Visual, Pre taller de Mantenimiento, Educación Física, Orientación Manual, Recursos Tiflotecnológicos, Educación Musical, Actividades Básicas Cotidianas.

\footnotetext{
${ }^{6}$ Tiflotecnología: tiflo procede del griego y significa ciego. El término refiere a todos las técnicas informáticas, adaptadas a la ceguera y disminución visual.
} 
El equipo de maestros de escolaridad en sede que brindan atención a los alumnos con el objetivo de nivelar y ubicar posteriormente, de acuerdo a sus características, en la modalidad educativa que corresponda: Inicial, Primaria, Secundaria, Adultos, Especial o Formación Laboral. También realizan un abordaje especial de los alumnos que además de la discapacidad visual tienen otros déficits agregados (Multiimpedidos y sordo-ciegos), para mejorar la calidad de vida del niño y su familia.

Actividades curriculares. El tratamiento educativo de los alumnos consiste en la habilitación de todas aquellas capacidades que pueden quedar obturadas en su desarrollo por la incidencia de la discapacidad. Se realiza mediante técnicas y criterios de rehabilitación, donde se establecen estrategias para el desarrollo de habilidades en el desplazamiento, aseo personal, ocio, relaciones sociales, etc. Una intervención periódica de seguimiento se hace necesaria para ir adaptando las técnicas a las nuevas demandas que acompañan al desarrollo del escolar.

La escuela no es graduada sino que se organiza por áreas, motivo por el cual en función de las necesidades particulares de cada alumno, es que se van definiendo a qué área deben concurrir. El aprendizaje del sistema de escritura Braille comienza a los cinco años para que puedan alfabetirzarse. El área de orientación y movilidad apunta a la independencia, a que puedan movilizarse por sus propios medios.

En síntesis, la escuela cuenta con recursos materiales apropiados y recursos humanos capacitados para la atención de este colectivo particular de alumnos, desde el nacimiento hasta los estudios secundarios. No obstante resulta de interés ilustrar con las respuestas obtenidas en las entrevistas realizadas a diferentes referentes de la institución sus perspectivas frente a una serie de cuestiones a considerar en las futuras elecciones de los alumnos.

\section{Ilustración particularizada de las entrevistas realizadas}

\section{Perspectiva sobre la escuela y la discapacidad}

Entrevistador: ¿Cómo definirías la escuela?

Directora: Considero que la definición como institución, por su historia, es la de integración. Porque hace más de 60 años que la escuela empezó con esa idea, 
cuando nadie en Argentina y en toda Latinoamérica pensaba que un chico ciego podía ir a una escuela común, acá se trataba de trabajar en la posibilidad de que así fuera.

\section{Funciones y Objetivos de la escuela}

Entrevistador: ¿Podrías enunciar cuáles son los objetivos de la escuela?

Vicedirectora: Que los chicos transcurran todos los niveles, terminen y prepararlos para el egreso, pero no hay seguimiento. Antes había pos-escolares, donde los chicos venían un año más, concluida su formación escolar. Pero llegamos a un punto donde caducó porque no tenemos herramientas.

Maestra: La escuela especial es muy distinta a una escuela común. El objetivo aquí es la integración, es ayudar a los chicos a la inclusión a cualquier escuela normal (jardín, primaria, secundaria). Hay ciertos chicos que concurren aquí que no pueden ser incluidos a las escuelas llamadas normales ya que presentan múltiples patologías, es decir que a la ceguera o disminución visual se les agrega otras patologías como autismo, retraso mental, etc. Mientras que hay otros que si pueden concurrir a una escuela común; estos niños vienen a esta escuela a contraturno del horario de su escuela común, pero no lo hacen todos los días, vienen una o dos veces a la semana (a la mañana o a la tarde). Los chicos concurren desde muy chiquitos, algunos desde bebes, los niños de 5 años vienen dos veces por semana mientras que otros como los disminuidos visuales solo uno o a lo sumo dos, dependiendo del caso.

\section{Perspectiva del equipo docente sobre los alumnos}

Entrevistador: ¿Cómo ven a los alumnos que tienen?

Directora: Es un panorama muy amplio. Tenemos alumnos que están bien integrados, con un buen nivel pedagógico, es decir que van a la par de sus compañeritos de la escuela normal a la que asisten, con un buen nivel de alfabetización. Mientras que también hay otros que nosotros vemos que les falta, que en sus escuelas los hacen pasar de grado y nosotras decimos ¿Cómo? No tendrían que estar ahí, y muchas veces vemos que son los mismos padres 
quienes presionan para que los chicos pasen de grado, cuando hay algunos de ellos que ni siquiera alcanzaron un nivel de alfabetización, y nosotros tratamos de decirles a estos padres que hay otras oportunidades, que hay capacitaciones laborales para que los chicos no se frustren pedagógicamente.

\section{Atención temprana}

Entrevistador: ¿A qué edad comienzan las actividades de atención temprana y hasta que edad prosiguen?

Maestra: Hay un equipo de atención temprana a partir de los tres meses y a los dos o tres años, se los integra al jardín. En esta escuela contamos con diez alumnos no integrados y, el resto, ciento sesenta y cuatro alumnos que están integrados.

\section{Alfabetización de los discapacitados visuales}

Entrevistador: ¿Cómo es tu experiencia como maestra de Braille? ¿En qué consiste tu actividad?

Maestra (ciega que enseña el sistema de escritura Braille): Tratamos de que los chicos estén integrados, trabajamos con chicos distintos todos los días, por eso intentamos hacer grupitos de trabajo. En el área de Braille los chicos comienzan a partir de los 5 años, se trabaja con ellos desde la última sala de jardín hasta que adquieren todo el código Braille. Igualmente esto dependerá de las características de cada chico. A esa edad se trabaja desde la preparación para la tacto escritura. No es lo mismo tactar (que se hace con la mano) que tocar (que se hace con las yemas). Una vez que el chico adquirió todo el código, hay una asignatura que es Estenografía o grado 2 que es un nivel de código Braille donde se aprende una forma abreviada del mismo....en el área vamos trabajando lo que el alumno va necesitando. En ese sentido todo depende de las características del niño (si aprende más rápido, si tiene ejercitado bien el aspecto táctil-motriz para poder aprender a escribir, etc.) todo dependerá de lo que el chico necesite.

El código se trasmite con las manos, entonces solo lo puede trasmitir alguien que conoce el código, solo el que conoce el código puede trasmitirlo, y es por esto que 
considero que es muy importante que en el equipo haya una persona ciega, porque pasa a ser un referente para los chicos, para que ellos aprendan. Una maestra por ejemplo, puede aprender el código Braille, pero lo hace como si fuese una asignatura más, y entonces la transmisión de lo que ella pueda enseñar sobre el código es muy diferente de lo que puede trasmitir una persona ciega. Yo por ejemplo a los chicos no les digo que soy ciega, son ellos los que lo van descubriendo solos. En el equipo escolar es necesario entonces que haya una persona ciega, porque una cosa es vivir la situación. Y fundamentalmente por los padres, es bueno que vean que se puede actuar lo más normalmente posible y, además, porque una se vuelve un referente y esto es muy importante. A mí me ven caminando por los pasillos y no se imaginan que soy ciega. Es muy importante también por nuestros derechos. Existe la Convención de los Derechos de personas con discapacidad que en el 2006 sostiene el lema "nada acerca de nosotros sin nosotros". Nosotros como ciegos tenemos derechos a realizar todas las actividades que cualquier otra persona normal realiza, pero esto es posible siempre y cuando se nos brinden las mismas oportunidades, teniendo en cuenta la inclusión. La inclusión parte de la base de la igualdad de derechos que toda persona tiene. Pero la inclusión no es poner a un chico ciego en una escuela normal, porque eso es depositar gente, la inclusión implica que a cada persona se le brinde las oportunidades o las herramientas que necesita para desarrollarse. Eso hace que la inclusión sea real. Lo que hace real la inclusión es la integración. En este sentido, no es cuestión de igualación, sino cuestión de equiparación de oportunidades.

\section{Posición frente a la discapacidad visual de los alumnos y sus padres}

Entrevistador: ¿Qué ocurre con los alumnos y sus padres respecto de la ceguera o disminución visual?

Vicedirectora: Es un gran problema la aceptación de la ceguera, están quienes la aceptan y quienes no y que realmente esto trae una posición diferente en los chicos. Incluso la no aceptación no es solo un problema en ellos, sino también en los padres, "nadie desea un chico con discapacidad". Estas dificultades se 
agravan muchísimo con la falta de aceptación de los padres. De hecho hay padres que no entraron nunca a la escuela, se quedan afuera y no pasan la puerta

\section{Problemáticas psicosociales}

Entrevistador: ¿Cuáles son a su juicio las problemáticas psicosociales con las que se enfrentan estos chicos?

Directora: Es tan variado el espectro de alumnos que vemos. Creo que tiene que ver con el medio social de cada uno y con las herramientas que tiene cada familia para salir adelante. Por ejemplo muchos de nuestros alumnos cuando llueve ya no vienen, porque en sus barrios las calles son de tierra y no pueden pasar, o se les moja la ropa y tal vez es la única que tienen, entonces no pueden venir....entonces creo que las problemáticas, para mi dependen mucho del medio social de donde vienen y de las herramientas que cada familia tiene para sobreponerse a eso o no.

\section{Funciones del psicólogo en la escuela}

Entrevistador: ¿Los psicólogos ejercen sus cargos como tales? ¿Cuáles son sus funciones?

Vicedirectora: No, no hay cargo de psicólogo en educación, es una gran falencia. Nosotros orientamos a los papás; ahora hay un taller de adolescentes para trabajar la aceptación, en el que intervienen los psicólogos.

\section{Expectativas de los alumnos frente al egreso}

Entrevistador: ¿Podrías contarnos qué expectativas tienen los chicos cuando egresan de la escuela?

Psicólogo: Nosotras tratamos de lograr que sean independientes, que ellos mismos busquen el material que necesiten, que no dependan de otros. Pero se nota que dejan algo acá. Nuestro objetivo es que se independicen.

Entrevistador: Y cuando egresan de esta institución ¿Ya lograron esa independencia? 
Psicólogo: En realidad se egresa de acá cuando terminan su escuela común. Antes se los acompañaba hasta séptimo grado pero con el cambio de plan de estudio se los acompaña hasta sexto año del secundario.

\section{Destino laboral}

Entrevistador: ¿Qué cantidad de chicos consiguen trabajo?

Psicólogo: ¡Que tema ese! Conozco por ejemplo el caso de un chico disminuido visual que se caso con una chica ciega, que sabe mucho de computación y que gracias a eso trabajo en un proyecto del Ministerio de Nación, y además da clases particulares de computación. Pero en realidad estos son casos contados, lo que se de chicos que hayan podido incorporarse al ámbito laboral.

Los testimonios proporcionados esclarecen algunas cuestiones, dando cuenta de la perspectiva y conocimientos de los que se dispone en esta institución, que no siempre se corresponden con los recursos de otras instituciones, suplida por las ayudas que prestan las maestras integradoras. Pero cabe señalar que esos recursos no aparecen o aparecen de manera insuficiente cuando se trata del ingreso a los estudios superiores.

\subsection{Resultados sobre los alumnos universitarios con discapacidad visual} Con el objetivo de ampliar la información recogida en el Proceso específico individual y Microproceso con estudiantes que finalizaban sus estudios secundarios y se encontraban en situación de elegir su destino educativo u ocupacional, resulto de interés indagar cuestiones similares en los estudiantes con discapacidad visual que estaban cursando estudios universitarios en diferentes unidades académicas, para observar las semejanzas o diferencias que pudieran aparecer en las temáticas indagadas, respecto del colectivo particular de alumnos con disminución visual.

Por esa razón, durante el año 2012 se realizó una propuesta de intervención orientadora con esos estudiantes de la UNLP. La necesidad de implementar este tipo de propuestas, a los fines de esta investigación, se debe a que, en general, no es una población destinataria de este tipo de intervenciones. 
Las personas con discapacidad que estudian en la universidad, enfrentan permanentemente la necesidad de revisión de su proyecto, debido a las barreras con las que se encuentran cotidianamente en su transitar por ese ámbito, sean estas arquitectónicas, académicas y/o actitudinales. A su vez, tampoco siempre se generan los espacios para que los estudiantes de este colectivo puedan encontrarse, compartir y nuclearse para luchar por sus derechos. En este marco, diseñamos e implementamos una propuesta de intervención con estudiantes en situación de discapacidad visual de la UNLP, bajo la modalidad taller. Esta experiencia comprendió un trabajo colectivo e interdisciplinario, ya que en la coordinación participaron también integrantes de la Comisión Universitaria sobre Discapacidad de la UNLP, de la Comisión sobre Discapacidad de la Facultad de Psicología, y alumnos sin discapacidad de la Cátedra de Orientación Vocacional de la carrera de Psicología. Los resultados de ese dispositivo permiten sintetizar los hallazgos en las siguientes categorías.

a. Caracterización de los participantes: participaron 9 estudiantes con discapacidad visual, que cursaban distintas carreras en la UNLP y una alumna que aún no había ingresado pero pensaba hacerlo.

Se realizaron cuatro talleres con el objetivo de generar un espacio de reflexión e intercambio sobre las problemáticas/realidades cotidianas que encuentran en su transitar por la vida universitaria.

\section{b. Principales factores que obstaculizan o favorecen el transcurso de los estudios universitarios}

\section{b.1. Factores que obstaculizan}

La desinformación respecto de las características de los estudios universitarios en general y en particular de cada carrera, que funciona como la principal causa de exclusión.

> La escasa o nula disponibilidad de material digitalizado adaptado y en diapositivas Power Point.

> Las barreras arquitectónicas de los edificios (ascensor, baños, barandas, señalización). 
La invisibilidad entre los compañeros.

b.2. Factores facilitadores

> Disponibilidad de Digitalización del material/Textos desgrabados

> Supresión de barreras arquitectónicas que permiten contar con condiciones de acceso y tránsito adecuadas.

> Aulas señalizadas con sistema de escritura Braille/carteles grandes, legibles.

- Información específica sobre las características de la carrera, con especial referencia a las exigencias propias de los estudios superiores.

$>$ Comunicación, compartir vivencias con compañeros con y sin la misma discapacidad.

c. Disponibilidad de Orientación Educativa y Ocupacional/Equipos de Orientación Escolar. Transición hacia los estudios superiores o el mundo del trabajo

De los nueve estudiantes incluidos, sólo uno había tenido en cuenta para la elección de su carrera, el resultado obtenido en un "test" de orientación. Los participantes no habían recibido Orientación desde la escuela secundaria, ni asesoramiento para la transición hacia los estudios superiores.

\section{d. Factores involucrados en la elección de carrera y/u ocupación}

Un tema de interés fue el factor "presión social y familiar" para la elección de carrera, particularmente en el caso de alumnos ciegos. En tal sentido apareció el mandato de estudiar leyes, vinculado al imaginario social según el cual "todos los ciegos estudian derecho". Aparecieron expresiones tales "a mí me pasó algo parecido. Desde la escuela me sugerían derecho, o magisterio". En otros casos comentaron que 30 años atrás, las personas con discapacidad visual, sólo podían estudiar la carrera de Ciencias Jurídicas y Sociale, acotando: "ahora ya no, con todos los avances tecnológicos y demás ya no es tan así, han facilitado mucho y hay un abanico más amplio".

A pesar de ello el factor que priorizaron se vincula con el interés en realizar las actividades que se desarrollan en la profesión elegida. A ello se adicionaba tener en cuenta la discapacidad visual, por las posibles dificultades que podría acarrear. Uno de los participantes mencionó que en ese momento, no se manejaba sólo en micro, 
por ese motivo eligió una carrera que funcionaba en las cercanías de su domicilio. Al respecto muchos señalaron frente a las posibilidades no presenciales de formación que se ofrecen actualmente, mediante clases y plataformas virtuales, que prefieren clases presenciales: "aunque sea por una o dos horas, cuando uno se hace un tiempo para juntarse a estudiar en grupo, se da un intercambio muy enriquecedor". Además, en los estudiantes con disminución visual, les resultaba mucho más rápida y fácil la lectura grupal: "A mí me ha facilitado mucho eso y también ir a los teóricos y grabar clases".

En este sentido, rescataron el trabajo en grupo, ya que hay personas que han dejado de cursar, porque no tenían compañeros para estudiar: "sería bueno que se cambie la manera individualista de trabajar y que desde el centro (de estudiantes) se haga algo para que los chicos con discapacidad puedan integrarse más y sentirse más cómodos en el trabajo en grupos".

\section{e. Estudios superiores y/u ocupación elegidos. Expectativas sobre el ejercicio profesional futuro}

Los participantes cursaban estudios en las Facultades de Psicología, Trabajo Social, Periodismo, Ciencias Jurídicas y Sociales e Informática.

Mediante la matriz Fortalezas, Oportunidades, Debilidades y Amenazas-FODA se trató el tema "El ejercicio profesional de las personas con discapacidad". Se obtuvieron las siguientes manifestaciones en torno a cada uno de los aspectos considerados.

Fortalezas. "Mirar más allá de lo aparente, predisposición a reflexionar con otro, autonomía, conocer y aceptar los tiempos (organización de la carrera en base a esto), poder transformar los obstáculos en algo positivo, romper con los propios prejuicios y los de los otros, predisposición para relacionarse, grupo familiar y compañeros, estrategias personales".

Oportunidades. "Uso de herramientas tecnológicas, que la facultad nos brinde herramientas para poder formarnos a la par del resto de las personas, tutorías, espacios de reflexión, intercambio de experiencias, trabajo en grupo, tener referentes, por ejemplo profesores ciegos o docentes con discapacidad, taller 
pedagógico, contactos en el área laboral, cambio de paradigma”.

Debilidades. "Miedos, temor que nos puede paralizar, incertidumbres, autolimitarse". Amenazas. "Ritmos universitarios, entorno no facilitador (prejuicios), pocos espacios de intercambio, desconocimiento de los profesores sobre cómo tratar la discapacidad, ausencia de accesibilidad, ausencia de capacitación docente en temas de discapacidad, círculo avasallante (el entorno familiar muchas veces es limitante)".

Con respecto a las expectativas sobre la futura inserción laboral surgieron las siguientes manifestaciones.

"Es muy competitivo, es difícil para una persona sin discapacidad, más para una con, la ley del $4 \%$ no se cumple, por eso son muy importantes las estrategias de las relaciones, sólo es muy difícil".

"Yo también prefiero algo en equipo, el consultorio sería de las últimas opciones para mí. Creo que hay muchas cosas que se pueden hacer desde un lugar más comprometido, más social".

“Laboralmente me veo en una cuestión más grupal, con nenes, no sé si me veo trabajando sola, particularmente prefiero lo grupal

\section{f. Impacto de los Talleres}

Los estudiantes manifestaron respecto del impacto de los talleres lo siguiente.

"Si quiero cambiar algo debe moverme, por eso vengo a este taller, involucrarse, cambiar las cosas y poder aportar mi visión para dicho cambio".

"Si queres que algo cambie, hay que participar, sino uno se queda en la queja, o pasándola mal".

"Para que sea menos traumático, que no duela tanto pasar por la facu, y poder decir algo está bueno, si no la opción es dejar".

"Vengo al taller para poder compartir experiencias con gente como yo". 
"Me encanta el poder estar en el taller, rescato el trabajo grupal y tengo muy buenas expectativas de cambio".

A partir de esas manifestaciones y bajo la consideración de la Orientación como un proceso, se hace patente la necesidad de diseñar estrategias de intervención para su tránsito a lo largo de los estudios universitarios así como para su inserción profesional una vez que egresen. Este es un tema relevante y que aún no sido suficientemente desarrollado desde la Universidad. Si bien existen programas de inserción laboral para el egresado, no hay programas específicos que acompañen a las personas con discapacidad.

\subsection{Resultados de las entrevistas con padres de hijos con discapacidad visual} Con los padres resultó de interés especial indagar algunos datos de la historia de vida y, particularmente, sus perspectivas frente a la discapacidad de sus hijos. En las entrevistas individuales realizadas con ellos aparecieron manifestaciones sobre ambos aspectos.

Una de las madres, si bien reconocía la discapacidad visual de su hija, siempre tuvo expectativas altas sobre las posibilidades de su desempeño:

"Está haciendo el bachillerato común, me hubiera gustado inscribirla en el Colegio de la Universidad, pero prioricé el grupo, venían todas juntas con sus amigas.

La idea que tiene mi hija es estudiar en Bellas Artes escenografía. Yo por mi lado no la quiero desalentar, hay miles de personas que se dedican a esto y triunfan unos pocos. Lo veo como una vocación muy fuerte, ella yendo ahí se siente segura".

Vemos en este caso, más allá de la aceptación del déficit visual, expectativas de logro que no se condicen con la realidad, abandona la idea del Colegio de la Universidad por razones diferentes a las de su probable exigencia, para que continúe con las amigas. Sin embargo, en materia de estudios universitarios aparece tangencialmente que no es suficiente la realización de actividades por el placer de hacerlas o hacerlas de modo habitual, sino que está implícita la idea de "triunfo". 
Otra de las madres manifestó su interés para que su hijo cursara sus estudios en el Colegio de la Universidad, ya que "lo iba a formar con un grado de independencia...que sea lo más independiente posible”. Ahora está cursando el anteúltimo año (quinto año). Más adelante manifestó explícitamente el deseo de que su hijo concurra a un proceso de Orientación con el propósito de que "pueda trabajar desde la Orientación Vocacional que hay cosas que por la vista no las va a poder hacer.

En este caso existe el reconocimiento de las dificultades inherentes a la discapacidad con expectativas realistas, que priorizan la independencia, un autoconocimiento de mayor magnitud sobre sus reales posibilidades.

Los padres de uno de los participantes con discapacidad visual leve relataron las transformaciones de su posición frente al déficit de su hijo. La madre señaló que en oportunidad de comenzar con los tratamientos específicos se produjeron cambios:

"ahí se abrió algo distinto para mí, ahí empecé a conocer lo que era la enfermedad, lo que podía haber sido, agradecer lo que tengo y no lamentándome lo que no tengo....

Más delante acotó:

"Yo este año me recibo de intelectual, yo arranqué estudiando visuales, por esto que me dijo una mamá 'vos nunca vas a saber lo que ve tu hijo'; quería saber y descubrir, porque todas las emociones que viví acá no me las voy a olvidar nunca, y me metí a estudiar visuales... esta discapacidad" (se refiere a la institución en la que cursó sus estudios).

El padre, con respecto al traslado de su hijo aclaró:

"hasta ahora lo llevo yo al colegio de mañana, pero después viene con los compañeros, viene caminando, antes venía en colectivo, justo era la mano en que no tenía que cruzar la calle, pero le hace bien que se maneje un poco solo". 
Se trata en este caso del reconocimiento de lo que sucede con su hijo, de sus limitaciones, de sobreprotección, pero con intentos de modificarla en pos de la autonomía del hijo.

Otros padres de hijos con disminución visual leve plantearon lo siguiente:

"Anda bien en el cole. Hace un año, año y medio que quiere ser chef, que le gusta, así que le dijimos que sí, que si él quería que lo apoyábamos, que no tenemos ningún problema, así que ahora se va a poner en campaña para ver dónde se va a anotar".

En este caso no pudo continuar sus estudios por dificultades económicas, pero comenzó a trabajar en una pizzería, de modo tal que los padres manifiestan "Es muy independiente, no se deja estar. Le gusta algo y lucha por eso. Yo le digo que hay cosas que no puede hacer y me dice bueno dejame hacerlo. La dificultad que ahora no le interesa es la discriminación, tuvo compañeros crueles. Ahora hablamos y yo siempre le digo, 'para tener un problema hay que saber' porque él no te lo demuestra".

Uno de los problemas que enfrentaron fue cuando desde la institución especial aconsejaron que aprendiera el sistema de escritura Braille, que hasta la fecha no aceptó. No era necesario que lo utilizara obligatoriamente, sino desde un enfoque preventivo.

"Él nos decía que cuando tenía Braille que no quería ir. Yo le decía que no se iba a quedar ciego y él me decía que no le gustaba, pero bueno era una clase y yo se lo exigía. Él tendría 15 años más o menos. Él pidió una reunión con la profesora de Braille y otras docentes y les dijo que a él eso no le gustaba, no quería porque era para chicos ciegos. Él decía que estaba en una clase de braille con chicos ciegos y el los veía, que no era para él. Tenía una máquina en casa y todo...

Él nunca lo aceptó, nunca, nunca, cuando le pregunté a él me dijo 'no es necesario, porque yo no uso la máquina, yo uso mis ojos para ver". 
Más adelante relataron que su hijo quiere comprarse una moto pero el padre no quiere, "nosotros no queremos porque una vez salió en bicicleta a hacer un mandado y lo atropelló un auto, él pensó que venía lejos. Nosotros una moto no queremos".

Se trata en este caso de mayor aceptación de la discapacidad de parte de los padres que del propio participante. No obstante se observan cambios a lo largo del desarrollo del hijo así como la importancia de la mediación de agentes especializados para clarificar la situación y alcances de los afectados.

Señalamos con anterioridad que en la literatura especializada suelen mencionarse perspectivas a veces opuestas de parte de los progenitores respecto de la discapacidad de sus hijos: desde la aceptación, con la consiguiente sobreprotección hasta la negación, con su correlato de sobre exigencia.

En todos los casos presentados observamos distintas situaciones, en las que cobra un papel fundamental la perspectiva de los padres complementaria o no de la propia perspectiva de los afectados, situación que conforma uno de los factores más significativos a la hora de tomar decisiones sobre las elecciones educativas y/o laborales, que analizaremos en el Capítulo 6. 


\section{Capítulo 6 \\ Resultados. Participantes con discapacidad visual}

os resultados sobre los participantes con discapacidad visual que se presentan a continuación están organizados de acuerdo a la modalidad de obtención y al año en el que fueron recolectados los datos. Como se recordará las modalidades utilizadas fueron dos: Proceso específico individual y Microproceso, ya que ambas permiten observar semejanzas o diferencias en los factores que intervienen en las elecciones de los alumnos. El primero fue implementado durante los años 2010 y 2011. El segundo en el período 2012 a 2013. El seguimiento longitudinal, aunque relativamente breve, posibilitó una mayor precisión en los hallazgos.

\subsection{Resultados correspondientes al Proceso específico individual}

Los resultados que se ofrecen a continuación emergen, del análisis comparativo constante (Glaser \& Strauss, 1967) sobre el contenido temático del corpus de los materiales obtenidos a través de las diferentes técnicas e instrumentos incluidos en el proceso individual: entrevistas (en número variable según el caso) y técnicas e instrumentos de exploración psicológica (necesarias según el caso). Este procedimiento, junto a la información sobre los datos correspondientes a cada uno de los participantes, permitió elaborar las categorías de análisis que sistematizan y sintetizan los resultados de la siguiente manera.

\section{a. Caracterización de los participantes}

En el año 2010 los jóvenes seleccionados fueron 5 (cinco), 3 varones y 2 mujeres, con un promedio de edad de 17 años. Todos presentaban disminución visual o baja visión, dos de ellos en grado profundo, uno de los cuales, cuya discapacidad era adquirida, "funcionaba" como una persona ciega, es decir, utilizando soportes específicos, entre ellos el sistema de escritura Braille y el bastón blanco para su desplazamiento. El otro, con discapacidad congénita no necesitó de tales recursos. Los tres casos restantes, presentaban disminución visual leve a moderada, con discapacidad congénita. Dos de ellos con diagnóstico de retinopatía del prematuro. 
Cuatro asistían a distintas escuelas públicas y uno a un establecimiento privado, en ambos casos de enseñanza común, en las que cursaban sus estudios secundarios.

En el año 2011 se incluyeron otros 5 (cinco) participantes, 4 varones y 1 mujer, cuyas edades comprendían entre los 16 y 21 años, 4 varones y una mujer. Todos presentaban disminución visual o baja visión, dos en grado leve a moderada y tres en grado profundo, de los cuales, sólo uno utilizaba el sistema de escritura Braille. En todos los casos, la causa era congénita, en el diagnóstico encontramos retinopatía del prematuro, amaurosis congénita de Leber y corearetinitis bilateral congénita a causa de toxoplosmosis. Tres asistían a distintas escuelas públicas y dos a establecimientos privados, en ambos casos de enseñanza común, en los que cursaban sus estudios secundarios

\section{b. Disponibilidad de Orientación Educativa y Ocupacional/Equipos de Orientación Escolar/ Transición hacia los estudios superiores.}

En las escuelas de enseñanza secundaria común, mayoritariamente no se realizan procesos de orientación. Tres de los establecimientos educativos contaban con Equipo de Orientación Escolar (EOE), pero el tema de futuros estudios $u$ ocupaciones no había sido abordado en profundidad, más bien abocados a las urgencias que se presentan cotidianamente

En algunas de las instituciones, se ofrecieron charlas informativas sobre las distintas opciones educativas o pasantías, pero sin tener en cuenta las necesidades específicas de los jóvenes para las elecciones posibles de su futura carrera u ocupación.

No se realizan intervenciones formales de orientación, sino más bien "informales", como charlas con profesionales o docentes de distintas unidades académicas, comentarios de los profesores, etc. Al no tratarse de intervenciones planificadas encontramos que los profesionales de la institución, en general, no tienen en cuenta (o desconocen) las necesidades específicas de los jóvenes con discapacidad visual para la elección de su futura carrera u ocupación. 


\section{c. Factores involucrados en la elección de carrera y/u ocupación}

En los jóvenes seleccionados en este estudio encontramos que la posibilidad de elaborar un proyecto de vida vinculado a la continuación de sus estudios en una carrera de nivel superior, comienza de manera similar a los jóvenes que no presentan esta discapacidad, es decir, con un proceso de duelo. El mismo se genera por la pérdida del rol de alumno de escuela secundaria, acompañado de miedos, incertidumbres y expectativas relacionadas con el comienzo del tránsito hacia otra posición diferente, que en muchos casos se relaciona con el rol de alumno universitario. Rol que se asocia a representaciones sociales como la autonomía, independencia y responsabilidad que implica la "vida universitaria", al que le adjudican una prioridad mayor, aunque no aparezcan diferencias marcadas respecto de aquello que ocurre con los jóvenes videntes.

Todos los jóvenes que participaron de la investigación, pensaron en un proyecto vinculado con la posibilidad de continuar estudios superiores.

De la información recabada se extrae que no existen diferencias de importancia entre los jóvenes que presentan disminución visual y los videntes. En líneas generales puede señalarse que aparecen similares inquietudes, temores $y$ expectativas frente a la elección de un proyecto de vida, ya que priorizan para su futuro desempeño las actividades que les interesan y les agradan.

En líneas generales y sin realizar ninguna jerarquización los jóvenes priorizan en su elección factores tales como:

Las tareas que se realizan en la profesión elegida.

$>$ El interés en lograr un lugar de reconocimiento social.

La disponibilidad de recursos económicos.

> Las condiciones de accesibilidad y adecuaciones que ofrecen las unidades académicas.

La disminución/ discapacidad visual.

Sin embargo, deben hacerse algunas distinciones analíticas según la intensidad de la disminución visual y la perspectiva subjetiva frente a la misma. Para los jóvenes con disminución visual leve que re conocen su condición, generalmente las limitaciones 
específicas que les genera no emergen como un factor determinante de la elección. No obstante, valoran positivamente los apoyos que pueda brindar la Facultad como institución $y$, en particular los docentes, en relación con la accesibilidad y adecuaciones bibliográficas.

Cuando se trata de jóvenes con una disminución visual profunda, por el contrario, aparece su influencia de manera prioritaria, ya que reconocen que les resultaría muy difícil sostener los estudios en algunas carreras. Sin embargo, no por esto, dejan de pensar en un proyecto de vida que les permita desempeñar las actividades que les interesan, teniendo en cuenta las limitaciones propias con las que cuentan y los apoyos necesarios para poder superarlas.

Sin embargo en algunos de estos casos, en los que se minimiza o no se reconocen subjetivamente las dificultades inherentes a la discapacidad visual aparecen elecciones que no tienen en cuenta las posibilidades de accesibilidad y adecuaciones bibliográficas o técnicas que ofrecen las distintas Facultades, para favorecer sus estudios.

En la mayoría de los casos es de señalar las dificultades que tienen para hacer conocer a los docentes su situación y las dificultades que conllevan, de modo tal que aparecen problemas adicionales ligadas a la insuficiencia o ausencia de las adaptaciones necesarias desde la perspectiva de la enseñanza para facilitar los estudios.

\section{d. Estudios superiores y/u ocupación elegidos}

Los participantes incluidos en ambos años se pronunciaron mayoritariamente por la prosecución de estudios superiores, universitarios y no universitarios. En este último caso emerge en ellos el temor a la masividad que implica la vida universitaria, con las dificultades asociadas al pertenecer a una institución de esas características sumadas a los inconvenientes que podrían generarse debido al déficit visual sumado a los problemas relacionados con el traslado hasta la institución y con el desplazamiento en su interior. Tres de los jóvenes que trabajan de manera informal manifestaron que su proyecto se vinculaba con la posibilidad de seguir estudiando y trabajando, ya que dos de ellos ayudan actualmente al sostén económico familiar. 
Los participantes incluidos en el año 2010 se pronuncian por la prosecución de estudios superiores. Entre ellos, en primer lugar aparece una predominancia del área artística y proyectual (Licenciatura en Publicidad, Diseño Gráfico, Diseño en Comunicación Visual). En segundo lugar el área de las Ciencias sociales (Licenciatura en Ciencias Sociales).

En relación con las carreras relacionadas con el área artística, cabe señalar el impacto de las nuevas tecnologías y el manejo que los jóvenes tienen de ellas. Esta circunstancia influye favorablemente para que se decidan por carreras de esta área, en contraposición a lo que sucedía años atrás. Efectivamente, los jóvenes seleccionados, aducen que les resulta más fácil y cómodo leer textos y realizar trabajos haciendo uso de distintos programas y software de la computadora, que en soporte papel.

Los participantes incluidos en el año 2011 eligieron carreras universitarias del área humanística (Licenciatura en Psicología. UNLP), del área social (Licenciatura en Comunicación Social. UNLP), y una carrera terciaria (Cheff internacional).

\section{e. Impacto del proceso de orientación}

En general los alumnos y los padres incluidos tuvieron una gran disposición para trabajar en el proyecto, se comprometieron con las actividades planteadas y colaboraron en el desarrollo del plan de trabajo.

En general los alumnos y los padres incluidos tuvieron una gran disposición para trabajar en el proyecto, se comprometieron con las actividades planteadas y colaboraron en el desarrollo del plan de trabajo.

Manifestaron que el paso por este proceso de orientación, les permitió pensar en primer lugar, en un proyecto de vida relacionado con la elección de una carrera. Con anterioridad no lo habían hecho, ni habían podido reflexionar sobre su independencia y autonomía personal. En segundo lugar, destacaron que les proporcionó la posibilidad de reflexionar sobre su independencia y autonomía personal. 
El conjunto de los resultados analizados pone de manifiesto la necesidad de orientación de este colectivo particular, a la hora de tener que optar entre elecciones posibles una vez finalizados sus estudios secundarios.

\section{Ilustración particularizada sobre los casos estudiados}

Participante 1. Se trata de una joven de 17 años con disminución visual de grado leve. Se realizaron con ella 15 entrevistas individuales, 12 en el año 2010 y 3 de seguimiento durante el año 2011 y 3 con la madre. Cuando comenzamos el proceso de orientación ya había decidido, con el apoyo de su familia, la continuación de los estudios superiores en el área artística (Comedia Musical). A partir de su inclusión en ese proceso, su elección recayó en la carrera de Diseño en Comunicación Visual de la Facultad de Bellas Artes de la UNLP.

En las entrevistas seguimiento se evidenció que había desarrollado y potenciado su autodeterminación, de modo tal que la carrera elegida se vinculada con sus intereses y preferencias. Comenzó con la carrera elegida el año anterior, y luego de haber transitado el curso introductorio se mostró muy conforme y manifestó no necesitar apoyos específicos. A mitad de año, empezó a notar que los necesitaba a medida que comenzaron los exámenes parciales. Frente a esta circunstancia, desde la Comisión Universitaria sobre Discapacidad se organizó una reunión con los docentes, autoridades de la Facultad y de la escuela de enseñanza especial a la que asistió. La importancia de la misma radica en la posibilidad de transmitir a los docentes actuales las dificultades que enfrentó, que no había comunicado por sí misma, y las estrategias que facilitarían sus estudios. Los docentes se mostraron muy dispuestos a ayudarla por las vías sugeridas, ya que desconocían cómo hacerlo. No obstante es necesario continuar el trabajo con ella, en función de los temores e incertidumbres que ha manifestado.

Surge de este caso que el tipo de intervenciones sugeridas deberían realizarse antes de que los jóvenes ingresen a los estudios superiores, ya que con anterioridad a la finalización de los estudios secundarios muchos desconocen o no han elaborado aún las dificultades que se les pueden presentar a nivel de los estudios superiores. 
Participante 2. Se trata de un adolescente de 17 años, con disminución visual de grado leve. Se realizaron entrevistas durante dos años seguidos, cuando cursaba su $5^{\circ}$ y $6^{\circ}$ año de la escuela secundaria. Realizamos un total de 20 entrevistas individuales, 2 de ellas de seguimiento durante el año 2011 y 3 con su madre durante la implementación de la intervención. Durante el primer año, la tarea principal consistió en la posibilidad de reflexionar sobre el autoconocimiento, y en el reconocimiento de sus propios intereses y gustos, como también de sus aptitudes y competencias. Se trabajó sobre las limitaciones que acarrea su discapacidad, para poder afrontarlas y realizar una elección educativa desde sus competencias y no desde su discapacidad. En el transcurso del año 2010, se profundizó en la información educativa y laboral a nivel universitario, terciario y cursos de formación profesional. Se realizó un trabajo de información, que consistió en un nivel de profundización creciente y extensión decreciente. Esto posibilitó la selección de un área de conocimiento de acuerdo a su grado de interés (artística y proyectual), a partir de la cual eligió la carrera de Licenciatura en Publicidad, en una universidad de gestión privada. Esta elección fue acorde con las materias optativas que decidió cursar en los últimos años de la escuela secundaria, relacionadas con la estética, lo artístico y lo creativo. Una vez que elegido el área de estudios, tomó contacto con un profesional de la disciplina, para luego de un cotejo de los planes de estudio y sus orientaciones, decidiera la facultad en la que estudiaría. Para ello, teniendo en cuenta que la carrera de Licenciatura en Publicidad se dictaba en ese momento en una universidad de gestión privada ubicada en la Capital Federal, se analizaron las posibilidades económicas de la familia así como las de movilidad independiente.

Del trabajo realizado, se destaca en primer lugar, el desarrollo de su autonomía y autodeterminación, de modo tal de generar las condiciones de posibilidad de su elección, vinculada a sus intereses y sus gustos. En segundo lugar, haber generado las herramientas necesarias para superar eventuales. Favorece positivamente esta situación el apoyo de la familia, ya que ha podido dialogar con críticamente con ellos sobre esta elección y apreciar el recorrido que ha realizado en su proceso de decisión. 
En el año 2011, en el que se realizaron la entrevistas de seguimiento, aparece muy conforme con su elección y desempeño. Los factores que han facilitado su tránsito son los recursos con los que cuentan la institución: computadoras con monitores grandes, manejo de diapositivas y Power Point facilitados por los docentes para que pueda seguirlos en la clase desde su computadora personal.

Participante 3. Se trata de un adolescente de 16 años, con disminución visual de grado leve. Se realizaron tres entrevistas individuales y una con sus padres. No se pudo finalizar con el proceso, ya que se dificultó la organización para que él pueda asistir a los encuentros pautados. Algo a destacar es que le restaba un año para terminar la escuela secundaria, motivo por el cual, hubiese sido importante seguir trabajando en la elaboración del "primer diagnóstico", para poder delimitar si efectivamente había una demanda, y si es así, de dónde provenía la misma. De la entrevista inicial con sus padres, su madre demostró gran entusiasmo en la propuesta, no obstante, la situación que estaba atravesando el participante siguiendo a Bohoslavsky (1985) sería pre- dilemática, dónde el adolescente no se da cuenta que tiene que elegir.

Participante 4. Se trata de una adolescente de 17 años, con disminución visual de grado profundo. Se realizaron tres entrevistas individuales y una con su madre. Con la participante, se abordó principalmente la posibilidad de tener un desempeño más autónomo e independiente, ya que su decisión era estudiar en la Universidad. Sus intereses se vinculaban a materias de corte humanístico y se decidió por una carrera acorde con los mismos, Licenciatura en Ciencias Sociales en la UBA.

Durante el año 2011, si bien no pudimos concretar con ella una entrevista de seguimiento, las autoridades de la institución pudieron informarme que continuaba cursando sus estudios universitarios y que había podido comenzar a movilizarse de manera independiente, viajando sola en el micro a la sede de su facultad.

Participante 5. Se trata de un adolescente de 17 años, con disminución visual de grado profundo. Se realizaron un total de ocho entrevistas, de las cuales tres fueron de seguimiento. De estas últimas, dos fueron individuales y una grupal, con los alumnos que finalizaban la escuela en el 2011. También se realizó una entrevista 
con su abuela, quién era la tutora del participante. Cuando comenzamos con el proceso de orientación, había decidido capacitarse en algún curso de formación profesional vinculado al diseño gráfico. Durante el desarrollo de la intervención orientadora, decidió hacerlo en una carrera universitaria, eligiendo Diseño Gráfico en la UBA. En esta decisión un factor que incidió fue una pasantía que organizó su escuela, que consistió en compartir un día de trabajo con un editor, dónde pudo vivenciar la profesión, teniendo un contacto directo (Brea,1965) Un aspecto relevante que se trabajó durante el proceso, fue la convivencia con sus abuelos y cómo esta situación, generaba dificultades en el desarrollo de su independencia. Fue un tema que se abordó también en el taller con otros adolescentes, por lo cual considero que fue una situación netamente preventiva.

Durante el año 2011, realicé dos entrevistas de seguimiento, una a mediados de febrero y otra a mediados de año, antes que comiencen los primeros exámenes parciales, donde sucedió algo similar a lo de la participante 1. Comenzó su carrera y se mostró muy conforme y sin necesidad de ningún apoyo específico. En el transcurso del año esta dificultad se hizo evidente en la materia Dibujo. motivo por el cual se contactó con la Comisión Universitaria sobre Discapacidad de la UBA y según sus propias palabras "no supieron asesorarlo". Frente a esta situación decidió abandonar la carrera, pero para priorizar su formación en una capacitación en esta área y en la posibilidad de conseguir un empleo.

Esta situación, generó el diseño de una intervención preventiva, realizando una entrevista grupal con los participantes que estaban culminando sus estudios secundarios en el 2011. El objetivo que se persiguió, fue que el participante pueda transmitirles su experiencia, dando cuenta de los factores que tuvo en cuenta al momento de elegir su carrera, y las estrategias a implementar para superar las posibles dificultades que pueda generarles el déficit visual.

Participante 6. Se trata de un adolescente de 16 años, con disminución visual de grado profundo. Se realizaron entrevistas durante dos años seguidos, cuando cursaba su $5^{\circ}$ y $6^{\circ}$ año de la escuela secundaria. Realizamos un total de 3 entrevistas individuales, y una con sus padres. Durante el primer año, la tarea 
principal consistió en entrevistas de profundización. En el transcurso del año 2011, no se pudo finalizar con el proceso de orientación, ya que se dificultó la organización para que él pueda asistir a los encuentros pautados y sólo se pudo concretar una entrevista. Algo que incidió fue que el participante no se movilizaba de manera independiente, motivo por el cual, dependíamos de la disponibilidad de su padre para que pueda llevarlo a la escuela. Una de las carreras que mencionó, fue Abogacía ya que su prima la estaba estudiando, pero no se pudo problematizar sobre los motivos que lo acercaban a esta elección. Considero que frente a esta situación, se pueden diseñar estrategias de intervención desde un enfoque preventivo, que apunten al trabajo conjunto con el joven y su familia, para acompañar el desempeño de una vida autónoma e independiente, que posibilite un contacto más real con el mundo externo y con el contexto interrelacional.

Participante 7. Se trata de un adolescente de 17 años, con disminución visual de grado leve. Se realizaron un total de doce entrevistas, de las cuales ocho fueron individuales, una fue grupal junto con un ex alumno que había participado de la propuesta el año anterior y las tres restantes, fueron de seguimiento durante el año 2012. Con sus padres se mantuvieron tres entrevistas durante el año 2011. En un primer momento la tarea consistió en la posibilidad de reflexionar sobre el autoconocimiento y en el reconocimiento de sus propios intereses y gustos, como también de sus aptitudes y competencias. Se trabajó sobre las limitaciones que acarrea su discapacidad, para poder afrontarlas y realizar una elección educativa desde sus competencias y no desde su discapacidad. Durante este primer momento, emergieron también temores vinculados al desempeño en la vida universitaria, tales como la masividad de estudiantes y el acceso a través de los medios de transportes públicos.

En un segundo momento, se profundizó en la información educativa y laboral, teniendo en cuenta los tres niveles: universitario, terciario y cursos de formación profesional. El trabajo con la información consistió en un nivel de profundización creciente y extensión decreciente, corrigiendo distorsiones sobre diferentes profesiones y ocupaciones. Esto posibilitó que se decidiera por la carrera de 
Licenciatura en Psicología en la Universidad Nacional de La Plata, ya que su interés, se vinculaba con la posibilidad de especializarse luego en los trastornos del aprendizaje.

Del trabajo realizado, se destaca el desarrollo de la autodeterminación, ya que pudo transitar desde una posición de incertidumbre sobre su proyecto de vida, hacia el conocimiento sobre las posibilidades de formación a futuro y de la oferta educativa disponible. Esta situación posibilitó la elección de una carrera vinculada a sus intereses y gustos.

Cabe destacar que su familia acompañó todo este proceso de decisión, generando las condiciones necesarias para el desarrollo de su autonomía. En una ocasión el participante se trasladó sólo a la institución utilizando un medio de transporte público, ya que siempre era su padre quién lo llevaba.

En las entrevistas de seguimiento, durante el curso introductorio, se trabajó en la posibilidad de brindarle los apoyos necesarios, pero él manifestó que en ese momento no requería ningún tipo de ayuda. En el transcurso del año, comenzó a tener dificultades para entender y aprobar los parciales de las materias del primer cuatrimestre. Se trabajó en la posibilidad de asesorar a los docentes sobre sus dificultades con la visión, sin embargo, más allá de la letra de algún profesor en el pizarrón, su principal dificultad no se relacionaba con su déficit visual, sino con la comprensión de los textos. Por ese motivo, se lo contactó con el Programa de Ingreso, Inclusión y Permanencia de la Facultad, para que pueda participar de talleres sobre lectura y comprensión de textos académicos y para que pueda estar acompañado por un alumno tutor. No obstante, pese a estas estrategias, se mostró reticente y concluyó el año no pudiendo aprobar ninguna asignatura. Esta situación es habitual en los alumnos que cursan su primer año de carrera, ya que es parte del aprendizaje del oficio de estudiante universitario. En este sentido, el participante decidió recursar nuevamente todas las materias, para arrancar con otra actitud el año próximo, pero reconociendo como experiencia, cómo es el funcionamiento de la facultad, así como, la organización para estudiar. 
Si bien la Facultad cuenta con muchos espacios y actores institucionales que puedan acompañarlo para superar sus dificultades, será parte de su proceso de elaboración subjetiva el aceptar o no, este tipo de acompañamiento, ya sea a nivel En la misma línea debe ir la aceptación de su condición de discapacidad, ya que estas dificultades académicas, podrían estar encubriendo cómo afecta su déficit visual, en el desempeño del oficio de estudiante universitario.

Participante 8. Se trata de una joven 21 años, con disminución visual de grado profundo. Realizamos tres entrevistas y como era mayor de edad, no fue necesario entrevistarme con sus padres. Estaba cursando su $5^{\circ}$ año de escuela secundaria en un bachillerato de adultos, ya que había repetido dos veces porque no le gustaba estudiar. En su proyecto a futuro, priorizaba en primer lugar, la búsqueda de un empleo, para luego capacitarse en alguna carrera corta, ya sea terciaria o curso de formación profesional, vinculada al área artística- proyectual, ya que ha desarrollado muy buenas competencias y aptitudes en el dibujo y pintura. Trabajaba de manera informal cuidando niños, y en varias ocasiones había dejado de asistir a la escuela, ya que manifestaba cierto cansancio por continuar dentro del nivel de escolaridad secundaria. No obstante, era muy independiente, se organizaba sus tiempos y había desarrollado la capacidad de elegir con autonomía. Como le restaba un año para culminar sus estudios, sólo se realizaron tres entrevistas de profundización, para continuar trabajando al año siguiente, en el reconocimiento de sus intereses y en la posibilidad de generar herramientas para la inserción laboral.

Participante 9. Se trata de una joven 20 años, con disminución visual de grado profundo. Se realizaron un total de nueve entrevistas, de las cuales tres fueron de seguimiento durante el año 2012. Todas se realizaron en el Centro de Orientación Vocacional de la Facultad de Psicología de la UNLP. También se llevó a cabo una entrevista con su madre. El participante tenía 20 años, era muy independiente y autónomo, trabaja de manera informal y quería continuar estudiando Cheff, ya que tenía grandes intereses por el arte culinario. Por otro lado, la Escuela secundaria común a la que asistía, había sido seleccionada para participar del Programa de Extensión Universitaria: "Equidad y Orientación: el desafío de una propuesta”, del 
cual, la tesista era integrante. Esto posibilitó que él pudiera participar de un espacio de trabajo grupal junto a sus compañeros, apropiándose de la información educativa y laboral. De esta manera, se pudo trabajar de manera conjunta con el equipo de extensionistas, realizando un entrecruzamiento entre lo colectivo y la particularidad de su subjetividad En este sentido, la propuesta de trabajo individual, posibilitó el reconocimiento de su déficit visual y la incidencia del mismo en la elección de su carrera. Se profundizó en el trabajo de sus intereses, vinculados al deporte y al fútbol específicamente, dónde investigó sobre las carreras de Periodismo Deportivo y Profesor de Educación Física. Finalmente se decidió por la carrera de Cheff, ya que le interesaba seguir perfeccionándose en esta área para mejorar el rendimiento y la calidad del trabajo que realizaba en ese momento (pizzería) y con expectativas de poder seguir progresando en el mismo. Esta carrera sólo se dicta en instituciones privadas, por lo tanto, trabajamos analizando las distintas opciones de estudio, teniendo en cuenta sus posibilidades económicas y la calidad de la formación.

Ha podido desarrollar su autodeterminación, lo que le permitió elegir una carrera vinculada a sus intereses y gustos, teniendo presente, las eventuales dificultades que le pueda generar su déficit visual, pero con herramientas suficientes para poder superarlas.

En el seguimiento realizado a comienzos del año siguiente, no había podido comenzar la carrera de Cheff, ya que se había quedado sin trabajo y no podía solventar los gastos. Hacia mitad de año, dio las materias que adeudaba y culminó el secundario. En ese momento realizamos una entrevista, ya que estaba interesado en inscribirse en el SECLAS (Servicio de Colocación Laboral Selectiva para las Personas con Discapacidad, dependiente del Ministerio de Trabajo. Buenos Aires) Se le brindó información sobre el mismo y trabajamos en la confección de su Currículum Vitae, consiguiendo empleo primero en una carnicería y luego en una fábrica de hielo. Algo a destacar del participante, es el contacto permanente que mantuvo conmigo durante dos años luego de finalizado el proceso, comentándome cómo se iba desarrollando su vida en cuanto a estudios y trabajo. Cuando necesitó ayuda no dudó en reunirse conmigo para que pueda asesorarlo. Es un rasgo a destacar, ya que ha desarrollado las competencias que le permitieron superar las 
eventuales dificultades que se le presentaron. Entre ellas tramitó el certificado de discapacidad, ya que con el mismo, pudo alivianar algunos gastos, como el transporte hacia su lugar de trabajo.

Participante 10. Se trata de un adolescente 18 años, con disminución visual de grado leve. Realizamos sólo cuatro entrevistas, ya que no contábamos con medios para organizar los encuentros porque él no disponía de teléfonos ni de acceso a internet. Con sus padres no pude entrevistarme por sus compromisos laborales Realicé una entrevista con la Orientadora Escolar de la escuela secundaria común a la que asistía, quién pudo brindarme información sobre su historia de vida y sobre su trayectoria escolar, destacando sus buenos recursos intelectuales. Se desenvolvía con total autonomía, trabajaba en un lavadero de autos, y en su proyecto de vida, en primer lugar priorizaba el trabajo ya que él contribuía a la economía familiar, y en segundo lugar, la posibilidad de continuar estudios superiores. Se lo asesoró para que participe en una capacitación que organizó la Facultad de Infomática de la UNLP, junto con la Comisión Universitaria sobre Discapacidad, sobre recursos informáticos para personas con discapacidad visual. Esta intervención posibilitó un acercamiento del participante con nuevas herramientas y que serían fundamentales para el desempeño en el ámbito de los estudios superiores. Eligió una carrera universitaria, Licenciatura en Comunicación Social, la cual se vinculaba con los intereses que había desarrollado a lo largo de su trayecto educativo. La Facultad en la que se dicta la carrera, cuenta con varios alumnos con esta discapacidad y con Comisión de Discapacidad, motivo por el cual, podrán acompañarlo en todos aquellos apoyos que requiera para poder cursar sus estudios de grado.

\subsection{Resultados del Programa correspondiente al Microproceso}

Durante los años 2012-2013, se implementó con los jóvenes seleccionados, como se señalara precedentemente, un Microproceso de Orientación Educativa y Ocupacional (Gavilán, 2006).

La obtención de datos refiere, en este caso, al dispositivo taller, correspondiente a la modalidad seleccionada, en el que se privilegia el trabajo grupal, que permite a los participantes reflexionar, pensar y producir en pequeños grupos en relación con la 
temática de las opciones de elección que se presentan. Ese dispositivo, generó un clima de trabajo productivo, que posibilitó tanto un espacio para el trabajo en grupo como para la reflexión personal.

El número de talleres fue de 7 en cada año. Su duración fue en todos los casos de una hora y media reloj, con una frecuencia promedio quincenal, en el día asignado por la escuela de enseñanza especial, alternando el lugar de realización entre esa institución y el Centro de Orientación Vocacional Ocupacional de la Facultad de Psicología. Toda vez que se realizaron en la escuela nos acompañó en el desarrollo de los talleres, la Asistente Educacional.

Los resultados que se ofrecen a continuación emergen, del mismo modo que los informados respecto del Proceso específico individual, del análisis comparativo constante (Glaser y Strauss, 1967) sobre el contenido temático del corpus obtenido, compuesto en este caso del registro correspondiente a los talleres implementados. Este procedimiento, junto a la información sobre los datos correspondientes a cada uno de los participantes, permitió sintetizar los resultados en las categorías que aparecen a continuación.

\section{a. Caracterización de los participantes}

Participaron 12 adolescentes en el período incluido, 6 en cada año. Sus edades se ubican entre los 16 y los 19 años. Cuatro de ellos son varones y ocho mujeres. La discapacidad visual corresponde a ceguera en 5 casos, disminución visual profunda en 4 casos y disminución visual leve en 3 casos.

Todos estaban vinculados con la escuela de enseñanza especial desde sus estudios primarios y recibían apoyo en sus estudios secundarios, que estaban por finalizar, 9 en una escuela de gestión pública y 3 en un establecimiento de gestión privada.

En todos los casos prestaron su consentimiento para participar de este estudio, sobre el que hicieron manifiesto su interés.

b. Disponibilidad de Orientación Educativa y Ocupacional/Equipos de Orientación Escolar en la transición hacia los estudios superiores o el mundo del trabajo 
La información proporcionada por los adolescentes a este respecto es coincidente con la obtenida de otros informantes clave (Capítulo 5). Las escuelas secundarias de educación común, sean de gestión pública o privada, a la que asisten, no cuentan con Equipos de Orientación Escolar. No realizan, a través de otros dispositivos, intervenciones formales de Orientación Vocacional para el conjunto del alumnado, ni informales que consideren las necesidades específicas de los jóvenes con discapacidad visual para su elección educativa u ocupacional.

\section{c. Factores involucrados en la elección de carrera y/u ocupación}

Temores y fantasías. Emergieron en el grupo los temas característicos que aparecen en todo proceso de OEC que inciden en las futuras elecciones: miedo y fantasías respecto del futuro en el ámbito universitario, a la masividad del alumnado, la independencia y los hábitos de estudio que se requieren, incertidumbre sobre la carrera a elegir, etc. Se trabajó para que puedan reconocer tales temores y fantasías y repensar las situaciones de otra manera y se abordaron temas específicos: independencia, movilidad, traslado, acceso al material. Se fomentó tal como lo propone la escuela, la independencia de los alumnos, ya que es de importancia el desarrollo de su autonomía, mediante la búsqueda activa de sus propios intereses y espacios futuros a transitar, sean estos educativos, laborales $\mathrm{y} /$ o sociales.

Conocimiento de la oferta educativa. Entre los factores que pueden intervenir en las elecciones cuenta el conocimiento de los estudios terciarios universitarios y no universitarios. En función de ello, analizamos en primer lugar el bagaje de información sobre la oferta educativa del que disponían, para pasar en un segundo momento, a corregir distorsiones y ampliar la información mediante la aplicación de la técnica Realidad Ocupacional. Se les propuso que investiguen sobre aquellas carreras que desconocían, para poder analizar posteriormente las ventajas y desventajas relativas que podían plantarles.

Se utilizaron guías del estudiante, monografías profesionales y se articuló el trabajo con el Servicio de Información Orientada que brinda el Centro de Orientación Vocacional Ocupacional de la Facultad de Psicología de la UNLP que permite el trabajo con guías del estudiante y monografías profesionales. 
Asimismo se los invitó a participar en los talleres que dictamos en la UNLP con estudiantes en situación de discapacidad para recibir información de su parte sobre las implicancias del tránsito en la vida universitaria de los estudiantes con esta condición y a la Expo Universidad Comunidad, que organiza anualmente la Universidad Nacional de La Plata sobre su oferta educativa, que les permitió un acercamiento más "vivencial" en relación con la vida universitaria Complementariamente se informaron las ayudas que pueden prestarles desde la Comisión Universitaria sobre Discapacidad de la UNLP en los espacios de tutorías que ofrecen, así como las distintas instancias con las que cuentan algunas Facultades a las que puedan recurrir frente a posibles dificultades, tales como los equipos pedagógicos y los espacios de tutorías.

Asmismo, se les brindó información sobre un curso gratuito que dictaba CILSA. sobre informática y destinado a personas con y sin discapacidad, entre 16 a 35 años de edad. Los contenidos del curso eran: Informática Básica: Windows 7, Word, Excel, Power Point, Internet, Taller de preparación para el mundo del trabajo: Autoconocimiento y Perfil laboral, Construcción del CV y Carta de presentación, Búsqueda y Entrevista laboral, Elaboración de Proyectos y Orientación VocacionalOcupacional. El interés de ese curso, radica en el abordaje de temáticas vinculadas con las de los talleres, específicamente con relación a los contenidos de informática, que proporcionan las herramientas básicas que se utilizan comúnmente en las cursadas de las carreras de Educación Superior.

La disponibilidad de información recabada, vinculada con la duración de los estudios, los contenidos teóricos y prácticos, las adaptaciones necesarias, los soportes facilitadores del estudio (por ej. el lector de pantalla Jaws) y la salida laboral, condujo a la posibilidad que evalúen en su elección los recursos de infraestructura, adecuaciones bibliográficas y técnicas que les ofrece la Institución destinataria, y en caso de no encontrarlas, encontrar el modo de prevenirlas en el año próximo para encontrar cómo sobrellevarlas.

Factores vinculados a las opciones de elección. Encontramos en los jóvenes con discapacidad visual, en primer lugar, que los factores que inciden en sus opciones de 
elección resultan semejantes a los que se presentan en cualquier adolescente. En segundo lugar, que se agregan otros a tener en cuenta a la hora de pensar en elecciones futuras. Se trata de limitaciones reales, en función de las dificultades asociadas a su discapacidad y limitaciones vinculadas con los temores que su condición despierta. En ambas interviene la perspectiva subjetiva de aceptación o negación de su condición. Cuando esa condición es negada o minimizada aparecen opciones de elección que la minimizan o no la consideran, por ejemplo estudiar una carrera en la que es fundamental el sentido de la visión. Por ejemplo, una de las participantes manifestó su interés en estudiar enfermería, pero descartó esa posibilidad por el temor a viajar en colectivo sin acompañantes, aunque no tuvo en cuenta las dificultades visuales para este tipo de carrera. Otra mencionó que le interesaba estudiar Psicopedagogía, porque la institución quedaba cerca de la casa de su padre y en ese momento, aún no se movilizaba sola por la ciudad.

\section{d. Estudios superiores y/u ocupación elegidos}

Cuando se trabajó con la posibilidad de que elijan estudios u ocupaciones vinculadas con sus intereses y preferencias, aparecieron al principio elecciones que no contemplaban en demasía las limitaciones específicas que acarrea su discapacidad visual. A medida que se fue profundizando en el trabajo, reconocieron aquellas carreras en las cuales iban a tener dificultades para llevarlas adelante o para bien para el ejercicio profesional, en razón de su déficit visual.

Con respecto a sus proyectos, los jóvenes seleccionados pusieron de manifiesto diferentes opciones. Muchos se inclinaron por la posibilidad de seguir estudiando a nivel terciario universitario y no universitario y otros estuvieron relacionados con el mundo laboral, con oficios (peluquería, enfermería)

Los que se pronunciaron por la continuación de los estudios superiores mostraron preferencias por las carreras de Psicopedagogía, Psicología, Educación Especial, Periodismo, Ciencias Económicas, y Tecnicatura Superior en Periodismo deportivo, Abogacía, Tecnicatura Superior en Gestión Cultural, Lengua y Literatura, Profesorado en Educación Especial, Productor de Radio y T. V, Profesorado o 
Licenciatura en Comunicación Social. Asimismo mencionaron alguna carrera vinculada con el mundo artístico.

\section{e. Impacto del Microproceso de orientación}

Como resultado de la elaboración realizada a partir de los talleres implementados en el Microproceso, concluyeron que lo ideal sería elegir una carrera que permita un equilibrio entre lo que les interese y les agrada, pero que al mismo tiempo no les acaree demasiadas complicaciones vinculadas con la visión.

Asimismo se evidenció un avance en la consolidación de la independencia de los alumnos, particularmente en términos del desarrollo de su autonomía, mediante la búsqueda activa de información ligada a sus propios intereses y espacios futuros a transitar, sean estos educativos, laborales y/ o sociales.

Las correcciones en las distorsiones de la información disponible y el conocimiento más acabado de la oferta educativa y de las adaptaciones y ayudas necesarias, permitió ampliar las elecciones posibles.

\section{Ilustración particularizada sobre los talleres y casos individuales}

A continuación, se presentarán, en primer lugar, los principales temas abordados en cada uno de los talleres. Se ofrece en el Anexo 2 un ejemplo del diseño del primer taller. En segundo lugar, se presentarán cuatro casos, dos por cada año y de cada tipo de discapacidad, de los doce incluidos, destinados a ilustrar los hallazgos obtenidos, numerados de acuerdo a como parecen en las matrices de datos.

Principales temas abordados en el desarrollo de los talleres:

En el primer taller, se apuntó a la consolidación del grupo y a establecer un primer diagnóstico sobre la orientabilidad de los participantes. Para ello se exploró sobre las expectativas de los participantes frente al espacio del taller, se revisaron los motivos que los acercan a la problemática de la elección, se examinaron los temores, ansiedades, fantasías, miedos, pérdidas frente al proyecto futuro, así lo positivo de la nueva etapa que comenzarán a transitar.

En el segundo taller, se trabajó en el autoconocimiento de los participantes. mediante frases disparadoras que sirvieron para problematizar la situación de elección, se 
intentó que los jóvenes puedan empezar a reflexionar sobre sus gustos e intereses, así como la incidencia de su déficit visual, para el desempeño de las actividades que a ellos les interesan.

En el tercer taller se trabajó en la jerarquización de intereses, delimitando cuáles son de tiempo libre y cuáles profesionales. En muchas ocasiones un hobbie también se convierte en una salida profesional (por ejemplo fotografía). Se comenzaron a delinear las áreas de conocimiento, teniendo presente las siguientes seis: salud, humanísticas, sociales, naturales y exactas, ingeniería e informática, artísticamusical. Los participantes fueron eligiendo sus áreas de interés.

En el cuarto taller, se trabajó en el primer nivel de información, general, a partir de la administración de la técnica Realidad Ocupacional. Se apuntó a que los participantes puedan ampliar el conocimiento sobre la oferta educativa en sus tres niveles (universitaria, terciaria y cursos de formación profesional), así como se fueron corrigiendo distorsiones en relación a la información.

En el quinto taller, se profundizó en el segundo nivel de información, específica, dónde se terminaron de delimitar las áreas del tercer taller, y se comenzó a profundizar en la información, mediante guías de carreras y monografías profesionales. Para ello participaron del Servicio de Información Orientada que se brinda en el Centro de Orientación Vocacional. Facultad de Psicología. UNLP. Se seleccionaron también las ventajas y desventajas de estudiar determinadas carreras teniendo presente el déficit visual y las condiciones de accesibilidad y académicas que brinda la institución destinataria.

En el sexto taller, se abordó el tercer nivel de información, contacto directo, dónde en primer lugar, participaron de la Expo Universidad (UNLP) y en segundo lugar, varios participantes, especialmente los que presentaban ceguera o disminución visual profunda, junto con la docente de Orientación y Movilidad de la escuela seleccionada, realizaron el recorrido hacia la institución elegida. Ello permitió que puedan reconocer los tiempos que demandan, los micros que lo llevan etc.

En el séptimo y último taller, se realizó un cierre y una evaluación de los participantes así como de la coordinadora del espacio de los talleres. Se administró una encuesta 
final (ver Anexo 3) dónde se evalúa los factores (poner) que tuvieron en cuenta para la elección de su proyecto, así como el impacto de la intervención.

\section{Algunos Participantes: año 2012}

Participante 11. Se trata de una adolescente de 17 años que presenta ceguera. Participó de cinco talleres y se realizó una entrevista individual de seguimiento durante el año 2014. En una primera instancia, en los talleres se trabajó en la reflexión acerca del autoconocimiento de intereses propios, así como de aptitudes y competencias. En este sentido, aparecieron las limitaciones que acarrea el déficit visual, reconociéndolas para poder afrontarlas y realizar una elección desde sus competencias y no desde su discapacidad.

Cuando comenzaron los encuentros había pensado en la carrera de Profesorado en Educación Especial con modalidad en discapacidad visual. Es esperable que los jóvenes, tengan o no una discapacidad, realicen sus primeras elecciones en función de las carreras que conocen sin tener un real conocimiento sobre las implicancias efectivas del rol profesional. En este sentido fue muy clarificador una intervención que realizó una de las docentes en uno de los talleres, quién además, era profesora de la carrera mencionada. Ella funcionó como una "fuente viva de información" aportó visibilidad sobre las reales posibilidades laborales, ya que si bien iba a poder ejercer como docente del Sistema Braille, le iba a ser muy complejo sostener otras actividades, por ejemplo, realizar integraciones escolares.

Como resultado de este encuentro, la participante tuvo un "contacto directo" con la información y pudo empezar a visibilizar las limitaciones que le podría generar su déficit, para el ejercicio profesional de esa carrera. Esto permitió que pueda abrirse a pensar en otras posibilidades ya que hasta ese momento, no lo había podido realizar.

Se profundizó en la información educativa y laboral a nivel universitario, terciario y cursos de formación profesional. Se realizó un trabajo de información, que consistió en un nivel de profundización creciente y extensión decreciente, se. corrigieron ciertas distorsiones sobre las profesiones y esto la llevó a pensar en una tecnicatura de Radio y TV. Se exploraron los intereses vinculados a esta carrera, y encontramos 
muchos de los mismos, también en la carrera de Comunicación Social de la UNLP. Se evaluaron las ventajas de esta última opción, entre ellas que no tienen examen de ingreso eliminatorio, cuenta con el asesoramiento de la Comisión sobre Discapacidad de la Facultad, y hay varios estudiantes de esta carrera que también presentan discapacidad visual. En este sentido, cuentan con estrategias para acompañarla a superar las eventuales dificultades que se le puedan presentar, por ejemplo, el uso del programa Jaws. Se trabajó en el afianzamiento de su autonomía e independencia, ya que su proyecto era mudarse a la ciudad de La Plata (ella no es de allí) recién en el año 2014. Se instalaría junto con su hermana menor en la ciudad, ya que esta última también va a estudiar allí.

Se realizó el seguimiento en el año 2014, estaba cursando la carrera de abogacía en la UNLP. Solicitó el asesoramiento a la Comisión Universitaria sobre Discapacidad, ya que necesitaba conseguir el material de estudio. Para ello una alumna avanzada de la carrera, que participa de la Comisión y presenta ceguera, pudo asesorarla con mucha predisposición para que pueda acceder a los materiales.

Participante 12. Se trata de una adolescente de 17 años, con disminución visual de grado leve. Concurrió a 3 talleres, asistió 2 veces al servicio de información orientada del Centro de Orientación Vocacional de la Facultad de Psicología y realicé en el mismo lugar, dos entrevistas individuales: una durante el año 2012 y la otra, de seguimiento, durante el año 2013.

Cuando comenzamos a trabajar, había pensado en la posibilidad de seguir algún tipo de estudio superior, pero tenía mucho desconocimiento sobre la oferta educativa disponible. Se mostró muy interesada y comprometida con su elección a futuro, analizando la oferta educativa disponible en función de sus intereses, pero también, teniendo presente sus limitaciones y desempeño en una futura inserción laboral. En el transcurso de los encuentros, se fue profundizando en la exploración de sus intereses, de tal modo que en un comienzo había pensado en alguna carrera vinculada con la lengua y literatura, especialmente por su gusto e interés en la lectura. Al indagar en la salida laboral, se encontró que la docencia y no es algo que ella quisiera desempeñar. Otra carrera que contemplaba su interés por la lectura, era 
Tecnicatura en Museología, pero tampoco le agradó la salida laboral. La fotografía también le interesaba pero como actividad de tiempo libre o hobbie, reconociendo las eventuales dificultades que le puede acarrear su baja visión para dedicarse profesionalmente a este tipo de actividades. Finalmente se decidió por una carrera dentro del área de las ciencias sociales: Abogacía de la UNLP. En esta carrera, ella encontró su gusto por las ciencias sociales y la facilidad de acceso al material de estudio mediante formato digital o grabaciones. En este sentido, los factores que llevaron a su elección se relacionan con las condiciones de accesibilidad y adecuaciones que ofrece la facultad, así como con las limitaciones que acarrea su disminución visual. En este aspecto, la Comisión Universitaria sobre Discapacidad de la UNLP, puede facilitarles los apoyos que ella considere necesario. Cabe destacar que si bien su padre es abogado y puede ayudarla con el contenido de algunas materias, se trabajó en el desenvolvimiento de un desempeño más autónomo que incluya la posibilidad de acudir a compañeros $u$ otros referentes.

Frente a las posibles dificultades que puedan surgir para cursar la carrera de abogacía, consideró la opción de una carrera más corta y que se relacionaba con sus intereses por la lectura: Tecnicatura Superior en Gestión Cultural, ya que se relaciona con sus intereses por la lectura.

En el seguimiento realizado al año siguiente, se encontraba cursando la carrera de abogacía en la UNLP, estaba muy conforme y había aprobado el curso de ingreso. En relación con las materias de primer año, tuvo algunas dificultades que tuvieron que ver con dos aspectos: el primero, cuestiones de salud, y el segundo, académicas, ya que tuvo dificultad para adaptarse al ritmo de estudio. Destaca positivamente la predisposición de los docentes facilitando el material digitalizado, para poder acceder a los mismos con el lector de pantalla. Ha contado con la colaboración de su padre en la explicación de algún contenido y evalúo para el año próximo cursar sólo algunas materias y no todas las que corresponden a segundo año. Por otro lado, va a ayudar a su padre en el estudio jurídico ya que considera que podrá comprender mejor los conocimientos teóricos, a través de la práctica. 


\section{Algunos participantes: año 2013}

Participante 16. Se trata de una joven de 19 años que presentaba ceguera. Concurrió a siete talleres y realizamos tres entrevistas individuales, una de ella de seguimiento en el 2014. Cuando comenzamos con las actividades iniciales, había pensado en la carrera de Periodismo. Teniendo presente este interés, se la asesoró para que asista a una charla que organizaba la Comisión sobre Discapacidad de la Facultad de Comunicación Social y Periodismo. Allí se contactó con los referentes, varios de los cuales eran alumnos de la carrera y presentaban ceguera, quienes, a lo largo del año la invitaron a participar de diferentes eventos que organizaron.

Durante el desarrollo de la Expo universidad ${ }^{7}$, se acercó al stand de la mencionada facultad, donde la asesoraron sobre la carrera. En el desarrollo de los talleres, también trabajamos con la información sobre otras carreras y mediante la técnica de Realidad Ocupacional, pudimos ir corrigiendo las distorsiones que tenía sobre algunas profesiones y ocupaciones. Conoció otras opciones que también se vinculaban con su interés por la lectura como la carrera de Bibliotecología, pero se decidió por la Licenciatura en Comunicación Social con orientación en Periodismo En función de esta elección, se articuló con el área de Orientación y Movilidad de la escuela especial, para que trabajen con ella en el recorrido para llegar a la Facultad.

Entre los factores que tuvo en cuenta para la elección de la carrera, priorizó las condiciones de accesibilidad que ofrece la facultad. Destacó particularmente el asesoramiento de la Comisión sobre discapacidad y los contactos que pudo generar para su futuro desempeño en esa facultad. Entre las razones, las principales fueron su interés en investigar y preguntar,

Rescató de este espacio, el trabajo grupal, ya que ella al ser más "cerrada" pudo compartir las distintas experiencias y sensaciones frente egreso junto con otros compañeros.

\footnotetext{
${ }^{7}$ Expo Universidad un evento que organiza todos los años la UNLP, para presentar toda la oferta educativa de la UNLP, mediante distintas actividades como stand interactivos, charlas con profesionales y docentes, entre otras. .
} 
En el seguimiento realizado, estaba estudiando la carrera elegida, formaba parte de la Comisión de Discapacidad y participaba del Programa de radio que tenía la misma, en la temática sobre discapacidad denominado "Nos sobran los motivos".

Participante 15. Se trata de una joven de 19 años que presentaba disminución visual de grado leve. Participó durante dos años seguidos. En el 2012, cuando estaba cursando su $5^{\circ}$ año, asistió a 4 talleres y durante el año 2013 cuando cursaba su $6^{\circ}$ año, asistió a 6 talleres. También se realizaron dos entrevistas individuales, una de ellas, de seguimiento durante el año 2014. Ambas se llevaron a cabo en el Centro de Orientación Vocacional.

En el transcurso de esos dos años, se notó un progreso en la toma de decisiones, y a nivel grupal, se convirtió en el "portavoz", planteando dudas e interrogantes que resonaron a nivel individual en cada uno de los participantes.

En una primera instancia se hiceron reflexiones sobre el autoconocimiento y reconocimiento de sus propios intereses y gustos, como también de sus aptitudes y competencias. Se trabajó sobre las limitaciones que acarrea su déficit para poder afrontarlas y realizar una elección educativa desde sus competencias y no desde su discapacidad. Los intereses que mencionó, se relacionaban con lo artístico, la actuación y la comedia musical. No obstante, al comienzo de los encuentros había pensado en las carreras de enfermería y peluquería. Se trabajó para que ella pueda evaluar las competencias visuales que se requieren para el ejercicio profesional, especialmente de la carrera de enfermería, ya que era algo que no había pensado.

Se profundizó seguidamente la reflexión sobre el desarrollo de su autonomía. Esto era un motivo que limitaba la elaboración de su proyecto, ya que a pesar de tener 20 años, dependía de un tercero, generalmente de su padre, para movilizarse. En este sentido, en un comienzo sus elecciones priorizaban la ubicación y distancias de los lugares de estudio. Se elaboró una intervención, conjuntamente con su familia y la escuela para favorecer el desarrollo de su autonomía. Se la citó para una entrevista individual en el Centro de Orientación Vocacional Ocupacional, y concurrió por primera vez sola a un espacio nuevo para ella. Participó del servicio de información orientada que se desarrolla allí y se la asesoró sobre distintos institutos para estudiar 
teatro, como así también, sobre la carrera Tecnicatura Superior en Gestión Cultural, ya que se vinculaba a sus intereses. Esta intervención posibilitó que solicite luego el apoyo del área de Orientación y Movilidad que ofrece la escuela, para comenzar a trabajar en su desenvolvimiento individual.

En el seguimiento realizado, se encontraba realizando un curso de peluquería, al que concurría sola, tres veces por semana. Decidió postergar para otro momento, la formación en actuación.

El conjunto de las informaciones obtenidas en el Proceso Específico Individual y en el Microproceso resultan coincidentes y han permitido la categorización de los factores que prevalentemente inciden en las elecciones de los adolescentes con discapacidd visual, cuyos alcances serán retomados en el Capítulo 7, destinado a sintetizarlos, en relación con los interrogantes, objetivos e hipótesis formulados y presentar las principales conclusiones a las que han dado lugar, así como las limitaciones del estudio y algunas orientaciones sobre perspectivas futuras de investigación. 


\section{Capítulo 7 Discusión general y conclusiones}

sta investigación, estuvo destinada a examinar los factores que inciden en las elecciones que realizan las personas con discapacidad visual en la etapa de finalización de la escolaridad secundaria. A partir del análisis comparativo constante (Glaser \& Strauss, 1967) de la información recabada en los procesos de orientación con los participantes con discapacidad visual y de las entrevistas y talleres con los informantes clave, pudimos elaborar las categorías de análisis del contenido temático. Ellas sistematizan y sintetizan los resultados, y dan lugar a la discusión y conclusiones que presentamos, toda vez que es posible hacerlo, en la interrelación que guardan unos factores con otros.

En consonancia con los interrogantes, objetivos e hipótesis de partida, el análisis del corpus del material obtenido permite observar la intervención de factores de distinta naturaleza. Cabe señalar al respecto que los resultados emanados del Proceso Específico Individual y del Microproceso son semejantes.

En primer lugar, pudimos distinguir factores que denominamos intrínsecos y extrínsecos, coincidiendo con Graves y Lyon (1985) cuya delimitación no siempre puede ser precisa ya que aparecen íntimamente articulados. Los intrínsecos operan en los mismos sujetos, y se refieren al posicionamiento frente a la propia discapacidad que se vincula con los intereses, motivaciones y preferencias prevalentes. Los factores que consideramos extrínsecos, a las características de los contextos educativos, laborales y sociales en general, que pueden facilitar $u$ obstaculizar el proyecto que se puede formular a partir de su articulación con los intrínsecos.

A continuación explicitaremos la discusión y conclusiones a las que dan lugar los principales hallazgos de esta tesis. 


\subsection{Factores intrínsecos}

\section{a. Factores relativos al posicionamiento de los sujetos frente a su discapacidad}

Los jóvenes seleccionados se encontraban atravesando la etapa de la adolescencia, etapa en la que por lo general este colectivo necesita reelaborar su situación de discapacidad, tal como señala González Fernández (2003). En nuestro trabajo aparecen dos perspectivas diferenciadas y matices entre ellas. Particularmente en el caso de los disminuidos visuales leves una suerte de perspectiva subjetiva que niega o rechaza la discapacidad, de modo tal que los factores que suelen orientar sus elecciones no difieren drásticamente de los que aparecen en otros adolescentes videntes. El funcionamiento con un resto visual generalmente los impulsa a posicionarse de forma idéntica a la del resto de los adolescentes, que pone de manifiesto la necesidad de pertenencia al grupo de pares, característica de esta etapa. Como consecuencia suele aparecer la resistencia y el rechazo a usar las ampliaciones de los textos, o a recibir un trato diferencial en las tareas o el uso de los anteojos. Por ello es importante que consideremos que hay que atender y entender la adolescencia de la persona con discapacidad, acentuando y estudiando lo que tiene de común con la adolescencia en general así como aquello que le es propio por su condición. Esto se refuerza cuando esa perspectiva es compartida por los padres, situación que puede comportar una sobre exigencia respecto de aquello que pueden hacer.

Cuando se trata de personas ciegas o con disminución visual profunda, la perspectiva de nuestros examinados cambia. Aparece una mayor aceptación de ellos mismos y de sus progenitores, que a veces se traduce en una suerte de sobre protección, que puede llegar a obstaculizar el desempeño de una vida autónoma o independiente.

\section{b. Factores vinculados con las expectativas del futuro educativo $y / u$ ocupacional}

En los adolescentes con discapacidad visual suelen aparecer expectativas similares de cara a su futuro semejantes a las del resto de los adolescentes. Sin embargo, estrechamente vinculados con los anteriores, se observan algunos rasgos particulares. 
Distorsiones en la información. Las distorsiones respecto de la información de la que disponen en general todos los adolescentes, se ve acentuada por la escasa o nula consideración de sus posibilidades, mayor cuando la perspectiva subjetiva es de negación o rechazo de la discapacidad. Complementariamente, al comienzo también aparecen elecciones fantaseadas relacionadas con la identificación con los "otros" significativos, poniendo de manifiesto el deseo de realizar actividades desempeñadas por personas cercanas al ámbito familiar y o social (por ej., profesión de los hermanos, de los padres) ámbito institucional (por ej., docentes, profesionales, etc.). Se trata en muchos de estos casos de carreras sobrevaloradas social y familiarmente, por ejemplo medicina, abogacía, frecuentemente asociadas a la propia historia familiar.

Resulta significativo apreciar que entre las áreas de conocimiento que los jóvenes eligen en función de sus intereses aparece con una prevalencia mayor el área artística. La misma está relacionada con la música, la danza, el canto, la actuación y la comedia musical, entre otras. Es posible que este interés se derive de las dificultades que atribuyen a otro tipo de áreas de las ciencias básicas y tecnológicas, o el de las ciencias naturales.

Se producen en consecuencia elecciones "poco realistas", más allá de lo elaborado en procesos específicos de orientación (generalmente ausentes), que requieren en consecuencia intervenciones que exceden las propias de la orientación.

Inquietudes/Temores. Si bien se observan inquietudes y temores frente al futuro semejantes a los de cualquier adolescente, aparecen signados por la situación de discapacidad, en el caso de la insuficiencia de su pleno reconocimiento. Los temores muchas veces están exacerbados por las dificultades que acarrea el desplazamiento hasta los lugares de estudio o trabajo, el tránsito dentro de las mismas instituciones, el reconocimiento de las instalaciones, entre otras, que guardan estrecha relación con el desarrollo de la independencia/autonomía. Estos aspectos se relacionan a su vez, por un lado con la perspectiva y consecuente conducta de los padres, por otro con las características de las instituciones en relación con las adaptaciones que resultan necesarias. 
Interrelación con pares y docentes. La interrelación con pares y docentes se ve obstaculizada por cuestiones inherentes tanto a los propios sujetos con discapacidad como a los mismos pares y docentes. En el primer caso, aparecen en muchas ocasiones las dificultades en comunicar las necesidades ligadas a la discapacidad, más acentuadas cuando la perspectiva subjetiva es la de negación o rechazo. En el segundo, al desconocimiento de parte de los docentes de tales necesidades y consecuentemente de las adaptaciones necesarias para atenderlas. Coincidimos con Grzona (2009), en señalar las distintas barreras que los jóvenes encuentran en el ámbito de los estudios superiores. Respecto de los pares, también aparece el desconocimiento de las necesidades específicas de sus compañeros con discapacidad visual.

\subsection{Factores extrínsecos}

\section{a. Factores vinculados a la disponibilidad de procesos de orientación}

Entre ellos cobra especial relevancia la posibilidad de ser asistidos en procesos de orientación, que pueden mediar en la articulación con los factores intrínsecos para favorecer elecciones, que se adecuen más acabadamente a las características particulares de las necesidades educativas y/u ocupacionales específicas de este colectivo particular.

Hemos observado que en la mayoría de las escuelas de enseñanza común se carece de programas de este tipo o bien que las acciones que se despliegan son insuficientes o poco adecuadas a las necesidades específicas de las personas con discapacidad visual.

\section{b. Factores relativos a las adaptaciones académicas}

Por adaptaciones académicas se entienden aquellas modificaciones o ajustes necesarios para favorecer los estudios de las personas con discapacidad visual, que permiten acceder al mundo educativo en equidad de oportunidades. Tal como señalan Abejón Mendoza, Martínez Solana, y Terrón López (2001) para el caso de España, en nuestro medio, si bien progresivamente se han ido incorporando servicios específicos de atención a la diversidad, resultan aún insuficientes. En la U.N.L.P. la creación de la Dirección de Inclusión, Discapacidad y DDHH y de la Comisión Universitaria sobre Discapacidad supone un avance en la materia, que ha 
continuado con la incorporación de comisiones específicas en algunas unidades académicas. No obstante, aún no se consideran suficientemente todos los aspectos de la vida estudiantil, a saber:

b.1. Colaboración de los docentes. La inclusión educativa de los alumnos con discapacidad visual requiere que toda la comunidad educativa este sensibilizada y comprometida con la diversidad, fomentando una comunicación fluida, continuada y bidireccional, basada en relaciones de colaboración y respeto. Ahora bien, la falta o insuficiencia de formación e información muchas veces afecta a todos los agentes implicados en el proceso educativo de estos alumnos. Por un lado, los profesores de las escuelas secundarias comunes, son idóneos en su materia, pero muchas veces no están preparados para abordar la necesidad educativa particular de algún alumno con discapacidad visual. El alumno precisa de un personal docente formado y competente, con capacidad de respuesta y adaptación a todas las necesidades que se le presentan en el aula. A su vez, la falta de implicación de los docentes, muchas veces se refleja en su ausencia de flexibilidad a la hora de adaptar materiales y contenidos, siendo los propios alumnos los que deben asesorarlos en las adaptaciones que necesitan para poder cursar las asignaturas. Consideremos, sin embargo, que durante la escolaridad secundaria los alumnos, tal como sucede con los incluidos en este trabajo, cuentan con el apoyo de docentes integradores de la Escuela de Enseñanza Especial, situación que no se replica en los estudios terciarios ni en los universitarios. Cuando se trabaja en la transición hacia los estudios superiores, se registra que sobre el profesor universitario se generan representaciones sociales que lo perciben, en ocasiones, como menos implicado, lo que conlleva que al alumno con discapacidad no le resulte sencillo mostrar sus necesidades y exigir sus derechos.

Por otro lado, los alumnos con discapacidad, no deben ser minimizados frente a posturas paternalistas, que sólo reflejan la falta de expectativas frente a sus reales capacidades. Tampoco deben ser forzados a una igualdad que ignore las necesidades específicas y discrimine las diferencias. Por eso, es fundamental que el diálogo entre el alumno y la persona que realiza las adaptaciones se genere desde una óptica de respeto e igualdad. Si bien, la mayoría de los jóvenes seleccionados 
expresan que están satisfechos con respecto a los apoyos específicos que les brindan los profesores y sus compañeros en clases de escolaridad secundaria común, a veces reconocen que los mismos son excesivos, obturando en muchas oportunidades las potencialidades que tienen los propios jóvenes para desarrollar las actividades por si solos.

b.2. Adaptaciones de acceso a los contenidos de la enseñanza. En concordancia con lo expresado más arriba, se trata en este caso, en primer lugar, de adaptaciones metodológicas, sobre la forma de enseñar, en la que entre otras cuestiones se debe privilegiar la transmisión oral de aquello que transcurre en el seno de una clase, del mismo modo que en los sistemas de evaluación, que suelen requerir, además, la disponibilidad de un tiempo mayor. En segundo lugar, de los materiales necesarios, entre los que se encuentra la disponibilidad de textos específicos, ampliados o en sistema de escritura Braille, y de otros recursos posibilitados por la tecnología digital.

En los casos estudiados aparece una diferencia significativa entre los recursos con los que cuenta la Escuela de Enseñanza Especial respecto de las escuelas secundarias de enseñanza común, situación moderada por las ayudas integradoras que se reciben en este nivel, pero ausentes en los estudios superiores.

b.3. Adaptaciones de acceso físico. Refieren por un lado a características del ambiente, con la eliminación de barreras espaciales, mobiliario adaptado y aulas accesibles con iluminación adecuada. Por el otro, a los docentes y compañeros de apoyo que faciliten la movilidad. Muchos de los temores de los alumnos secundarios y universitarios entrevistados se relacionan justamente con la posibilidad de traslado hacia la institución universitaria y de movilidad dentro de la misma institución. Las barreras arquitectónicas a las que aludíamos más arriba se inscriben en el mismo sentido.

\section{b.4. Adaptaciones de acceso a la comunicación, al estudio y al desempeño laboral.}

Consisten en las ayudas técnicas, entre las que se encuentran los sistemas de comunicación aumentativos, materiales, accesorios, elementos específicos y 
facilitadores a nivel comunicacional (disponibilidad del sistema de escritura Braille digitalizado, lupas, computadoras, grabadoras, entre otros).

Entre ellos, la utilización del sistema Braille y/o de los recursos tiflotecnológicos resultan relevantes. Cabe señalar que la sociedad actual ha sido calificada como sociedad de la información y el conocimiento, apoyada, de forma preponderante, en las denominadas Tecnologías de la Información y la Comunicación (TICs). En este contexto, el desarrollo personal y social de las personas va a estar determinado, en gran medida, por su cualificación en el manejo de estas tecnologías. Ahora bien, no todos los dispositivos tecnológicos existentes en el mercado son susceptibles de ser utilizados fácilmente por cualquier sujeto. Tal es el caso del contenido visual de estas tecnologías, que afecta principalmente a las personas con ceguera o disminución visual. En razón de ello, se requiere su adaptación o mejora en su accesibilidad desde el mismo momento de su concepción, diseño y producción, para evitar que supongan un factor más de desventaja o segregación. La aplicación de la tecnología, en general, implica una fuente constante de soluciones para las personas con discapacidad visual en los diferentes ámbitos de su autonomía y bienestar: vida cotidiana, movilidad, educación, empleo, ocio, cultura, etc.

En este contexto el uso de computadoras conjuntamente con sistemas informáticos auxiliares también resultan ser de utilidad para el docente que trabaja en esta problemática, que no siempre resulta suficientemente conocido por ellos. Dicho de otro modo, los propios sujetos deben estar suficientemente capacitados en el uso de esas tecnologías, pero sus alcances deben ser conocidos por los docentes a cargo

Estas tecnologías son las que proveen al niño/joven discapacitado de variadas experiencias educacionales que le permiten "acercar" a su mundo vivencias multisensoriales, y posibilitan al pedagogo proveer de instancias alternativas al apresto escolar y a la promoción del desarrollo, de una manera que resulta atractiva y motivadora (Ferreyra; Méndez y Rodrigo, 2009, p.56 año)

El uso de la computadora permite alcanzar de modo independiente ciertos objetivos, que redundan en el logro de un sentimiento de igualdad, con una mejor predisposición hacia sí mismos y los demás. (Ferreyra; Méndez y Rodrigo, 2009) 
Una de las principales barreras que hemos encontrado en los jóvenes que ingresan a nuestra Universidad (UNLP), es el desconocimiento o la ausencia/insuficiencia de capacitación en el manejo de las herramientas informáticas de adaptación que los asisten en el uso de la computadora, a partir de los cuales pueden tener mayor accesibilidad a la información.

Cabe señalar que entre los participantes de este estudio encontramos una disponibilidad diferente en la utilización del sistema de escritura Braille y/o recursos tiflotecnológicos. Los jóvenes que presentan ceguera o disminución visual profunda, los utilizan en razón de que facilitan la lectura y el acceso a los textos desde el uso de la PC, a diferencia de lo que ocurre en los textos en soporte papel. El uso de estas herramientas, les permitió pensar en carreras vinculadas al área artística y proyectual, en contraposición a lo que sucedía años atrás, cuando se priorizaban carreras que contaran con el material bibliográfico adaptado.

Si bien el uso de estas tecnologías requiere de una capacitación específica, la incorporan con naturalidad como parte integral de su proceso de aprendizaje. Este conocimiento debería estar complementado con el de los docentes de la escolaridad común, tal como señalamos con anterioridad, que no siempre conocen el alcance de las mismas, y desaprovechan vías alternativas para posibilitar el acceso al conocimiento, que trascienden a las tradicionales, pensadas para el alumno "ideal".

El resto de los jóvenes seleccionados que presentan disminución visual leve, suele no utilizar ningún recurso tiflotecnológico específico y manejan las herramientas informáticas más genéricas, como correo electrónico, redes sociales, messenger, etc.

Cabe señalar, que las adaptaciones mencionadas, revisten un carácter particular, es decir, que deben realizarse en función de las necesidades específicas de cada alumno. En este sentido, las mismas deben convertirse en un proceso abierto y flexible, dónde no sólo deben participar el profesor y/o la persona encargada de las mismas, sino que el alumno debe ser parte activa de este proceso de coconstrucción de "ajustes razonables". En los participantes estudiados, observamos la 
importancia de la mediación de los docentes de integración que proporcionan los elementos de los que la escuela común no dispone.

\section{c. Factores relativos a la movilidad. Vida independiente}

El concepto de Vida Independiente, que hemos desarrollado en el capítulo 2, se refiere a un derecho fundamental para todas las personas con discapacidad. Revela la intención primordial de que cada sujeto mantenga el control sobre su propia vida, eligiendo opciones estables que minimicen la dependencia de los demás en la realización de las actividades cotidianas. La independencia, entonces, es una de las capacidades más valoradas socialmente en la vida adulta y como tal, es un tema fundamental a trabajar desde la Orientación. Ahora bien, la familia es el primer eslabón de la integración social y como tal debe posibilitar la instancia de realización de una vida independiente.

A partir de las entrevistas realizadas con los padres de los participantes, coincidimos con Cangelosi (2006), que plantea que la aceptación de un hijo afectado de alguna discapacidad, no significa que los padres olviden la angustia, los sueños perdidos (sobre el hijo ideal), sino que atraviesan por un proceso de elaboración en el que, además, aprenden a conocer las necesidades particulares, asistidas en programas y escuelas especiales destinados a desarrollar el mayor potencial de los niños, y a promover la confianza en la propia capacidad para buscar lo mejor para el hijo. Por lo tanto, las familias que cuentan con una persona con discapacidad se enfrentan, a procesos de cambio, de aceptación y de rechazo de esta condición en diferentes circunstancias íntimas, privadas y públicas, que suelen diferir a lo largo del ciclo vital. La independencia, entonces, es un estado al que se llega luego de hacer un largo recorrido. Sin embargo, en los jóvenes con discapacidad este proceso muchas veces se dificulta, ya que el exceso de dependencia que entretejen los padres no los ayuda al logro de la independencia sino a una dependencia mutua. Coincidimos con Schorn (2003) en que el "no puedo" marca el existir de muchos niños y jóvenes, sosteniendo la falsa ilusión de que son los padres o los adultos los que pueden. De este modo, cuando los padres sostienen una dependencia excesiva ponen de manifiesto ser solo ellos los que saben que necesita, desea o quiere su hijo. En ocasiones, la falta de 
expectativas de las familias (escasa confianza en las capacidades de las personas con discapacidad), lleva muchas veces a ejercer una sobreprotección que limita la autonomía y la capacidad de decisión.

También sucede lo contrario, tal como describe Schorn (2003) cuando los padres suprimen el no y aparece "él puede" sin el reconocimiento de las verdaderas posibilidades y capacidades del hijo, que conduce a profundizar la sobre exigencia.

Si bien en la escuela se trabaja por la autonomía y la independencia de los alumnos, en muchas ocasiones en el núcleo familiar sigue apareciendo cierta prolongación de los "vínculos endogámicos", de modo tal que solo admiten a los miembros de la familia directa como los únicos referentes y acompañantes, circunstancia verificada en muchas de las entrevistas con los progenitores.

\section{d. Factores relativos al conocimiento de las barreras en carreras universitarias inherentes a la ausencia/disminución de la visión}

Existe consenso entre los especialistas que la elección educativa y/o laboral es uno de los pilares que contribuyen al logro de la identidad. Muchas veces hemos encontrado que los jóvenes con discapacidad visual idealizan las profesiones y/o ocupaciones de su ámbito más cercano, a saber, escolar y/o familiar, con un total desconocimiento de sus capacidades y limitaciones.

Si bien como menciona Rocha (2013) "el deseo no se encuentra discapacitado", las intervenciones orientadoras con sujetos con discapacidad visual desde un enfoque preventivo, deben ser dobles: en primer lugar, como en todo proceso de Orientación, lograr que el sujeto aprenda a elegir, elaborando un proyecto de vida ya sea educativo, laboral, social, personal u otro. Por otro lado, se debe trabajar para que el sujeto pueda elaborar internamente los conflictos personales para aprender a elegir y realizar una opción viable, teniendo en cuenta tanto las posibilidades como las limitaciones que acarrea su déficit visual para poder concretar su proyecto. De ahí que nuestra función como orientadores es acompañar en el desarrollo del autoconocimiento, especialmente, en aquellas trayectorias que conduzcan a profesiones y/u ocupaciones, dónde la vista aparece como un factor fundamental. En el trabajo realizado con los participantes próximos a finalizar los estudios 
secundarios, las elecciones por las que manifestaron optar no siempre tuvieron en cuenta las posibles barreras ligadas a su condición de discapacidad que pueden obstaculizar su inserción en los estudios superiores. En algunos de los casos hemos observado, como señalamos precedentemente, que se obvian, por falta de implicación subjetiva respecto de lo que su discapacidad supone, de modo tal que aparecen elecciones poco realistas.

\section{e. Factores relativos a la presencia/ausencia de autodeterminación. Las decisiones inducidas.}

La autodeterminación refiere a tener la capacidad de actuar como impulsor de la propia vida. Para la Orientación alcanzar la autodeterminación en sujetos que presentan alguna discapacidad es ineludible, ya que esto les va a permitir hacer elecciones y tomar decisiones siendo conscientes de sus capacidades y limitaciones, para plantearse objetivos personales, educativos y/o laborales, tal como plantean Aznar y Gonzales Castañón (2009). Los componentes que señalan los autores adquieren una tonalidad particular en el caso de la discapacidad visual, como observamos en los participantes incluidos.

Con respecto a las Elecciones, no siempre o casi nunca disponen de la información necesaria que los conduzca a opciones reales, particularmente relacionadas con su situación, que les permitan experimentar, intentar, tantear sus elecciones, las ganancias y las pérdidas que se ponen en juego en cada una de sus decisiones. En muchos casos observamos que tales elecciones están determinadas por la familia o identificaciones con personas del entorno más cercano, circunstancias que es necesario esclarecer en función de sus posibilidades reales, tal como observamos en algunos de los participantes.

El Protagonismo necesario en términos de iniciativas personales que habilitan a poner en palabras aquello que precisan y desean, muchas veces aparece menoscabado. Los ejemplos de los datos recabados en los talleres pusieron de manifiesto el papel facilitador del trabajo grupal para hacerlo.

En cuanto a la Libertad que implica poder distanciarse del deseo y opiniones de los otros, para tomar decisiones autónomas requiere, en muchas ocasiones, poder oponerse y rechazar lo que viene de ellos si no está en consonancia con los propios 
deseos. En algunos de los casos examinados observamos, por el contrario, una suerte de aquiescencia a aquello que manifiestan otros.

La Responsabilidad implica no solo tomar decisiones de manera consciente, sino también asumir sus consecuencias. En algunas oportunidades observamos que solo la experiencia permite experienciar las consecuencias de una decisión no acorde con las posibilidades, sea en razón de las mismas o de la insuficiencia de recursos institucionales.

Finalmente considerar el Contexto interrelacional en la autodeterminación de las elecciones es imprescindible y en ello se articulan factores relativos a las familias y a las instituciones receptoras en las que se desenvuelven las personas con discapacidad.

En el momento de la toma de decisiones con relación al proyecto de vida de los jóvenes con discapacidad visual, hemos encontrado que el nivel de información de los padres sobre la discapacidad de sus hijos incide en la confianza en sus posibilidades y en la proyección de expectativas favorables para su futuro. La desinformación deviene en prejuicios y los conocimientos inadecuados en este terreno suelen ser mayores cuanto más alto es el nivel educativo de los padres, aunque también influyen otras variables como el interés y la motivación. Se ha encontrado que algunos padres no tenían un real reconocimiento sobre las posibilidades y capacidades de sus hijos. Esto suele conducir a profundizar la sobre exigencia y exposición a situaciones en las que no se reconocen las verdaderas limitaciones. Uno de los observables a ese respecto es el deseo de que sus hijos continúen con algunas de las profesiones y ocupaciones de los miembros de la familia, sin tener en cuenta las verdaderas posibilidades, con la consiguiente implicación en su subjetividad. En algunas ocasiones se ha observado que en el proceso de Orientación por primera vez han tenido la oportunidad para tomar la palabra con respecto a sus intereses y deseos, corriéndose justamente del "deseo de los otros", tal como apareció en las entrevistas y en los talleres realizados con los participantes. 
En este punto, acordamos con el concepto de Deuteroelección que plantea BohosIvasky (1985), es decir cómo el adolescente eligió elegir. Particularmente, en el caso de los jóvenes con discapacidad visual, encontramos que muchas veces no se las ha dado la posibilidad de elegir. De este modo, la toma de decisiones viene mediada por la mirada del otro, circunstancia que genera cierta "pasividad" al momento de elegir su proyecto de vida. Encontramos evidencia, por ejemplo, en el momento de la búsqueda de información en la que emerge una conducta de inacción, en espera de la provisión de parte de los otros de las acciones necesarias.

Las particularidades señaladas respecto de los factores de autodeterminación han resultado especialmente sensibles en los participantes con disminución visual leve, que tienden ellos mismos y sus familias a hacer elecciones poco realistas, sean estas autodeterminadas o inducidas por otros.

\section{f. Factores relativos las dificultades enfrentadas en el trayecto educativo pasado}

En los alumnos seleccionados en este estudio, en general observamos que no presentaban mayores dificultades pedagógicas o de aprendizaje, excepto en algunas materias que requieren el uso del pizarrón como por ejemplo matemática y química. En tales casos manifiestan que se pierden o dispersan en la dinámica de la clase, generándose el desinterés por esta área de conocimiento, justamente por las dificultades para su acceso. Esto se observa en las elecciones manifestadas por los participantes, que recaen en carreras con otros contenidos.

\section{g. Factores relativos a la disponibilidad de equipos de Orientación. Transición a los estudios superiores y al mundo del trabajo}

Esta categoría refiere a la indagación sobre la disponibilidad de Equipos de Orientación Escolar en las escuelas secundarias de procedencia de los alumnos, o bien si desde algún espacio de la institución, se brinda algún tipo de apoyo o asesoramiento en relación con los proyectos de vida, una vez que egresen.

Encontramos que son pocas las escuelas de los jóvenes seleccionados que cuentan con Equipos de Orientación Escolar-EOE (hay que tener en cuenta que varios 
alumnos fueron a la misma escuela). De los que contaban con EOE, encontramos que las actividades que realizan son las siguientes:

Están abocados a las urgencias que se presentan cotidianamente.

No se realizan intervenciones formales de Orientación, sino "informales", como charlas con profesionales o docentes de distintas unidades académicas, comentarios de los profesores, etc. Al no ser intervenciones planificadas encontramos que los profesionales de la institución, en general, no tienen en cuenta las necesidades específicas de los jóvenes con discapacidad visual para su elección.

Las propuestas que se ofrecen sobre Orientación, no consisten en una profundización de los aspectos meramente vocacionales de los alumnos. No se observaron espacios donde se estimule el protagonismo en una búsqueda activa de los propios intereses y en el desarrollo de aptitudes para alcanzar los logros deseados.

No se implementan dispositivos grupales de Orientación en las escuelas de educación común. En la escuela de educación especial se realizan talleres con todos los adolescentes que asisten a la institución, motivo por el cual muchas veces se abordan los temas vinculados al egreso.

En el discurso de los actores institucionales, se concibe a la Orientación como un hecho puntual que se realiza al final de la escolarización y no como un proceso que se da a lo largo de la vida del sujeto.

Esto lo observamos en los datos obtenidos de los propios participantes y en las entrevistas con distintos informantes clave, que transmiten la ausencia/insuficiencia de equipos de orientación y de otras acciones orientadoras. En los pocos casos en los que están presentes visualizan la orientación como un hecho puntual o un proceso de ajuste o adecuación a las competencias individuales, concepción que contrasta con la del modelo teórico que ha orientado esta investigación.

En síntesis: tres hallazgos clave emergen de esta tesis: en primer lugar la incidencia de la perspectiva subjetiva de los propios sujetos frente a su discapacidad visual 
como factor preponderante en sus elecciones, acentuada o morigerada según la perspectiva de los familiares. En segundo lugar la semejanza de los factores responsables de las elecciones educativas y/u ocupacionales con los que operan en la población vidente, pero matizados por la situación de discapacidad. En tal sentido la distorsión de la información sobre los requerimientos de los estudios superiores y/o el trabajo, los temores, inquietudes y la interrelación con pares y docentes aparecen acentuados por la necesidad de un conocimiento más exhaustivo, de una capacitación adecuada sobre los recursos necesarios y de la disponibilidad de adaptaciones acordes con las necesidades educativas especiales. Finalmente, la insuficiencia de procesos de orientación, o bien su implementación conforme al modelo que sustentamos aparece como uno de los factores de relevancia en la toma de decisiones sobre las elecciones a producir.

\subsection{Limitaciones del presente estudio y perspectivas para futuras investigaciones}

Las conclusiones a las que hemos arribado no pueden dejar de lado que se ha incluido exclusivamente un número reducido de sujetos con discapacidad visual que están finalizando los estudios secundarios. Esto habla de manera secundaria, de su pertenencia a un nivel socioeconómico determinado. Replicar el estudio con participantes más numerosos y de procedencia más diversa enriquecería nuestra comprensión de los factores que operan en las elecciones educativas $\mathrm{y} / \mathrm{u}$ ocupacionales así como en las condiciones de su posibilidad.

En investigaciones futuras, además, deberían analizarse exhaustivamente las trayectorias educativas en el nivel superior de alumnos con discapacidad visual y con otro tipo de discapacidades y los recursos necesarios, materiales y humanos, para dar respuestas a las necesidades específicas que presentan.

Destacamos entre tales recursos la disponibilidad de procesos de orientación. Nuestro marco teórico nos ha permitido visualizar su potencialidad para esclarecer el conjunto de estar cuestiones con el propósito último de garantizar la equidad de oportunidades para todos. 


\section{Referencias}

Abejón Mendoza, P; Martínez Solana, M.Y \& Terrón López, M.J (2010) “Propuestas de acción para la integración de universitarios con discapacidad visual y auditiva ante el reto de Bolonia" REDU. Revista de Docencia Universitaria; Vol.8 n'2. Disponible on line, http://redaberta.usc.es/redu/idex.php/REDU/article/view/184 Recuperado el 27 de marzo de 2012.

Agencia Europea para el desarrollo de la Educación Especial, Ministerio de Educación Portugués (2007). Declaración de Lisboa. Las opiniones de los Jóvenes sobre Inclusión Educativa. p.2 Disponible on line, http://www.europeanagency.org/news/euronews/euronews-18-1/euronews18_estext.pdf.

Recuperado el 18 de diciembre de 2011.

Angelino, M. (Coord.) (2009). Discapacidad e ideología de la normalidad. Desnaturalizar el déficit. Buenos Aires: Noveduc.

Anuies (2002) Manual para la Integración de Personas con Discapacidad en las Instituciones de Educación Superior. México D.F: ANUIES.

Aznar, A., \& González Castañón, D, (2008). ¿Son o se hacen? El campo de la discapacidad intelectual estudiado a través de recorridos múltiples. Buenos Aires: Noveduc.

Batistuta, M., \& Falco, A. (1997). Los adolescentes y sus padres. Una investigación argentina. Paraná: Centro de Producción en Comunicación y Educación de la Universidad Nacional de Entre Rios (UNER).

Bayot, A., Rincón, B \& Hernandez Pina, F. (2002) Orientación y atención a la diversidad: descripción de programas y acciones en algunos grupos emergentes. Revista Electrónica de Investigación y Evaluación Educativa, 8, (1) ,66-87.

Blanco, R. (1999). Hacia una escuela para todos y con todos. Santiago de Chile: UNESCO

Boholavsky, R. (1985). Orientación Vocacional - La Estrategia Clínica. Buenos Aires: Nueva Visión.

Braslavsky, B (2006) El ciego en la teoría de Vigotsky en F. Mon \& N. Pastorino (Eds.) Discapacidad Visual. Aporte interdisciplinario para el trabajo con la ceguera y la baja visión. Cap. 2. Buenos Aires: Noveduc.

Brea, M. (1965) La información ocupacional como etapa del proceso de orientación vocacional. En Actas de las Primeras Jornadas Argentinas de Orientación Vocacional. Buenos Aires.

Bregain,G. (2011) Historiar los derechos a la rehabilitación integral de las personas con discapacidad en Argentina (1946- 1974) Parte II. La producción de la investigación 2010-2011. En L. Pantano (Comp.) Discapacidad e investigación: aportes desde la práctica. Buenos Aires: Educa. 
Brolin, D.E. (1976). Vocational Preparation of Retarded Citizens. Ohio: Bell \& Howell Company

Buela Casal, G.; Carrasco Giménez, T. \& Fernandez Ríos, L (1997) Psicología Preventiva. Madrid: Pirámide.

Burlingham, D. (1979). To be blind in a sighted word. The Psychoanalytic Study of the Child, 34, 5-30.

Bush-Lafrance (1988): Educational ocupational expectations, legally blind VS sighted 9th-13th graders, Canada; Journal of Visual Impairment and Blindness, 1988 (Apr), Vol. 82 (4), 132-136.

Calleja \& Britez (2003) El ámbito ocupacional en la educación especial. Ocupación y discapacidad mental Cuaderno de Cátedra. Facultad de Psicología y Psicopedagogía. Universidad del Salvador. Buenos Aires.

Cancelo, S. (2006, agosto). Interrogantes e investigación pendiente. XIII Jornadas de Investigación y Segundo Encuentro de Investigadores en Psicología del Mercosur. Facultad de Psicología Universidad de Buenos Aires:Buenos Aires.

Cangelosi, D. (2006) La integración del niño discapacitado visual. Buenos Aires: Noveduc.

Capel, G. (2013, diciembre) Buenas prácticas en OV un derecho de todos. Trabajo presentado en el II Congreso Iberoamericano de Orientación. La Plata.

Caplan, G. (1986) Principios de Psiquiatría Preventiva. Buenos Aires: Paidos.

Carabajal Arregui M. (2003). Orientación Vocacional Ocupacional. Montevideo: Frontera.

Castignani María Laura (2012) Transición Escuela- Trabajo en jóvenes con necesidades educativas en poblaciones vulnerables. Cap. 8 en M. Gavilán (Ed) Equidad y Orientación. El desafío de una propuesta. (p. 143). Buenos Aires: Lugar.

Castoriadis, C. (1988) Los dominios del hombre. Barcelona: Gedisa.

Cattáneo, M. (2008) Metas de adolescentes argentinos: un estudio exploratorio. Revista Orientación y Sociedad, 8, 91-100.

CILSA-ONG (2014). Programa Poeta. Disponible on line: https://www.cilsa.org/

Córdoba Andrade, L., Aya Gomez, V., Ibañez García, A. Monsalve Robayo, A. \& Gómez Salazar, M. (2011) Herramientas de Evaluación para medir el impacto de programas de transición a la vida adulta dirigido a jóvenes con discapacidad intelectual. Disponible on line http://www.urosario.edu.co/urosario files/be/be5b842fabb0-4261-be06-8aa8b70547d7.pdf. Recuperado el 19 de mayo de 2017.

Crudden, A. (2002). Employment after Vision Loss: Results of a Collective Case Study. Journal of Visual Impairment and Blindness, 96(9), 615 - 621. 
Cuevas, M. (2006). El niño con déficit visual: una población creciente. En F. Mon \& N. Pastorino (Eds.) Discapacidad Visual. Aporte interdisciplinario para el trabajo con la ceguera y la baja visión. Cap. 7. Buenos Aires: Noveduc.

Di Doménico, C., \& Amadío, D. (2007, julio). Orientación Vocacional. ¿Articulación o desarticulación entre enseñanza media y superior? Trabajo presentado en el XXXI Congreso Interamericano de Psicología. México.

Dupes, F. (2005) Rehabilitación Profesional Ayudando a las personas con discapacidades a definir sus objetivos profesionales y encontrar empleo, 15 (1) Enero/Febrero 2005. Disponible on line http://www.amputeecoalition.org/spanish/inmotion/jan feb 05/vocrehab.pdf. Recuperado el 14 de mayo de 2017.

Estatuto de la Universidad de La Plata (2008). Disponible on line: http://www.unlp.edu.ar/uploads/docs/estatuto 2008 final.pdf. Recuperado el 19 de mayo de 2017.

European Agency for Development in Special Needs Education (2002) Programas Individuales de Transición. Apoyo al tránsito de la escuela al empleo. Disponible on line: www.european-agency.org. Recuperado el 19 de mayo de 2017.

Farley, R., Bolton, R., \& Little, N. D. (1990). Employability Assessment and Planning in Rehabilitation and Educational Settings. Vocational Evaluation and Work Adjustment Bulletin, 23,117-123.

Federación Argentina de instituciones de ciegos y ambliopes. FAICA http://www.faica.org.arl

Fernández Ríos, L. \& Gómez Fraguela, J. (2007) La Psicología Preventiva en la intervención social. Santiago de Compostela: Síntesis.

Ferreyra, J., Méndez, A., \& Rodrigo, M. (2009) El uso de las TIC en la Educación Especial: Descripción de un Sistema Informático para Niños Discapacitados Visuales en Etapa Preescolar, Revista Iberoamericana de Tecnología en Educación y Educación en Tecnología, 3, 55-56.

García Pastor, C. \& Alvarez Rojo, V. (1997). Orientación Vocacional de jóvenes con necesidades especiales. Un programa de transición a la vida adulta. Madrid: Eos.

Gavilán, M. (2006). La Transformación de la Orientación Vocacional. Hacia un nuevo paradigma. Rosario: Homo Sapiens.

Gavilán, M. (2012). Equidad y orientación educativa y ocupacional. El desafío de una propuesta. Buenos Aires: Lugar.

Gavilán, M. (2015) De la salud mental a la salud integral. Aportes de la Psicología Preventiva. Buenos Aires: Lugar.

Gavilán, M. (2017). La Transformación de la Orientación Vocacional. Hacia un nuevo paradigma. Buenos Aires: Lugar.

Gavilán, Cha, Quiles \& Neer (1997) Imaginario Social-Realidad Ocupacional Proyecto de Investigación. Secretaría de Ciencia y Técnica. UNLP: La Plata. 
Gavilán, M, Desuk, I., Di Meglio, M, Galli, M., Garcia, M., \& Maya, C. (2005). La Monografía Profesional como estrategia de información orientada. Memorias de las XII Jornadas de Investigación. Primer Encuentro de Investigadores en Psicología del Mercosur. UBA, (pp-253-255). Facultad de Psicología de la UBA.

Gavilán, M. \& Souto, G. (1982) La primera entrevista en el proceso de Orientación Vocacional. En Revista Psicología, Docencia e Investigación, 9. Departamento de Psicologia: FHCE. UNLP: La Plata.

Glaser, B. G., \& Strauss, A. L. (2006). The Discovery of Grounded Theory Strategies for Qualitative Research (Reimprinted 1967). London: Aldine.

Goldberg, R.T. (1992). Toward a Model of Vocational Development of People with Disabilities. Rehabilitation Counseling Bulletin, 35(3), 161- 173.

Gomez Jarabo, G. \& Bonantini, C.(2008) Discapacidad. Empleo y políticas sociales en la Argentina en Anales de discapacidad y salud mental. Vol. 7 y 8 . Rosario: UNR.

Gonzalez Bello, J (2007) La orientación en la diversidad. Una mirada desde América Latina. Revista Internacional "Orientación y Sociedad", Edición Especial № 7 (pp 57-65) La Plata: Editorial de la Universidad.

González Fernández, J. (2003). Adolescencia. En J. Checa Benito, P. Diaz Veiga \& R. Pallero González (Coords) Psicología y Ceguera: manual para la intervención psicológica en el ajuste a la deficiencia visual. Segunda Parte (pp.302-337). Madrid: ONCE.

Graves, W. \& Lyon, S. (1985): «Perception of career development, needs and their pupilment blind 9th graders»; Special Issue: Career Development, Journal of Visual Impairment and Blindness, 1985 (Dec), Vol. 79 (10), 444-449.

Grzona, M. (2009) Personas con discapacidad y acceso a servicios educativos en latinoamérica. Breve análisis de situación. Integración o inclusión de las personas deficientes visuales en la República Argentina? realidades y contradicciones. I, 369-379. España: Cinca.

Hanley-Maxwell, Ch., \& Szymanski, E. (1996). Career Development of People with Developmental Disabilities: An ecological model. Journal of Rehabilitation 62(1), 48-55.

Hernández Sampieri, M. C., Fernández Collado, C., \& Baptista Lucio, P. (2010). Metodología de la investigación (5ta. ed.). México: McGraw-Hill.

Jenaro, C. (1997). Orientación Profesional en Personas con Discapacidad: Desarrollo y Aplicación de Instrumentos de Evaluación e Intervención. Tesis doctoral no publicada. Universidad de Salamanca, Salamanca, España.

Jenaro, C. (1999, marzo) La transición a la vida adulta en jóvenes con discapacidad: necesidades y demandas. Comunicación presentada a la III Jornadas Científicas de Investigación sobre Personas con Discapacidad. Salamanca. 
Jenaro, C., Caballo Escribano, C. \& Verdugo Alonso, M. A. (1999, marzo) Desarrollo y validación del Cuestionario de Evaluación del Potencial de Autoempleo para personas con discapacidad. Comunicación presentada a la III Jornadas Científicas de Investigación sobre Personas con Discapacidad. Salamanca.

Jurado, P (2005) La transición hacia el mundo del trabajo para las personas con discapacidad. El papel de las tecnologías. Disponible on line: https://dialnet.unirioja.es/servlet/articulo?codigo=2913667. Recuperado el 19 de mayo de 2017.

Katz, S. \& Larroca, D. (2009). Políticas públicas y derechos en discapacidad: lógicas y problemáticas. Comisión Universitaria sobre discapacidad. UNLP. En Argentina Angelino, M. (Coord.). Discapacidad e ideología de la normalidad. Desnaturalizar el déficit. Buenos Aires: Noveduc.

Kligman, C. (2003) Técnicas proyectivas y psicométricas. Para O.V.P. y Psicología Educacional. Cuaderno de Cátedra. Facultad de Psicología y Psicopedagogía. Universidad del Salvador. Buenos Aires

Larramendy, A., Peryera, M. \& Rusler, V. (2012) Aportes para una Universidad inclusiva desde una perspectiva transversal. Revista Espacios Educativos, 49, $32-45$

Leonhardt, M. (1992) El bebé ciego. Primera atención. Un enfoque psicopedagógico. España: Masson. O.N.C.E

Ley 24147. Talleres protegidos de producción. Disponible on line. http://servicios.infoleg.gob.ar/infoleglnternet/anexos/0-4999/545/norma.htm Recuperado el 25 de mayo de 2017

Ley 25689 Sistema de protección integral de los discapacitados. Disponible on line. http://www.trabajo.gov.ar/downloads/discapacidad/ley25689.pdf Recuperado el 25 de mayo de 2017

Ley 24314. Accesibilidad de personas con movilidad reducida. Disponible on line. http://solesdebuenosaires.org.ar/Leyes/Ley-24314.html Recuperado el 25 de mayo de 2017

Ley 24521 (1995). Ley Nacional de Educación Superior. Disponible on line. http://www.me.gov.ar/consejo/cf_leysuperior.html Recuperado el 18 de mayo de 2017.

Ley 25573 (2002). Ley Nacional de Educación Superior. Disponible on line http://www.unl.edu.ar/files/Ley_24.521_-_Titulo_I_II_y_IV.pdf. Recuperado el 27 de marzo de 2012.

Ley 26378 (2008) Aprobación de la Convención sobre los Derechos de las Personas con Discapacidad y su protocolo facultativo. Disponible on line http://www.infoleg.gov.ar/infoleglnternet/anexos/140000144999/141317/norma.h tm. Recuperado el 30 de noviembre de 2014. 
López-Justicia, M. D., Fernández de Haro, E., Amezcua, J. A., \& Pichardo, M. C. (2000). ¿Difieren en autoconcepto los adolescentes con baja visión de los adolescentes con visión normal? Integración, 33, 14-20.

Lowenfeld B.(1977) On blindness and blind people. Nueva York: American F. Blind.

Mendia, R. (1994) La transición a la vida activa en jóvenes con necesidades especiales. Disponible on line. http://www.rafaelmendia.com/mendia/Conferencias files/CIVITAS.pdf Recuperado el 30 de noviembre de 2014

Migliano, A. (1986). Árbol genealógico vocacional. Ficha interna de cátedra de Orientación Vocacional. USAL

Müller, M. (2004). Descubrir el camino (2da, ed.). Buenos Aires: Bonum.

Müller M. (2009) Orientación Vocacional. Aportes clínicos y educacionales. Buenos Aires: Bonum.

Ochaita, E. \& Rosa, A (1988) Estado actual de la investigación en psicología de la ceguera. Infancia y aprendizaje, 41, 53-62.

Ohler, D.L., \& Levinson, E.M. (1995). Career Maturity in young adults with learning disabilities: What employment counsellors should know. Journal of Employment Counselling, 32(2), 64-77.

Organización de las Naciones Unidas (2006). Convención Internacional sobre los derechos de las personas con discapacidad. Disponible on line. Recuperado el 11 de mayo de 2008 de http:/www.un.org/spanish/disabilities- convention.htm

Organización Internacional del Trabajo -OIT-(1998). Informe sobre el Empleo en el Mundo 1998-1999. http://www.ilo.org/public/spanish/bureau/inf/pkits/.

Organización Mundial de la Salud (1997) Clasificación Internacional de Deficiencias, Discapacidades y Minusvalías. Madrid: IMSERSO.

Organización Mundial de la Salud (2001) Clasificación Internacional del Funcionamiento, de la Discapacidad y de la Salud. Madrid. IMSERSO.

Organización Mundial de la Salud (2014). Diez datos sobre la ceguera y la discapacidad visual. Disponible on line. http://www.who.int/features/factfiles/blindness/es/. Recuperado el 18 de mayo de 2017.

Oyarzabal, C. (2011) Ciegos. El maravilloso mundo de la percepción. Psicoanálisis, Neurociencias, Filosofía. Buenos Aires: Lugar.

Palacios, A., \& Romañach, J. (2007). El modelo de la diversidad. La bioética y los derechos humanos como herramientas para alcanzar la plena dignidad en la diversidad funcional. España: Diversitas

Pallisera Diaz, M. (2010). Apoyando proyectos de vida inclusivos. Claves para transformar las prácticas socioeducativas de personas adultas con discapacidad intelectual. Revista Educación Inclusiva, 3(3), 69-88. 
Pantano, L. (2007). La palabra discapacidad como término abarcativo. Observaciones y comentarios sobre su uso. En Cuestiones Sociales y Económicas, 5(9), 105-126. Facultad de Ciencias Sociales y Económicas. Buenos Aires: Universidad Católica Argentina.

Pantano, L. (2011). Enfoque social de la discapacidad. El derecho a tener oportunidades para cumplir obligaciones. Revista Novedades Educativas 246, 30-35.

Pérez, C., Rivas, F. \& Rocabiert, E. (1992), Sistema de Asesoramiento Vocacional para Ciegos: S.A.V.-C. Revista de Psicología General y Aplicada, 45, (4), 461467.

Philips, S. D. (1992). Career counselling: Choice and implementation. En Brown, S.D. y Lent, R.W. (Eds.), Handbook of counselling psychology (pp.513-547). New York: Wiley.

Polo Sanchéz, M., \& López Justicia, M (2004). Análisis de factores que influyen en el proceso de inserción sociolaboral de estudiantes con discapacidad de la Universidad de Granada. Revista de Enseñanza Universitaria, 24; 87-98.

Quiles, C. (2012). El Proceso Específico Individual en el marco del Modelo Teórico Operativo de la Orientación. Documento de cátedra. Facultad de Psicología. UNLP: La Plata.

Rascovan, S. (2013). Prólogo. En M. Rocha, Discapacidad, Orientación Vocacional y proyectos de vida. El desarrollo de la autonomía (pp.21-22) Rosario: Laborde

Repetto, E. (2001-2002). La orientación intercultural: problemas y perspectivas. Revista Orientación y Sociedad, 3. Disponible on line : http://www.scielo.org.ar/pdf/orisoc/v3/v3a02.pdf. Recuperado el 19 de mayo de 2017.

Reznik, L. (2012). Aportes para una Universidad inclusiva desde una perspectiva transversal. Revista Espacios Educativos, 49, 4-11

Riaño Galán, A. (2012). Programa de cualificación inicial. Itinerario laboral y planificación centrada en las personas con necesidades diversas. Revista Española sobre Discapacidad Intelectual, 43(4), 5-20.

Rivas, F. (1988): Psicologia vocacional: Enfoques del asesoramiento. Madrid: Morata.

Rivas, F., Rocabert, E., Ardit, I.; Martinez, J. R.; Gil, J. \& Rius, J. (1990).Sistema de Asesoramiento Vocacional. SAV. Segunda Edition. Valencia: Coure

Rivas, F., Tormos, M.J. \& Martinez, B. (2005) Tecnología informática en asesoramiento vocacional. Psicothema, 17, (3), 382-389.

Rocha; M. (2013) Discapacidad, Orientación Vocacional y proyectos de vida. El desarrollo de la autonomía. Rosario: Laborde.

Rocha, M., Capel, G., Durand, F., Gomez, A., \& Balero, D (2011, septiembre). Estado de situación de las prácticas de Orientación Vocacional Ocupacional en sujetos 
con discapacidad en la República Argentina. Trabajo presentado en las XI Jornadas Argentinas de Estudios de Población. Neuquén.

Rocha, M., \& Perilli, H. (2008). Vivir en la discapacidad. Estructura subjetiva e imaginario social. Rosario: UNR

Rodriguez Fuentes, A. (2003). Integración escolar de alumnos con deficiencia visual en España: Algunas sugerencias espaciales y contribuciones tecnológicas y tiflotecnológicas. Estududios Pedagógicas, 29, 143-153. Disponioble on line. doi: 10.4067/S0718-07052003000100010.

Rodriguez, F. (2007). Madurez vocacional de jóvenes colombianos con discapacidad: evaluación e intervención. Disponible on line http://3datos.es/wp content/uploads/2011/02/200709-11.pdf. Recuperado el 30 de noviembre de 2014.

Rucci, A. (2013) Consideraciones generales para la inclusión de personas con discapacidad en la Universidad Área de Accesibilidad Facultad de Ciencias Económicas- Comisión Universitaria sobre Discapacidad. UNLP. Disponible on line:

http://www.cud.un|p.edu.ar/uploads/docs/consideraciones generales para la inclusion de personas con discapacidad en la universidad.pdf. Recuperado el 20 de mayo de 2017.

Sacks, J. \& Levy, S. (1967) El test de frases incompletas. En Abt y Bellak: Psicología Proyectiva. Buenos Aires: Paidós.

Saforcada, E. (2010). El factor Humano en la salud pública. Una mirada psicológica hacia la salud colectiva (2da. Ed.). Buenos Aires: Proa XXI.

Shaferstein, C., \& Aisenson, D. (2010). Algunas reflexiones acerca de la práctica del psicólogo orientador en la orientación de los estudiantes universitarios sordos o con hipoacusia. Disponible on line: http://www.culturasorda.org/biblioteca/articulos/psicologial. Recuperado el 19 de mayo de 2017

Shaferstein, C., Batlle, S., \& Aisenson, D. (2005). Pensando en mi futuro: relato de una experiencia de orientación con jóvenes sordos e hipoacúsicos. Servicio de Orientación Vocacional y Ocupacional de la Cátedra de Orientación Vocacional y Ocupacional, de la Facultad de Psicología de la Universidad de Buenos Aires: Buenos Aires.

Schorn, M. (2005). La Capacidad en la Discapacidad: Sordera, discapacidad intelectual, sexualidad y autismo. Buenos Aires: Lugar.

Suarez, C. (2005). Entrevista individual y grupal en Orientación Educativa y Orientación Vocacional Ocupacional Cuaderno de Cátedra. Facultad de Psicología y Psicopedagogía. Universidad del Salvador. Buenos Aires.

Super, D. E. (1977), Vocational Maturity in Mid-Career. Vocational Guidance Quarterly, 25, 294-302. doi:10.1002/j.2164-585X.1977.tb01242.x

Tejerina de Walsh, E. (1970) Nada más que una oportunidad. Revista Periscopio. 
Tobin, M., \& Hill, E. (1988) Future aspiration vocational goals and acttitudes toward marriage and recreation, blind and partially sighted 16-18 years old; Journal of Visual Impairment and Blindness, 1988 (Dec), Vol. 82 (10), 414-416.

UNESCO (1994). Declaración de Salamanca y Marco de Acción para las Necesidades Educativas Especiales. Salamanca: UNESCO. Disponible on line. Recuperado el 11 de mayo de 2008, de www.ineesite.org /toolkit/docs/098427so.pdf

UNESCO (2009). Conferencia Mundial sobre la Educación Superior - 2009: La nueva dinámica de la educación superior y la investigación para el cambio social y el desarrollo. Disponible on line. Recuperado el 18 de mayo de 2017 de http://www.unesco.org/education/WCHE2009/comunicado_es.pdf

UNESCO/ IELSAC (2006) Informe sobre la Educación Superior en América Latina y el Caribe. 2000-2005. La metamorfosis de la Educación Superior. Venezuela: Disponible on line. Recuperado el 15 de septiembre de 2011, de www.iesalc.unesco.org.ve.

UNICEF (2014) Experiencias de inclusión educativa desde la perspectiva de aprender juntos. Estudio de casos en regiones de Argentina. Disponible on line http://www.unicef.org/argentina/spanish/Inclusion Educativa.pdf. Recuperado el 30 de noviembre de 2014.

Verdugo, M. A., Jenaro, C., \& Arias, B. (1998). Outcomes of a program of vocational evaluation for persons with physical disabilities and deafness. Journal of Vocational Rehabilitation.11, 181-194.

Williamson, K., Albrecht, A., Shauder, D., \& Bow, A. (2001). Australian Perspectives on the Use of the Internet by People Who Are Visually Impaired and Professionals Who Work with Them. Journal of Visual Impairment and Blindness, 95(9), 690-701 


\section{Anexo 1 \\ Técnicas e instrumentos utilizados en el proceso específico individual}

Autobiografía vocacional. Se focaliza en las elecciones realizadas hasta el momento del proceso, en los intereses y sus formas de concreción, hobbies, elecciones de ocupaciones y estudios, grado de autonomía, persistencia en el logro de intereses, frustraciones y obstáculos. Se solicita para ello la escritura en no más de dos carillas de la autobiografía, indicándose que se trata de la historia de las elecciones realizadas hasta el momento. Posteriormente se profundiza la información obtenida través de preguntas que posibilitan ampliar los aspectos significativos (Kligman, 2003)

Argevoc (Árbol genealógico vocacional). Se utilizó una modificación adecuada para disminuidos visuales y ciegos, siempre que fue necesario, de la técnica grafo-verbal. Originalmente implica la solicitud del dibujo del árbol genealógico de la familia, que fue obviado en el caso de ciegos y disminuidos visuales profundos. Está destinada a recabar información sobre los nombres, edades, estudios y ocupaciones de las personas más significativas para el participante. Permite obtener información sobre: aspectos vocacionales de los seres significativos y su incidencia en la situación de elección actual, mandatos y expectativas familiares; aspectos de la historia familiar vinculados a las ocupaciones y a los estudios. Posteriormente se trabaja con el material aportado por el sujeto, se indaga sobre la forma en que lo confeccionó: búsqueda de información, datos nuevos que no conocía, interés demostrado por los adultos ante sus preguntas, entre otras. (Migliano, 1986, citado por Kligman, 2003).

Test de frases incompletas. Adaptado por Bohoslavsky (1985) de la técnica original de Sacks y Levy (1967). Consiste en una serie de frases incompletas adecuadas a la situación de elección, que el sujeto debe completar. Permite explorar aspectos relativos a la identidad profesional (Carbajal Arregui, 2003, p. 178). La administración en el caso de los participantes ciegos, consistió en la lectura oral de las frases por parte del tesista y la respuesta oral de los examinados, que se registraba por escrito. 
Con los participantes con disminución visual, simplemente se ampliaron las letras de las frases.

Técnica de Realidad Ocupacional (R.O): se utilizó la adaptación que realizó Müller (2009) de la que caracterizó de la descripta por Bohoslavsky ${ }^{8}$ (1985). Según Müller, puede suplantar a los cuestionarios de intereses (p. 63). Para el desarrollo de la técnica, los orientadores preparan un mazo de tarjetas, dónde escriben con letra grande, el nombre de una carrera, extraída de una Guía del Estudiante actualizada, y se incluyen las carreras de las universidades públicas y privadas y los institutos de enseñanza terciaria de la zona, así como de cursos de formación profesional. Para la administración, se presenta el mazo de tarjetas y se procede por etapas en las que deben realizarse las siguientes actividades: a) agrupación de las tarjetas formando áreas o conjuntos que tengan relación entre sí; b) asignación de un nombre representativo de cada conjunto; c) descripción de las características de las personas que se dedican a esas profesiones y ocupaciones; d) manifestaciones acerca de la vida y valoración a de tales personas; cómo viven y qué cosas valoran; e) selección de las profesiones-ocupaciones elegibles según sus preferencias actuales, para obtener información más detallada; f) definición de las profesiones-ocupaciones seleccionadas que se consideran afines con las preferencias e intereses.

Para los participantes con disminución visual, se prepararon las tarjetas en color blanco con el nombre de la carrera en letra Arial 28 , mayúscula y en negrita, para permitir un buen contraste. En el caso de los participantes ciegos, esta técnica no se utilizó y se reemplazó por algunas de las que mencionaremos a continuación.

Lectura de Guías del estudiante: las mismas contienen información sobre los lugares de estudio, y principales características de las carreras en relación al campo laboral, lugares de trabajo y plan de estudios. (Müller, 2004)

Selección de noticias periodísticas que interesen: se solicitó la selección y lectura (con lector de pantalla) noticias periodísticas que de interés. Luego, se comenta cada noticia y se indagan las razones de la selección, las ocupaciones y profesiones involucrados, especificando las distintas maneras de involucrase en ella (Müller,

${ }^{8}$ Cabe aclarar que la técnica original, pertenece a Sturm Nora (1965).

Tesis Doctoral. "Orientación y Discapacidad Visual. Factores que inciden en la elección de los adolescentes" 
2004 , p. 55) A continuación se le pide que realice un listado de las ocupaciones relacionadas con la noticia.

Elaboración de un listado de 10 carreras u ocupaciones preferidas: Requiere anotar en una hoja las carreras $u$ ocupaciones que les interesan, con sus respectivos campos de trabajo, conocimientos requeridos; condiciones o aptitudes necesarias y todo otro dato de interés para formarse una idea de esa actividad laboral. Luego se consulta sobre sentimientos en el desempeño de la actividad, posibles datos faltantes y la manera de obtenerlos conocer (Müller, 2004, p. 55)

Monografías profesionales. Se trata de un recurso informativo a propósito de cada profesión. Forman parte del banco de datos del Servicio de Información Orientada del Centro de Orientación Vocacional Ocupacional, de la Facultad de Psicología de la UNLP. Es un servicio gratuito y abierto a la comunidad. (Gavilán, M, Desuk, I., Di Meglio, M, Galli, M., Garcia, M. \& Maya, C., 2005). 


\section{Anexo 2 \\ Ejemplo de taller (Microproceso)}

LUGAR: Escuela de Educación Especial

FECHA: Lunes 28 de mayo de 2012.

HORARIO: $13: 30$ a 15.30 hs.

COORDINADORA: María Laura Castignani junto a las integrantes del EOE de la escuela.

\section{Objetivos generales:}

1. Conocer al grupo y constituirlo.

2. Realizar una aproximación al primer diagnóstico de orientabilidad.

3. Generar un clima propicio para el trabajo grupal.

\section{Objetivos específicos:}

1. Explorar las expectativas que traen los alumnos en relación a los talleres de orientación, para delimitar el encuadre de trabajo.

2. Revisar los motivos que los acercan a esta problemática de la elección.

3. Comenzar a conocerlos y a que se conozcan entre ellos, para generar un clima propicio para el trabajo grupal en los próximos encuentros.

4. Explorar los temores, ansiedades, fantasías, miedos, pérdidas que ellos consideran sufrirán.

5. Reparar en cierta medida, en lo positivo que ellos ven de este cambio, para así disminuir las ansiedades posibilitándoles posicionarse en el momento de elección. 


\section{Primer momento: Apertura}

- Presentación de los coordinadores y de la propuesta: objetivos, roles, frecuencia.

- Presentación de ellos. Técnica de identificación con un objeto: cada uno se presenta y nos dice: 1) nombre y apellido, 2) escuela, 3) edad, 4) un objeto con el cual se identifica (justificar esta elección).

- Una vez que se presentaron nos cuentan qué expectativas tienen con respecto a estos talleres, que se imaginan que haremos y cómo trabajaremos.

- Delimitar el encuadre de trabajo a partir de la ampliación y/o corrección de las expectativas con respecto al taller.

- Cada uno comenta cómo está pensando el egreso, si están pensando en alguna carrera y/o trabajo.

Tiempo estimado: 30 minutos

\section{Segundo momento: Desarrollo}

Cada alumno retirará un papel a elección que lleva impreso en el anverso una frase alusiva a la situación del egreso.

Cada uno leerá la frase que le tocó al resto del grupo y dará su opinión. A continuación se debatirá de la manera grupal sobre las mismas.

Aclaración: si se dificulta la lectura de las mismas, el coordinador leerá la frase que le tocó a cada alumno al resto del grupo.

Frases:

1. Todos opinan sobre lo que tengo que hacer en mi futuro y eso me desorienta.

2. Me da miedo elegir ya que es la primera vez que tomo una decisión propia sobre mi futuro. 
3. Aunque me digan: "estudia lo que quieras" yo sé que en el fondo podré estudiar una carrera que no me genere demasiadas dificultades con mi vista.

4. Yo voy a elegir algo que se relaciona con aquello en lo que me destaco y me interesa.

5. Tengo ganas de empezar a estudiar una carrera universitaria ya que me va a permitir conocer gente nueva y manejarme con más autonomía.

6. No me importa tener que esforzarme y estudiar muchos años, para trabajar en un futuro de lo que me gusta.

Tiempo estimado: 40 minutos

\section{Tercer momento: evaluación y cierre}

Se lee una síntesis de lo trabajado, se los invita a que puedan sugerirnos temas para trabajar.

Nos despedimos con una palabra que represente como nos sentimos en este taller.

Tiempo estimado: $\mathbf{3 0}$ minutos 


\section{Anexo 3 \\ Encuesta de evaluación}

(Nota: la encuesta fue leída a los ciegos y presentada en letra ampliada a los disminuidos visuales leves)

\section{1) DATOS DE IDENTIFICACIÓN}

1.1 Apellido y Nombre:

1.2 Edad:

1.3 Escuela de procedencia: $\square$ pública $\square$ privada

1.4 Curso escolar/ año:

1. 5 Ciudad de Residencia actual:

2) ORIENTACIÓN VOCACIONAL

2.1 ¿Consideras que este proceso de orientación te ayudó para pensar en un proyecto para tu egreso?

Sí

NO

¿Qué hubieras necesitado?

2.2 Si contestaste Sí, marca qué tipo de proyecto decidiste

$\square$ Estudiar

¿Qué carrera vas a estudiar?

Trabajo

¿Dónde te gustaría trabajar?

$\square$ Estudio y trabajo 
Otro

¿Cuál?

2.3 - Si vas a estudiar ¿Qué factores tuviste en cuenta para la elección de la carrera? (Selecciona tres opciones en orden de importancia y numéralas del 1 al 3 )

1. las tareas que realizan en la profesión elegida

2. la opinión de tu grupo de amigos

3. la opinión de tus padres

4. interés en lograr un lugar de reconocimiento social

5. factores económicos

6. las condiciones de accesibilidad y adecuaciones que ofrece la facultad

7. la disminución/ discapacidad visual

8. resultados del proceso de orientación

9. otros 
2.4 Antes de realizar este proceso, ¿Habías pensado en alguna elección?

sí ¿Cuál?

NO $\square$ 


\section{Anexo 4 \\ Ejemplo de taller con informantes clave alumnos universitarios}

LUGAR: Aula Alfredo Palacios. Presidencia

FECHA: jueves 4 de octubre de 2012.

HORARIO: 9: 30 a 12 hs.

COORDINACIÓN: Castignani María Laura e integrantes de la Comisión Universitaria sobre Discapacidad. UNLP.

REGISTRO: alumnos de la cátedra Orientación Vocacional

MATERIALES: cartelitos, caramelos, afiche, fibrón.

\section{Objetivos generales:}

- Conocer a los integrantes que conformarán el grupo y constituirlo.

- Realizar una aproximación diagnóstica sobre el estado de cada uno y del grupo en su situación en los estudios superiores.

- Generar un clima propicio para el trabajo grupal.

\section{Objetivos específicos:}

- Explorar las expectativas que traen los alumnos en relación a los talleres, para delimitar el encuadre de trabajo.

- Revisar los motivos que los acercan a esta problemática a ser abordada en los talleres.

- Comenzar a conocerlos y a que se conozcan entre ellos, para generar un clima propicio para el trabajo grupal en los próximos encuentros. 


\section{Primer momento: Apertura}

- Presentación de los coordinadores y observadoras. (roles). Breve presentación de la propuesta y de las autoridades de la UNLP y de la CUD.

- Presentación de los participantes. "Cada uno se presenta diciendo: 1) nombre y apellido, 2) edad, 3) carrera, 4) motivos de la elección de esa carrera, 5) expectativas que tienen con respecto a estos talleres, que se imaginan que haremos y cómo trabajaremos". A medida que se presentan, se les entrega un cartelito con su nombre, y se aclara para que lo utilizaremos.

- Delimitar el encuadre de trabajo con respecto al taller: objetivos, duración, frecuencia.

Tiempo estimado: $\mathbf{3 0}$ minutos

\section{Segundo momento: Desarrollo}

División en grupos: Técnica "Caramelos" en una bolsa ponemos caramelos de dos formas distintas: sugus y palitos de la selva,. Cada integrante retira de la bolsa un caramelo y se agrupa con los compañeros que tienen el mismo caramelo. La idea es que se armen 2 grupos y mantener, en lo posible, el mismo grupo de trabajo en el desarrollo de los siguientes talleres.

Consigna de trabajo: "Se van a agrupar y la idea es que empiecen a conocerse, para ello van a presentarse nuevamente, se van a contar qué carrera cursan y van a debatir y conversar sobre lo siguiente: (se entrega por grupo una copia impresa con las consignas)

1) ¿Qué factores tuve en cuenta para la elección de la carrera?:

a) resultados de la Orientación Vocacional (si los hubiera).

b) La orientación que brindó la escuela de procedencia al finalizar los estudios secundarios. 
c) las actividades que se realizan en la profesión elegida.

d) interés por lograr un lugar de reconocimiento social.

e) factores económicos

f) las condiciones de accesibilidad y adecuaciones que ofrece la facultad

g) la discapacidad

h) otros

2) ¿Qué factores/ condiciones facilitan el tránsito por los estudios superiores?

3) ¿Qué factores/condiciones obstaculizan o dificultan el tránsito por los estudios superiores?

4) Enumeren algunos temas que les gustaría abordar en estos talleres (aclarar que nosotros tenemos algunos pero nos gustaría que ellos también propongan temas ).

Tiempo estimado: 60 minutos

\section{Tercer momento: plenario}

Cada grupo expone lo que estuvieron conversando y las coordinadoras vamos anotando los emergentes en un afiche.

Tiempo estimado: 50 minutos

\section{Cuarto momento: evaluación y cierre}

Se lee una síntesis de lo trabajado, se los invita a que puedan sugerirnos temas para trabajar.

Nos despedimos con una palabra que represente como nos sentimos en este taller. 